\title{
Seismic Design Coefficients for SpeedCore or Composite Plate shear Walls - Concrete Filled (C-PSW/CF)
}

\section{Final Project Report}

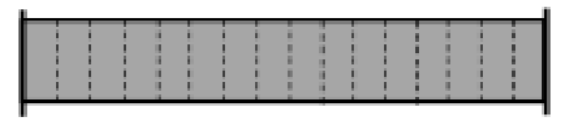

(a) Planar rectangular wall with flange plates and tie bars

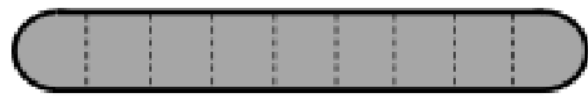

(b) Planar wall with semi-cincular boundary elements and the bars

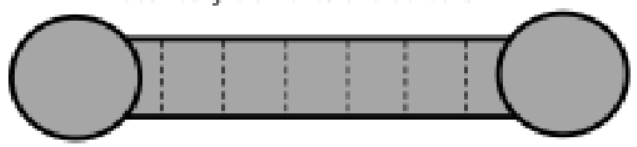

(c) Planar wall with circular boundary elements and tie bars

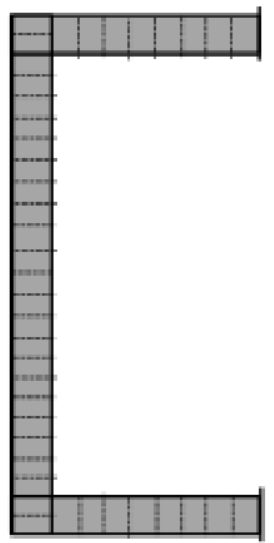

(d) C-shaped walls with flange (closure) plates and tie barg
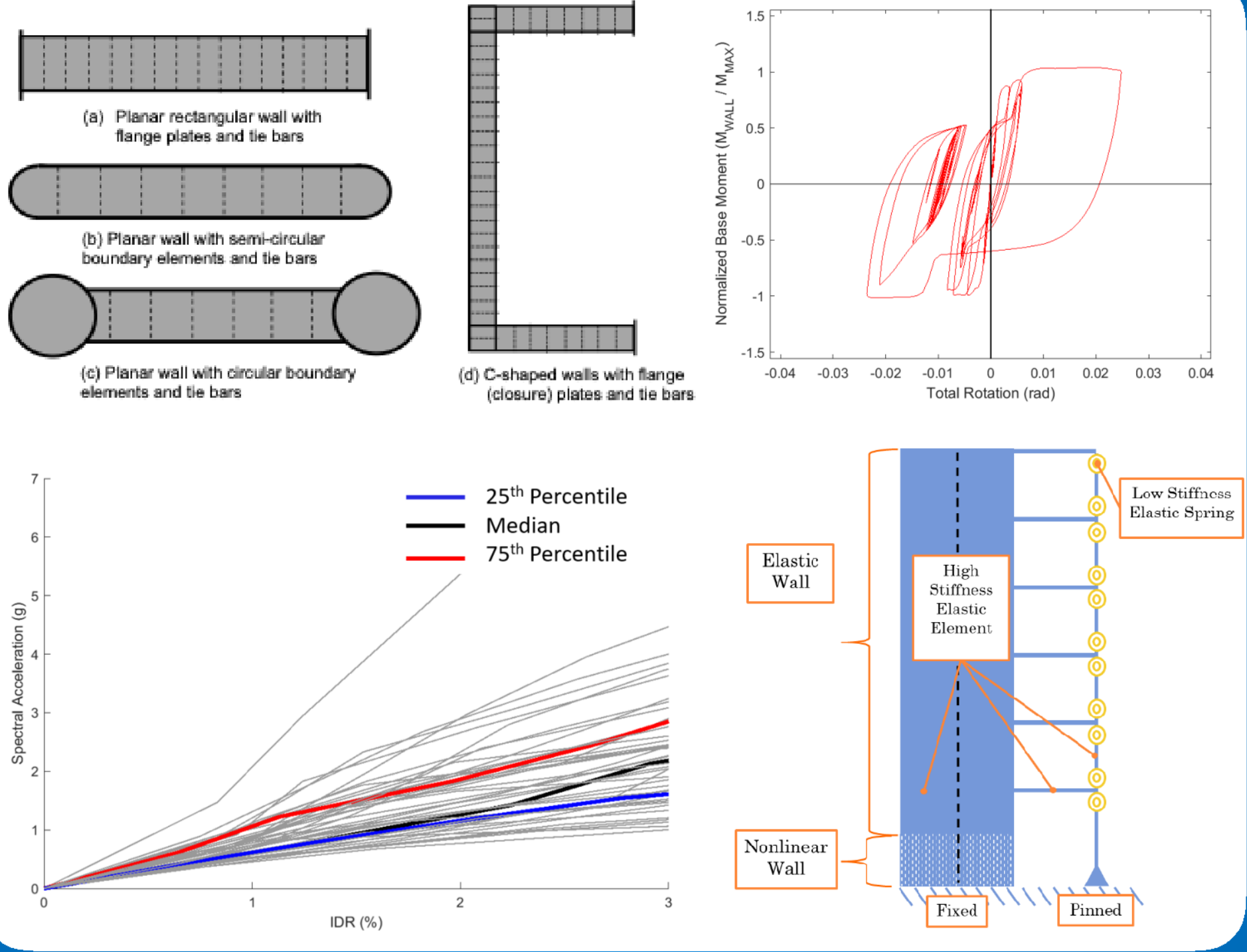

Shubham Agrawal

Morgan Broberg

Amit H. Varma

Purdue University

Lyles School of Civil Engineering

West Lafayette, IN

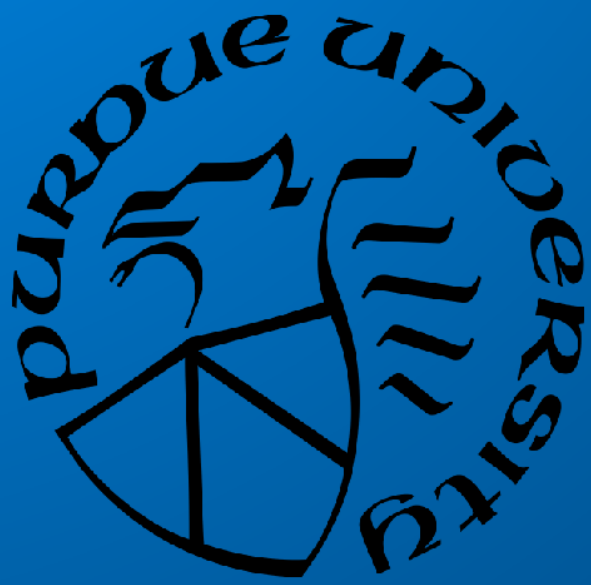




\section{SEISMIC DESIGN COEFFICIENTS FOR SPEEDCORE OR COMPOSITE PLATE SHEAR WALLS - CONCRETE FILLED (C-PSW/CF)}

Final Project Report

Prepared for

\section{AMERICAN INSTITUTE OF STEEL CONSTRUCTION}

\section{Purdue University}

Lyles School of Civil Engineering

West Lafayette, IN

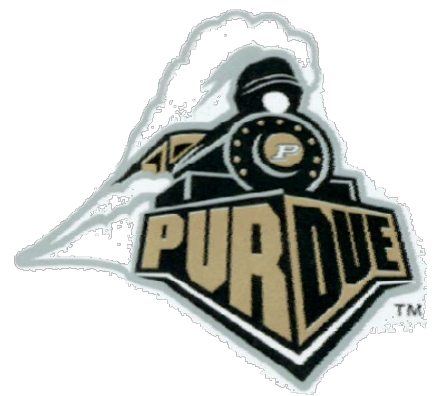

Shubham Agrawal

Graduate Research Assistant

Morgan Broberg

Graduate Research Assistant

Dr. Amit H. Varma

Karl H. Kettelhut Professor

March 2020

Addendum August 2020 


\section{ACKNOWLEDGMENTS}

This research titled "Seismic Design Coefficients for Composite Plate Shear Walls - Concrete Filled" was supported by the American Institute of Steel Construction (AISC).

The researchers are also grateful to the members of the FEMA P695 Peer-Review Panel:

- $\quad$ Ron Klemencic, Chairman \& CEO, Magnusson Klemencic Associates (MKA);

- Rafael Sabelli, Principal and Director of Seismic Design, Walter P. Moore, and;

- Sanj Malushte, Bechtel Fellow and Technology Manager, Bechtel Corporation for their technical guidance.

The researchers would also like to thank Devin Huber, Director of Research, American Institute of Steel Construction for his valuable support. 


\section{EXECUTIVE SUMMARY}

This report summarizes the results from FEMA P695 analytical studies conducted to verify the seismic design factors for composite plate shear walls - concrete filled (C-PSW/CF), also referred to as Speedcore. ASCE 7-16 provides the seismic design factors, which include the seismic response modification factor, $R$, deflection amplification factor, $C_{d}$, and overstrength factor, $\Omega_{o}$, for various approved seismic systems in Table 12.2-1. Steel and concrete composite plate shear walls (C-PSW/CFs) are in row 13 of Table 12.2-1 under building frame systems (item B). The value of $R, C_{d}$, and $\Omega_{o}$ is $6.5,5.5$, and 2.5 , respectively. The seismic design factors for CPSW/CFs were selected based on the seismic performance of similar structural systems and engineering judgment of the committee. This analytical study investigated and verified the appropriateness of these seismic design factors.

The FEMA P695 procedure for evaluating seismic design factors consists of: (i) selecting the seismic design criteria and requirements for the system, (ii) designing several archetypes following the design requirements, (iii) developing and benchmarking a numerical modeling approach, (iv) conducting incremental dynamic analyses for 22 sets of ground motions, and (v) statistical analysis of the results to evaluate the system's performance and adequacy of the seismic design factors.

C-PSW/CFs can be used as shear walls, or as part of the building's elevator core to provide lateral force resistance. They can be either planar, C-shaped, or I-shaped walls. When used as part of the building's core, the C-PSW/CF system may consist of walls that are coupled in one direction and uncoupled in the orthogonal direction. A previous FEMA P695 study was conducted (Bruneau et al. 2019) to establish an $R$-factor of 8 for coupled composite walls (CC-PSW/CF). This higher value was appropriate was coupled wall systems due to their additional ductility from the coupling beams and coupling action in the walls. The current study focuses on the uncoupled walls and builds on the coupled walls study by using similar structural floor plans for the archetype structures, and similar benchmarked numerical models for the composite (C-PSW/CF) walls.

The seismic design criteria for uncoupled C-PSW/CF walls were based on AISC 341-16, Section H7, with some minor modifications. Section H7 permits the use of walls without or with boundary elements, where the boundary elements are permitted to be half-circular or full-circular concrete filled tubes (CFTs). As part of this study, flange plates (also referred to as closure plates)

are also permitted as boundary elements, based on the research and results of Wang et al. (2018). Based on the recommendations of the peer review panel, this study focuses primarily on C- 
PSW/CF walls with flange plates as boundary elements. Walls with half-circular or circular concrete filled steel tubes and walls without closure plates were not included due to perceived constructability issues and architectural considerations. The cyclic behavior of walls with halfcircular or circular CFTs as boundary elements is typically better than that of walls with rectangular ends achieved using flange plates. Therefore, the findings from this study can be extended to those walls with half-circular or circular CFT boundary elements. A brief study on walls without closure plates was conducted, but this analysis concluded that walls without closure plates should be removed from AISC 341 Section H7 in the next code revision.

This study focused on the behavior and performance of four archetypes with planar walls (3-story, 6-story, 9-story, and 12-story) and three archetypes with C-shaped C-PSW/CF walls (15story, 18-story, and 22-story). The structural floor plans were developed based on the recommendations of the peer review panel to provide a reasonable representation of the feasible design space for low-rise and mid-rise buildings. The C-PSW/CF walls were designed following the requirements of AISC 341-16, Section H7, with minor modifications. These modifications will be recommended for the next revision of AISC 341.

OpenSees, an open-source structural analysis software, was used to develop nonlinear finite element (FE) models and conduct nonlinear time-history analyses of the archetype structures. The uncoupled walls were modeled using displacement-based fiber elements and appropriate steel and concrete material models developed by Shafaei et al. (2020) and recommended in Bruneau et al. (2019). The steel material model accounted for the effects of yielding, local buckling, stiffness and strength degradation due to cyclic loading, and low-cycle fatigue leading to fracture. The concrete material model accounted for the effects of tension cracking, compression softening, crushing, confinement, and crack opening and closing behavior under cyclic loading. The numerical models for the walls were benchmarked using experimental data.

The nonlinear models were used to conduct nonlinear static (pushover) analyses and nonlinear incremental dynamic (time-history) analyses. The static analyses were used to calculate the period, $T_{n}$, period-based ductility, $\mu_{t}$, and overstrength factor, $\Omega$. The dynamic analyses were used to assess median spectral acceleration collapse intensity, $S_{C T}$, and collapse margin ratio, $C M R$. 44 far-field ground motions (for example Chi-Chi, Kobe, and Northridge) as specified in the FEMA procedure were used to conduct incremental dynamic analyses. The collapse of the uncoupled C-PSW/CF walls was assumed to occur at an inter-story drift ratio of $3 \%$, which was conservative with respect to actual collapse. 
The performance of the archetype structures was assessed using the results of static and dynamic analyses. The adjusted collapse margin ratio, $A C M R$, was determined for the selected collapse criteria (3\% inter-story drift) considering a period-based ductility factor $\left(\boldsymbol{\mu}_{\mathrm{T}}\right)$ of greater than 8 . The period-based ductility values for all structures were over 8 , but the structures still meet the required performance even if this ductility factor is conservatively considered as 3 . The calculated ACMR values were compared to the FEMA P695 recommended ACMR $10 \%$ and ACMR $_{20 \%}$ values which corresponds to the $10 \%$ and $20 \%$ acceptable collapse probability, respectively. The behavior of planar and C-shaped C-PSW/CF walls at different hazard levels were analyzed and some of the local (stress and strain) responses of C-PSW/CFs were checked.

Summary Table of Results for Archetype Structures

\begin{tabular}{|c|c|c|c|c|c|c|}
\hline \multirow{2}{*}{ Structure } & \multirow{2}{*}{$\begin{array}{c}\text { Overstrength, } \\
\Omega\end{array}$} & \multirow{2}{*}{$\mathrm{S}_{\mathrm{ct}}(\mathrm{g})$} & \multirow{2}{*}{ CMR } & \multirow{2}{*}{$\begin{array}{l}\text { ACMR } \\
\left(\boldsymbol{\mu}_{\mathrm{T}}>8\right)\end{array}$} & \multicolumn{2}{|c|}{ FEMA Limits } \\
\hline & & & & & $\mathrm{ACMR}_{10 \%}$ & $\mathrm{ACMR}_{20 \%}$ \\
\hline 3-story planar & 1.44 & 2.18 & 1.58 & 2.16 & \multirow{5}{*}{1.96} & \multirow{5}{*}{1.56} \\
\hline 6-story planar & 1.69 & 2.01 & 2.12 & 3.08 & & \\
\hline 9-story planar & 2.02 & 1.63 & 2.39 & 3.72 & & \\
\hline 12-story planar & 2.34 & 1.16 & 2.24 & 3.61 & & \\
\hline Avg-planar & 1.87 & 1.75 & 2.08 & 3.14 & & \\
\hline 15-story C-shape & 2.63 & 1.2 & 2.62 & 4.22 & \multirow{4}{*}{1.96} & \multirow{4}{*}{1.56} \\
\hline 18-story C-shape & 2.66 & 1.1 & 2.82 & 4.53 & & \\
\hline 22-story C-shape & 2.75 & 0.7 & 2.29 & 3.68 & & \\
\hline Avg-C-shape & 2.68 & 1.0 & 2.58 & 4.14 & & \\
\hline
\end{tabular}

The table summarizes the results of static and dynamic analyses conducted on planar and $\mathrm{C}$-shaped C-PSW/CF archetype structures. In general, a larger value of the collapse margin ratio was observed for taller structures. The $A C M R$ was equal to 2.2, 3.1, 3.7, 3.6, 4.2, 4.5, and 3.7 for the $3,6,9,12,15,18$ and 22 story archetypes, respectively. These values satisfy both the ACMR $10 \%$ and $\mathrm{ACMR}_{20} \%$ values of 1.96 and 1.56 , respectively. The average deflection amplification factor, $C_{d}$, was 5.3. This value was calculated at the $90^{\text {th }}$ percentile confidence level for the design basis earthquake (DBE). The overstrength factor reported in the table does not include the material overstrength effect. In summary, the seismic design factors of $R, C_{d}$, and $\Omega_{o}$ equal to 6.5, 5.5, and 2.5, respectively, are reasonable and acceptable for uncoupled C-PSW/CF walls. 


\section{TABLE OF CONTENTS}

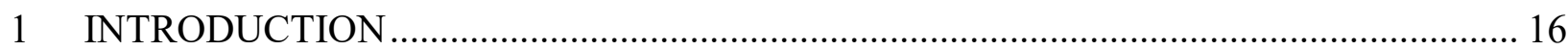

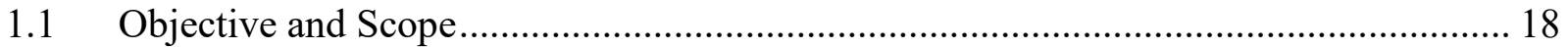

$1.2 \quad$ C-PSW/CF and Coupled C-PSW/CF Seismic System................................................. 19

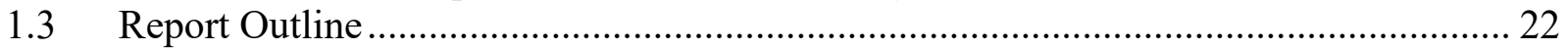

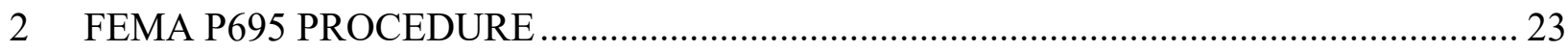

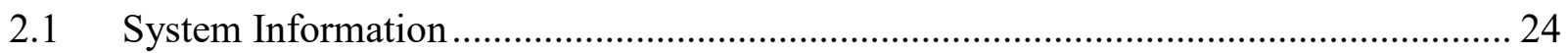

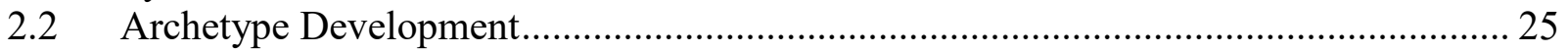

2.3 Nonlinear Model Development ............................................................................... 26

2.4 Nonlinear Analysis and Performance Evaluation ...................................................... 26

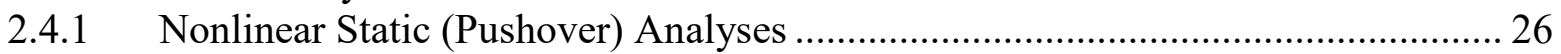

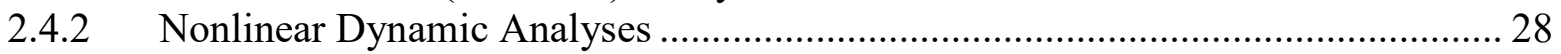

2.4.3 Collapse Performance Evaluation.................................................................. 29

3 DESIGN REQUIREMENTS FOR C-PSW/CF BASED ON AISC 341............................ 32

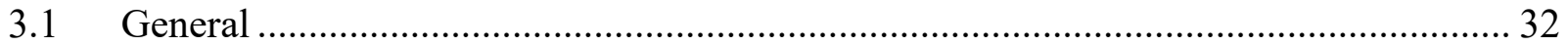

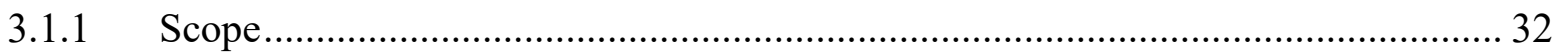

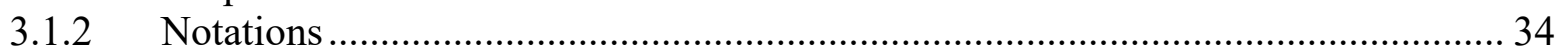

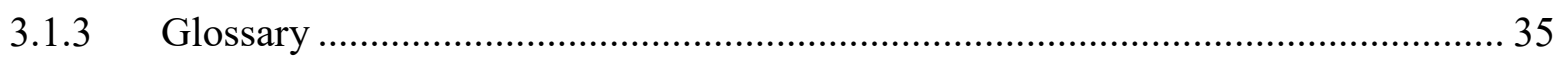

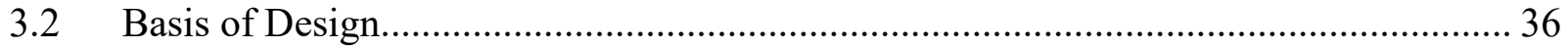

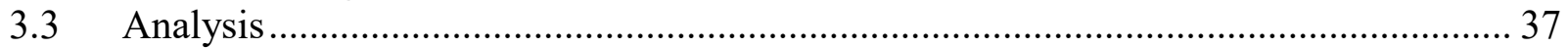

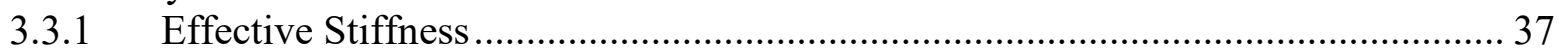

3.4 System Requirements for C-SPW/CF with Flange (Closure) Plates ............................. 37

3.4.1 Minimum Thickness of Plate ................................................................................ 37

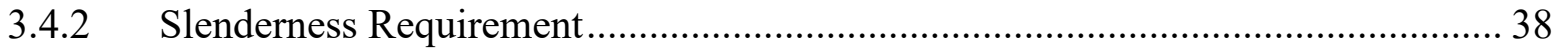

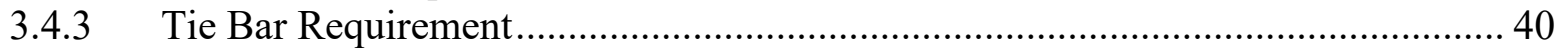

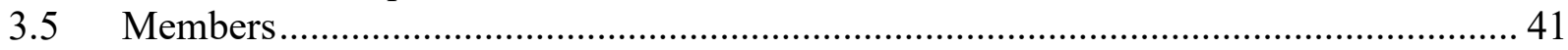

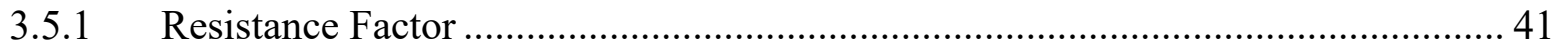

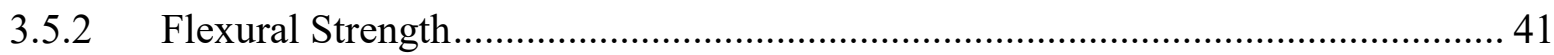

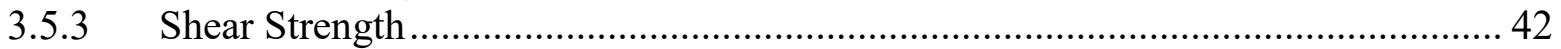

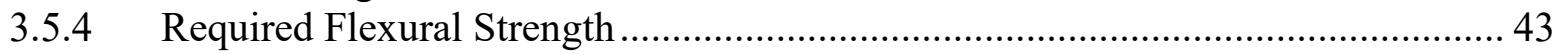

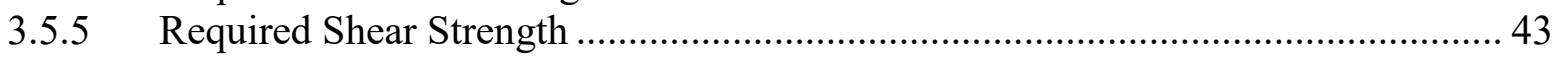

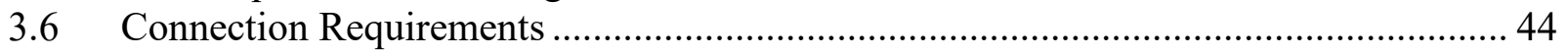

3.6.1 Connection between Tie Bars and Steel Plates...................................................... 44

3.6.2 Connection between C-PSW/CF Steel Components ............................................... 44

3.6.3 Composite Wall-to-Foundation Connections ...................................................... 44

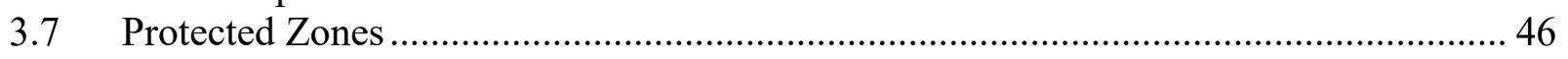

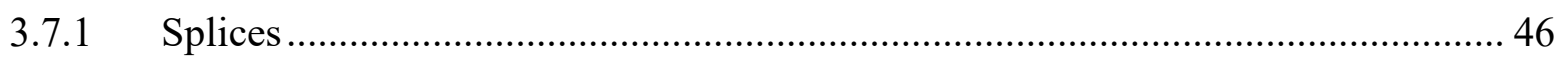

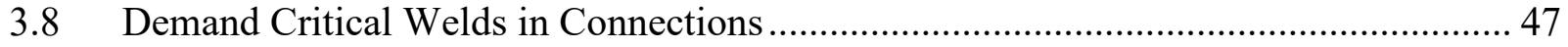

4 DETAILED DESIGN PROCEDURE FOR ARCHETYPE STRUCTURES ……................ 48

4.1 Archetype Structure Initial Parameters …………....................................................... 49

4.2 Equivalent Lateral Force Analysis ....................................................................... 51

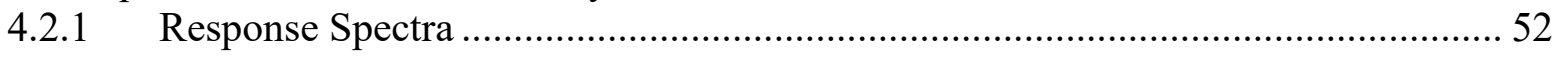




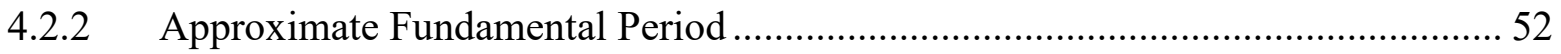

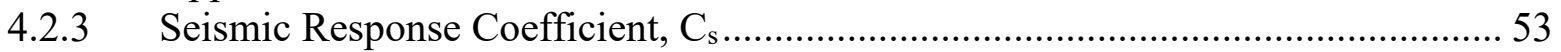

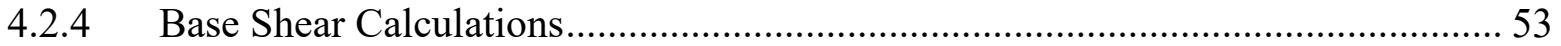

4.2.5 Vertical Distribution of Seismic Forces............................................................... 54

4.2.6 Composite Walls Required Shear Strength and Amplification Factor ................... 54

4.2.7 Overturning Moment at the Base ..................................................................... 55

4.3 Preliminary Design....................................................................................... 55

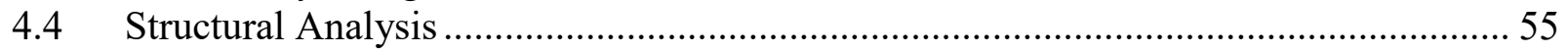

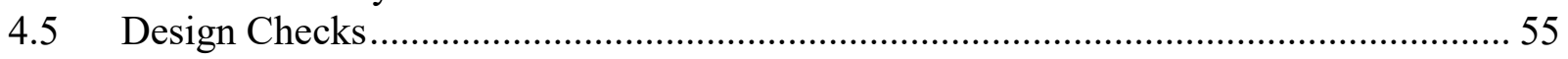

4.5.1 Wall Steel Plate Slenderness Requirement ......................................................... 56

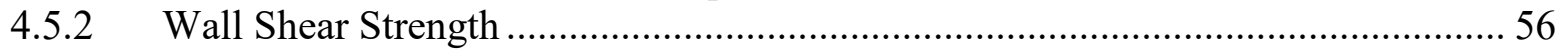

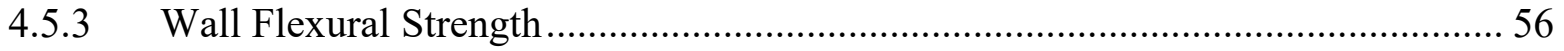

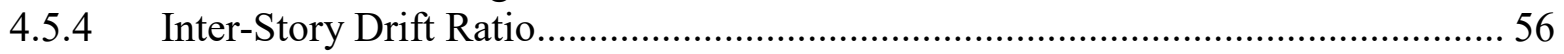

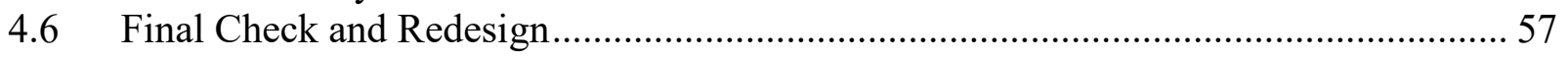

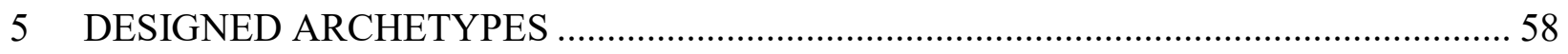

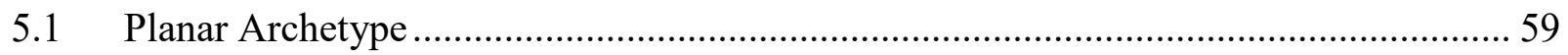

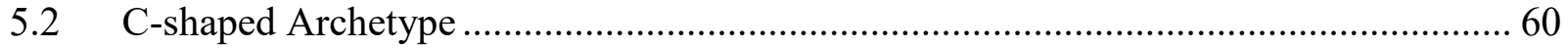

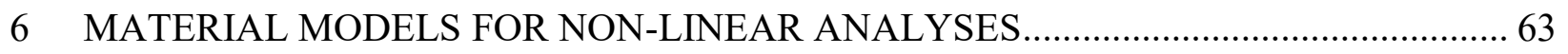

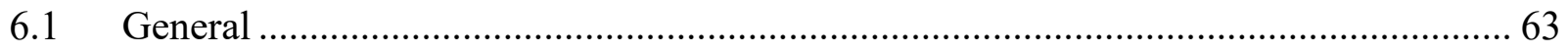

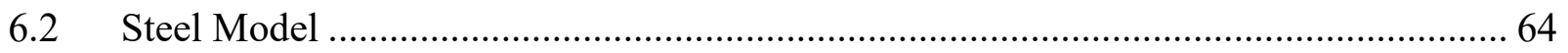

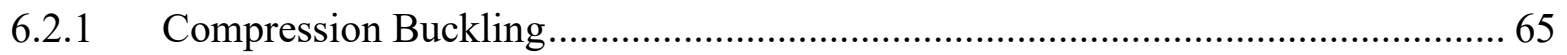

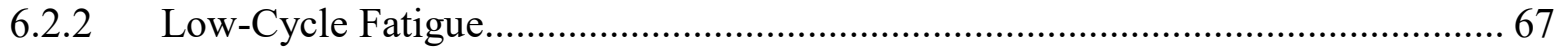

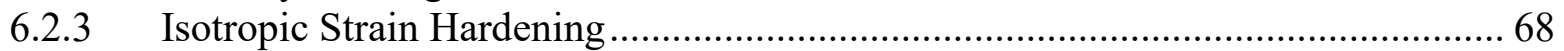

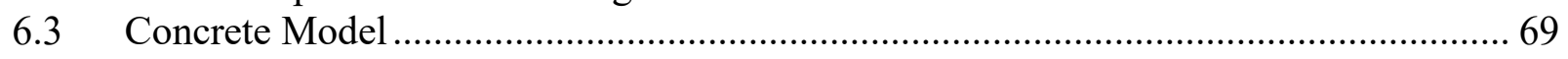

7 MODEL BENCHMARKING AND CALIBRATION ………………………….............. 71

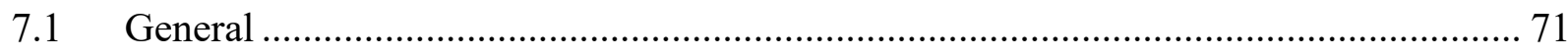

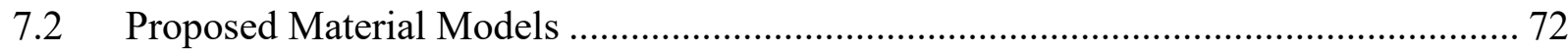

7.3 OpenSees Material Model and Parameters ................................................................... 72

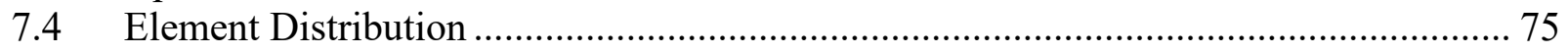

7.5 OpenSees model and Test Data Comparison ……………........................................ 75

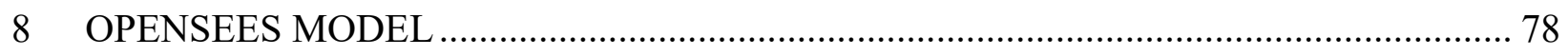

8.1 Steel and Concrete Material Parameters …………………………………………..... 78

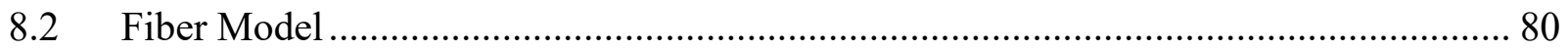

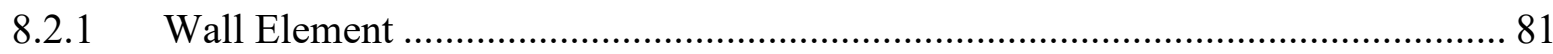

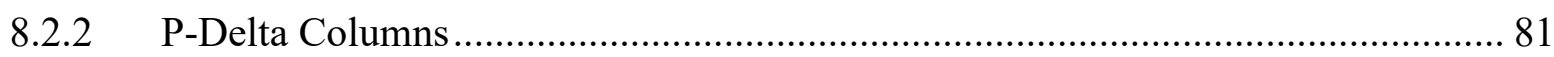

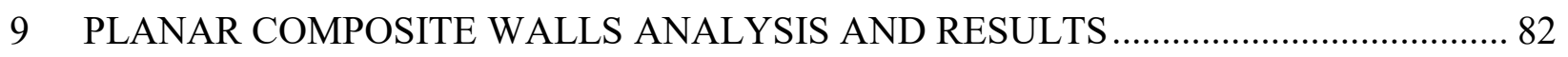

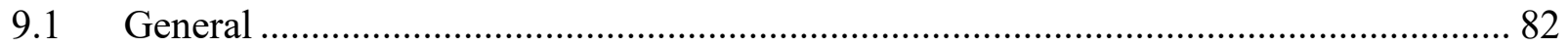

9.2 Nonlinear Pushover (Static) Analysis ..................................................................... 82

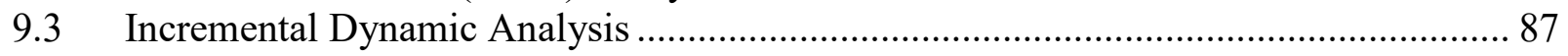

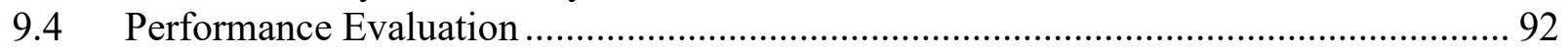

10 C-SHAPED COMPOSITE WALLS ANALYSIS AND RESULTS ………….................... 94 


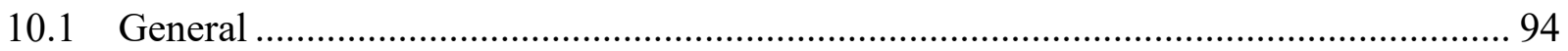

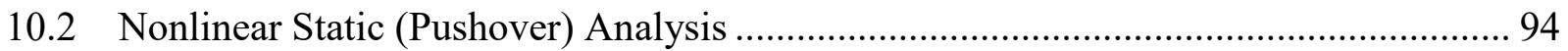

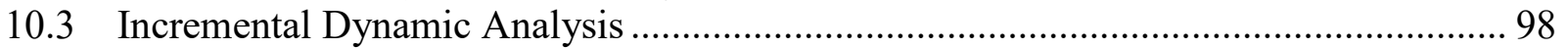

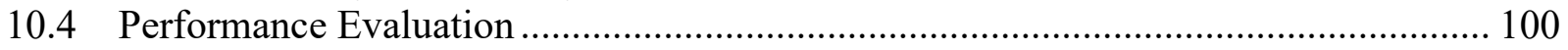

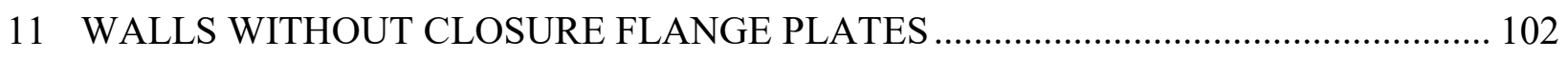

11.1 Material Models and Model Benchmarking............................................................. 102

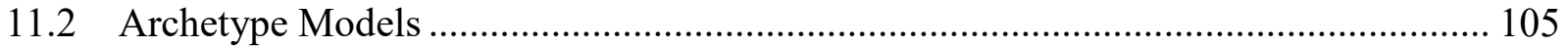

11.3 Nonlinear Pushover (Static) Analysis .................................................................... 107

11.4 Incremental Dynamic Analysis ......................................................................... 110

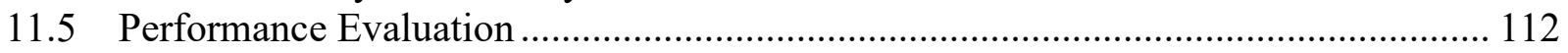

12 STIFFNESS AND SEISMIC PERFORMANCE FACTOR ESTIMATES AND

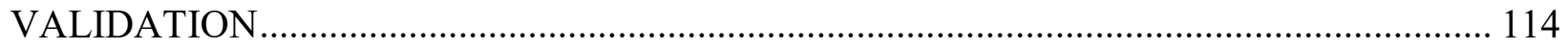

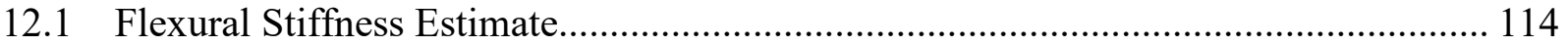

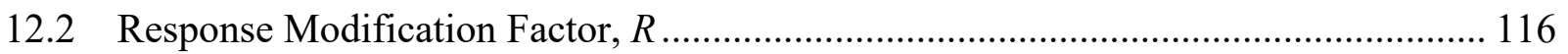

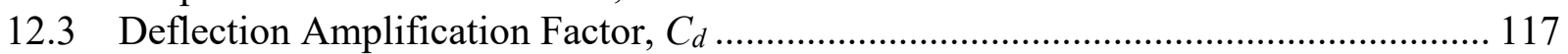

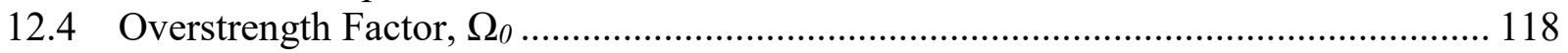

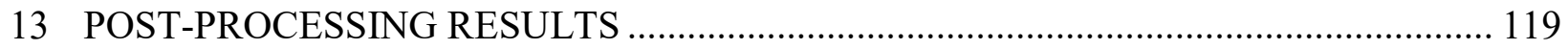

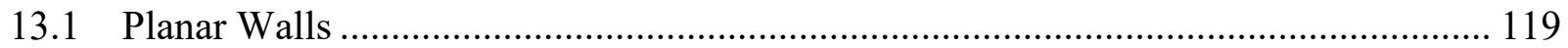

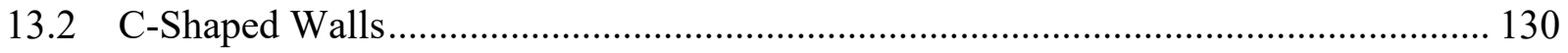

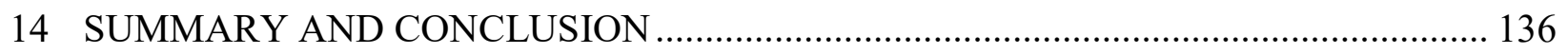

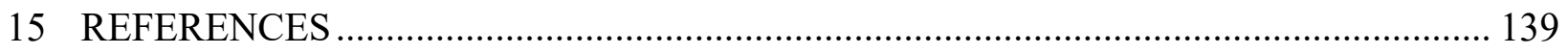

16 APPENDIX A - PLASTIC MOMENT AND STIFFNESS CALCULATION .................... 146

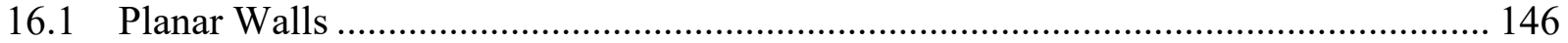

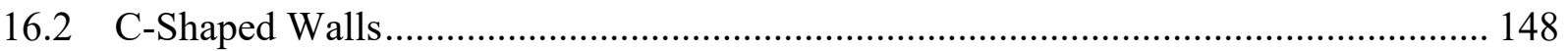

17 APPENDIX B - EQUIVALENT LATERAL FORCE CALCULATIONS FOR 6-STORY

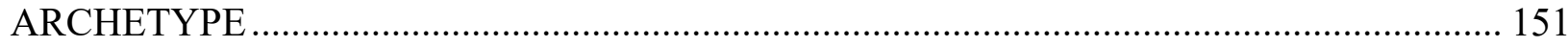

18 APPENDIX C - ARCHETYPE DESIGN PROCEDURE ................................................. 156

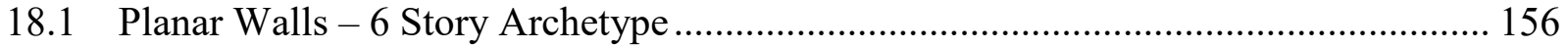

$18.2 \quad$ C-Shaped Walls - 18-Story Archetype ………………........................................... 160 


\section{List of Figures}

Figure 1-1. Typical components in C-PSW/CF (Shafaei et al. 2019, Broberg et al. 2019)......... 16

Figure 1-2. Walls with boundary elements (a) Planar walls with closure plate; (b) Planar walls with half-circular boundary elements; (c) Planar walls with full-circular concrete filled tubes; (d) C-

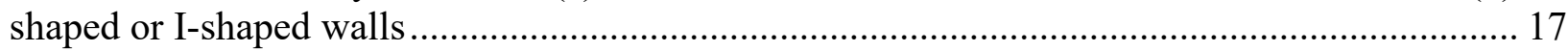

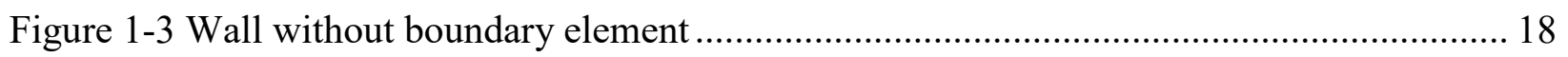

Figure 1-4. Planar walls seismic force-resisting system for 5-story structure .......................... 19

Figure 1-5. C-shaped and I-shaped composite walls around elevator cores (Shafaei et al. 2019) 20

Figure 1-6. Nonlinear static pushover behavior and plastic hinge formation sequence in CCPSW/CF system (Broberg et al. 2019)................................................................................. 21

Figure 2-1. Flow chart FEMA P695 procedure .................................................................... 24

Figure 2-2. Flow chart for the archetype design procedure ............................................... 25

Figure 2-3. Idealized nonlinear static (pushover) curve .................................................... 28

Figure 2-4. Detailed flow chart for FEMA P695 procedure ................................................. 31

Figure 3-1. C-PSW/CF with boundary elements or flange (closure) plates ............................ 33

Figure 3-2. Typical Cyclic lateral load-displacement response of C-PSW/CF (Shafaei et al. 2020a)

Figure 3-3. Local buckling of steel plates, and plot of normalized critical buckling strain vs.

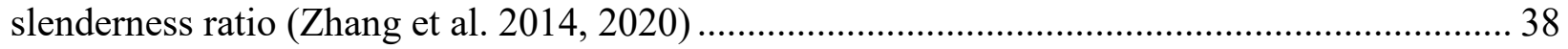

Figure 3-4. In-plane shear force-stain response of composite walls, and comparison of experimental results with shear strength calculated using Equation 3.7 (Seo et al. 2016) .......... 43

Figure 3-6. Composite wall to basement connections (a) with welded base plate and rebar couplers (Bhardwaj and Varma, 2016); (b) wall embedded into the concrete foundation (Bruneau et al.,

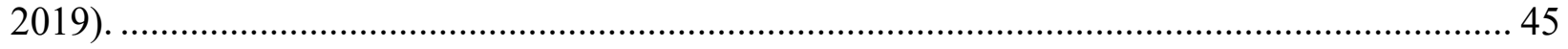

Figure 4-1. C-PSW/CF typical cross-section: (a) Planar, (b) C-shaped .................................. 48

Figure 4-2. Floor plan a) planar walls b) C-shaped walls ..................................................... 50

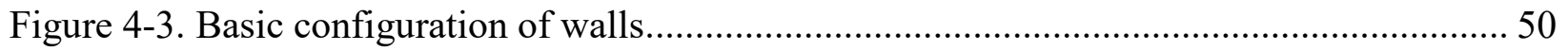

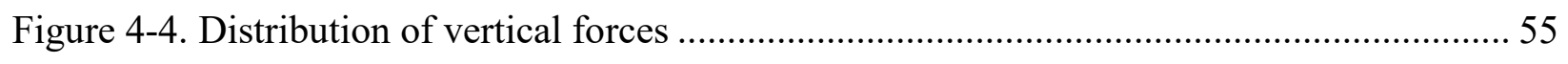

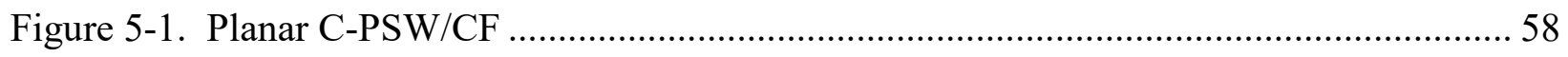

Figure 5-2. C-shaped composite plate shear wall Archetype configuration ............................. 58

Figure 5-3. C-shaped composite plate shear wall cross-section .......................................... 59

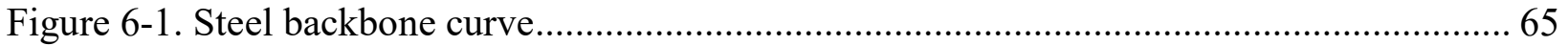

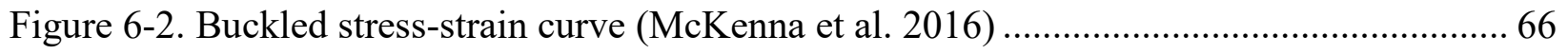

Figure 6-3. Effect of change in sample parameters on buckling model (McKenna et al. 2016). . 67

Figure 6-4. Concrete02 model in OpenSees (McKenna et al. 2016) ....................................... 70 
Figure 7-1. Proposed effective steel stress-strain curve for (a) steel and (b) concrete 72

Figure 7-2. Comparison between steel effective steel stress-strain curve in OpenSees to the model developed in Abaqus (Broberg et al. 2019) .......................................................................... 73

Figure 7-3. Comparison between concrete effective stress-strain curves in OpenSees to material models developed in Abaqus (a) SP1; (b) SP2; (c) SP3; (d) SP4; (e) SP5 .............................. 74

Figure 7-4. Force versus displacement curves for SP1. (a) Matching effective stress-strain curves;

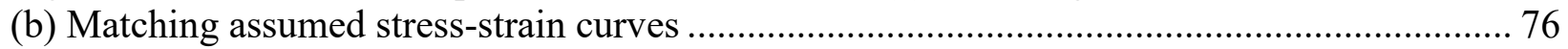

Figure 7-5. Force-Displacement comparison using assumed effective stress-strain curves for (a)

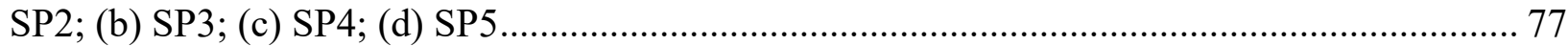

Figure 8-1. Steel material behavior (a) Monotonic stress-strain curve; (b) Cyclic behavior ....... 79

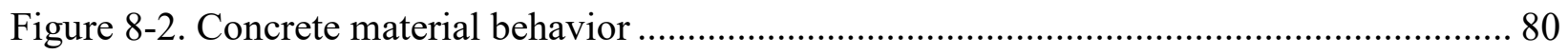

Figure 8-3. OpenSees model for 6 story archetype structure (a) Elevation view; (b) Wall crosssection 81

Figure 9-1. Pushover analysis results for 3-story archetype (a) Base shear versus IDR; (b) Base shear vs maximum IDR; (c) Moment vs roof displacement ................................................. 83

Figure 9-2. Pushover analysis results for 6-story archetype (a) Base shear versus IDR; (b) Moment

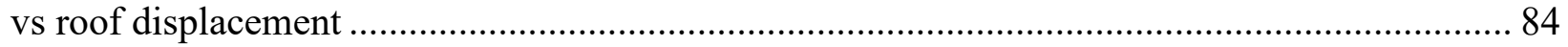

Figure 9-3. Pushover analysis results for 9-story archetype (a) Base shear versus IDR; (b) Moment

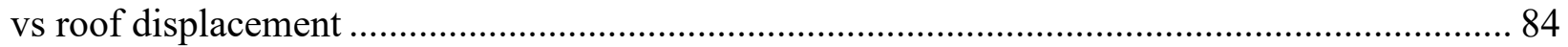

Figure 9-4. Pushover analysis results for 12-story archetype (a) Base shear versus IDR; (b)

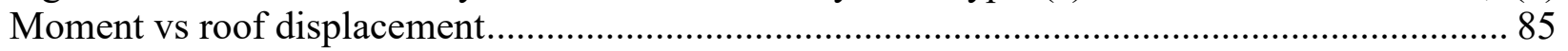

Figure 9-5. Maximum base shear capacity, ELF displacement and ultimate displacement (a) 3S1;

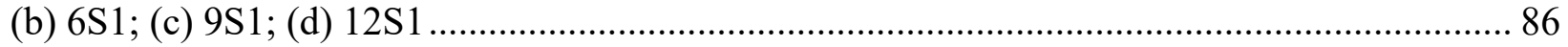

Figure 9-6. Response history analysis for 6-story archetype (a) IDR vs time (s); (b) Roof

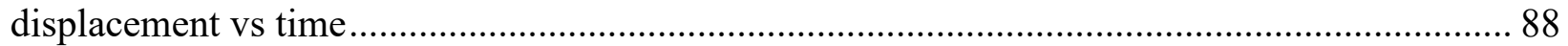

Figure 9-7. 6-story archetype scale factor vs IDR ........................................................... 89

Figure 9-8. 6-story archetype spectral acceleration vs IDR .............................................. 89

Figure 9-9. 6-story archetype IDA plot, spectral acceleration vs IDR .................................. 90

Figure 9-10. IDA Plot for 3-story archetype with 5\% collapse criterion (a) Spectral acceleration vs IDR; (b) Cumulative probability of failure vs spectral acceleration........................................ 90

Figure 9-11. IDA plot for 3-story archetype with 3\% collapse criterion (a) Spectral acceleration vs IDR; (b) Cumulative probability of failure vs spectral acceleration.................................... 91

Figure 9-12. IDA plot for 6-story archetype with 3\% collapse criterion (a) Spectral acceleration vs IDR; (b) Cumulative probability of failure vs spectral acceleration..................................... 91

Figure 9-13. IDA plot for 9-story archetype with 3\% collapse criterion (a) Spectral acceleration vs IDR; (b) Cumulative probability of failure vs spectral acceleration...................................... 92 
Figure 9-14. IDA plot for 12-story archetype with 3\% collapse criterion (a) Spectral acceleration vs IDR; (b) Cumulative probability of failure vs spectral acceleration ........................................ 92 Figure 10-1. Pushover analysis results for 15-story archetype (a) Base shear vs IDR; (b) Base shear vs maximum IDR; (c) Moment vs roof displacement ..................................................... 95

Figure 10-2. Pushover analysis results for 18-story archetype (a) Base shear vs IDR; (b) Moment

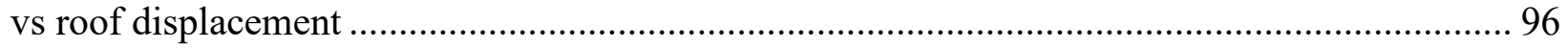

Figure 10-3. Pushover analysis results for 22-story archetype (a) Base shear vs IDR; (b) Moment

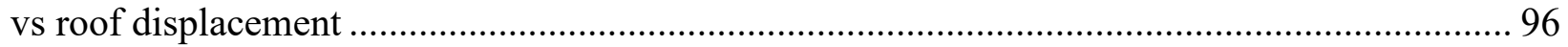

Figure 10-4. Maximum base shear capacity, ELF base shear and ultimate displacement (a) 15S1;

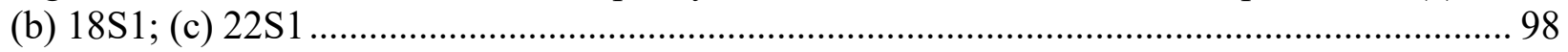

Figure 10-5. IDA plot for 15-story archetype with 3\% collapse criterion (a) Spectral acceleration vs IDR; (b) Cumulative probability of failure vs spectral acceleration ...................................... 99

Figure 10-6. IDA Plot for 18-story archetype with 3\% collapse criterion (a) Spectral acceleration vs IDR; (b) Cumulative probability of failure vs spectral acceleration 99

Figure 10-7. IDA Plot for 22-story archetype with 3\% collapse criterion (a) Spectral acceleration vs IDR; (b) Cumulative probability of failure vs spectral acceleration ....................................... 100

Figure 11-1. Planar composite plate shear wall without closure plate ..................................... 102

Figure 11-2. Effective stress-strain curve for the first case with the Tao confined concrete model (a) Steel stress vs strain; (b) Confined concrete stress vs strain ............................................... 103

Figure 11-3. Effective stress-strain curve for the second case with the Popovics unconfined concrete model (a) Steel stress vs strain; (b) Unconfined concrete stress vs strain.................... 104

Figure 11-4. Experiment result vs OpenSees model (a) First model (Tao concrete); (b) Second

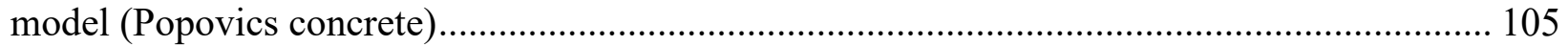

Figure 11-5. Stress distribution assumed to calculate the yield moment (Kurt et al. 2016)...... 106

Figure 11-6. Pushover analysis results for 3-story archetype (3WF1 - Tao concrete model) (a)

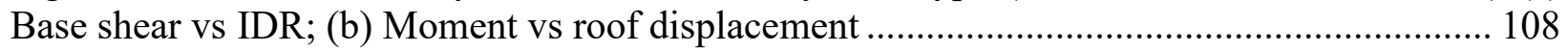

Figure 11-7. Pushover analysis results for 3-story archetype (3WF2 - Popovics concrete model) (a) Base shear vs IDR; (b) Moment vs roof displacement....................................................... 108

Figure 11-8. Pushover analysis results for 6-story archetype (6WF1 - Tao concrete model) (a) Base shear vs IDR; (b) Moment vs roof displacement ........................................................... 109

Figure 11-9. Maximum base shear capacity, yield displacement and ultimate displacement (a) $3 \mathrm{WF} 1$; (b) 6WF1 109

Figure 11-10. IDA plot for 3WF1 with 3\% collapse criterion (a) Spectral acceleration vs IDR; (b) Cumulative probability of failure vs spectral acceleration ..................................................... 111

Figure 11-11. IDA plot for 3WF2 with 3\% collapse criterion (a) Spectral acceleration vs IDR; (b) Cumulative probability of failure vs spectral acceleration ..................................................... 111

Figure 11-12. IDA plot for 6WF1 with 3\% collapse criterion (a) Spectral acceleration vs IDR; (b) Cumulative probability of failure vs spectral acceleration ....................................................... 112 
Figure 12-1. Ratio of the overturning moment and design strength for the 18-story archetype. 115 Figure 13-1. Spectral acceleration (g) vs IDR (\%) for 3-story archetype highlighting three selected ground motions

Figure 13-2. Normalized moment vs time of 3-story archetype for median response for different hazard levels (a) DBE level; (b) MCE level; (c) 3\% IDR 121

Figure 13-3. Normalized moment vs time of 3-story archetype at 3\% IDR hazard level (a) $25^{\text {th }}$ percentile; (b) $75^{\text {th }}$ percentile ground motion response 121

Figure 13-4. Normalized moment vs change in rotation of 3-story archetype for median response at 3\% IDR (a) Element 1; (b) Element 2; (c) Element 3; (d) Element 4. 123

Figure 13-5 Normalized moment vs change in rotation for element 1 of 3-story archetype at median response (a) DBE; (b) MCE; (c) 3\% IDR 124

Figure 13-6. Normalized moment vs total plastic rotation of 3-story archetype for the median response (a) DBE level; (b) MCE level; (c) 3\% IDR 125

Figure 13-7. Normalized moment vs total plastic rotation of 3-story archetype at 3\% IDR hazard level for (a) 25th percentile ground motion response; (b) Median ground motion response; (c) 75th percentile ground motion response 126

Figure 13-8. Stress-strain curve for extreme steel fibers of 3-story archetype at the median response (a) DBE level; (b) MCE level; (c) 3\% IDR .... 127

Figure 13-9. Spectral acceleration (g) vs IDR (\%) highlighting $25^{\text {th }}$ percentile, $50^{\text {th }}$ percentile, and $75^{\text {th }}$ percentile ground motion response 130

Figure 13-10 Normalized moment vs time of 15-story archetype for median response (a) DBE level; (b) $3 \%$ IDR 131

Figure 13-11 Normalized moment vs time of 15-story archetype for 25th percentile response (a) DBE level; (b) 3\% IDR. 131

Figure 13-12 Normalized moment vs time of 15-story archetype for $75^{\text {th }}$ response (a) MCE level; (b) $3 \%$ IDR. 131

Figure 13-13. Normalized moment vs total plastic rotation of 15 -story archetype for the $75^{\text {th }}$ percentile response (a) DBE level; (b) MCE level; (c) 3\% IDR ........................................ 132

Figure 13-14. Stress-strain curve for extreme steel fibers of 15-story archetype for the $75^{\text {th }}$ percentile response at (a) DBE level; (b) MCE level; (c) 3\% IDR. 133

Figure 16-1. Stress distribution assumed in concrete infill and steel plates of Planar C-PSW/CFs for calculating the plastic moment capacity, $\mathrm{M}_{\mathrm{p}}$. 146

Figure 16-2. Stress distribution assumed in concrete infill and steel plates of C-Shaped C$\mathrm{PSW} / \mathrm{CFs}$ for calculating the plastic moment capacity, $\mathrm{M}_{\mathrm{p}}$ 148 


\section{List of Tables}

Table 1-1. Seismic design coefficients (a) CC-PSW/CF; (b) C-PSW/CF ..................................... 21

Table 2-1. Required adjusted collapse margin ratio .................................................................. 30

Table 4-1. Archetype building parameters............................................................................... 51

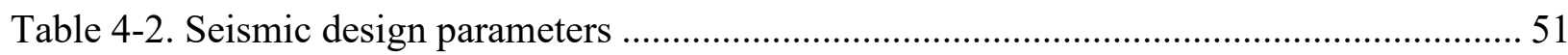

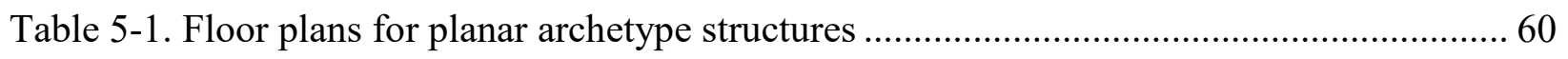

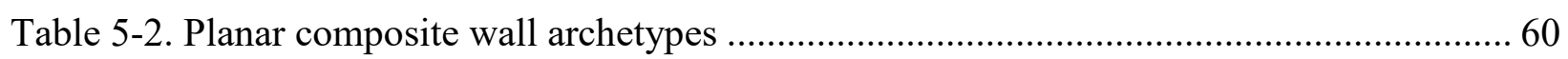

Table 5-3. Planar archetype structures - aspect ratio, strength, and inter-story drift ratio ............ 60

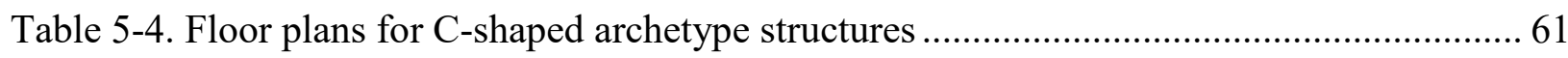

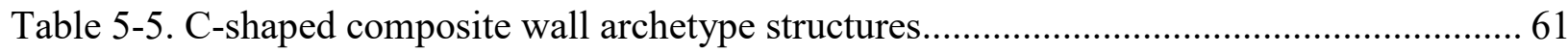

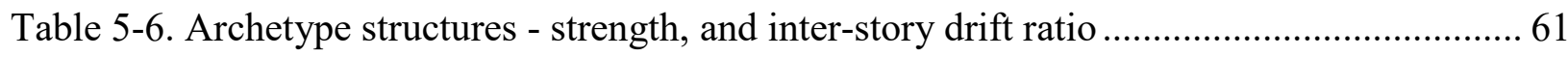

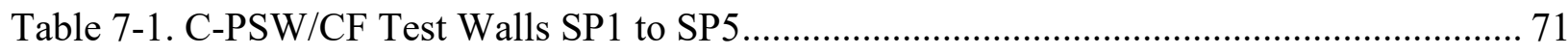

Table 7-2. Steel material parameters for assumed stress-strain curves ........................................ 73

Table 7-3. Concrete material parameters for assumed stress-strain curves ................................ 75

Table 8-1. Steel material parameters used for OpenSees wall model............................................ 79

Table 8-2. Concrete material parameters used for OpenSees wall model ................................... 79

Table 9-1. Pushover analysis results for planar archetype structures ........................................... 86

Table 9-2. Performance evaluations results for planar archetype structures ................................ 93

Table 10-1. Pushover analysis results for C-shaped archetype structures .................................... 97

Table 10-2. Performance evaluations results for C-shaped archetype structures ........................ 100

Table 11-1. Planar composite wall archetypes .................................................................... 107

Table 11-2. Pushover analysis results for planar archetype structures ....................................... 110

Table 11-3. Performance evaluations results for C-shaped archetype structures ....................... 112

Table 11-4. Performance evaluation results for C-shaped archetype structures.......................... 113

Table 11-5. Performance evaluation results for C-shaped archetype structures......................... 113

Table 12-1. Effective stiffness estimate for C-PSW/CF archetype structures............................. 115

Table 12-2. Deflection amplification factor, Cd, estimate for C-PSW/CF archetype structures 117

Table 12-3. Overstrength for planar and C-shaped archetype structures. $\Omega_{1}$ considers nominal material properties and $\Omega_{2}$ considers the expected strength of steel. ...................................... 118

Table 13-1. Post-processing results for 3-story planar archetype structures .............................. 128

Table 13-2. Post-processing results for 6-story planar archetype structures ………………........ 128

Table 13-3. Post-processing results for 9-story planar archetype structures ............................. 129

Table 13-4. Post-processing results for 12-story planar archetype structures ............................ 129 
Table 13-5. Post-processing results for 15-story C-shaped archetype structure....................... 133

Table 13-6. Post-processing results for 18-story C-shaped archetype structure....................... 134

Table 13-7. Post-processing results for 22-story C-shaped archetype structure....................... 135 


\section{INTRODUCTION}

Composite Plate Shear Walls - Concrete Filled (C-PSW/CF) are a highly efficient and effective seismic force resisting system. C-PSW/CFs are comprised of two steel faceplates with concrete infill in between. The steel faceplates are connected using tie bars which are embedded in the infill concrete. Shear headed stud anchors also can be provided, in combination with tie bars, to achieve composite action with the concrete. Closure plates or boundary elements can be provided at the ends of steel faceplates. In these walls, the steel faceplate acts as the primary shear reinforcement and replaces the normal formwork required in reinforced concrete wall construction. The steel plates also provide confinement to the infill concrete. The tie-bars and infill concrete help to prevent buckling of the steel faceplates.

Figure 1-1 shows the typical components present in a C-PSW/CF system. Benefits of using CPSW/CFs include: (a.) similar or better strength and stiffness compared to reinforced concrete walls, (b.) no complex formwork required since the faceplates and closure plates acts as formwork, (c.) no rebar congestion issues, (d.) empty steel module can be designed as falsework for construction activities eliminating time often required in reinforced concrete wall construction spent waiting for the concrete to gain strength (Varma et al. 2017, Bruneau et al. 2019). Overall C-PSW/CFs significantly improve construction speed and efficiency (Varma et al. 2019).

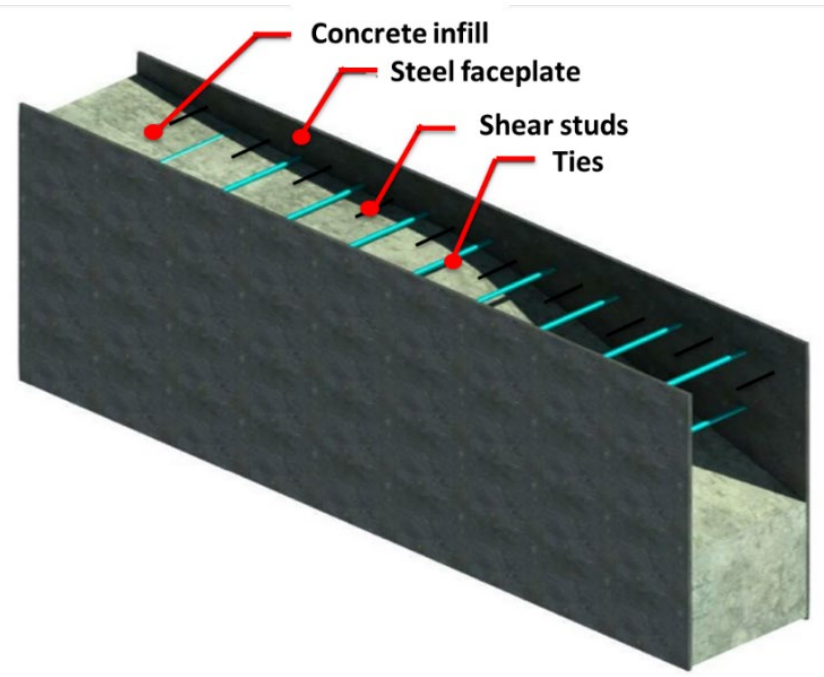

Figure 1-1. Typical components in C-PSW/CF (Bruneau et al. 2019, Broberg et al. 2019) 
The C-PSW/CF system generally consists of planar, C-shaped or I-shaped walls. In this study, the seismic design criteria for uncoupled C-PSW/CFs are based on AISC 341-16, Section H7, with some minor modifications. Section H7 of AISC 341-16 permits the use of walls with or without boundary elements, where the boundary elements are permitted to be half-circular, as shown in Figure 1-2b, or full-circular concrete filled tubes (CFTs), as shown in Figure 1-2c. Rectangular planar walls with flange plates (closure plates) as the boundary elements, as shown in Figure 1-2a, are also permitted, based on the research of Wang et al. 2018.

C-shaped or I-shaped walls, as shown in Figure 1-2d, are generally used for mid-rise or high-rise structures. Walls without any boundary elements (Figure 1-3) have different behavior than walls with boundary elements (Figure 1-2). These differences are discussed in Chapter 11 and Kurt et al. 2017. Walls with half-circular and full-circular boundary elements are not common and are not included in this study because of perceived constructability issues and architectural considerations. The cyclic behavior of walls with half-circular or full-circular boundary elements is typically better than that of rectangular walls with flange plates. Therefore, the findings from this study can be extended to those walls with half-circular or full-circular boundary elements.

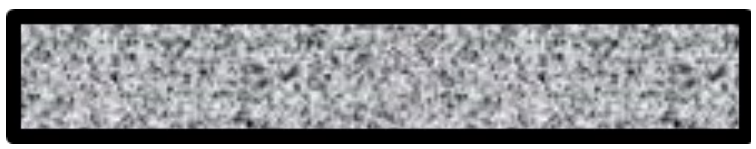

(a.)

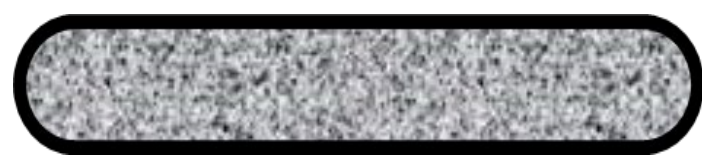

(b.)
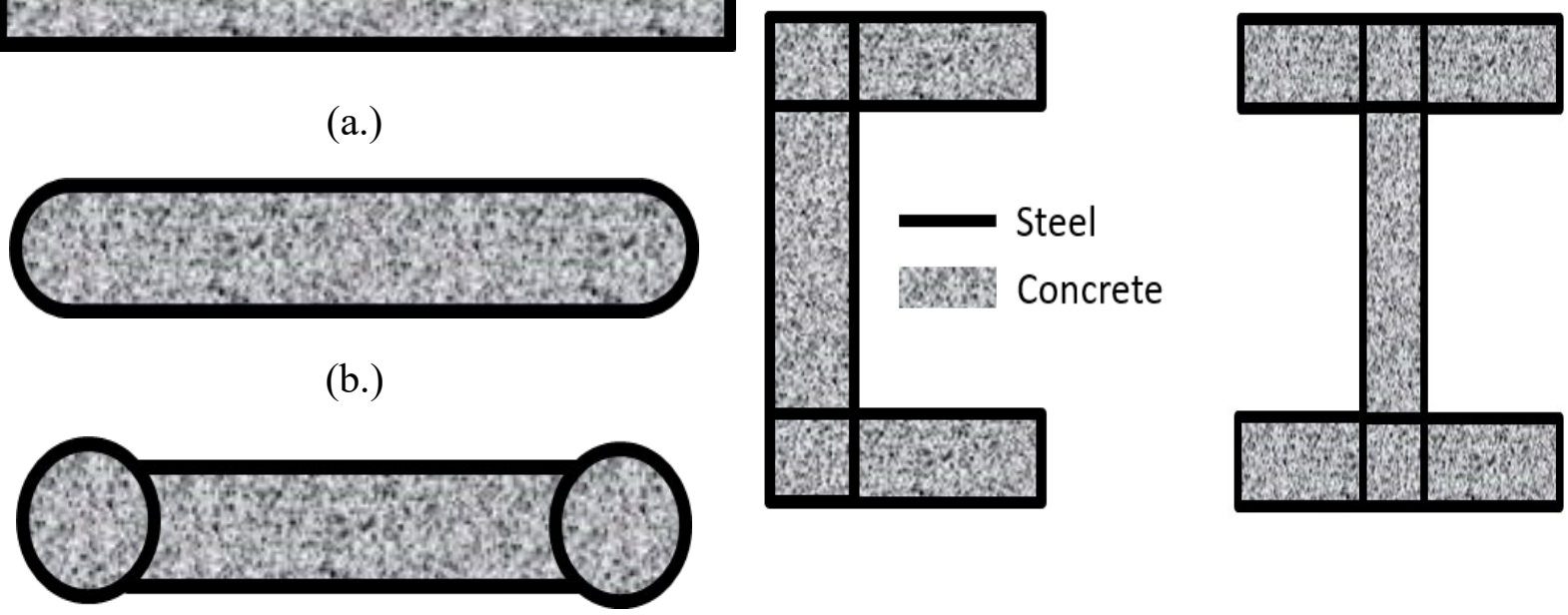

(c.)

Figure 1-2. Walls with boundary elements (a) Planar walls with closure plate; (b) Planar walls with half-circular boundary elements; (c) Planar walls with full-circular concrete filled tubes; (d) C-shaped or I-shaped walls 


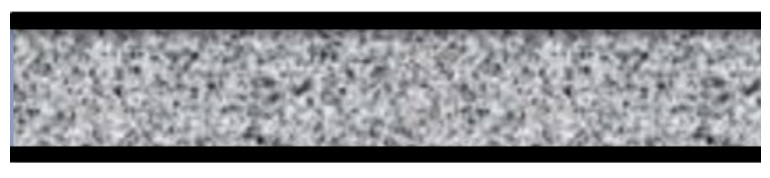

\section{Figure 1-3 Wall without boundary element}

\subsection{Objective and Scope}

Quantifying the seismic response of a structure is a necessary part of many structural designs. The seismic response of structures is often estimated using the Equivalent Lateral Force (ELF) analysis method, as presented in ASCE 7-16. This method relies on three factors: (1) response modification factor, R; (2) deflection amplification factor, $\mathrm{C}_{\mathrm{d}}$; and (3) system overstrength factor, $\Omega_{0}$. These factors are used with the ELF approach to approximate nonlinear forces and deflections experienced by a system subjected to seismic loading from a linear analysis.

This study seeks to confirm the seismic response factors $\left(R, C_{d}\right.$, and $\left.\Omega_{0}\right)$ for composite plate shear walls concrete-filled (C-PSW/CFs). ASCE 7-16 assigns a response modification factor of 6.5, a deflection amplification factor of 5.5, and an overstrength factor of 2.5 to C-PSW/CFs. These values were selected based on the engineering judgment of the committee and previously known response capabilities of similar systems. This study seeks to apply FEMA P695 Quantification of Building Seismic Performance Factors analysis methods to rigorously investigate the appropriateness of the current values and make recommendations for future iterations of the code.

A companion FEMA P695 study was recently completed for the coupled composite wall system (Broberg et al. 2019, Bruneau et al. 2019). This study found a higher R factor of 8 was appropriate for coupled C-PSW/CF systems as the coupling beams contributed to the system's energy dissipation, improving the seismic performance of the system. The model benchmarking, material models, and structure models developed herein follow the approaches recommended in the coupled composite wall system study. 


\subsection{C-PSW/CF and Coupled C-PSW/CF Seismic System}

The C-PSW/CF seismic force-resisting system can be designed as (1) uncoupled Composite Plate Shear Walls - Concrete Filled (also called as C-PSW/CF) or (2) coupled Composite Plate Shear Walls - Concrete Filled (also called as CC-PSW/CF). The uncoupled system (C-PSW/CF) consists of independent walls. The coupled system (CC-PSW/CF) consists of walls and composite coupling beams at most of the floors along the height of the structure.

Figure 1-4 shows the typical configuration of planar C-PSW/CF and CC-PSW/CF for a 5-story structure. The uncoupled system is typically provided as independent shear walls, and the coupled system is generally provided around the elevator cores. Figure 1-5 shows the typical configuration of C-shaped and I-shaped composite walls around the elevator core. Here, two C-shaped composite walls are connected to an I-shaped composite wall using composite coupling beams on each floor. As a result, a coupled configuration is provided in one direction to create an opening for the elevator system and an uncoupled configuration is provided in the perpendicular direction.

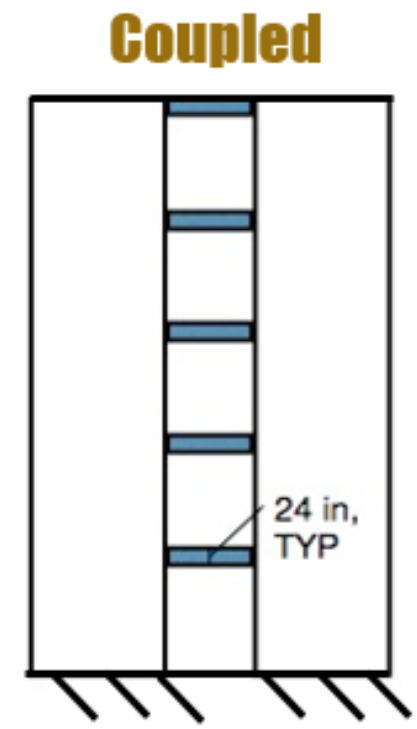

(a.)

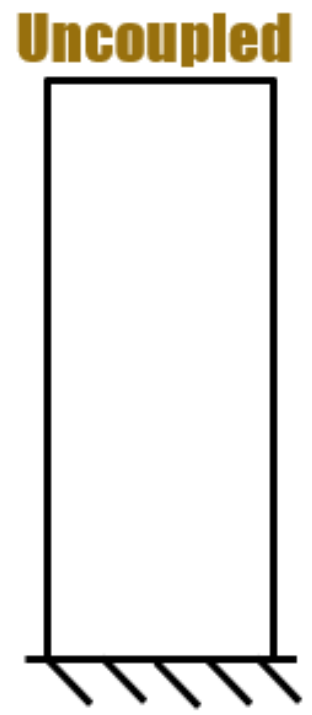

(b.)

Figure 1-4. Planar walls seismic force-resisting system for 5-story structure (a.) CCPSW/CF; (b.) C-PSW/CF 


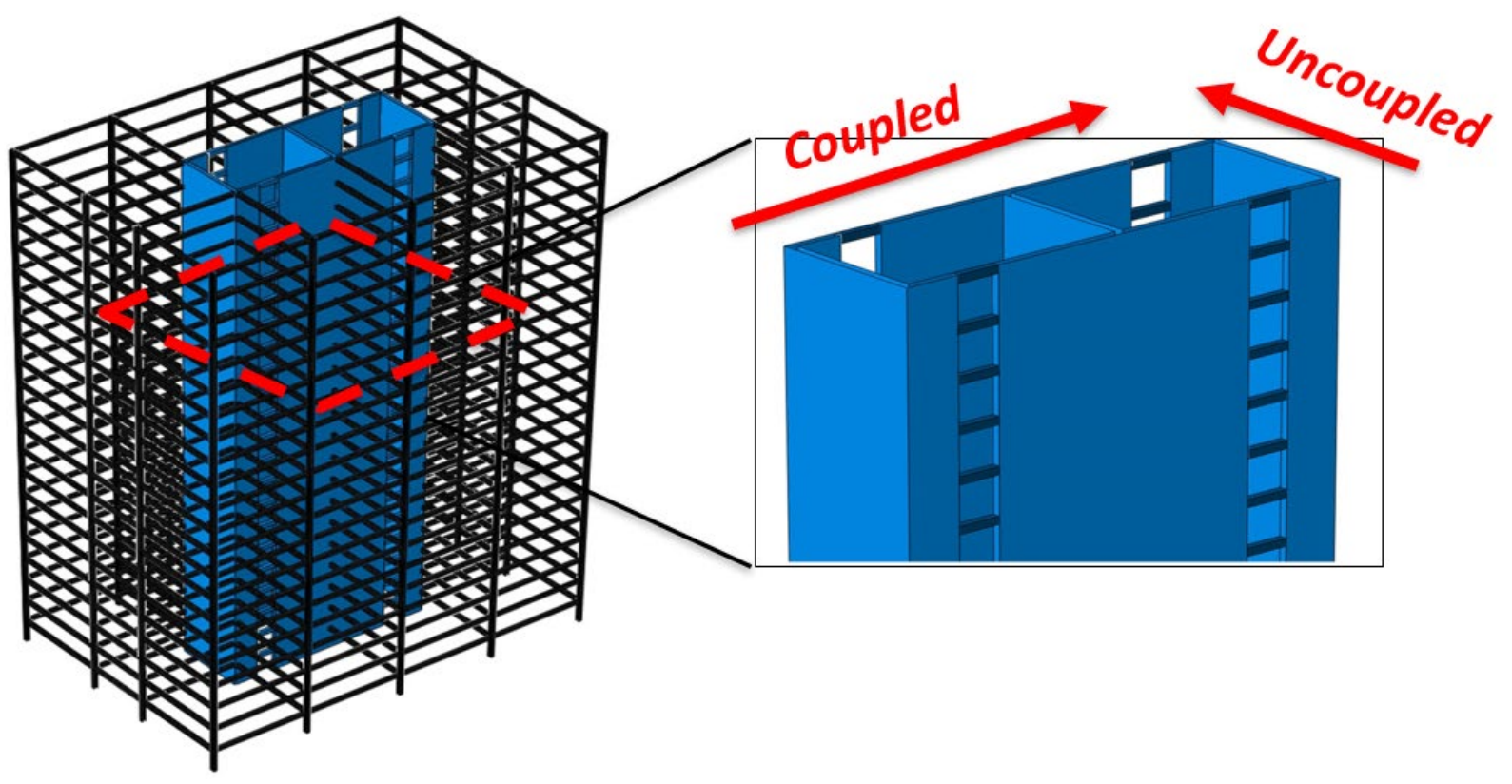

Figure 1-5. C-shaped and I-shaped composite walls around elevator cores (Bruneau et al. 2019)

The behavior and seismic performance of the coupled system (CC-PSW/CF) differ from that of the uncoupled system (C-PSW/CF system). The CC-PSW/CF system has better ductility and energy dissipation compared to the uncoupled C-PSW/CF system. In the CC-PSW/CF system both composite walls and coupling beams are designed to have ductile behavior and develop inelastic flexural capacity during severe ground motion. The design criteria for the CC-PSW/CF system is based on strong-wall and weak-beam design philosophy.

Figure 1-6 shows the typical nonlinear static pushover behavior and assumed mechanism of the plastic hinge formation in the CC-PSW/CF system. At first, the composite coupling beam near mid-height of the structure undergoes flexural yielding, as shown in point A. As the lateral forces are increased, the rest of the composite coupling beams undergo plastic hinging. At point $\mathrm{B}$, all the composite coupling beams develop flexural hinges at both ends. At point $\mathrm{C}$, composite walls yield at the base and form plastic hinges. Finally, fracture failure of the CC-PSW/CF is represented by point $\mathrm{D}$. 
In comparison to the CC-PSW/CF system, the C-PSW/CF undergoes plastic hinging just at the base of the wall. The plastic hinging and energy dissipation in the composite coupling beams along the height of the structure results in a greater R factor of 8 for the CC-PSW/CF system compared to $\mathrm{R}$ factor of 6.5 for the C-PSW/CF system.

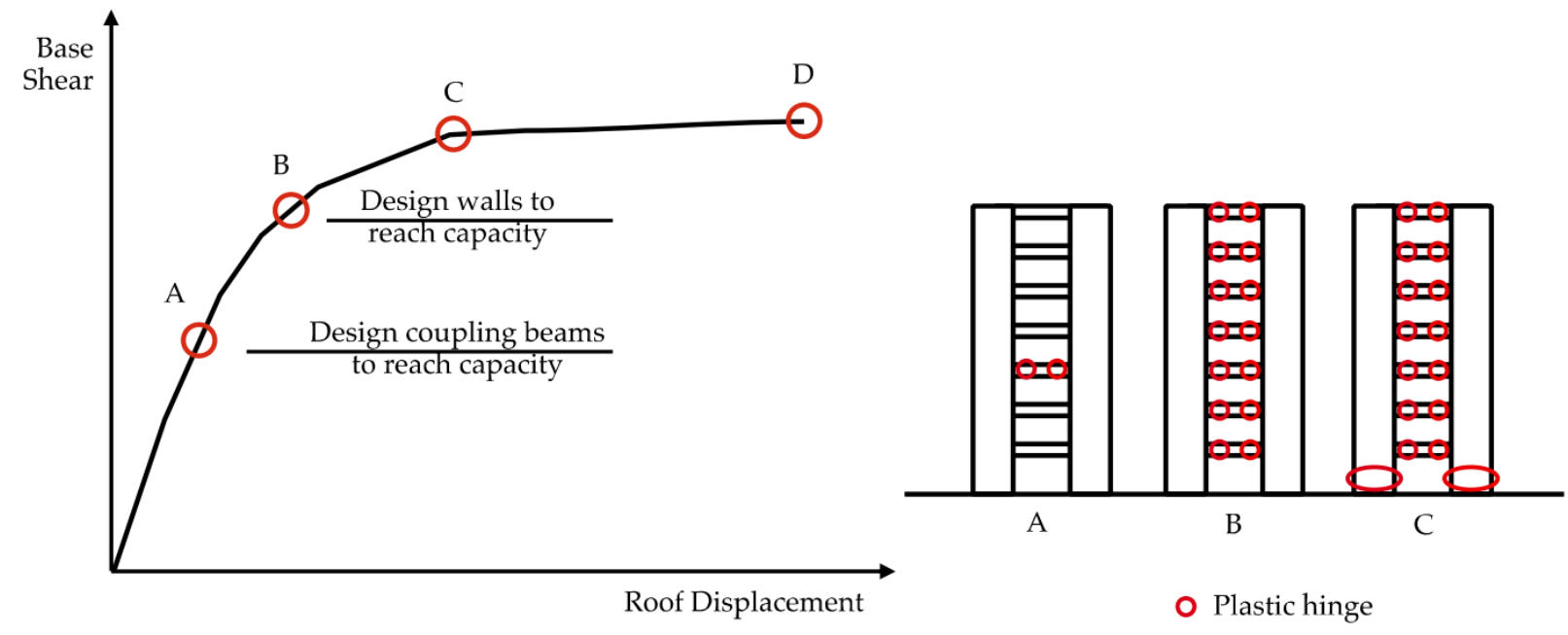

Figure 1-6. Nonlinear static pushover behavior and plastic hinge formation sequence in CC-PSW/CF system (Broberg et al. 2019)

Table 1-1 summarizes the seismic performance factors for both coupled (CC-PSW/CF) and uncoupled (C-PSW/CF) systems. The R factor of 8 for the CC-PSW/CF was validated in a FEMA P695 study completed by Broberg et al. (2019) and Bruneau et al. (2019). This study mainly focuses on the FEMA P695 based study for the C-PSW/CF to verify an R factor of 6.5.

Table 1-1. Seismic design coefficients (a) CC-PSW/CF; (b) C-PSW/CF

\begin{tabular}{|c|c|c|}
\hline Parameter & CC-PSW/CF & C-PSW/CF \\
\hline Response Modification Factor, R & 8 & 6.5 \\
\hline Seismic Ductility Factor, $C_{d}$ & 5.5 & 5.5 \\
\hline Overstrength Factor, $\Omega$ & 2.5 & 2.5 \\
\hline
\end{tabular}




\subsection{Report Outline}

This chapter outlines the general layout of this report. Chapter 2 outlines the FEMA P695 procedure used to quantify C-PSW/CF performance. This chapter serves as an outline of the steps required to determine the $\mathrm{R}, \mathrm{C}_{\mathrm{d}}$ and $\Omega_{0}$ factors. Chapter 3 details the design requirements for $\mathrm{C}$ $\mathrm{PSW} / \mathrm{CF}$ walls. These requirements are implemented in the detailed design procedure presented in Chapter 4. Chapter 5 presents the structural designs following the requirements and recommendations of Chapter 3 and 4. Material models and model benchmarking are performed in Chapters 6 and 7, respectively.

The structural model combines these elements into one model in Chapter 8 . The analysis results are presented in Chapters 9, 10 and 11 for planar walls, C-shape walls, and walls without closure plates, respectively. The seismic performance factors are detailed in Chapter 12. The model results are further post-processed in Chapter 13.

Summary and conclusions are presented in Chapter 14. The steps for plastic moment calculation and stiffness calculation are detailed in Appendix A. An example of the equivalent lateral force calculation is presented in Appendix B. An example of a planar and C-shaped archetype design procedure is summarized in Appendix C. 


\section{FEMA P695 PROCEDURE}

This chapter details the FEMA P695 methodology used to quantify the performance of building systems and define initial parameters used for seismic design. FEMA P695 presents a standard procedure for quantifying the inelastic response characteristics and the ability of the seismic system to meet desired performance objectives. The methodology is used to establish seismic response parameters of a new seismic resisting system and check the reliability of the existing system. The seismic performance factors quantified in this procedure include the response modification factor ( $R$ factor), deflection amplification factor $\left(C_{d}\right)$, and the system overstrength factor $\left(\Omega_{0}\right)$. These factors are then used to estimate the strength and deformation demand of a nonlinear response using only a linear analysis method (Equivalent lateral force method). Figure 2-1 lists the various steps required to conduct a FEMA P695 based study on C-PSW/CF. The FEMA P695 procedure for evaluating seismic design factors consists of: (1.) developing system concepts like selecting the seismic force-resisting system and system components, (2.) obtaining required system information like design criteria, seismic design coefficients, and nonlinear response for the system, (3.) designing several archetypes following the design requirements to represent the design space, (4.) developing and benchmarking a numerical modeling approach, (5.) conducting incremental dynamic analyses for 22 sets of appropriately scaled ground motions, and (6.) analyzing results (collapse margin ratio, $C M R$ and adjusted collapse margin ratio, $A C M R$ ) to evaluate the performance and adequacy of seismic design factors for the system. These details are further outlined in this chapter. 


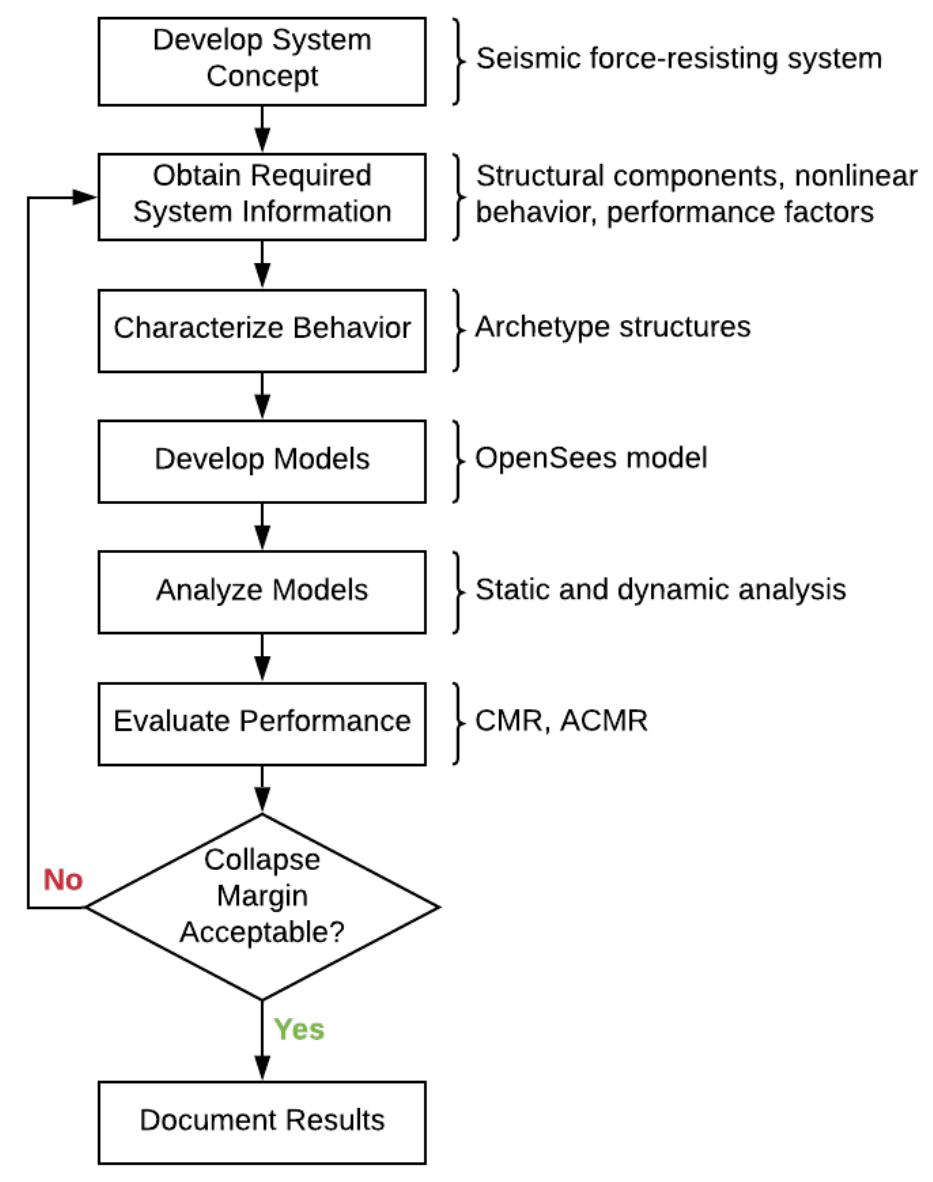

Figure 2-1. Flow chart FEMA P695 procedure (adapted from FEMA 2009)

\subsection{System Information}

This section presents the step of the FEMA P695 process used to obtain the required system information for the composite walls. Required information includes a comprehensive description, construction methods, design requirements, test data, and other supporting information for the proposed system. Chapter 3 of FEMA P695 documents describe the detailed procedure for obtaining the required information and assessing the quality of design requirements. This information and requirements are then used for the development of the archetype models for the proposed system. The details and requirements for the C-PSW/CFs system were discussed in Chapters 3 and 4. 


\subsection{Archetype Development}

An archetype configuration of the seismic resisting system that incorporates the behavior and features related to seismic performance is developed in this section. The archetype structure design uses the trial values of seismic performance factors $R, C_{d}$, and $\Omega_{0}$, selected for performance evaluation. The developed archetype structures must provide a reasonable representation of the design space and help quantify the performance of the entire class of structures and not only a single specific structure. The archetype structure should represent the range of feasible design space and situations permitted by the design guidelines. The details of the steps and procedures used to develop the archetype structure are provided in Chapter 4 of FEMA P695 guidelines. The planar and C-shaped archetype structures developed for the seismic performance evaluation are presented in Chapter 5. Figure 2-2 lists the steps required to design the seismic force-resisting member for the given archetype. These steps are elaborated in Chapter 3, 4 and 5.

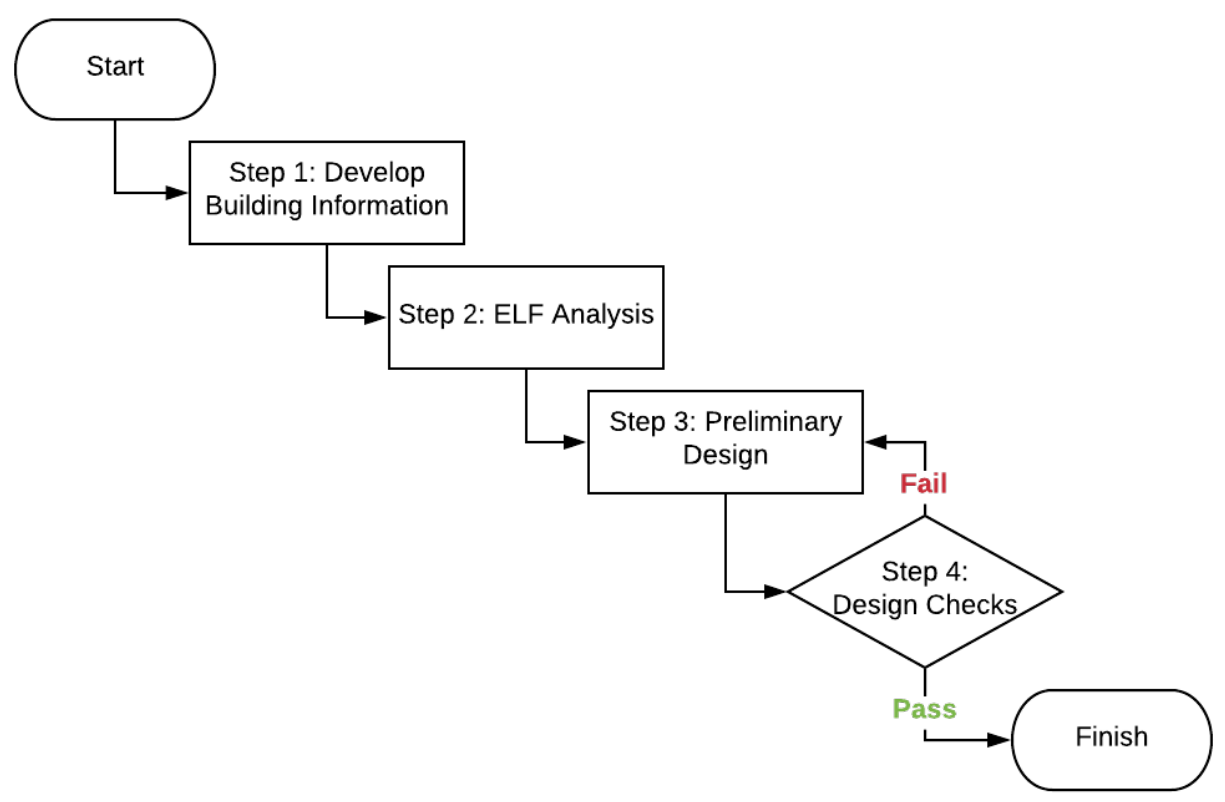

Figure 2-2. Flow chart for the archetype design procedure (adapted from FEMA 2009) 


\subsection{Nonlinear Model Development}

After developing the archetype structures, an analytical model of the seismic force-resisting system is developed for seismic performance evaluation and collapse assessment. The nonlinear model can capture key design features and behavioral modes of the proposed seismic resisting system. The model can capture nonlinear effects, strength, stiffness degradation, inelastic deformation, cyclic deterioration, and collapse behavior. The details of steel and concrete material models and nonlinear OpenSees FEA model developed for performance evaluation are presented in Chapter 8.

\subsection{Nonlinear Analysis and Performance Evaluation}

The nonlinear model developed in the previous step then is analyzed for collapse assessment in this step. Nonlinear pushover analysis and response history analyses are performed on all the archetype models developed using the methods described in Chapter 3. The nonlinear static analyses are performed to obtain the system's overstrength, $\Omega$, and period-based ductility, $\mu_{t}$. The nonlinear dynamic analysis is performed to assess median spectral acceleration collapse intensity, $S_{C T}$, and collapse margin ratio, $C M R$. Then, the acceptability of the trial seismic performance factor value is assessed based on the results of pushover and response history analyses. The nonlinear analyses and performance evaluation conducted on planar and C-shaped archetype structure are detailed in Chapter 9 and Chapter 10, respectively. The nonlinear analyses and evaluation of walls without boundary elements or closure plates are detailed in Chapter 11.

\subsubsection{Nonlinear Static (Pushover) Analyses}

The nonlinear pushover analysis is performed based on the nonlinear static procedure provided in ASCE41. The nonlinear pushover analysis is conducted for factored gravity load combination and static lateral forces. As mentioned previously this analysis is performed to estimate the overstrength, $\Omega$, and period-based ductility, $\mu_{\mathrm{t}}$. The lateral forces, $F_{i}$, at each story level, $i$, is proportional to the fundamental mode shape of the archetype as shown by Equation 2.1. 


$$
F_{i}=m_{i} \Phi_{1, i}
$$

where $\mathrm{m}_{\mathrm{i}}$ is the mass of structure at level $\mathrm{i}$; and $\Phi_{1, i}$ is the ordinate of the fundamental mode at level i.

The overstrength factor, $\Omega$, of the given archetype is defined as the ratio of the maximum base shear resistance capacity, $\mathrm{V}_{\max }$, to the design base shear, $\mathrm{V}$, per Equation 2.2.

$$
\Omega=\frac{V_{\max }}{V}
$$

The period-based ductility, $\mu_{\mathrm{t}}$, is determined by dividing the ultimate roof displacement, $\delta_{\mathrm{u}}$, at $20 \%$

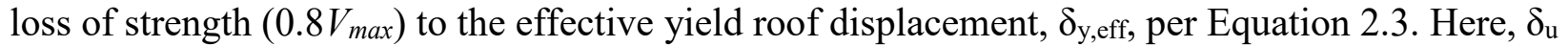
is the roof displacement obtained at $80 \% V_{\max }$ limit on the descending branch, the effective yield roof displacement depends on the coefficient, $\mathrm{C}_{0}$; fundamental period, $\mathrm{T}\left(C_{u} T_{a}\right.$, Equation 4.1); fundamental period using eigenvalue analysis, $T_{l}$; and normalized maximum base shear, $V_{\max } / W$. The coefficient $\mathrm{C}_{0}$ is calculated based on Equation 2.5, where $\Phi_{1, r}$ is the ordinate of the fundamental mode at the roof, $\mathrm{N}$ is the total number of levels.

$$
\begin{gathered}
\mu_{t}=\frac{\delta_{u}}{\delta_{y, e f f}} \\
\delta_{y, e f f}=C_{0} \frac{V_{\max }}{W}\left[\frac{g}{4 \pi^{2}}\right]\left(\max \left(T, T_{1}\right)\right)^{2} \\
C_{0}=\phi_{1, r} \frac{\sum_{1}^{N} m_{i} \phi_{1, i}}{\sum_{1}^{N} m_{i} \phi_{1, i}^{2}}
\end{gathered}
$$

Figure 2-3 shows the idealized pushover behavior of a typical seismic force-resisting system. It defines maximum base shear capacity, $V_{\max }$, and the ultimate roof displacement at a $20 \%$ reduction in shear carrying capacity, $\delta_{u}$ discussed previously. 


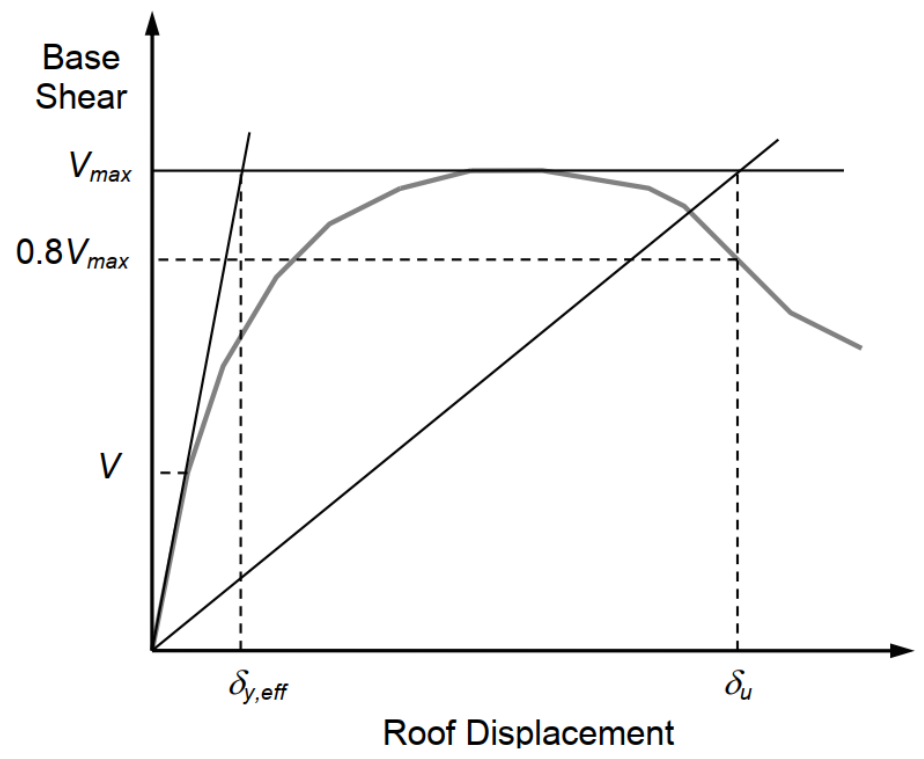

Figure 2-3. Idealized nonlinear static (pushover) curve (FEMA 2009)

\subsubsection{Nonlinear Dynamic Analyses}

Nonlinear dynamic analysis is performed to establish the collapse margin ratio, $C M R$, which is then used to evaluate performance and probability of collapse. Incremental dynamic analysis (IDA) is performed for a given archetype using the series of successive time-history analyses. The intensity of ground motions is scaled up gradually until the collapse of the given archetype is reached. For this study, 44 far-field ground motion as specified in FEMA P695 were considered. These ground motions are gradually scaled up from low intensity to the intensity that causes structural collapse. The individual ground motion records are first normalized by their peak ground velocities to remove unwanted variability between records. After normalizing the ground motions, the records are collectively scaled for anchoring the far-field record set to Maximum Considered Earthquake (MCE) spectral demand. The details of normalization and scaling of ground motion are discussed in Appendix A of FEMA P695. The increment step size for each analysis was limited to maintain enough accuracy. Further reducing the step size would have been computationally intensive for a small gain in the accuracy. The calculation of the collapse margin ratio was performed for different collapse criteria with inter-story drift limits ranging from three percent to five percent. Based on the experimental results and recommendation from industry experts and 
review panel the lesser but more conservative inter-story drift limit (three percent) was used for the collapse margin ratio calculation.

The collapse margin ratio is determined as the ratio of median collapse intensity, $\hat{\mathrm{S}}_{\mathrm{CT}}$, to the MCE ground motion spectral acceleration, $\mathrm{S}_{\mathrm{MT}}$, per Equation 2.6. Here, the median collapse intensity,

$\hat{S}_{C T}$, is taken as the spectral acceleration which results in the collapse of the structure for half of the 44 ground records.

$$
\mathrm{CMR}=\frac{\hat{\mathrm{S}}_{C T}}{S_{M T}}
$$

\subsubsection{Collapse Performance Evaluation}

After establishing the collapse margin ratio for archetype structures, the performance of the proposed lateral-force resisting system is assessed. In this step, the acceptability of the seismic performance factor selected is determined. This evaluation uses the results of the nonlinear static analyses and incremental dynamic analyses performed on the archetype structures. The collapse margin ratio obtained from IDA analyses is adjusted for the effects of the fundamental period, T, and period-based ductility, $\mu_{t}$, system uncertainty, $\beta$, and established collapse probability limits. The adjusted collapse margin ratio, $A C M R$, is determined for different levels of collapse probability, i \%, and depends on spectral shape factor, $S S F$, and collapse margin ratio, $C M R$, per Equation 2.7.

$$
\mathrm{ACMR}_{i}=S S F_{i} \times C M R_{i}
$$

The values of spectral shape factor, $S S F$, are provided in Table 7-1 from FEMA P965 guidelines.

The calculated adjusted collapse margin ratio for a given archetype structure is then compared to the acceptable value of $\mathrm{ACMR}_{10 \%}$ provided in Table 7-3 of FEMA P695. The ACMR $10 \%$ value corresponds to the $10 \%$ acceptable collapse probability. FEMA P695 requires less than $20 \%$ probability of collapse for MCE ground intensity for each individual archetype and less than $10 \%$ 
probability of collapse across the performance group. Performance groups are organized based on structural configuration, gravity load level, seismic design category, and structural period (FEMA 2009). Based on this definition, structures with different building heights (and different structural periods) should be in different performance groups. This study had one structure for each building height; therefore, performance groups and structures were one-to-one. Each structure's performance was then evaluated against the more stringent requirement of a $10 \%$ failure probability.

In addition to considering the collapse probability, the ACMR value also considers the system uncertainty by qualitatively assigning ratings of "Superior", "Good", "Fair", and "Poor" to four sources of uncertainty. These sources are record-to-record uncertainty, design requirementsrelated uncertainty, test data-related uncertainty, and modeling uncertainty. FEMA P695 provides tables to interpret appropriate factors for uncertainty for each permutation of these uncertainty ratings. For brevity, Table 2-1 lists the value of ACMR required for $20 \%$ and $10 \%$ probability of collapse based on each source of uncertainty having the same quality rating.

This entire procedure including archetype design, nonlinear modeling and analyses, and performance evaluation are critically evaluated by a group of experts as an independent peer review panel. The peer review panel provided their review and comments on design requirements, archetype development, nonlinear analysis, and final selection of the systems proposed seismic performance factors. The detailed analysis procedure, performance evaluation, and seismic performance factor validation for C-PSW/CFs are provided in later chapters of this report.

Table 2-1. Required adjusted collapse margin ratio (FEMA 2009)

\begin{tabular}{|c|c|c|}
\hline \multirow{2}{*}{$\beta_{\text {TОтАL }}$} & ACMR $_{20 \%}$ & ACMR $_{10 \%}$ \\
\cline { 2 - 3 } & Individual Archetype & Performance Group Average \\
\hline Superior & 1.46 & 1.78 \\
\hline Good & 1.56 & 1.96 \\
\hline Fair & 1.84 & 2.53 \\
\hline Poor & 2.22 & 3.38 \\
\hline
\end{tabular}


The detailed flow chart representing FEMA P695 procedure is described in Figure 2-4 below.

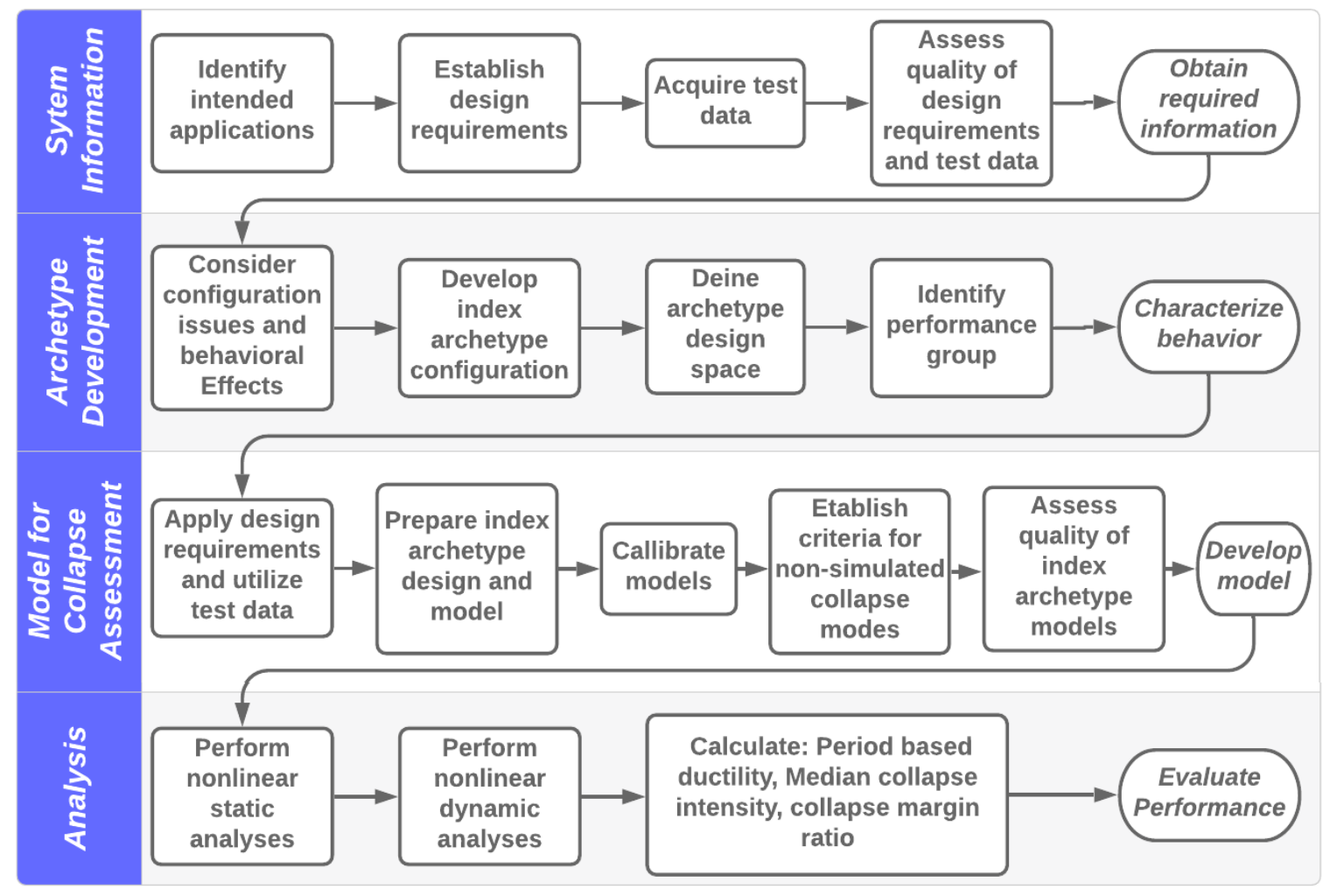

Figure 2-4. Detailed flow chart for FEMA P695 procedure (FEMA 2009) 


\section{DESIGN REQUIREMENTS FOR C-PSW/CF BASED ON AISC 341}

\subsection{General}

Composite plate shear walls-concrete filled (C-PSW/CF) shall be designed in conformance with this section.

\subsubsection{Scope}

\section{C.3.1.1 Scope}

C-PSW/CF shall consist of planar, C-shaped, or I-shaped walls, where each wall element consists of two planar steel plates with concrete infill between them. Composite action between the plates and concrete infill is achieved using either tie bars or combination of tie bars and steel headed stud anchors.

In each wall element, the two steel plates shall be of equal nominal thickness and connected using tie bars. Steel plate thickness and concrete infill may be reduced at higher stories based on drift and strength requirements. The steel plates shall comprise at least $1 \%$, but no more than $10 \%$ of the wall element crosssection

Boundary elements or flange (closure) plates shall be used at the open ends of the wall elements. C-shaped and I-shaped walls shall consist of steel plates covering the section parameter with concrete infill. Interior steel plates can be provided to achieve further confinement in the concrete infill.

The wall height-to-length, $h_{w} / L_{w}$, ratio of the composite walls shall be greater than or equal to 3 . 


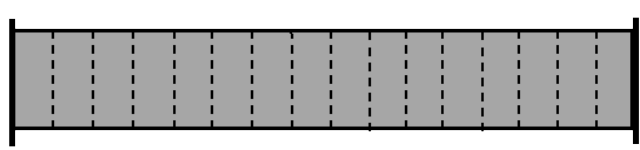

(a) Planar rectangular wall with flange plates and tie bars

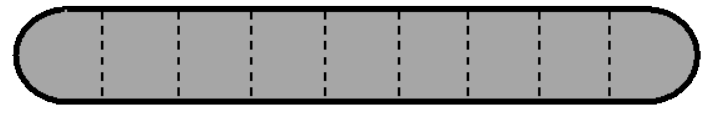

(b) Planar wall with semi-circular boundary elements and tie bars

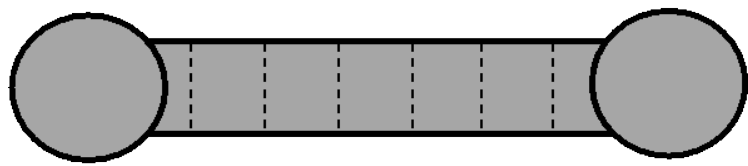

(c) Planar wall with circular boundary elements and tie bars

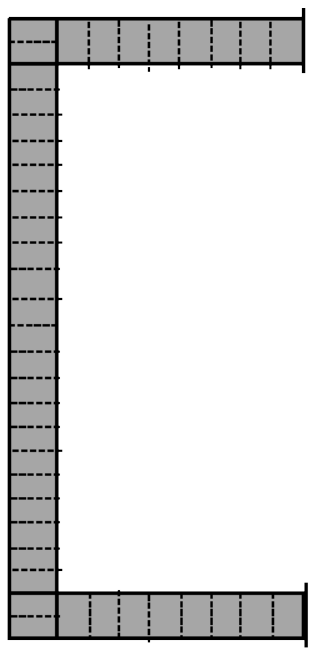

(d) C-shaped walks with flange (closure) plates and tie bars

Figure 3-1. C-PSW/CF with boundary elements or flange (closure) plates 


\subsubsection{Notations}

The symbols listed below are to be used in addition to or as replacements for those in AISC 360 and AISC 341.

$A_{c} \quad$ Area of concrete in the composite cross-section, in. ${ }^{2}\left(\mathrm{~mm}^{2}\right)$

$A_{S} \quad$ Area of steel in the composite cross-section, in. ${ }^{2}\left(\mathrm{~mm}^{2}\right)$

$A_{s w} \quad$ Area of steel section in the direction of shear

$A_{c w} \quad$ Area of concrete section in the direction of shear

$E_{c} \quad$ Modulus of elasticity of concrete

$=w_{c}^{1.5} \sqrt{f_{c}^{\prime}}, \operatorname{ksi}\left(0.043 w_{c}^{1.5} \sqrt{f_{c}^{\prime}}, \mathrm{MPa}\right)$

$E_{s} \quad$ Modulus of elasticity of steel

$=29,000 \mathrm{ksi}(200,000 \mathrm{MPa})$

$f_{c}{ }^{\prime} \quad$ Specified compressive strength of concrete, ksi (MPa)

$F_{y} \quad$ Specified minimum yield stress, ksi (MPa). As used in the Specification, AISC 360, "yield stress" denotes either the minimum specified yield point (for steels that have a yield point) or the specified yield strength (for steels that do not have a yield point).

$G_{s} \quad$ shear modulus of steel

$=11,150 \mathrm{ksi}(76,880 \mathrm{MPa})$

$G_{c} \quad$ shear modulus of concrete

$=0.4 \mathrm{Ec}$

$I_{c} \quad$ moment of inertia of the concrete section about the elastic neutral axis of the composite section, in. ${ }^{4}\left(\mathrm{~mm}^{4}\right)$

$I_{S} \quad$ moment of inertia of steel shape about the elastic neutral axis of the composite section, in. ${ }^{4}\left(\mathrm{~mm}^{4}\right)$

$R_{c} \quad$ Factor to account for expected strength of concrete $=1.5$

$R_{y} \quad$ Factor to account for expected strength of steel

$w_{c} \quad$ weight of concrete per unit volume $\left(90 \leq w_{c} \leq 155 \mathrm{lb} / \mathrm{ft}^{3}\right.$ or $\left.1500 \leq w_{c} \leq 2500 \mathrm{~kg} / \mathrm{m}^{3}\right)$ 


\subsubsection{Glossary}

The terms listed below are to be used in addition to those in AISC 360 and AISC 341. Some commonly used terms are repeated here for convenience.

Applicable building code. Building code under which the structure is designed. [AISC 360-16]

Available strength. Design strength or allowable strength, as applicable. [AISC 341-16]

Composite. Condition in which steel and concrete elements and members work as a unit in the distribution of internal forces. [AISC 360-16]

Flexural buckling. Buckling mode in which a compression member deflects laterally without twist or change in cross-sectional shape. [AISC 360-16]

Load effect. Forces, stresses, and deformations produced in a structural component by the applied loads. [AISC 360-16]

Nominal strength. Strength of a structure or component (without the resistance factor or safety factor applied) to resist load effects, as determined in accordance with the Specification, AISC 360. [AISC 341-16]

Required strength. Forces, stresses, and deformations acting on a structural component, determined by either structural analysis, for the LRFD or ASD load combinations, as applicable, or as specified by this Specification or Standard. [AISC 360-16]

Resistance factor, $\phi$. The factor that accounts for unavoidable deviations of the nominal strength from the actual strength and for the manner and consequences of failure. [AISC 341-16]

Steel anchor. Headed stud or hot rolled channel welded to a steel member and embodied in the concrete of a composite member to transmit shear, tension, or a combination of shear and tension at the interface of the two materials. [AISC 360-16]

Stiffness. Resistance to deformation of a member or structure, measured by the ratio of the applied force (or moment) to the corresponding displacement (or rotation). [AISC 360-16] 


\subsection{Basis of Design}

C-PSW/CF designed in accordance with these provisions are expected to provide significant inelastic deformation capacity through developing the plastic moment strength of the composite C-PSW/CF cross section, by yielding of the steel plate and the concrete attaining its compressive strength. The cross section shall be detailed such that the section is able to attain its plastic moment strength. Shear yielding of the steel web plates shall not be the governing mechanism.

\section{C.3.2 Basis of Design}

Shafaei et al. (2020a) have conducted experimental investigations on planar C-PSW subjected to different axial load and cyclic lateral loading up to failure. The parameters included in the experimental investigations were the axial load level, tie bar spacing, and steel plate slenderness. All the wall specimens developed and exceeded the plastic moment capacity corresponding to the axial load level. Shafaei et al. (2020b) have also developed and recommended effective stress-strain curves that can be used model the cyclic behavior and calculate the flexural capacity of C-PSW/CF. The typical cyclic lateral load-displacement of a planar C-PSW/CF is shown in Figure 3-2. The peak moment was reached due to yielding followed by local buckling of the flanges and webs of the C-PSW/CF. Strength degradation occurred due to fracture initiation in the flange plates of the wall. After fracture initiation, cyclic loading caused stiffness and strength degradation along with propagation of fracture through the flanges and webs of the wall crosssection. The specimen exceeded drift ratio of $3 \%$ before cyclic loading reduced the flexural strength of the wall to $0.8 \mathrm{M}_{\mathrm{p}}$. This occurred during the first $5 \Delta_{\mathrm{y}}$ cycle in the loading protocol corresponding to a plastic rotation of $0.02 \mathrm{rad}$. in the plastic hinge at the base of the wall.

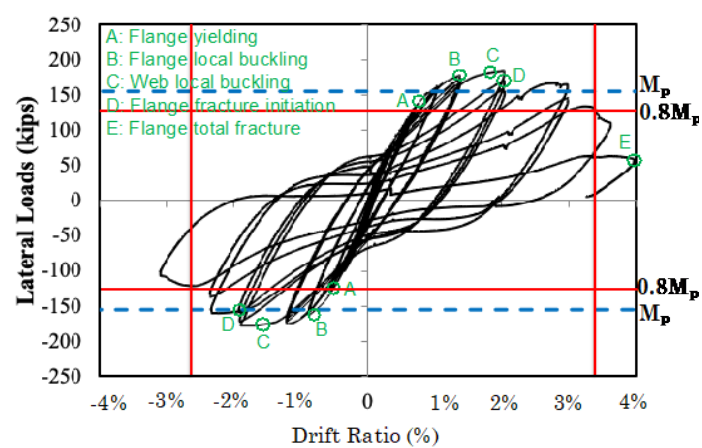




\section{Figure 3-2. Typical Cyclic lateral load- displacement response of $\mathrm{C}-\mathrm{PSW} / \mathrm{CF}$}

(Shafaei et al. 2020a)

\subsection{Analysis}

The effective stiffness of composite walls shall be calculated in accordance with the Specification, Section I1.5.

\subsubsection{Effective Stiffness}

Effective flexural and axial stiffnesses of planar, C-shaped, and I-shaped composite walls shall be calculated using cracked transformed section properties corresponding to $60 \%$ of the nominal flexural capacity. Alternatively, the effective flexural stiffness for walls is permitted to be calculated per Equation 3.1.

The flexural, axial, and shear stiffnesses of composite plate shear walls shall be calculated as follows:

$$
\begin{aligned}
& (E I)_{e f f}=E_{s} I_{s}+0.35 E_{c} I_{c} \\
& (E A)_{e f f}=E_{s} A_{s}+0.45 E_{c} A_{c} \\
& (G A)_{e f f}=G_{s} A_{s w}+G_{c} A_{c w}
\end{aligned}
$$

\subsection{System Requirements for C-SPW/CF with Flange (Closure) Plates}

The opposing steel plates shall be connected to each other using ties consisting of bars, structural shapes, or built-up members. For filled composite plate shear walls, the steel plates shall be anchored to the concrete using ties or a combination of ties and steel anchors.

\section{C.3.3.1 Effective Stiffness}

The cracked transformed properties method was developed and validated in Bruneau et al 2019. The equations developed to calculate the effective properties were developed in this study. Please refer to Section 12.1 for further details.

\section{C.3.4 System Requirements for C-SPW/CF with Flange (Closure) Plates}

The steel plates of composite plate shear walls must be connected using tie bars. These tie bars govern the structural behavior and stability of the empty steel modules before concrete placement. Additional steel headed stud anchors may be used along with tie bars to reduce the slenderness and improve the stability of steel plates after concrete placement. 


\subsubsection{Minimum Thickness of Plate}

The steel faceplates and closure plates shall have a minimum thickness of three sixteenth of an inch. 


\subsubsection{Slenderness Requirement}

In regions of flexural yielding (at the base), the steel plate slenderness ratio, $b / t$, shall be limited as follows.

$$
\frac{b}{t} \leq 1.05 \sqrt{\frac{E_{s}}{R_{y} F_{y}}}
$$

where,

$\mathrm{b}=$ largest unsupported length of plate between rows of steel anchors or ties, in. (mm)

$\mathrm{t}=$ thickness of plate, in. $(\mathrm{mm})$

\section{C.3.4.1 Slenderness Requirement}

The steel plates of composite walls are required to be nonslender, i.e., yielding in compression must occur before local buckling. When subjected to compressive stresses, the plate undergoes local buckling between the steel tie bars or anchors as shown below. The horizontal lines joining the steel anchors (or tie bars) act as fold lines, and local buckling occurs between them. The buckling mode indicates fixed-ends along the vertical lines with steel anchors, and partially fixity along the vertical lines between steel anchors.
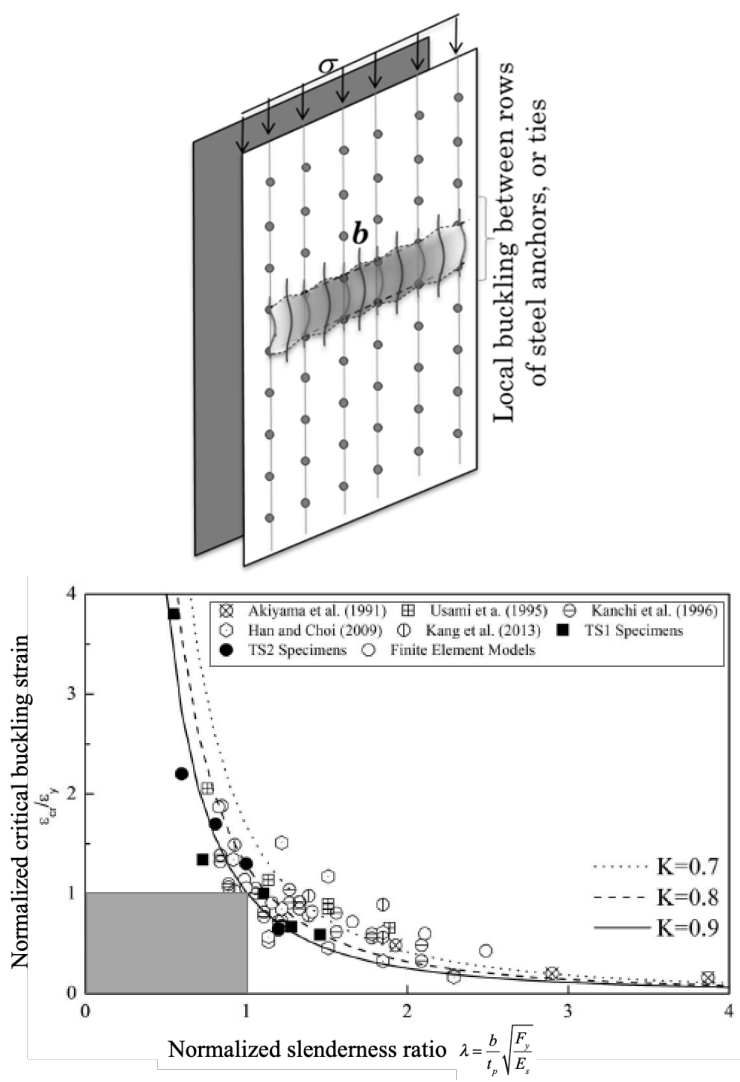

Figure 3-3. Local buckling of steel plates, and plot of normalized critical buckling strain vs. slenderness ratio (Zhang et al. 2014, 2020)

Experimental studies have been conducted to evaluate the effects of plate slenderness ratio, $b / t$, defined as the largest clear distance 
between rows of steel anchors, $b$, divided by the plate thickness, $t$, on local buckling of plates. Zhang et al. $(2014,2020)$ have summarized these experimental studies, and conducted additional numerical analyses to confirm and expand the experimental database. Figure 3-3 from Zhang et al. (2014, 2020) shows the relationship between the normalized critical buckling strain (buckling strain/steel yield strain, $\left.\varepsilon_{c r} / \varepsilon_{y}\right)$ and the normalized plate slenderness ratio $\left(b / t \times F_{y} / E\right)$. As shown, $\varepsilon_{c r}$ is reasonably consistent with Euler's curve with a partially fixed $(K=0.8)$ end condition. This leads to Equation 3-4 for the slenderness limit for non-seismic conditions. Since tie bars may also act as anchors, the equation considers the largest unsupported length between rows of steel anchors or tie bars, $b$. 


\subsubsection{Tie Bar Requirement}

The tie spacing, $S$, shall be limited as follows:

$$
\begin{gathered}
\frac{S}{t} \leq 1.0 \sqrt{\frac{E_{s}}{2 \alpha+1}} \\
\alpha=1.7\left[\frac{t_{s c}}{t}-2\right]\left[\frac{t}{d_{t i e}}\right]^{4}
\end{gathered}
$$

where,

$S=$ largest clear spacing of the ties, in. (mm)

$\mathrm{t}=$ thickness of the steel plate, in. (mm)

$t_{s c}=$ thickness of the composite wall, in. (mm)

$d_{\text {tie }}=$ effective diameter of the tie, in. ( $\mathrm{mm}$ )

\section{C.3.4.2 Tie Bar Requirement}

The tie bar spacing requirement is based on the flexibility and shear buckling of empty steel modules before concrete placement, discussed in detail in Varma et al. (2019). The flexibility of the empty modules for transportation, shipping and handling activities is dominated by their effective shear stiffness $(G A)_{\text {eff, which }}$ can be estimated accurately using numerical models as shown in Varma et al. or calculated conservatively (for a unit cell of the module) using Eq. C.3.1. In this equation, $I_{p}$ and $I_{t}$ represent the moments of inertia of the steel faceplates and tie bar. $S$ and $d_{\text {tie }}$ represent the tie bar spacing and bar diameter. Eq. C.3.2 defines $\alpha$, which is the ratio of the flexural stiffness of the steel pate to the flexural stiffness of the tie bar and simplifies to the form of Eq. 3.6.

$$
\begin{array}{r}
(G A)_{e f f}=24\left(\frac{E I_{p}}{S^{2}}\right) \frac{1}{(2 \alpha+1)} \quad(\text { C.3.1) } \\
\alpha=\frac{\left(\begin{array}{c}
E_{s} I_{p} \\
S
\end{array}\right)}{\left(\frac{E_{s} I_{t}}{t_{s c}-2 t}\right)}=\frac{\left(\frac{S t^{3}}{12 S}\right)}{\left(\frac{\pi d_{t e}^{4}}{64\left(t_{s c}-2 t\right)}\right)}=1.7\left[\frac{t_{s c}}{t}-2\right]\left[\frac{t}{d_{t e}}\right]^{4}
\end{array}
$$

(C.3.2)

After assembly, and before concrete casting, the empty modules provide structural support for construction activities, loads, and the steel framework connected to it. The buckling of the empty module subjected to compression loading is also governed by its effective shear stiffness $(G A)_{\text {eff }}$ and can be estimated conservatively using Eq. C.3.3. The requirements of Equation 3.5 and 3.6 will result in critical buckling stress greater than or equal to $1000 \mathrm{psi}$, which is equivalent to a distributed loading of 12,000 lbs per linear foot for walls with two $0.5 \mathrm{in}$. thick steel plates. The stresses and deflections induced by concrete casting hydrostatic pressure can also be estimated as shown in Varma et al. (2019). Research by Bhardwaj et al. (2018) indicates 
that modules that meet the plate slenderness requirement of Section I1.6(b) can be typically cast with concrete pour heights of up to $30 \mathrm{ft}$ without significant influence of induced deflections and stresses on the compressive strength and buckling of the steel plates.

$$
\sigma_{c r}=\frac{E}{\left(\frac{S}{t}\right)^{2}} \times \frac{1}{(2 \alpha+1)}
$$

\subsection{Members}

\subsubsection{Resistance Factor}

The nominal strength of the composite walls shall be calculated in accordance with this section. A resistance factor $(\phi)$ equal to 0.90 shall be used to calculate the available strength of the composite walls.

\subsubsection{Flexural Strength}

The nominal flexural strength shall be computed based on plastic limit analysis of the cross-section using the plastic stress distribution method according to AISC 360 Specification I1.2b. The steel plates shall be assumed to reach the yield stress of $F_{y}$ in either tension or compression. The concrete infill shall be assumed to have reached compressive stress equal to $0.85 f_{c}^{c}$, ksi. Concrete in tension shall be assumed to have zero stress capacity.

\section{C.3.5.1 Flexural Strength}

The flexural capacity of composite plate shear walls can be calculated using a plastic stress distribution over the wall cross-section. This is in accordance with AISC 360 Section I1.2a, where the steel yield stress in compression and tension is equal to $F_{y}$, and the concrete compressive stress is equal to $0.85 f^{\prime} c$. Additional discussion is included in the AISC 360 Commentary for Section I5(d). 


\subsubsection{Shear Strength}

The nominal in-plane shear strength, $V_{n}$, shall be determined as follows:

where,

$$
V_{n}=\frac{K_{s}+K_{s c}}{\sqrt{3 K_{s}^{2}+{K_{s c}}^{2}}} \times F_{y} \times A_{s w}
$$

$$
\begin{gathered}
K_{s}=G_{s} A_{s w} \\
K_{s c}=\frac{0.7\left(E_{c} A_{c}\right)\left(E_{s} A_{s w}\right)}{4 E_{s} A_{s w}+E_{c} A_{c}}
\end{gathered}
$$

\section{C.3.5.2 Shear Strength}

The in-plane shear behavior of composite walls is governed by the plane stress behavior of the plates and the orthotropic elastic behavior of concrete cracked in principal tension. Varma et al. (2014) and Seo et al. (2016) discuss the fundamental mechanics based model (MBM) for in-plane shear behavior of composite walls. The in-plane shear behavior can be estimated as the trilinear shear force-strain curve shown in Figure $3-4$. The first part of the curve is before the concrete cracks. The second part is after the concrete cracking but before the plate yielding. The third part of the curve corresponds to the onset of plate Von Mises yielding. The shear force corresponding to this onset of von Mises yielding is given by Equation 3.7. The corresponding principal compressive stress in the cracked (orthotropic) concrete is less than $0.7 f^{\prime} c$ for typical composite walls with reinforcement ratios $\left(2 t / t_{s c}\right)$ less than or equal to $10 \%$. For walls with very high reinforcement ratios (i.e., walls with very thick steel plates compared to overall thickness), the concrete principal compressive stress can be the limiting failure criterion (Seo et al. 2016, Varma et al. 2014).

Recent research by Booth et al (2020) has quantified the post-yield ultimate shear strength of composite walls with boundary elements. Typically, this ultimate shear strength is $25-30 \%$ greater than the yield shear strength calculated using Equation 3.7. 

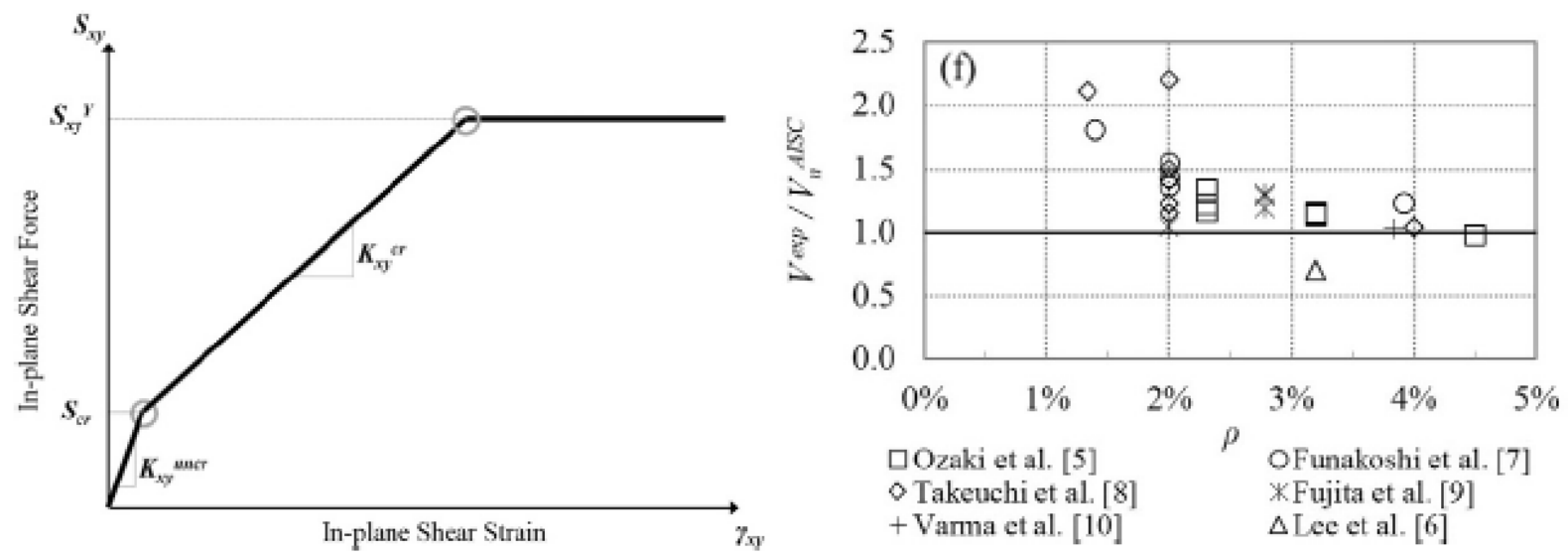

Figure 3-4. In-plane shear force-stain response of composite walls, and comparison of experimental results with shear strength calculated using Equation 3.7 (Seo et al. 2016)

\subsubsection{Required Flexural Strength}

The required flexural strength for the composite walls shall be calculated in accordance with applicable seismic design guidelines.

\subsubsection{Required Shear Strength}

The required shear strength of the composite walls shall be determined as the shear force obtained from the seismic analysis amplified by a factor of four.

\section{C.3.5.8 Required Shear Strength}

A base shear amplification factor of four is used to account for amplification found in higher modes of tall structures. This amplification factor is used only to calculate shear demand and is not used for overturning moment calculation. ACI 318-19 Section 18.10.3.1 prescribes a base shear amplification factor based on the number of stories and the ratio of the probable flexural strength of member $\left(\mathrm{M}_{\mathrm{pr}}\right)$ to the factored moment of the section $\left(\mathrm{M}_{\mathrm{u}}\right)$. In ACI, this amplification is limited to 3.0. The 4.0 factor used in this design to conservatively account for similar phenomenon without developing and validating an equation. 


\subsection{Connection Requirements}

\subsubsection{Connection between Tie Bars and Steel Plates}

Connection of the tie bars to the steel plate shall develop the full tension strength of the tie bar.

\subsubsection{Connection between C-PSW/CF Steel Components}

Welds between the steel web plates and the boundary elements or flange (closure) plates shall be complete-joint-penetration groove welds.

\subsubsection{Composite Wall-to-Foundation Connections}

Where the composite walls are connected directly to the foundation at a point of the maximum moment in the walls, the composite wall-to-foundation connections shall be detailed such that the connection is able to transfer the base shear force and the axial force acting together with the overturning moment, corresponding to 1.1 times the plastic composite flexural strength of the wall. The plastic flexural composite strength of the wall shall be obtained by the plastic stress distribution method, assuming that the steel components have reached a stress equal to the expected yield strength, $R_{y} F_{y}$, in either tension or compression and that concrete components in compression due to axial force and flexure have reached a stress of $0.85 f^{\prime} c$.

\section{C.3.6.3 Composite Wall-to-Foundation Connections}

The wall to basemat connections shall be designed for the expected flexural capacity of the composite wall accounting axial effects and the amplified shear force demand (amplification of 4). The examples of typical wall foundation and connection details are shown in Figure 3-5. 

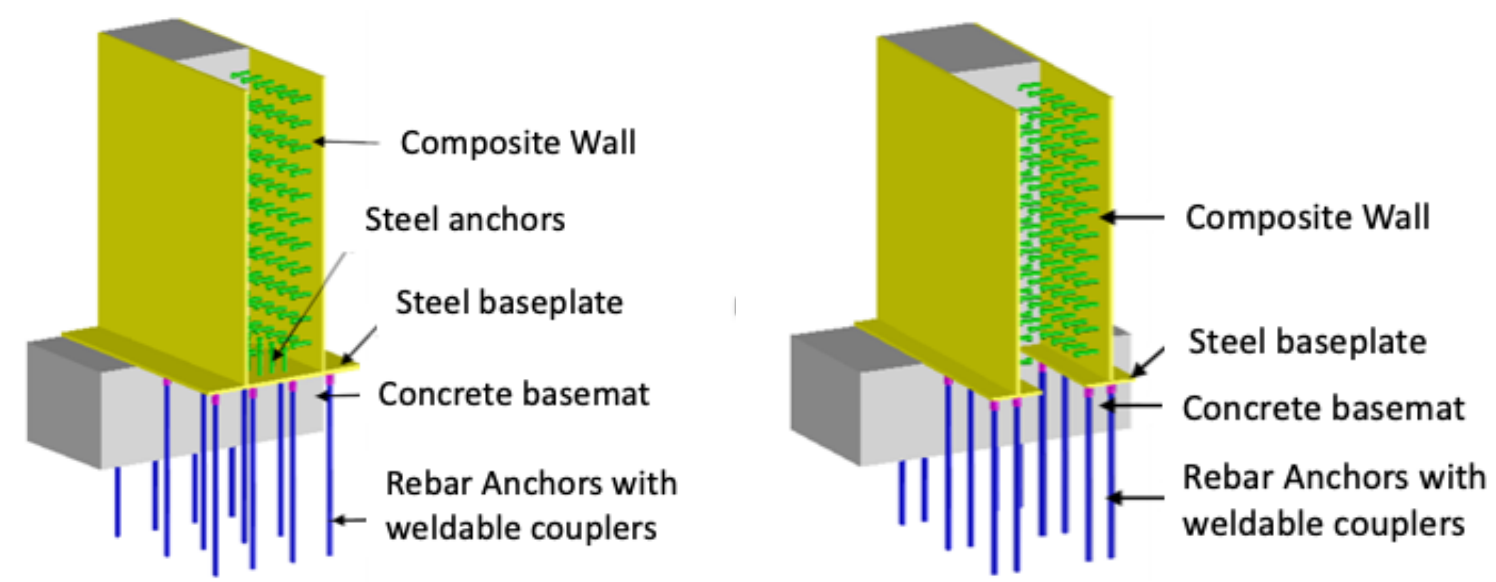

(a)

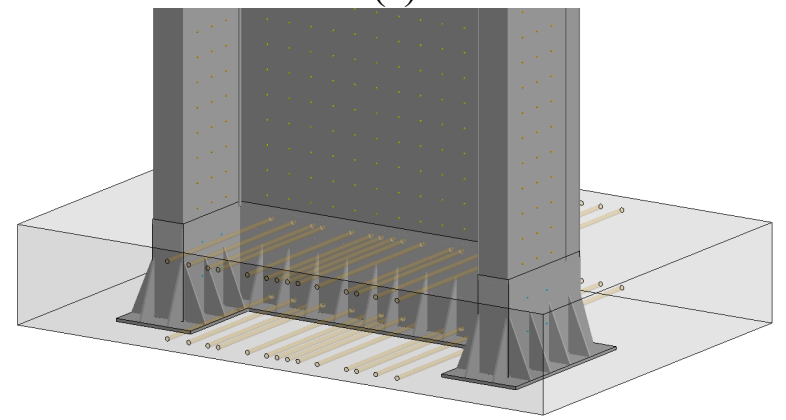

(b)

Figure 3-5. Composite wall to basement connections (a) with welded base plate and rebar couplers (Bhardwaj and Varma, 2016); (b) wall embedded into the concrete foundation (Bruneau et al., 2019). 


\subsection{Protected Zones}

The requirements for protected zones shall be in accordance with AISC 341 Section D1.3 and Section I2.1. The regions at the base of the composite walls subject to inelastic straining shall be designated as protected zones.

\subsubsection{Splices}

Steel plate and boundary element splices located in the designated protected zones shall develop the full strength of the weaker of the two connected elements.

\section{C.3.7 Protected Zones}

Protected zones are defined in AISC 341 as regions of members or connections of members undergoing large inelastic strains or plastic hinging to provide significant inelastic deformation capacity and energy dissipation during design-basis or higher magnitude earthquakes. FEMA / SAC testing has demonstrated the sensitivity of these regions to discontinuities caused by fabrication or erection activities or from other attachments. For this reason, operations specified in AISC 341 Section I2.1 are prohibited in the protected zones.

For the C-PSW/CF system, the protected zones are designated as the regions of the composite walls undergoing significant inelastic straining and plastic hinging. The extent of the plastic hinge region undergoing significant inelastic strains (and the protected zone) can depend on wall cross-section geometry, web plate and flange (closure) plate thickness and lengths, and the height-to-length ratios of the walls. The extent of the protected zone can be determined from analysis. 


\subsection{Demand Critical Welds in C.3.8 Demand Critical Welds in Connections Connections}

Demand critical welds are defined in AISC

The requirements for demand critical welds shall be in accordance with AISC 341 Section A3.4b and Section I2.3.

Where located within the protected zones, the following welds shall be demand critical and shall satisfy the applicable requirements:

(a) Welds connecting the composite wall closure plates to the faceplates

(b) Welds in the composite wall steel plate splices

(c) Welds at composite wall steel plate-to-base plate connections

341 , and the requirements are specified in Section A3.4b and I2.3. These include requirements for the filler metals in terms of minimum levels of CVN toughness using two different test temperatures and specified test protocols, unless exempted from testing. Demand critical welds are generally completejoint-penetration groove (CJP) welds because they are subjected to yield level or higher stress demand and located in joints where failure can result in significant degradation in strength or stiffness.

Welds used within the protected zone composite walls are designated as demand critical, and therefore required to meet the corresponding requirements. These include potential CJP welds connecting the composite wall flange (closure) plates to the web plates, potential CJP welds used in composite wall steel plate splices, and potential CJP welds used in composite wall steel plate-to-base plate connections. 


\section{DETAILED DESIGN PROCEDURE FOR ARCHETYPE STRUCTURES}

This chapter describes the detailed design approach used to design the low to mid-rise (3-22 stories) office buildings archetype structures with C-PSW/CF walls. The low-rise structures (3-12 stories) used planar composite walls, and the mid-rise structures (15-22 stories) used C-shaped composite walls as the seismic force-resisting system. The walls were designed following the provisions of applicable building code, seismic design code, and FEMA P695. The design procedure involved selecting initial parameters including building floor plan, load requirements, and seismic parameters. These parameters were selected after several iterations based on feedback from industry professionals and FEMA review panel. The archetype structures were designed to represent low-rise and mid-rise office buildings with dimensions following architectural considerations. One such architectural limitation was the length of composite walls which was limited to typical bay lengths and was varied in multiples of $5 \mathrm{ft}$. The parameters used for this study will be discussed further in this chapter.

Two composite walls were provided in the direction of consideration for both planar and C-shapes composite walls systems. The planar composite walls were designed to resist lateral forces along the length of the wall. C-shaped walls were designed as uncoupled walls in the direction of consideration of seismic ground motion (parallel to the web). These walls would be coupled in the perpendicular direction with the coupling action achieved using composite coupling beams connecting both the walls at each floor. Figure 4-1 shows the typical cross-section of the planar composite wall and $\mathrm{C}$-shaped composite walls.

(a)

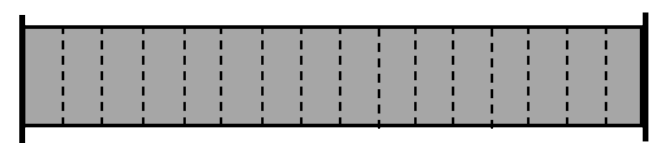

(b)

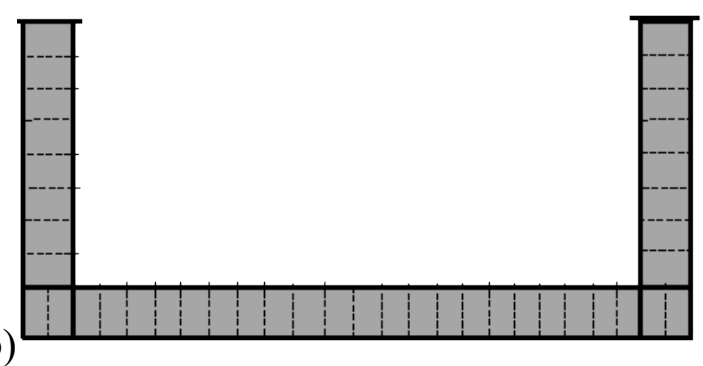

Figure 4-1. C-PSW/CF typical cross-section: (a) Planar, (b) C-shaped 


\subsection{Archetype Structure Initial Parameters}

Archetype structure parameters were based on the review panel recommendations and general industry practices. Considering the complexity and rigorous analysis requirements, the archetype design was limited to four structures with planar composite walls (3,6,9 and 12 stories) and three structures with C-shaped composite walls (15, 18 and 22 stories). Planar walls were considered for shorter structures (3-12 stories) while C-shaped walls were considered for taller structures (15-22 stories) because the core geometry typically used in taller structures includes C-shaped walls as the elevator core. The floor plan (Figure 4-2) varied based on the length of the composite walls. Seven bays were used in the east-west direction and three bays in the north-south direction. Two walls in both directions were used as lateral load carrying members for the archetype structure. shows the basic configuration of planar C-PSW/CF and C-shaped C-PSW/CF. The initial archetype parameters are listed in Table 4-1 below.

The seismic design parameters listed below in Table 4-2 were based on ACSE 7-16 guidelines and peer review committee recommendations. A response modification factor, $\mathrm{R}$, of 6.5 was chosen for validation in line with current ASCE 7-16 recommendations. A seismic ductility factor, $\mathrm{C}_{\mathrm{d}}$, of 5.5 was used. An importance factor, $\mathrm{I}_{\mathrm{e}}$, of 1.0 was used for risk category II. 

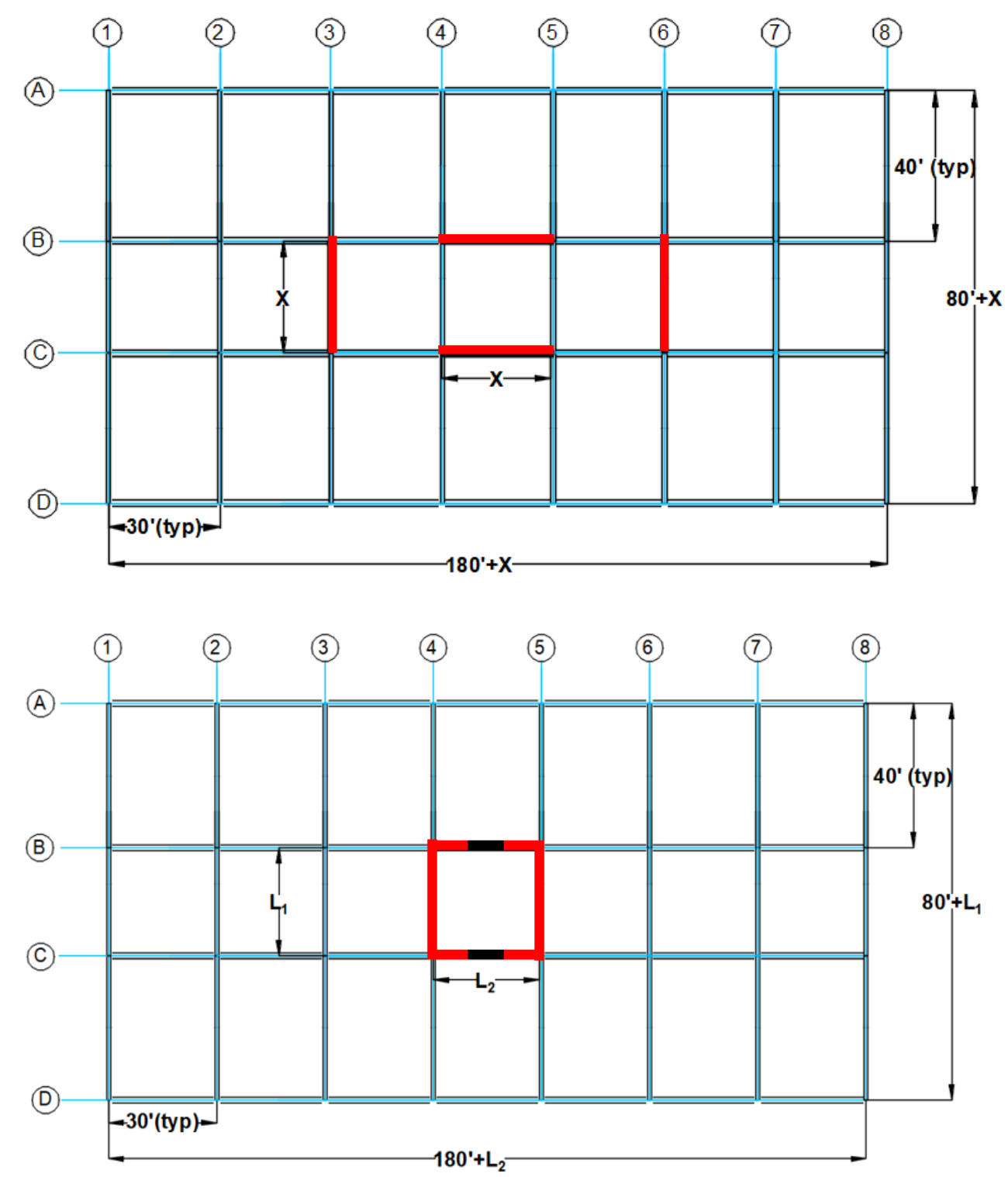

Figure 4-2. Floor plan a) planar walls b) C-shaped walls

Table 4-1. Archetype building parameters

\begin{tabular}{|c|c|l|}
\hline Parameter & Value & Reasoning \\
\hline $\begin{array}{c}\text { Floor } \\
\text { Dimensions }\end{array}$ & $\begin{array}{c}(80+\mathrm{X}) \mathrm{ft} \mathrm{x} \\
(180+\mathrm{X}) \mathrm{ft} \\
\text { where } \mathrm{X} \text { is the } \\
\text { length of the } \\
\text { center bay. }\end{array}$ & Review panel recommendation for typical buildings \\
\hline Story Height & $\begin{array}{c}\text { First story: } 17 \mathrm{ft} \\
\text { Typical story: } 14 \mathrm{ft}\end{array}$ & Review panel recommendation for typical story heights \\
\hline
\end{tabular}




\begin{tabular}{|c|c|l|}
\hline $\begin{array}{c}\text { Number of } \\
\text { Stories }\end{array}$ & 3 to 22 Stories & $\begin{array}{l}\text { Panel recommendation to represent low- and mid-rise } \\
\text { office buildings }\end{array}$ \\
\hline Seismic & $\begin{array}{c}\text { Floor load of } \\
120 \mathrm{psf}\end{array}$ & $\begin{array}{l}\text { Estimated from components: } \\
\text { Steel framing (12 psf) } \\
2.5 \text { " Normal Weight Concrete on 3" Steel Deck (50 psf) } \\
\text { Curtain Wall (15 psf on facade area) } \\
\text { Superimposed Dead Load (15 psf) } \\
\text { Partitions (15 psf) }\end{array}$ \\
\hline $\begin{array}{c}\text { Risk } \\
\text { Category }\end{array}$ & II & Office Building \\
\hline
\end{tabular}

Table 4-2. Seismic design parameters

\begin{tabular}{|c|c|}
\hline Parameter & Value \\
\hline Response Modification Factor & 6.5 \\
\hline Seismic Ductility Factor, $\mathrm{C}_{\mathrm{d}}$ & 5.5 \\
\hline Overstrength Factor, $\Omega$ & 2.5 \\
\hline
\end{tabular}

\subsection{Equivalent Lateral Force Analysis}

The seismic forces on the composite walls were calculated using the Equivalent Lateral Force (ELF) analysis following ASCE 7-16 guidelines. The steps used are summarized below. 


\subsubsection{Response Spectra}

The design response spectrum was built based on guidelines provided in Chapter 11 of ASCE7. The spectral response acceleration curve is plotted based on the design earthquake spectral acceleration parameters $S_{D S}$ and $S_{D 1}$. The spectral acceleration parameters are dependent on the site class, soil condition, mapped ground motion values and importance factor. $S_{D S}$ and $S_{D I}$ values of $1.0 \mathrm{~g}$ and $0.6 \mathrm{~g}$, respectively as specified in the FEMA P695 were used for the analysis.

\subsubsection{Approximate Fundamental Period}

The approximate fundamental period, $\mathrm{T}_{\mathrm{a}}$, was be calculated based on guidelines provided in Section 12 of ASCE7. The approximate fundamental period is calculated using Equation 4.1 considering approximate period coefficient $\mathrm{C}_{\mathrm{t}}$ as 0.02 and $\mathrm{x}$ as 0.75 per section 12.8-2 of ASCE7. The coefficient of the upper limit period, $\mathrm{C}_{\mathrm{u}}$, is taken as 1.4 based on a seismic acceleration parameter $\mathrm{S}_{\mathrm{D} 1}$ of 0.6. The upper limit of the fundamental period can be calculated using Equation 4.2. Once the initial guess of section size is developed, the fundamental period based on modal

analysis shall be determined. The fundamental period shall be adjusted to the minimum of the fundamental period from modal analysis and upper limit fundamental period.

$$
\begin{gathered}
T_{a}=C_{t} h_{n}{ }^{x} \\
T_{\text {upper }}=C_{u} T_{a}
\end{gathered}
$$




\subsubsection{Seismic Response Coefficient, $C_{s}$}

The seismic response coefficient, $C_{s}$, is calculated according to section 12.8.1 of ASCE7 guidelines. The guidelines and equations used for the calculation are summarized here. The seismic response coefficient, $\mathrm{C}_{\mathrm{s}}$ shall be calculated in accordance with Equation 4.3. The seismic response coefficient shall be adjusted according to the minimum and maximum allowable value based on Equation 4.4-4.7. A response modification factor, $R$, of 6.5, importance factor, $I_{e}$, of 1.0 and long period, $T_{L}$ of $8 \mathrm{~s}$ were used for the $C_{S}$ calculations.

$$
\begin{gathered}
C_{s}=\frac{S_{D S}}{\left(\frac{R}{I_{e}}\right)} \\
C_{s, \max }=\frac{S_{D 1}}{T\left(\frac{R}{I_{e}}\right)} \text { for } T \leq T_{L} \\
C_{s, \max }=\frac{S_{D 1} T_{L}}{T^{2}\left(\frac{R}{I_{e}}\right)} \text { for } T>T_{L} \\
C_{s, \min }=0.044 S_{D S} I_{e} \text { for } \geq 0.01 \\
\text { If } \mathrm{S}_{1} \geq 0.6 \mathrm{~g} C_{s, \min }=\frac{0.5 S_{1}}{\left(\frac{R}{I_{e}}\right)}
\end{gathered}
$$

\subsubsection{Base Shear Calculations}

The base shear, $V$, is calculated per Eq. 12.8-1 of ASCE7 as shown in Equation 4.8 below. The seismic weight, $W$, is taken from Table 4-1 and coefficient, $C_{s}$, is determined in Step 0.

$$
V=C_{s} W
$$




\subsubsection{Vertical Distribution of Seismic Forces}

The lateral seismic force distributed at any level of the building is determined by following Section 12.8.3 of ASCE7. The vertical distribution factor, $C_{v x}$, is determined according to Equation 4.9 using story level weight, $w_{i}$ and $w_{x}$, assigned to level $i$ or $x$, and height, $\mathrm{h}_{\mathrm{i}}$ and $\mathrm{h}_{\mathrm{x}}$, from the base to level $i$ or $x$. The story level shear is then calculated using Equation 4.10.

$$
\begin{gathered}
C_{v x}=\frac{w_{x} h_{x}^{k}}{\sum_{i=1}^{n} w_{i} h_{i}^{k}} \\
F_{x}=C_{v x} V
\end{gathered}
$$

\subsubsection{Composite Walls Required Shear Strength and Amplification Factor}

The required wall base shear strength is adjusted. A base shear amplification factor of four is used to account for amplification found in higher modes of tall structures. This amplification factor is used only to calculate shear demand and is not used for overturning moment calculation. ACI 31819 Section 18.10.3.1 prescribes a base shear amplification factor based on the number of stories and the ratio of the probable flexural strength of member $\left(\mathrm{M}_{\mathrm{pr}}\right)$ to the factored moment of the section $\left(\mathrm{M}_{\mathrm{u}}\right)$. In ACI, this amplification is limited to 3.0. The 4.0 factor used in this design to conservatively account for similar phenomenon without developing and validating an equation.

Figure 4-3 shows the typical vertical distribution of seismic forces along the height of the C$\mathrm{PSW} / \mathrm{CF}$. 


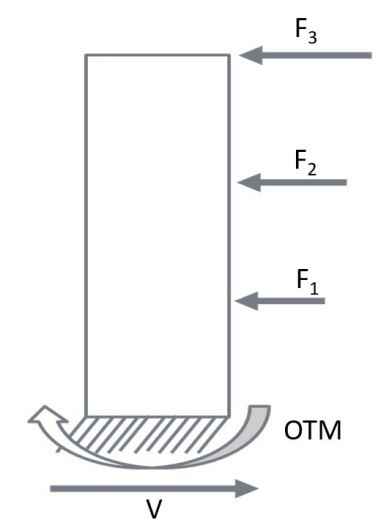

\section{Figure 4-3. Distribution of vertical forces}

\subsubsection{Overturning Moment at the Base}

The overturning moment at the base, OTM, of the wall is calculated based on the vertical distribution of seismic forces per Section 0 (See Figure 4-3). The amplification factor of four is not applied during the calculation of the overturning moment.

\subsection{Preliminary Design}

The preliminary design of composite walls consists of selecting wall length, total wall thickness, and steel plate thickness. The preliminary design was selected to withstand design forces and to satisfy drift requirements.

\subsection{Structural Analysis}

After selecting a preliminary design, structural analysis is performed. The composite walls are modeled in accordance with Section 3.3. The required strength in shear and flexure are accurately computed based on equivalent lateral force analysis presented in Section 4.2. The story deflections due to lateral loads are also calculated in this step. 


\subsection{Design Checks}

The composite wall design check includes steel plate slenderness requirements, tie reinforcement requirements, empty module requirements, shear and flexural strength check, and inter-story drift check. The required design checks are summarized in this section.

\subsubsection{Wall Steel Plate Slenderness Requirement}

The composite wall steel plate slenderness requirement shall satisfy tie spacing, s, requirement before and after placement of concrete using the guidelines provided in Section 3.4.2.

\subsubsection{Wall Shear Strength}

The in-plane shear strength required for the composite walls is calculated based on base shear, $V_{\text {base, }}$ computed in Section 4.2.4. The total base shear is then divided by the number of walls to distribute the forces to all walls equally and is then amplified by a factor of 4 (shear amplification factor) to calculate the required shear strength on each wall. The available design shear strength is calculated according to Section 3.5.3.

\subsubsection{Wall Flexural Strength}

The required flexural strength of the composite walls is calculated as the overturning moment (OTM) computed from Section 4.2.7 divided by the number of walls. The available design flexural strength of composite walls is calculated according to Section 3.5.2. Plastic hinge formation at the base of the wall acts as the energy dissipating mechanism.

\subsubsection{Inter-Story Drift Ratio}

The inter-story drift ratio (IDR) is calculated from the story displacement found from the structural analysis performed in Section 4.4. The IDR for each level is calculated as the ratio of the difference 
in the story displacement of two adjacent levels to the story height at that level. The maximum IDR shall be checked against a 2\% limit per Table 12.12-1 of ASCE7-16.

\subsection{Final Check and Redesign}

The design checks as mentioned in Section 4.5 shall be performed. Redesign of composite walls may be necessary, and the design of the walls is adjusted until the system meets all design requirements. Parameters like wall length, wall thickness, plate thickness, and the number of composite walls, can be adjusted to obtain the desired performance. 


\section{DESIGNED ARCHETYPES}

Archetype structures were divided into two performance groups, low-rise structures, and mediumrise structures. Planar/rectangular composite walls were used as the lateral system for the low-rise archetype structures and C-shaped composite walls were used for the medium-rise archetype structures. Figure 5-1, Figure 5-3 and Figure 5-3 represent the configuration and nomenclature of the lateral system used for the planar and C-shaped archetypes, respectively. The bay length of the center bay (CB) as shown in Figure 5-3 was varied for each archetype based on the length of the composite walls. The details of archetypes structures used for the FEMA P695 procedure are presented in this chapter. 


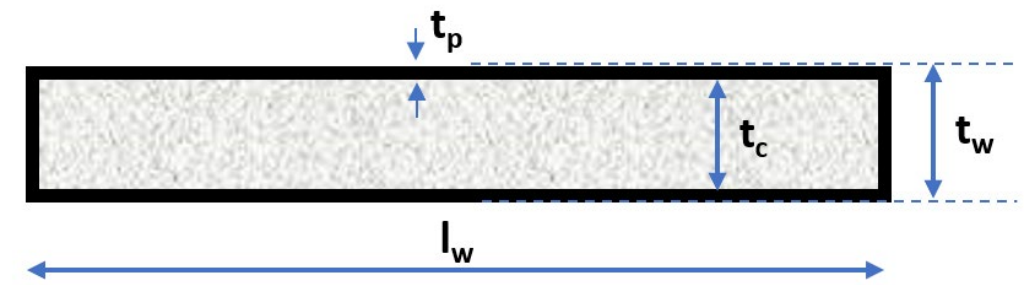

Figure 5-1. Planar C-PSW/CF

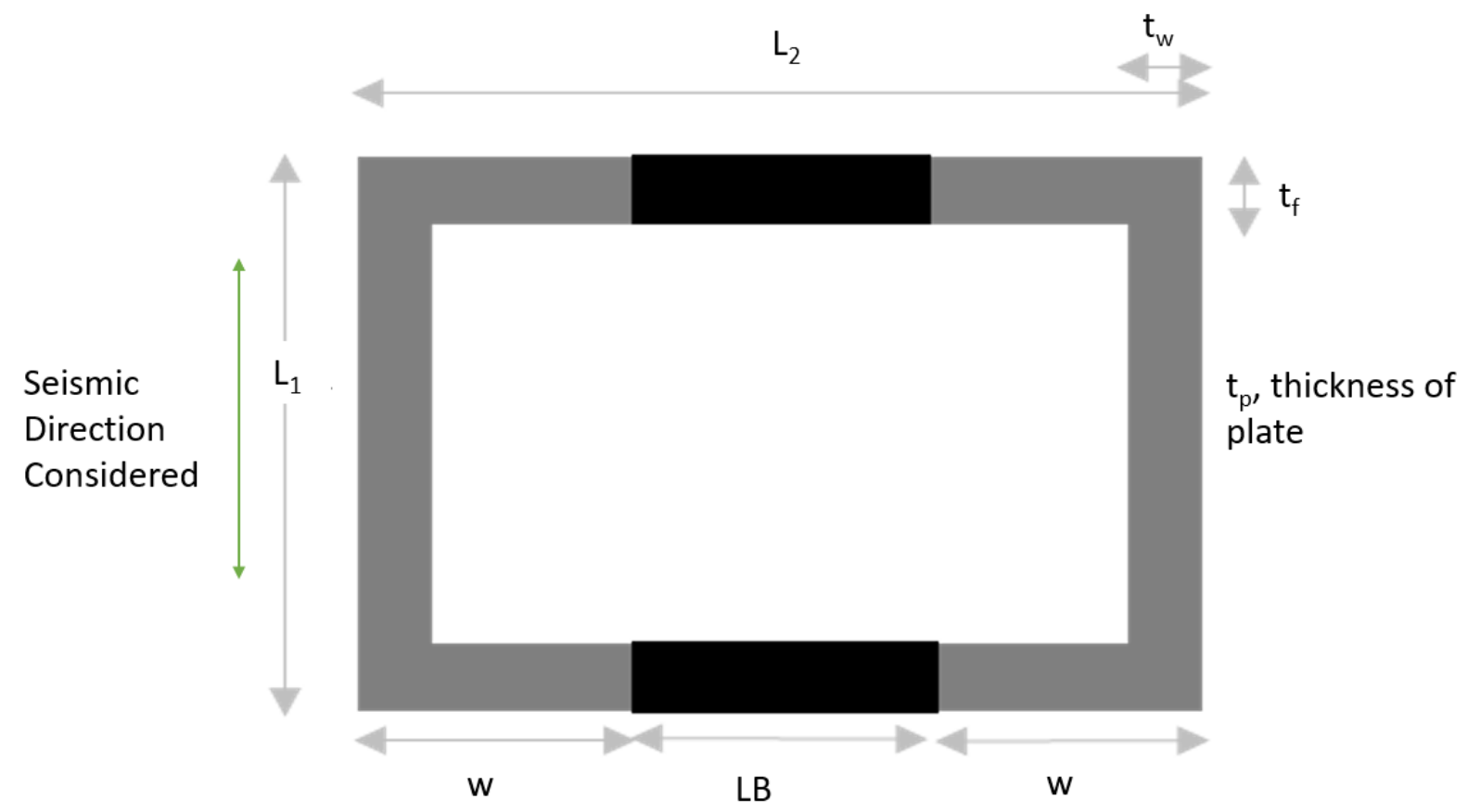

Figure 5-2. C-shaped composite plate shear wall Archetype configuration 


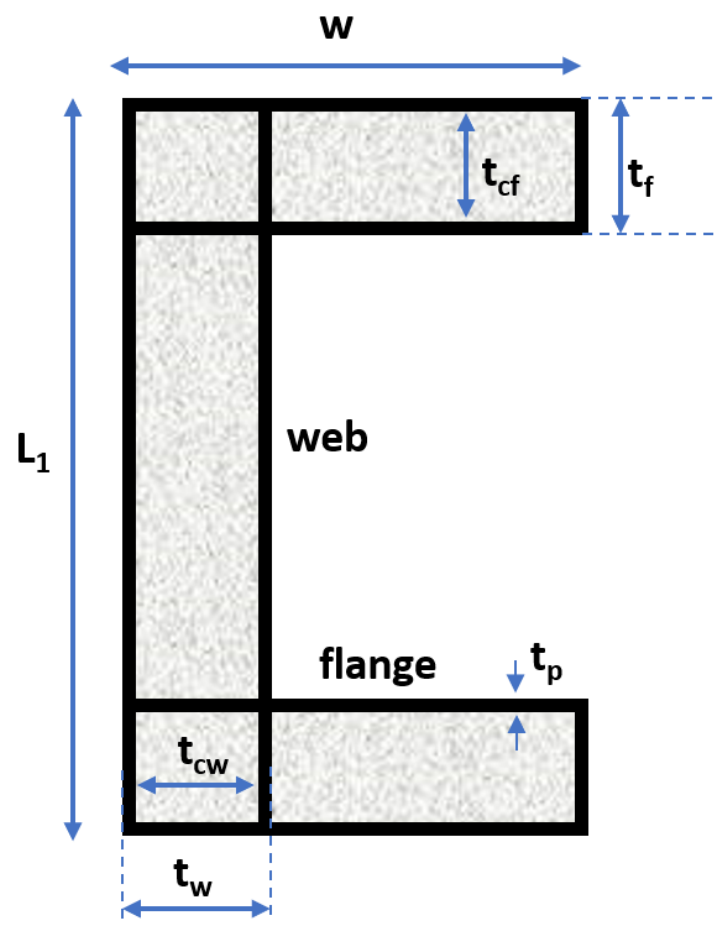

Figure 5-3. C-shaped composite plate shear wall cross-section

\subsection{Planar Archetype}

Four archetypes (3, 6, 9 and 12 story) were designed using planar composite walls as the lateral resisting system. The configuration of planar composite walls used for the archetype structure is presented in Figure 5-1. Two walls in each direction were used. The flange plate thickness was kept the same as the thickness of the web plates. Table 5-1 presents the floor plan used for the planar archetypes. Table 5-2 summarizes the dimensions of the wall used for each of the archetypes. Table 5-3 presents additional information on the designed lateral system including the wall aspect ratio, design strength compared to the required strength. This table also summarizes the maximum inter-story drift ratio estimated using the non-linear finite element models. 
Table 5-1. Floor plans for planar archetype structures

\begin{tabular}{|c|c|c|c|c|c|c|}
\hline Case & $\begin{array}{c}\text { No. of } \\
\text { Stories }\end{array}$ & $\begin{array}{c}\text { Center Bay } \\
\text { Length, } \mathrm{ft}\end{array}$ & $\begin{array}{c}\text { Center Bay } \\
\text { Width, } \mathrm{ft}\end{array}$ & $\begin{array}{c}\text { Length, } \\
\mathrm{ft}\end{array}$ & $\begin{array}{c}\text { Width, } \\
\mathrm{ft}\end{array}$ & $\begin{array}{c}\text { Story Weight, } \\
\text { kip }\end{array}$ \\
\hline 1 & 3 & 20 & 20 & 200 & 100 & 2400 \\
\hline 2 & 6 & 25 & 25 & 205 & 105 & 2583 \\
\hline 3 & 9 & 30 & 30 & 210 & 110 & 2772 \\
\hline 4 & 12 & 35 & 35 & 215 & 115 & 2967 \\
\hline
\end{tabular}

Table 5-2. Planar composite wall archetypes

\begin{tabular}{|c|c|c|c|c|c|}
\hline Case & No. of Stories & Wall Thickness, in & $\begin{array}{c}\text { Wall Length, } \\
\mathrm{ft}\end{array}$ & Plate thickness, in & Height, $\mathrm{ft}$ \\
\hline 1 & 3 & 12 & 15 & $4 / 16$ & 45 \\
\hline 2 & 6 & 16 & 25 & $5 / 16$ & 87 \\
\hline 3 & 9 & 24 & 30 & $7 / 16$ & 129 \\
\hline 4 & 12 & 32 & 35 & $8 / 16$ & 171 \\
\hline
\end{tabular}

Table 5-3. Planar archetype structures - aspect ratio, strength, and inter-story drift ratio

\begin{tabular}{|c|c|c|c|c|c|c|}
\hline \multirow{2}{*}{ Case } & \multirow{2}{*}{$\begin{array}{c}\text { No. of } \\
\text { Story }\end{array}$} & \multirow{2}{*}{$\mathrm{H}_{\mathrm{T}} / \mathrm{L}$} & \multirow{2}{*}{$\mathrm{H}_{1 \mathrm{st}} / \mathrm{T}_{\mathrm{sc}}$} & \multicolumn{2}{|c|}{ Wall Strength Margin } & \multirow{2}{*}{$\begin{array}{c}\text { Max. Inter-story Drift } \\
\text { Ratio, FE Model (\%) }\end{array}$} \\
\hline 1 & 3 & 3 & 17 & 1.30 & 1.83 & 2.0 \\
\hline 2 & 6 & 3.5 & 12.8 & 1.42 & 2.19 & 2.0 \\
\hline 3 & 9 & 4.3 & 8.5 & 1.78 & 3.30 & 2.0 \\
\hline 4 & 12 & 4.9 & 6.8 & 1.97 & 4.07 & 2.0 \\
\hline
\end{tabular}

\subsection{C-shaped Archetype}

Three archetypes (15, 18, and 22 story) were designed using the $\mathrm{C}$-shaped composite walls lateral resisting system. The floor plan used for each of the archetypes is presented in Table 5-4. Two Cshaped walls as shown in Figure 5-3 were used for lateral resistance. For the three archetype structures, C-shaped walls were designed as the uncoupled system in the north-south direction and coupled system in the east-west direction. The analysis was only conducted in the uncoupled 
direction. The coupled direction involves the use of different seismic performance factors compared to the uncoupled direction. A separate lateral analysis shall be performed for these walls in the coupled direction. The design iteration of these walls involves the variation of flange thickness, $t_{f}$, flange width, w, web length, $L_{1}$, web thickness, $t_{w}$, and steel plate thickness, $t_{p}$. The design was selected to satisfy architectural constraints and accommodate the elevator core in between two C-shaped walls. The total thickness of wall flanges, $t_{f}$, and web thickness, $t_{w}$, were kept the same for 15 and 18 story archetypes and different for 22 story archetypes. Thicker flanges compared to web thickness were used in 22 story structures which helped to increase the overall stiffness and hence reduce the inter-story drift ratio of the structure while maintaining the architectural constraints. The thickness of steel plates was kept the same for web and flange plates. Table 5-5 summarizes the dimensions of C-shaped archetype structures. Table 5-6 presents the additional information for the $\mathrm{C}$-shaped composite walls including the ratio of design strength compared to the required strength, the maximum inter-story drift ratio for the equivalent lateral forces.

Table 5-4. Floor plans for C-shaped archetype structures

\begin{tabular}{|c|c|c|c|c|c|c|c|}
\hline Case & $\begin{array}{c}\text { No. of } \\
\text { Stories }\end{array}$ & $\begin{array}{c}\text { Web } \\
\text { Depth, } \\
\mathbf{f t}\end{array}$ & $\begin{array}{c}\text { Flange } \\
\text { Length, } \\
\mathbf{f t}\end{array}$ & $\begin{array}{c}\text { Web } \\
\text { Thickness, } \\
\text { in }\end{array}$ & $\begin{array}{c}\text { Flange } \\
\text { Thickness, } \\
\text { in }\end{array}$ & $\begin{array}{c}\text { Plate } \\
\text { Thickness, } \\
\text { in }\end{array}$ & $\begin{array}{c}\text { Coupling } \\
\text { Beam } \\
\text { Length, ft }\end{array}$ \\
\hline 5 & 15 & 30 & 11 & 22 & 22 & $8 / 16$ & 8 \\
\hline 6 & 18 & 40 & 10 & 18 & 18 & $8 / 16$ & 10 \\
\hline 7 & 22 & 40 & 11 & 28 & 32 & $9 / 16$ & 8 \\
\hline
\end{tabular}

Table 5-5. C-shaped composite wall archetype structures

\begin{tabular}{|c|c|c|c|c|c|c|}
\hline Case & $\begin{array}{c}\text { No. of } \\
\text { Stories }\end{array}$ & $\begin{array}{c}\text { Center Bay } \\
\text { Length, ft }\end{array}$ & $\begin{array}{c}\text { Center Bay } \\
\text { Width, ft }\end{array}$ & $\begin{array}{c}\text { Length, } \\
\mathbf{f t}\end{array}$ & $\begin{array}{c}\text { Width, } \\
\mathbf{f t}\end{array}$ & $\begin{array}{c}\text { Story } \\
\text { Weight, kip }\end{array}$ \\
\hline 5 & 15 & 30 & 30 & 210 & 110 & 2772 \\
\hline 6 & 18 & 30 & 40 & 210 & 120 & 3024 \\
\hline 7 & 22 & 30 & 40 & 210 & 120 & 3024 \\
\hline
\end{tabular}

Table 5-6. Archetype structures - strength, and inter-story drift ratio 


\begin{tabular}{|c|c|c|c|c|c|c|}
\hline \multirow[b]{2}{*}{ Case } & \multirow[b]{2}{*}{$\begin{array}{l}\text { No. of } \\
\text { Story }\end{array}$} & \multirow[b]{2}{*}{$\begin{array}{c}\text { Height, } \\
\text { ft }\end{array}$} & \multicolumn{2}{|c|}{ Wall Strength Margin } & \multirow[b]{2}{*}{ Ieff, in ${ }^{4}$} & \multirow{2}{*}{$\begin{array}{c}\text { Max. Inter- } \\
\text { story } \\
\text { Drift Ratio, \% }\end{array}$} \\
\hline & & & $\phi M_{n, \text { wall }} / M_{u, \text { elf }}$ & $\phi V_{n, \text { wall }} / 4 V_{u, \text { elf }}$ & & \\
\hline 5 & 15 & 213 & 2.1 & 3.3 & $2.3 \mathrm{E} 7$ & 1.9 \\
\hline 6 & 18 & 255 & 2.2 & 3.7 & $4.1 \mathrm{E} 7$ & 1.9 \\
\hline 7 & 22 & 311 & 2.1 & 4.1 & $5.7 \mathrm{E} 7$ & 2.0 \\
\hline
\end{tabular}

Appendix B and Appendix $\mathrm{C}$ in this report provide a detailed design for the 6-story planar and 18 story C-shaped C-PSW/CF archetypes. 


\section{MATERIAL MODELS FOR NON-LINEAR ANALYSES}

This chapter presents the details of steel and concrete materials nonlinear models used for the finite element model and incremental dynamic analysis. This chapter is similar to the discussion presented in Bruneau et al (2019); identical material models were used to conduct the nonlinear analysis for both the coupled and uncoupled C-PSW/CF wall systems. This choice was made to maintain the parity between the two FEMA P695 studies - Bruneau et al (2019) for the coupled walls and this study for the uncoupled walls. The details of these material models are repeated here for completeness and ease of access.

\subsection{General}

OpenSees, an open-source earthquake simulation software, was used to conduct the FEMA P695 analyses. The material models present in the OpenSees element library (McKenna et al. 2016) were used to model the steel and concrete components of the composite walls. As described in Section 2.4, the FEMA P695 procedure involves a large number of analyses/simulations and needs to be repeated several times for different earthquakes records. Such a large number of analyses results in intense computation. OpenSees uses a macro fiber to model nonlinear behavior allowing rapid execution compared to other finite element software packages available. OpenSees have been utilized by several other researchers for FEMA P695 based IDA studies, e.g., (Kanvinde 2003; Rodgers et. al 2006; Lignos et. al 2008; Bruneau et al. 2019).

The material models were taken from the previous research conducted on coupled composite walls (Broberg et al. 2019, Shafaei et al 2020b). The details of the material models developed for the IDA analysis are described in this section. The steel material model used for the IDA study is described in Section 6.2. The steel effective stress-strain curve was developed to account for buckling of the steel plates, low-cycle fatigue, and isotropic strain hardening. Section 6.3 presents the details of the concrete material model used for this study. The material model for concrete was developed to account for the confinement provided by steel faceplates and closure plates (Broberg et al. 2019). The behavior of the model was then verified using the existing tests on the planar composite plate shear wall conducted by Purdue University (Wang et al. 2018). These material 
models were derived and verified using 3D FEA in ABAQUS (Shafaei et al. 2019, Shafaei et al 2020b).

The performance of walls without the closure flange plates was also compared with walls with closure plates. A previous study (Kurt et. al 2008) showed that concrete and steel behave differently in walls with and without closure plates. Boundary elements like closure plate or a W section provide high confinement to the concrete compared to walls without any boundary elements. Hence, a different set of steel and concrete material models were used for walls without closer plates as presented in Chapter 11 of this report.

\subsection{Steel Model}

The ReinforcingSteel material model from OpenSees material library was used to model steel fibers in the composite wall. The model was developed based on the work of Chang and Mander (1994) and Kunnath et al. (2009). It simulates compression buckling, low-cycle fatigue, and fracture. ReinforcingSteel is the only material in the OpenSees library capable of accounting the steel fracture. Past experiments showed that fracture rather than local buckling leads to strength degradation in the composite walls (Shafaei et al 2020a). To define the true tensile and compressive stress curve, ReinforcingSteel uses an effective stress-strain tensile backbone curve. Figure 6-1 represents the backbone curve compared to the engineering stress-strain curve. The parameters required to create the curve are yield stress, $f_{y}$, ultimate stress, $f_{u}$, initial Young's modulus, $E_{s}$, Modulus at strain hardening, $\mathrm{E}_{\mathrm{sh}}$, strain corresponding to initial strain hardening, $\varepsilon_{\mathrm{sh}}$, and ultimate strain at peak stress, $\varepsilon_{u}$. 


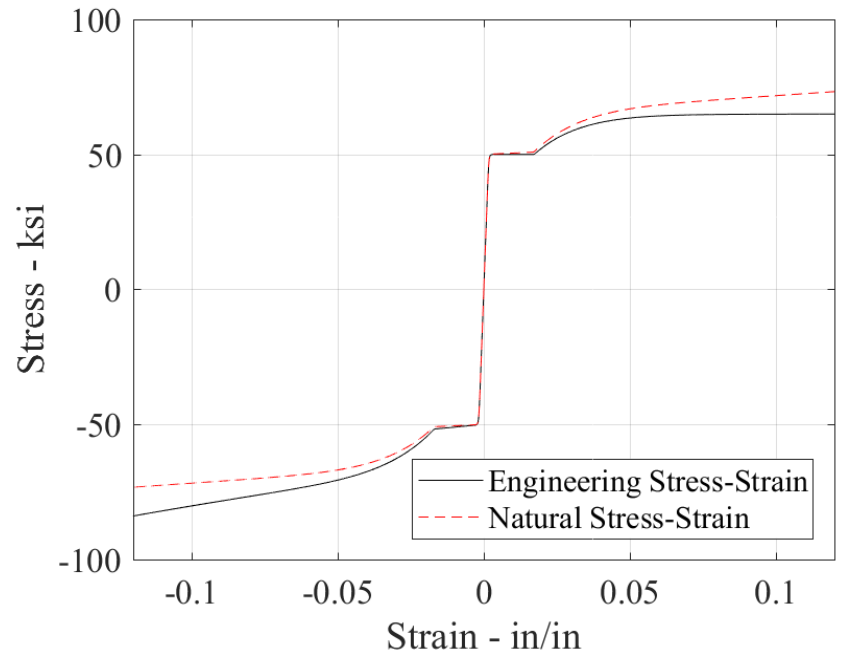

Figure 6-1. Steel backbone curve (Bruneau et al. 2019)

\subsubsection{Compression Buckling}

The buckling model of ReinforcingSteel material was based on Gomes and Appleton (1997). This model considers four parameters to model the buckling behavior in steel. These parameters are slenderness ratio, $1_{\mathrm{SR}}$, amplification factor, $\beta$, buckling reduction factor, $r$, and the buckling constant, $\gamma$. The slenderness ratio, $1_{\mathrm{SR}}$, for buckling of steel fibers is defined as the ratio of unsupported length, $\mathrm{L}_{\mathrm{u}}$, and diameter of re-bars, $\mathrm{d}_{\mathrm{b}}$, as shown in Equation 5.1.

$$
\mathrm{l}_{\mathrm{SR}}=\frac{\mathrm{L}_{\mathrm{u}}}{\mathrm{d}_{\mathrm{b}}}
$$

The unsupported length, $\mathrm{L}_{\mathrm{u}}$, of steel modules in the composite walls was taken as the spacing between the tie bars. The re-bar diameter, $d_{b}$, was taken to be the effective bar diameter, $d_{b \text {,eff, }}$ determined by equating radius of gyration of the steel plate of the walls to the radius of gyration of a re-bar having $d_{b, e f f}$. The effective re-bar diameter can be determined using Equation 6.2a and $6.2 \mathrm{~b}$ as shown below.

$$
\begin{array}{r}
I_{\text {plate }}=\frac{b t_{p}^{3}}{12\left(1-v^{2}\right)} \\
I_{\text {rebar }}=\frac{\pi d_{b}^{4}}{64}
\end{array}
$$


Figure 6-2 below describes the use of amplification factor, $\beta$, buckling reduction factor, $\mathrm{r}$, and the buckling constant, $\gamma$. The amplification factor, $\beta$, scales the buckling curve and adjusts the location of the bifurcation point. The buckling reduction factor, $r$, helps to adjust the shape of the postbuckling curve. The value of $\mathrm{r}$ ranges between 0 to 1 , with 1.0 representing unbuckled shape. The buckling constant, $\gamma$, helps in the imitation of buckling by reducing the stresses after $\gamma \mathrm{f}_{\text {su. Figure }}$ 6-3 shows the effect of the variation of sample parameters on the buckling model. The values of buckling parameters used for the non-linear model are defined in Chapter 8.

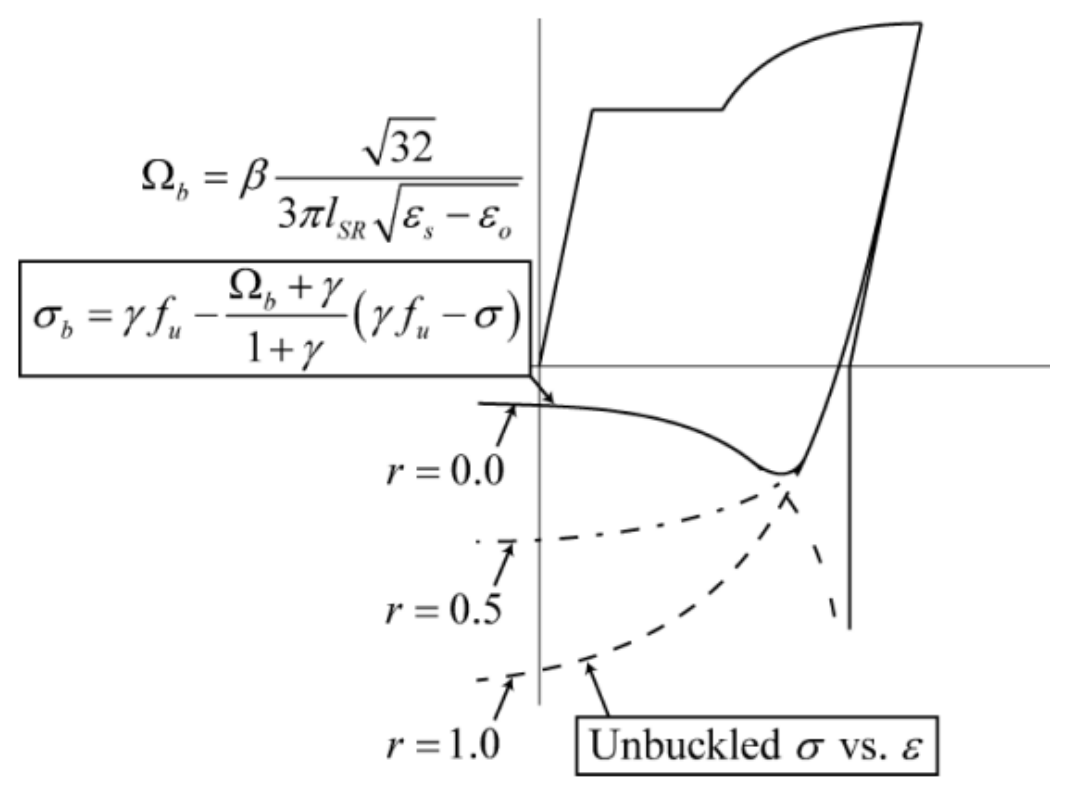

Figure 6-2. Buckled stress-strain curve (McKenna et al. 2016) 

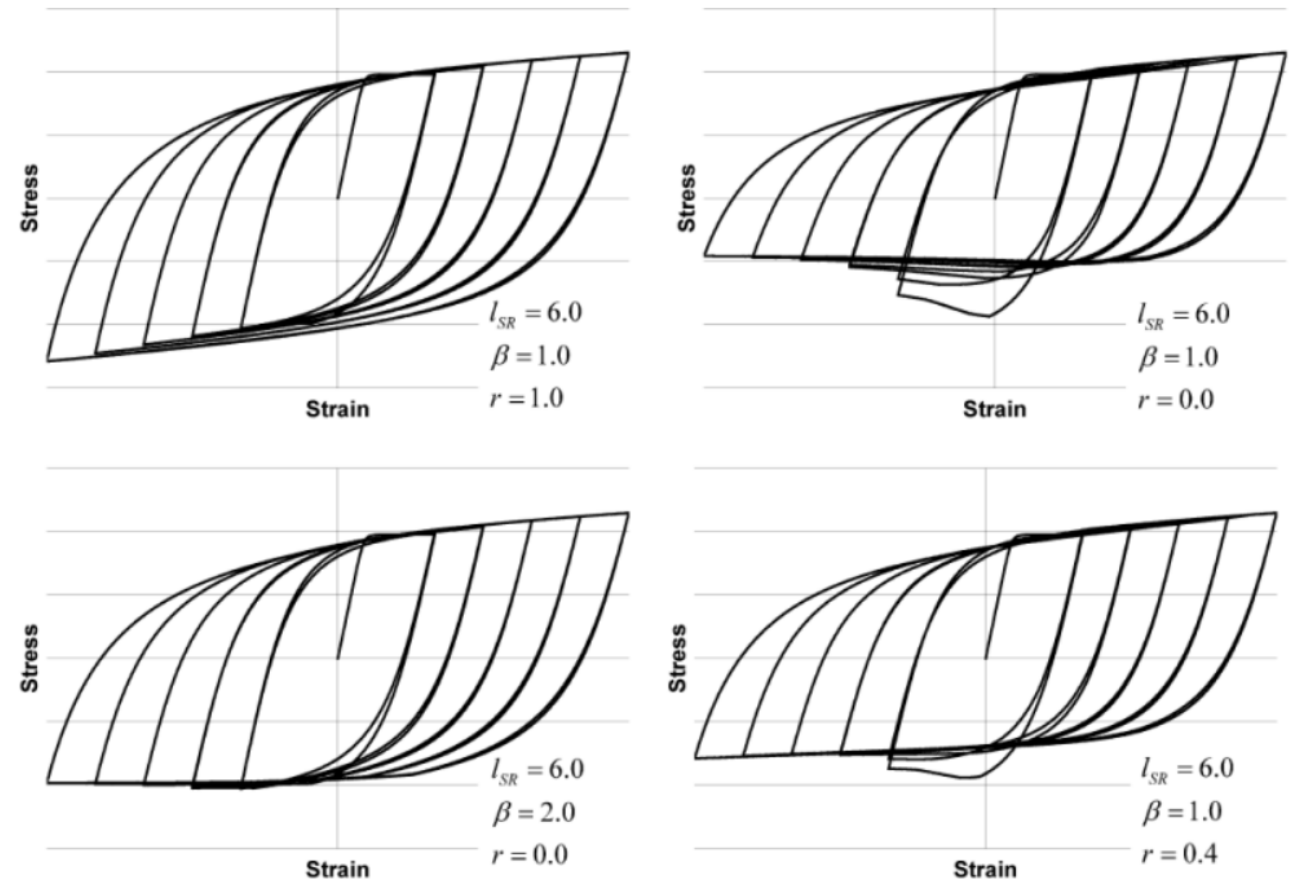

Figure 6-3. Effect of change in sample parameters on buckling model (McKenna et al. 2016).

\subsubsection{Low-Cycle Fatigue}

The strength degradation in composite walls is caused mainly due to the progress of fracture across the wall cross-section. The ReinforcingSteel model uses the Coffin-Mansion fatigue life equations (Coffin 1954; Manson 1965; Coffin 1971) to model low-cycle fatigue, shown in Equation 6.3. Here $\Delta \varepsilon_{\mathrm{P}}$ represents the plastic strain amplitude; $2 \mathrm{~N}_{\mathrm{f}}$ (Equation 6.4) represents the number of halfcycles to failure; $\varepsilon_{\mathrm{f}}^{\prime}$ represents the fatigue ductility coefficient; $\alpha$ represents the fatigue ductility exponent.

$$
\begin{gathered}
C_{f}=\Delta \varepsilon_{\mathrm{P}}=\varepsilon_{\mathrm{f}}^{\prime} *\left(2 \mathrm{~N}_{\mathrm{f}}\right)^{\alpha} \\
2 N_{f}=N_{\text {HalfCycles }}
\end{gathered}
$$

The amplitude of the plastic strain half cycle, $\varepsilon_{\mathrm{p}}$, in tension and compression are measured by Equation (6.5). The total number of half-cycles to failure is calculated in Equation 6.4. The cumulative damage factor, $\mathrm{D}_{\mathrm{f}}$, at various stages of half-cycles is determined using Equation 6.8. 
The cumulative damage factor, $\mathrm{D}_{0}$, is zero is applied to the fiber before the start of the application of strains. The final cumulative damage factor is 1.0 at fracture and once the steel fracture the stress carrying capacity rapidly degrades to zero.

$$
\begin{gathered}
\Delta \varepsilon_{\mathrm{P}}=\varepsilon_{\mathrm{t}}-\frac{\sigma_{\mathrm{t}}}{\mathrm{E}_{\mathrm{S}}} \\
\mathrm{N}_{\text {HalfCycles }}=\left(\frac{\Delta \varepsilon_{\mathrm{P}}}{\varepsilon_{\mathrm{f}}^{\prime}}\right)^{-\frac{1}{\alpha}} \\
\mathrm{D}_{\mathrm{i}}=\left(\frac{1}{\mathrm{~N}_{\text {HalfCycles }}}\right) \\
\mathrm{D}_{\mathrm{f}}=\Sigma \mathrm{D}_{\mathrm{i}}
\end{gathered}
$$

where $\Delta \varepsilon_{\mathrm{p}}$ is the plastic strain amplitude, $\varepsilon_{\mathrm{t}}$ is the total strain and $\sigma_{\mathrm{t}}$ is the stress amplitudes per cycle, $\mathrm{C}_{\mathrm{f}}$ and $\alpha$ are the material constants, $\mathrm{D}_{\mathrm{i}}$ is the fatigue damage per cycle, and $\mathrm{D}_{\mathrm{f}}$ is the cumulative fatigue damage.

The ReinforcingSteel model also implements strength degradation linked to damage caused by fatigue. The cumulative strength degradation is assumed to be proportional to the cumulative fatigue damage. The strength degradation is measured in terms of the per cycle loss of strength, fSR, per Equation 6.9 (Kunnath et al. 2009).

$$
\sum_{i=1}^{n}\left(f_{S R}\right)_{i}=z_{d} * D_{f}
$$

\subsubsection{Isotropic Strain Hardening}

The ReinforcingSteel material also accounts for isotropic hardening and diminishing yield plateau. Hardening constant, al, and hardening limit, HL, is used to define the hardening and yield plateau and to calculate the hardening factor, HF (Equation 6.10a). The stress-strain relationship in the region after the initiation of strain hardening is calculated based on Equation $6.11 \mathrm{a}$ and $6.11 \mathrm{~b}$ which were developed by Bruneau et al (2019). 


$$
\begin{gathered}
H F=1.0-a 1 * \Delta \varepsilon_{p} \\
\text { if } H F<H L \text { then } H F=H L \\
\text { if } H F>1.0 \text { then } H F=1.0 \\
\varepsilon_{\text {sh_location }}=\varepsilon_{y}+H F *\left(\varepsilon_{s h}+\varepsilon_{y}\right) \\
\varepsilon_{s h}=\log \left(1.0+\varepsilon_{\text {sh_location }}\right) \\
f_{\text {shp }}=f_{y} *\left(1.0+\varepsilon_{\text {sh_location }}\right)
\end{gathered}
$$

\subsection{Concrete Model}

The Concrete02 material model from the OpenSees material library was used for the composite walls. This model is based on the work of Hisham and Yassin (1994). It accounts for the effect of confinement provided by steel module, tension stiffening, degradation of stiffness in unloading and reloading curves, cyclic lading hysteretic response, and concrete crushing. The material model is computationally efficient and requires less memory compared to other materials like ConcreteCM present in OpenSees material library. Figure 6-4 shows the stress-strain curve definition and parameters required for the Concrete02 model definition. The parameters required are, concrete compressive strength, $\mathrm{f}_{\mathrm{pc}}$; strain at compressive strength, $\varepsilon_{0}$; crushing strength, $\mathrm{f}_{\mathrm{pc}}$; strain at crushing strength, $\varepsilon_{U}$; the ratio between unloading slope at $\varepsilon_{U}$ and initial slope $\left(2 * f_{p c} / \varepsilon_{0}\right)$, lambda; tensile strength, $\mathrm{f}_{\mathrm{t}}$; and tension softening stiffness, $\mathrm{E}_{\mathrm{ts}}$. The parameter values used for the concrete model was taken from the works of Broberg and Soheil (2018). 


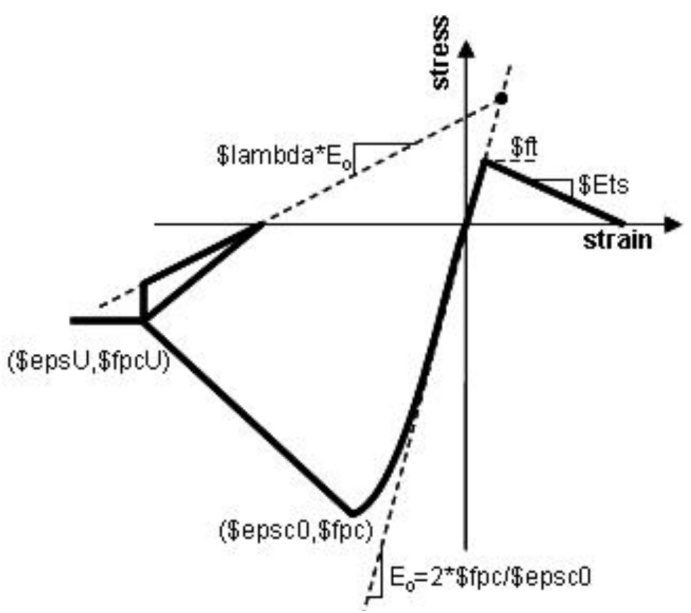

Figure 6-4. Concrete02 model in OpenSees (McKenna et al. 2016)

The steel faceplates and closure plates help to provide confinement to the infill concrete. The confined concrete model was developed based on the work of Susantha et al. (2001) on confined concrete uniaxial stress-strain for concrete-filled steel tubes. Susantha et al. model provided an empirical formula as shown in Equation 6.13 to calculate the strength of the confined concrete, $\mathrm{f}_{\mathrm{cc}}^{\prime}$. Here $\mathrm{f}_{\mathrm{c}}^{\prime}$ is the strength of the unconfined concrete, $\mathrm{f}_{\mathrm{rp}}$ is the maximum radial pressure on infill concrete, and $\mathrm{m}$ is an empirical coefficient taken as 4.0. A reduction factor of 0.85 is applied on the strength of unconfined concrete, $\mathrm{f}_{\mathrm{c}}^{\prime}$.

$$
\mathrm{f}_{\mathrm{cc}}^{\prime}=\mathrm{f}_{\mathrm{c}}^{\prime}+\mathrm{m} * \mathrm{f}_{\mathrm{rp}}
$$




\section{MODEL BENCHMARKING AND CALIBRATION}

This chapter presents the details of the numerical calibration of the planar and C-PSW/CF.

\subsection{General}

The OpenSees steel and concrete materials used for the nonlinear model and Incremental Dynamic Analysis are described in the previous chapter. The model calibration and verification were done using the existing experiment and test results for the planar walls performed by Wang et. al (2018). A total of five planar composite walls (SP1 to SP5) were tested, and the results of the test specimens and the final calibrated parameters are summarized in this section. The test walls were subjected to axial (compression) and lateral (Monotonic and cyclic) load. These walls had a length of 36 in and a height of 108 in resulting in an $\mathrm{h} / \mathrm{L}$ ratio of 3 . The steel faceplate and closure plates were $3 / 16$ in thick and the infill concrete had a thickness of 9 in. The details on axial compression and steel and concrete material are presented in Table 7-1. Two different material models were developed. The assumed stress-strain curves, presented in Figure 7-1, for the steel and concrete were built to match the effective stress-strain curves form the 3D ABAQUS model. These assumed curves follow the material behavior but are slightly conservative than the effective stress-strain curve. Although the effective stress-strain curve provides a better representation of the behavior, the assumed stress-strain curve is conservative, and it saves a significant amount of computation time. The assumed material effective stress-strain curve for steel and concrete is discussed further in this section.

Table 7-1. C-PSW/CF Test Walls SP1 to SP5

\begin{tabular}{|c|c|c|c|c|c|}
\hline$\#$ & Name & $\begin{array}{c}\text { P applied, } \\
\text { kip }\end{array}$ & $\begin{array}{c}\text { Day of Testing } \\
\text { Concrete Strength, } \\
\text { ksi }\end{array}$ & $\begin{array}{c}3 / 16 " \text { Plate } \\
\text { Fy, ksi }\end{array}$ & $\begin{array}{c}3 / 16 " \text { Plate } \\
\text { Fu, ksi }\end{array}$ \\
\hline SP1 & CW-42-55-10-T & 210.0 & 6.5 & 61.2 & 71.0 \\
\hline SP2 & CW-42-55-20-T & 505.0 & 7.8 & 61.2 & 71.0 \\
\hline SP3 & CW-42-14-20-T & 560.0 & 8.7 & 61.2 & 71.0 \\
\hline SP4 & CW-42-14-20-TS & 540.0 & 8.4 & 61.2 & 71.0 \\
\hline SP5 & CW-42-55-30-T & 710.0 & 7.4 & 61.2 & 71.0 \\
\hline
\end{tabular}




\subsection{Proposed Material Models}

The ReinforcingSteel material as described in Section 6.2 was used to model steel faceplates and closure plates. The steel model was developed to include Coffin-Manson fatigue degradation and fracture, Gomes-Appleton buckling, isometric hardening. The steel in tension was considered as elastic-plastic with strain hardening and the steel in compression was considered as elastic-plastic response. The infill concrete was modeled using Concrete02 material from OpenSees library as described in Section 6.3. The concrete compression uniaxial effective stress-strain is developed based on confined concrete ascending and descending branches by Tao et al. (2013). In the descending branch, the concrete strength reduced to $60 \%$ of capacity $\mathrm{f}_{\mathrm{c}}$ ' and becomes constant to account for the effect of confinement provided by steel modules. Figure 7-1 shows the proposed effective stress-strain for steel in compression and tension and concrete in compression.

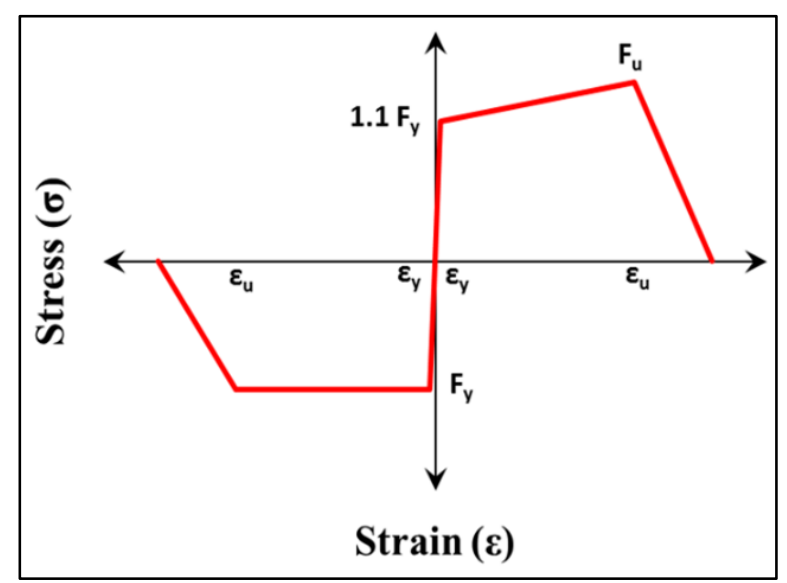

(a)

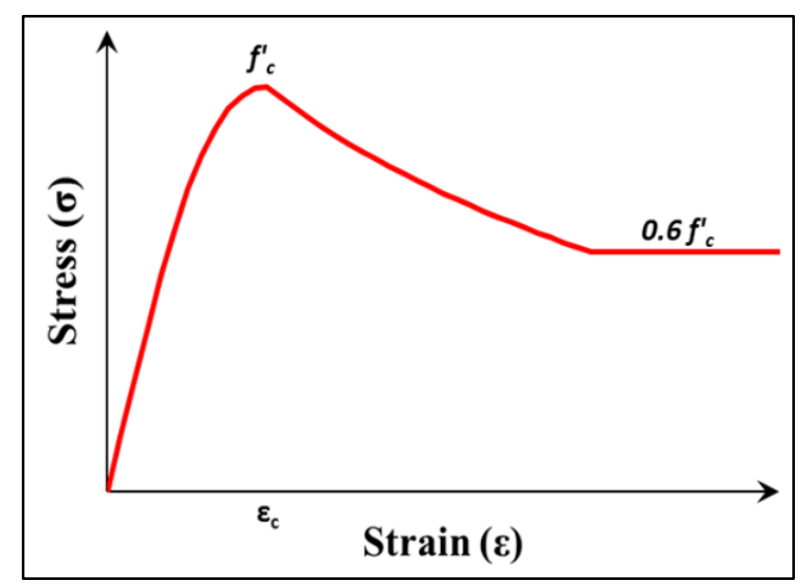

(b)

Figure 7-1. Proposed effective steel stress-strain curve for (a) steel and (b) concrete

\subsection{OpenSees Material Model and Parameters}

The OpenSees proposed material models as presented in Figure 7-1 were used to model this behavior. Table 7-2 and Table 7-3 present the OpenSees material parameters used to develop the assumed stress-strain relationships for steel and concrete, respectively. Figure 7-2 and Figure 7-3 show the comparison of the assumed stress-strain curve (OpenSees material behavior) developed using the above material parameters and ABAQUS FEA model for steel and concrete, respectively. 
This material behavior was then used to create OpenSees fiber models and benchmark its behavior with the experimental results conducted on planar walls.

Table 7-2. Steel material parameters for assumed stress-strain curves

\begin{tabular}{|c|c|c|c|}
\hline Parameter & Value & Parameter & Value \\
\hline $\mathrm{E}(\mathrm{ksi})$ & 29000 & $\mathrm{~L}_{\mathrm{sr}}$ & 10 \\
\hline b & 0.01 & beta & 1 \\
\hline $\mathrm{E}_{\mathrm{sh}}(\mathrm{ksi})$ & 290 & $\mathrm{r}$ & 0.65 \\
\hline $\mathrm{F}_{\mathrm{y}}(\mathrm{ksi})$ & 59.1 & gamma & 0.5 \\
\hline $\mathrm{F}_{\mathrm{u}}(\mathrm{ksi})$ & 68.5 & $\mathrm{C}_{\mathrm{f}}$ & 0.6 \\
\hline $\mathrm{e}_{\mathrm{sh}}$ & $2 * \mathrm{~F}_{\mathrm{y}} / \mathrm{E}_{\mathrm{s}}$ & alpha & 0.5 \\
\hline$e_{\text {ult }}$ & 0.1 & $\mathrm{C}_{\mathrm{d}}$ & 0.35 \\
\hline
\end{tabular}
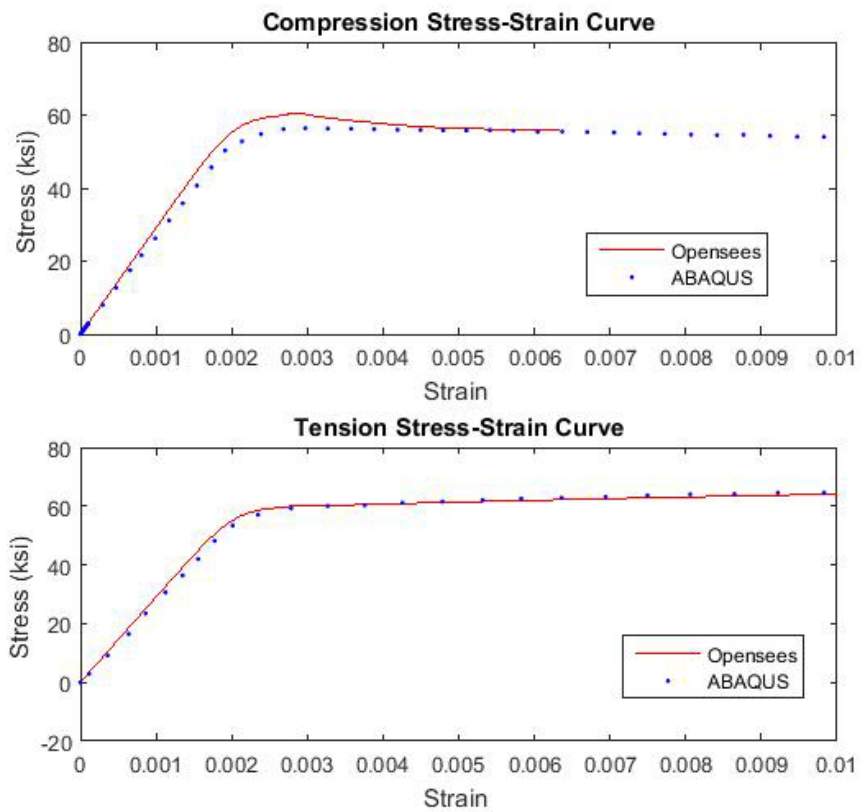

Figure 7-2. Comparison between steel effective steel stress-strain curve in OpenSees to the model developed in Abaqus (Broberg et al. 2019) 


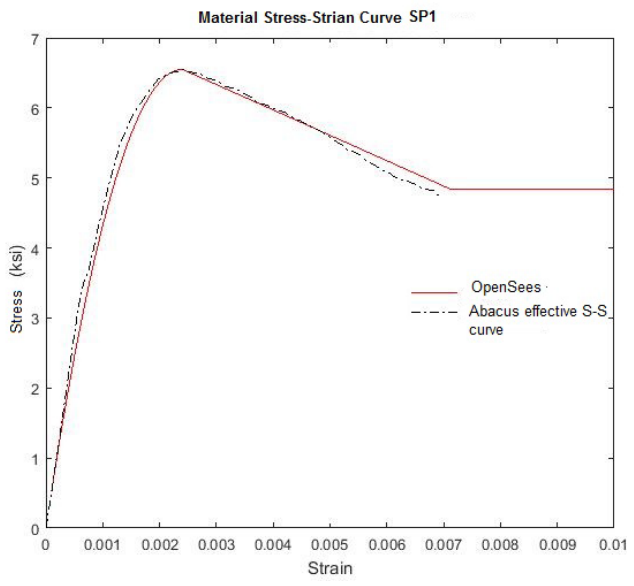

(a)

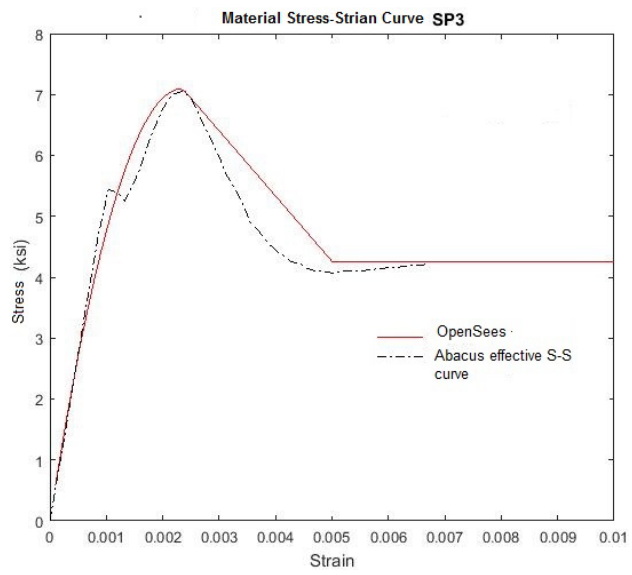

(c)

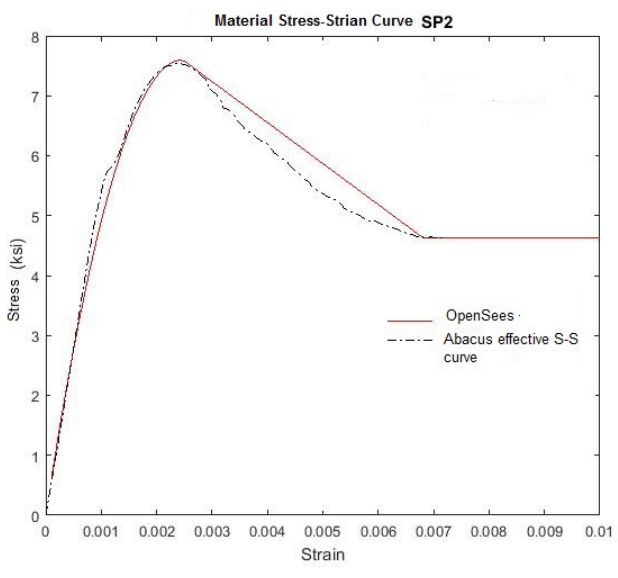

(b)

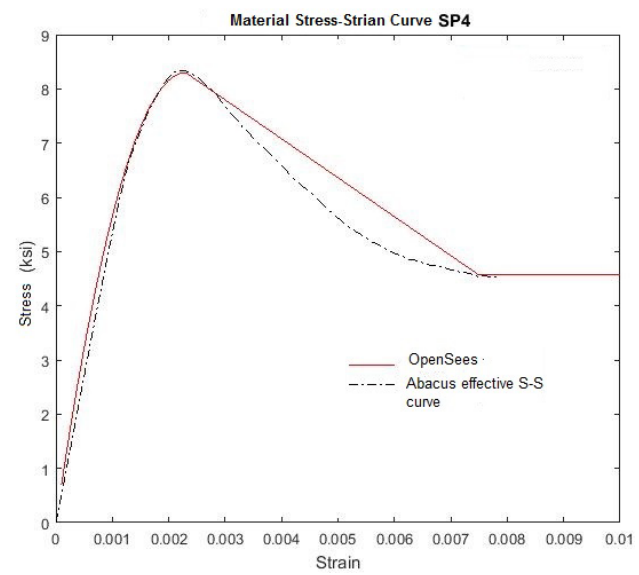

(d)

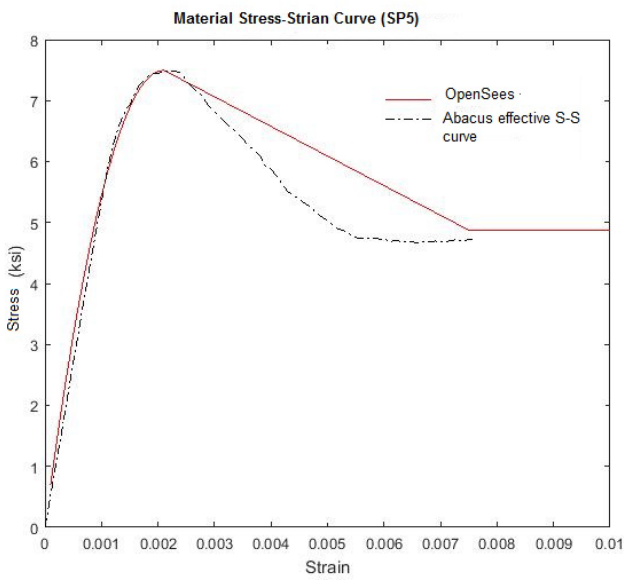

(e)

Figure 7-3. Comparison between concrete effective stress-strain curves in OpenSees to material models developed in Abaqus (a) SP1; (b) SP2; (c) SP3; (d) SP4; (e) SP5 
Table 7-3. Concrete material parameters for assumed stress-strain curves

\begin{tabular}{|l|c|c|c|c|c|}
\hline & SP1 & SP2 & SP3 & SP4 & SP5 \\
\hline $\mathrm{F}_{\mathrm{pc}}(\mathrm{ksi})$ & 6.5 & 7.8 & 8.7 & 8.4 & 7.4 \\
\hline $\mathrm{e}_{\mathrm{psc} 0}$ & 0.0023 & 0.0025 & 0.0026 & 0.0026 & 0.0024 \\
\hline $\mathrm{F}_{\mathrm{pcu}}(\mathrm{ksi})$ & 3.9 & 4.7 & 5.3 & 5.1 & 4.4 \\
\hline $\mathrm{e}_{\mathrm{psu}}$ & 0.0071 & 0.0071 & 0.0071 & 0.0071 & 0.0071 \\
\hline $\mathrm{E}_{\mathrm{ts}}$ & 4566 & 4996 & 5292 & 5190 & 4865 \\
\hline
\end{tabular}

\subsection{Element Distribution}

The OpenSees model was developed using the assumed material model discussed previously. The test results of planar walls showed that the inelastic behavior of composite walls was limited to a height of half of the wall width. The OpenSees model was divided into the nonlinear and elastic region where the non-linear effect was limited to half of the wall length from the base as mentioned above and the rest of the wall was assumed elastic. Three elements were used in the plastic hinge zone considering the effects of cumulative plastic strain on the steel properties. Three elastic elements were used for the rest of the wall outside the nonlinear range.

\subsection{OpenSees model and Test Data Comparison}

Based on the steel and concrete material models and element distribution, the OpenSees models were created to replicate the behavior of the test walls. Figure 7-4 shows the comparison of force versus displacement curve of the SP1 test specimen to the behavior obtained from OpenSees models with an effective stress-strain curve and assumed the stress-strain curve respectively. The OpenSees material model was based on the assumed stress-strain curves (Figure 7-1) mentioned above. The proposed stress-strain curve provided a conservative estimate in terms of strength compared to the effective stress-strain curve as seen in Figure 7-4. The use of the proposed curve is justified as it limits the capacity and performance as well as helps to significantly reduce the computation time required to run a large number of analyses. Figure 7-5 shows the comparison of the force-displacement curve of the OpenSees model and the test specimens SP2, SP3, SP4, and SP5. The benchmarking results suggest that the proposed material models used to develop the 
OpenSees model provides conservative behavior and would result in more critical performance factors. The actual structure shall have slightly better performance than the behavior showcased by the OpenSees model using proposed steel and concrete material behavior.

There is a lack of experimental data for C-PSW/CF C-shaped walls tested about their major axis. Therefore, no unique benchmarking could be performed for the C-shaped walls. The behavior of $\mathrm{C}$-shaped walls is governed by in-plane bending of the web walls and axial tension or compression behavior of the flange walls. The in-plane bending of the web wall will be very similar to the behavior of the planar wall. Given the lack of experimental data and the similarity of behavior between the web wall and planar walls, the benchmarked planar wall model was considered sufficient for the C-shaped walls.

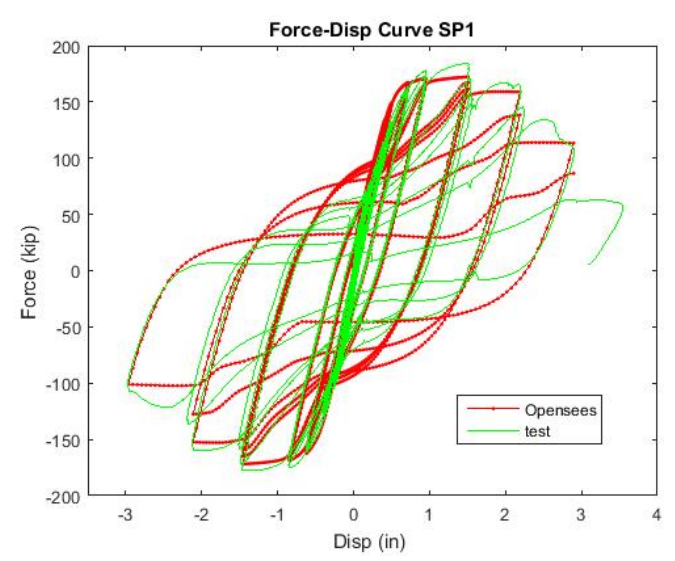

(a)

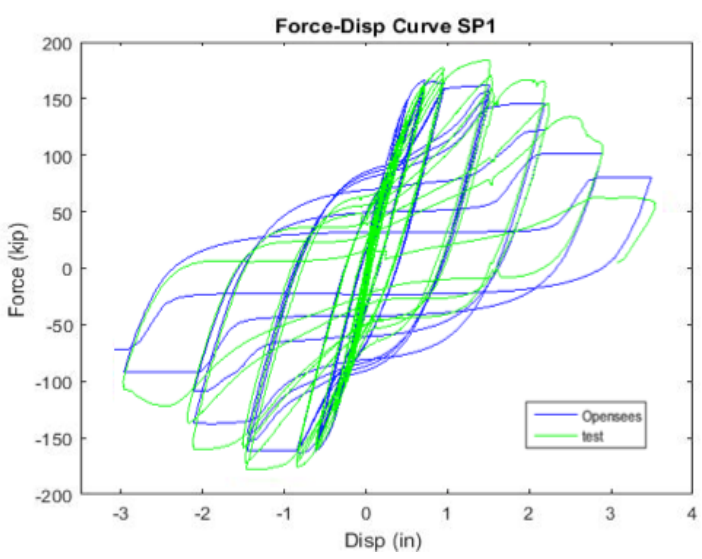

(b)

Figure 7-4. Force versus displacement curves for SP1. (a) Matching effective stress-strain curves; (b) Matching assumed stress-strain curves 


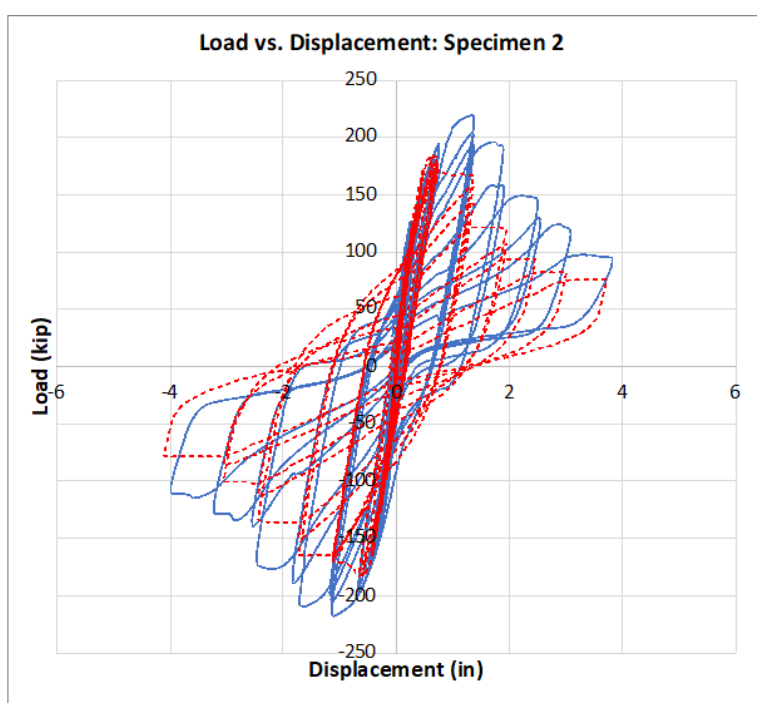

(a)

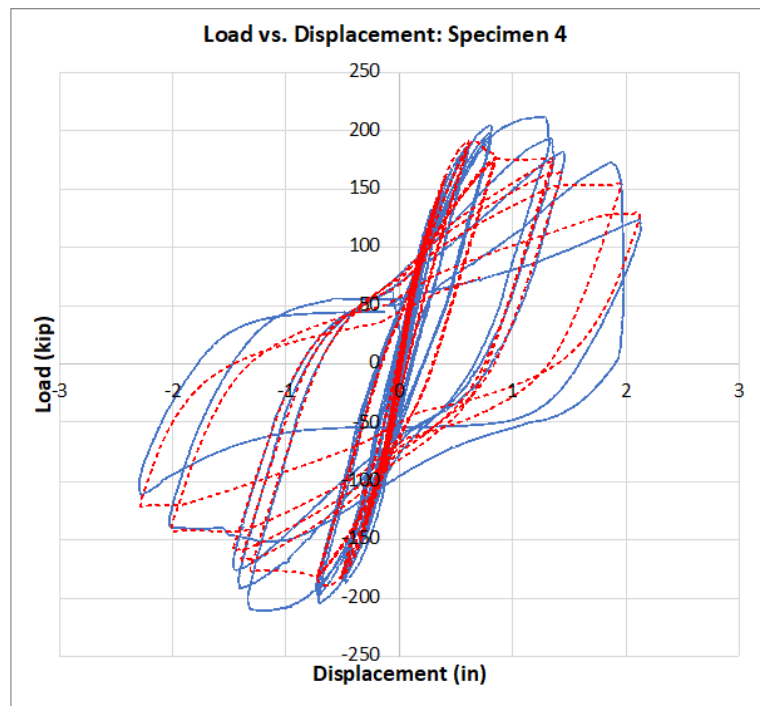

(c)

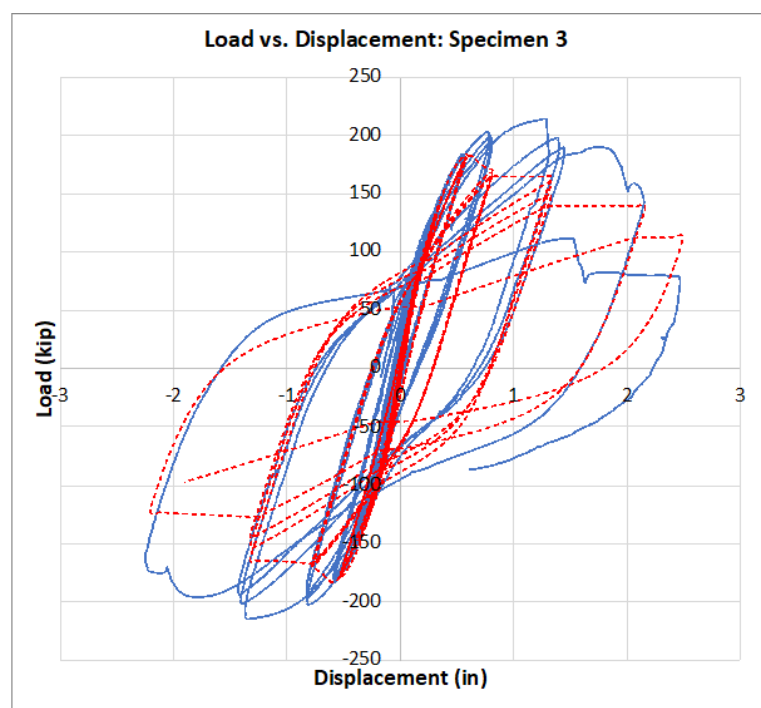

(b)

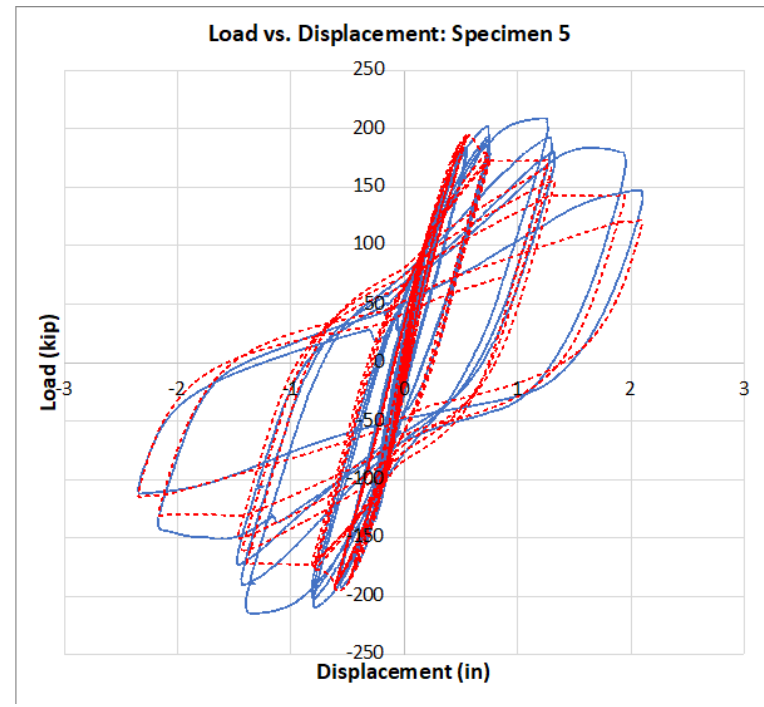

(d)

Figure 7-5. Force-Displacement comparison using assumed effective stress-strain curves for (a) SP2; (b) SP3; (c) SP4; (d) SP5 


\section{OPENSEES MODEL}

This chapter presents the details of the OpenSees FEA fiber model build for planar and C-shaped composite walls. This model will be used for nonlinear and dynamic analyses and, ultimately, to evaluate the performance of the archetype structures.

\subsection{Steel and Concrete Material Parameters}

As discussed in Section 7.3, the steel faceplates and closure plates were modeled using the ReinforcingSteel material model and the infill concrete was modeled using the Concrete02 material model. These material models are implemented in a 2D finite element OpenSees model. The material stress-strain curves discussed in Chapter 7 were used to model steel and concrete behavior. The steel material strength, buckling, and fatigue parameters are listed in Table 8-1. A yield strength, $F_{y}$, of $50 \mathrm{ksi}$ and ultimate strength, $F_{\mathrm{u}}$, of $65 \mathrm{ksi}$ was used. This model implemented the specified yield $\left(F_{y}\right)$ and ultimate strength $\left(F_{u}\right)$ and did not use expected values (i.e. $\left.R_{y} F_{y}\right)$. Figure 8-1 shows the steel material model used to model the OpenSees wall and its behavior under cyclic loading. The concrete material parameters used to model the infill concrete are listed in Table 8-2. The compressive strength of concrete, $\mathrm{f}_{\mathrm{c}}$, was taken as $6 \mathrm{ksi}$ with residual stress capacity of $0.6 \mathrm{f}_{\mathrm{c}}$. Figure 8-2 shows the concrete material model used to model the OpenSees wall.

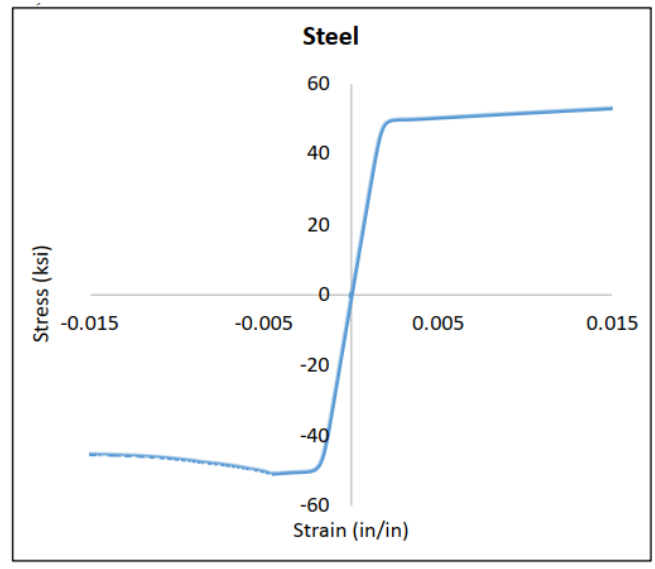

(a)

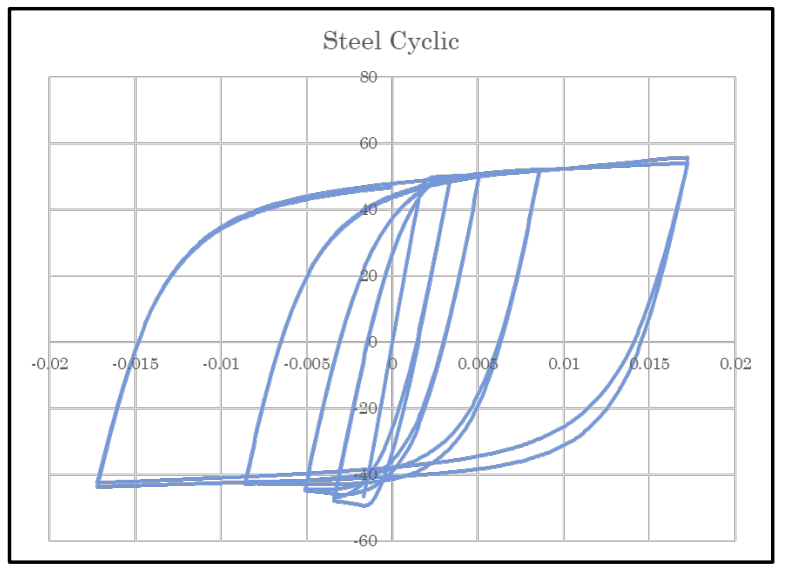

(b)

Figure 8-1. Steel material behavior (a) Monotonic stress-strain curve; (b) Cyclic behavior 
Table 8-1. Steel material parameters used for OpenSees wall model

\begin{tabular}{|l|l|r|}
\hline Parameter & Symbol & \multicolumn{2}{|l|}{ Value } \\
\hline Modulus of elasticity & $\mathrm{E}(\mathrm{ksi})$ & 29000 \\
\hline Hardening ratio & $\mathrm{b}$ & 0.01 \\
\hline Initial strain hardened tangent & $\mathrm{E}_{\mathrm{sh}}(\mathrm{ksi})$ & 290 \\
\hline Yield stress in tension & $\mathrm{F}_{\mathrm{y}}(\mathrm{ksi})$ & 50.0 \\
\hline Ultimate stress in tension & $\mathrm{F}_{\mathrm{u}}(\mathrm{ksi})$ & 65.0 \\
\hline Strain at the start of strain hardening & $\mathrm{e}_{\mathrm{sh}}$ & $2 * \mathrm{~F}_{\mathrm{y}} / \mathrm{E}_{\mathrm{s}}$ \\
\hline Strain at peak stress & $\mathrm{e}_{\mathrm{ult}}$ & 0.1 \\
\hline Buckling Parameters & \multicolumn{2}{|r|}{} \\
\hline Slenderness Ratio & $\mathrm{L}_{\mathrm{sr}}$ & 10 \\
\hline $\begin{array}{l}\text { Buckled stress-strain curve Amplification } \\
\text { factor }\end{array}$ & beta & \\
\hline Buckling reduction factor & \multicolumn{2}{|r|}{} \\
\hline Buckling constant & gamma & 0.65 \\
\hline Fatigue Parameters & \multicolumn{2}{|l}{} \\
\hline Coffin-Manson Constant & $\mathrm{C}_{\mathrm{f}}$ & 0.6 \\
\hline Coffin Manson Constant & alpha \\
\hline Cyclic strength reduction factor & $\mathrm{C}_{\mathrm{d}}$ & 0.35 \\
\hline & & \\
\hline
\end{tabular}

Table 8-2. Concrete material parameters used for OpenSees wall model

\begin{tabular}{|l|l|r|}
\hline Parameter & Symbol & Value \\
\hline Compressive strength & $\mathrm{f}_{\mathrm{c}}(\mathrm{ksi})$ & -6 \\
\hline Strain at compressive strength & $\mathrm{e}_{\mathrm{c} 0}$ & -0.002 \\
\hline Initial modulus of concrete & $\mathrm{E}_{\mathrm{c}}(\mathrm{ksi})$ & $57 \times \sqrt{f_{c}^{\prime}}$ \\
\hline Concrete crushing strength & $\mathrm{f}_{\mathrm{cu}}(\mathrm{ksi})$ & 3.6 \\
\hline Ratio of unloading and loading slope & lambda & 0.1 \\
\hline Strain at concrete crushing & $\mathrm{e}_{\mathrm{final}}$ & -0.008 \\
\hline Tension Parameters & \multicolumn{2}{|l|}{} \\
\hline Tensile strength & $\mathrm{f}_{\mathrm{t}}(\mathrm{ksi})$ & $-0.1 \times f_{c}^{\prime}$ \\
\hline Strain at the tensile strength & $\mathrm{e}_{\mathrm{t}}$ & 0.00008 \\
\hline
\end{tabular}




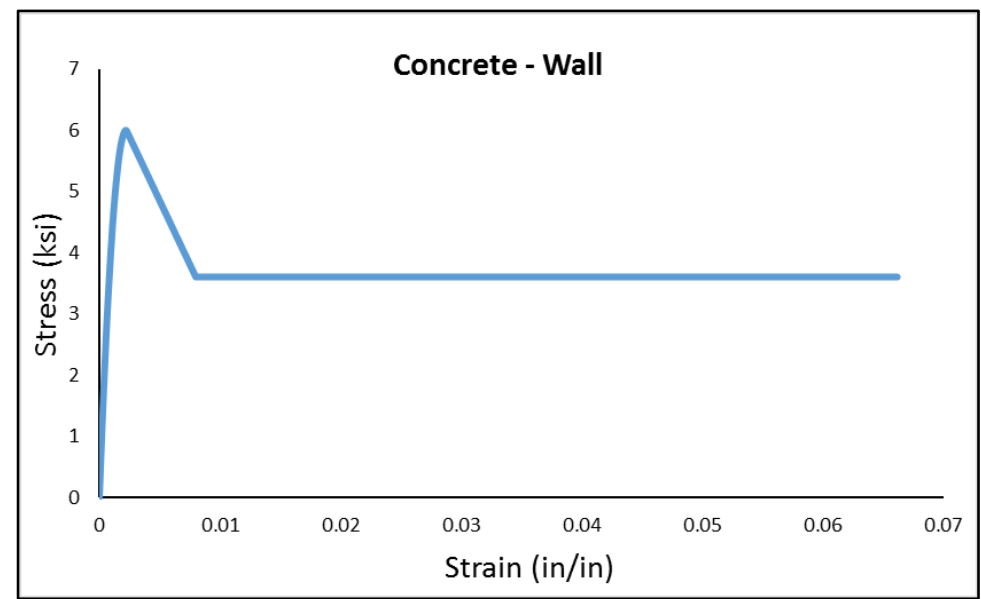

Figure 8-2. Concrete material behavior

\subsection{Fiber Model}

The steel and concrete material models mentioned in Section 8.1 were used to create a 2D fiberbased model for the archetype structure. This model consisted of nonlinear fiber elements for the base of the wall and elastic elements for the remainder of the wall. Figure 8-3 depicts the OpenSees model configuration used to model the 6-story archetype structure. This model is divided into two main components: (1) the composite wall fiber element and (2) the P-Delta column.

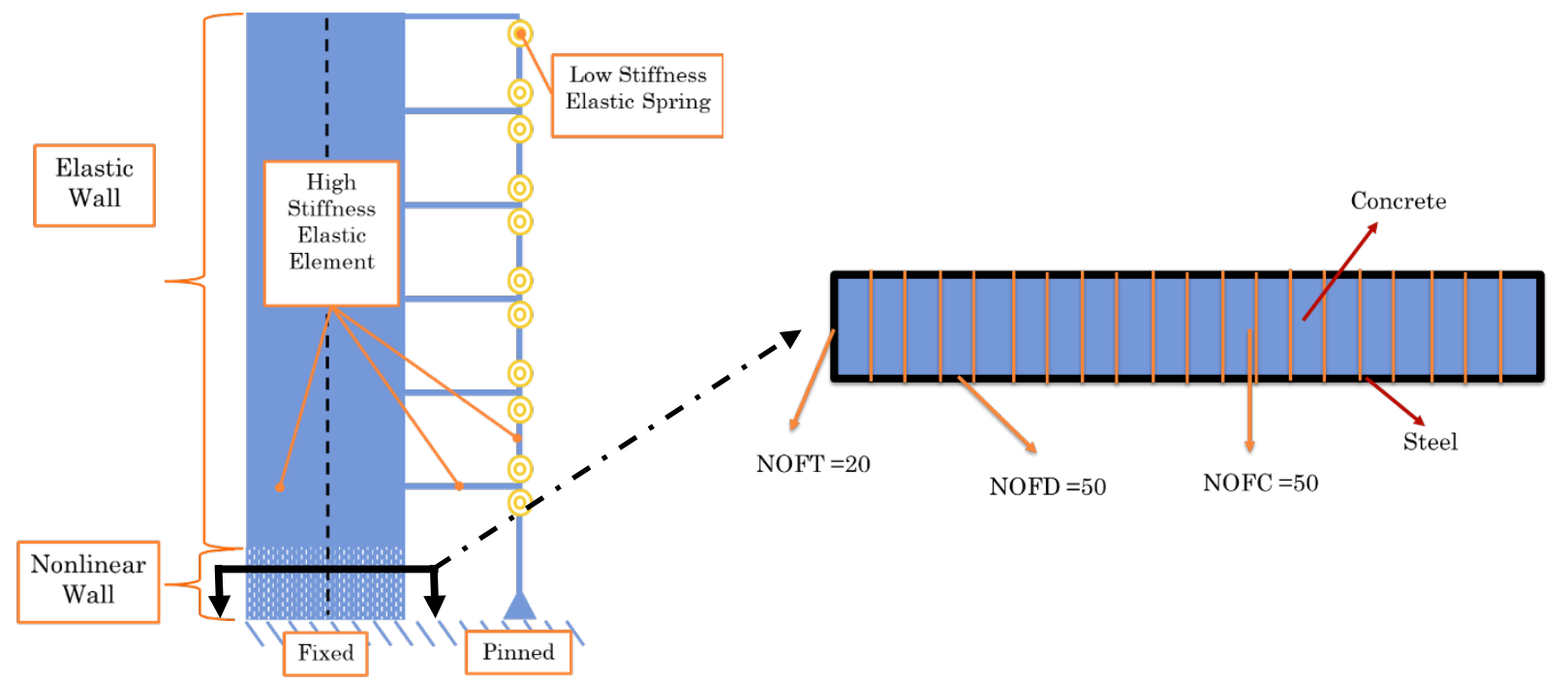

(a)

(b)

Figure 8-3. OpenSees model for 6 story archetype structure (a) Elevation view; (b) Wall cross-section 


\subsubsection{Wall Element}

As shown in Figure 8-3, the OpenSees model has nonlinear fiber elements defined at the base and elastic elements at the top. The wall was fixed at the base. The nonlinear wall elements extended to the minimum of half of the wall length or the height of the first story $(17 \mathrm{ft})$. The nonlinear fiber cross-section was developed using the nominal properties of steel and concrete materials discussed in Section 8.1. Figure 8-3b shows the cross-section and fiber distribution of the nonlinear wall elements. Four displacement-based fiber elements at an equal distance were used to model the nonlinear part of the wall. The rest of the composite wall was modeled using the elastic elements. The elastic elements used the effective stiffness EI $\mathrm{I}_{\text {eff }}$ as estimated in Section 3.3.1. The gross properties of the composite wall were used to define the axial and shear stiffness of the elastic element. One elastic element at each floor was used to model the elastic part. The tributary mass was applied at each story level.

\subsubsection{P-Delta Columns}

The p-delta columns were used to represent the weight of the remainder of the building. The configuration of the p-delta column used in the OpenSees model is shown in Figure 8-3. The pdelta columns' elements are high stiffness elastic elements. The two p-delta elements were connected using two low stiffness elastic spring elements. The low stiffness springs prevented any transfer of moment from one p-delta column element to the other. The p-delta column was pinned at the base of the structure to prevent the p-delta columns from contributing to the moment resistance of the system. The p-delta column elements were connected to the wall elements using elements with high elastic stiffness. The gravity load was applied to the p-delta columns at the nodes of each story level. 


\section{PLANAR COMPOSITE WALLS ANALYSIS AND RESULTS}

This chapter presents the nonlinear static pushover and incremental dynamic analysis study conducted on the planar composite walls. It also summarizes the results of collapse assessment and performance evaluation of the planar walls.

\subsection{General}

Section 2.4.3 discusses the key components which are required to perform collapse assessment of the composite wall system. The details of each of the four planar composite walls archetypes are discussed in Chapter 5. The design and sizing details of planar walls archetype are discussed in Table 5-1 and Table 5-2. The calibrated steel and concrete material models used for the OpenSees analysis are described in Chapters 6 and 7. The details of the OpenSees fiber model used for the nonlinear analyses are described in Chapter 8 . Chapter 9 presents the non-linear analysis and the collapse assessment of the planar wall archetypes.

\subsection{Nonlinear Pushover (Static) Analysis}

Nonlinear static pushover analyses were conducted to estimate the overstrength factor, $\Omega_{0}$, and period-based ductility, $\mu_{\mathrm{t}}$, in compliance with FEMA P695 approach as described in Section 2.4.1. The results of the pushover analyses of 3-story, 6-story, 9-story, and 12-story archetypes are presented below. Figure 9-1 to Figure 9-4 provides base shear versus IDR plot, base shear versus maximum IDR plot, and moment versus roof displacement plot for the 3-story, 6-story, 9-story, and 12 -story archetypes, respectively. 

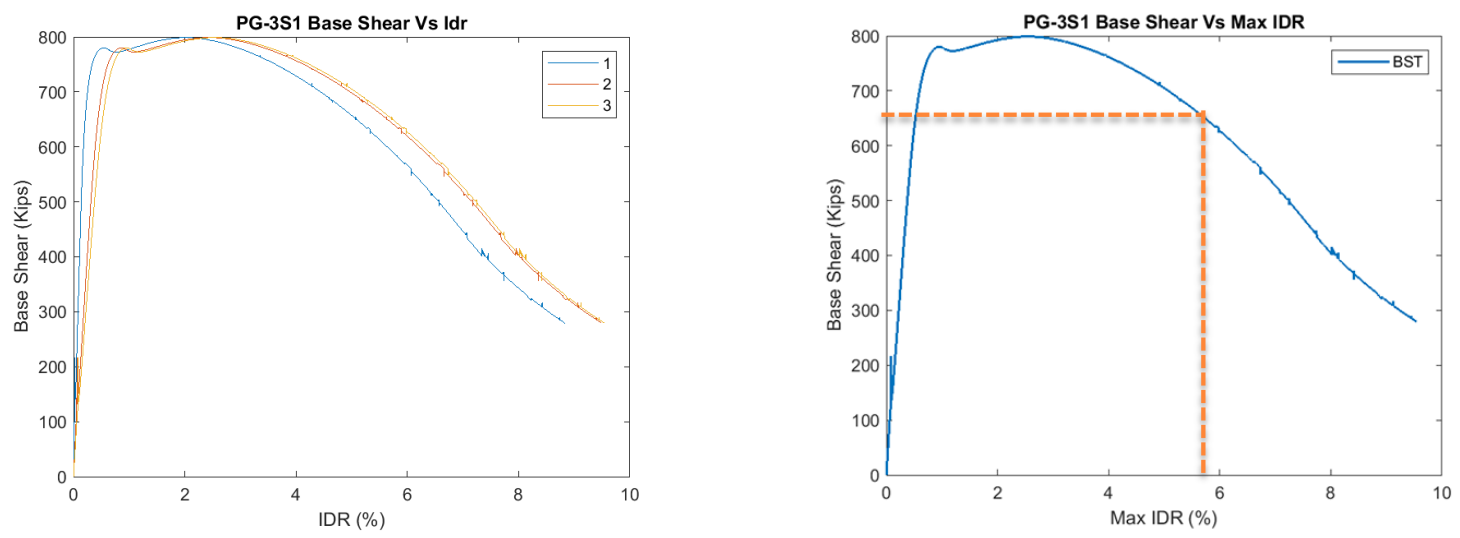

(a)

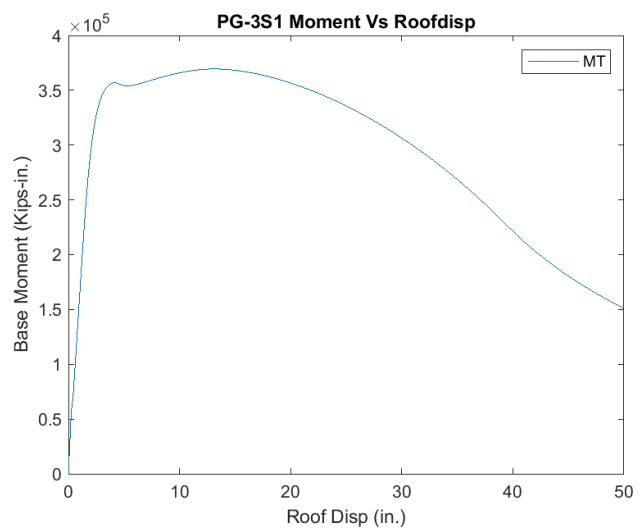

(b)

(c)

Figure 9-1. Pushover analysis results for 3-story archetype (a) Base shear versus IDR; (b) Base shear vs maximum IDR; (c) Moment vs roof displacement

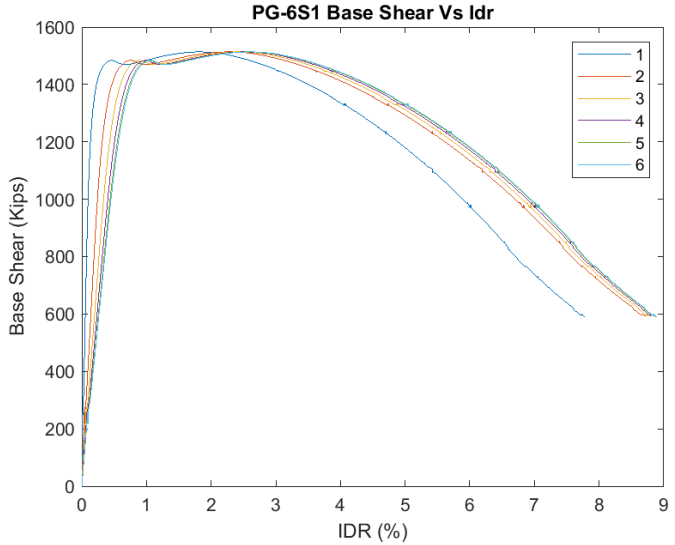

(a)

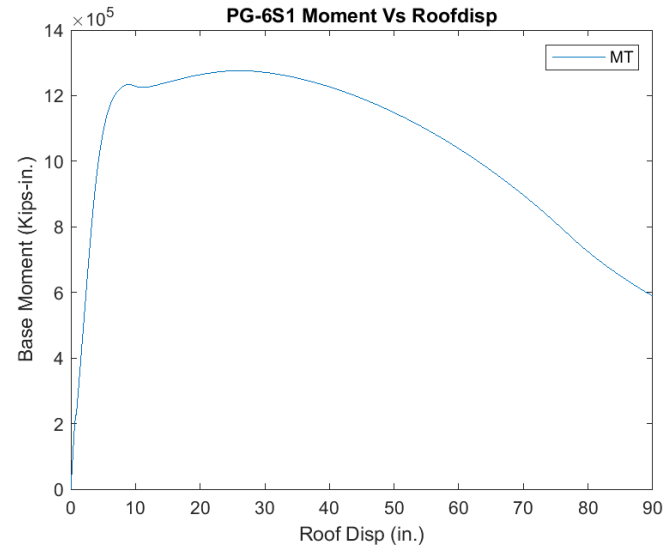

(b)

Figure 9-2. Pushover analysis results for 6-story archetype (a) Base shear versus IDR; (b) Moment vs roof displacement 


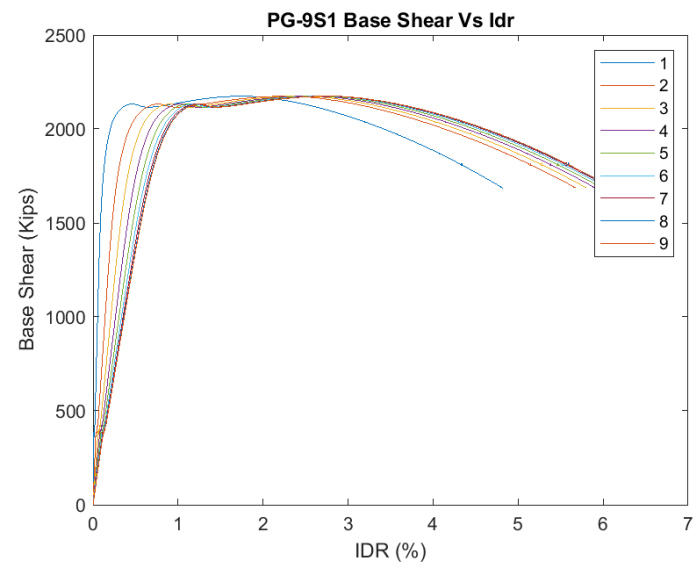

(a)

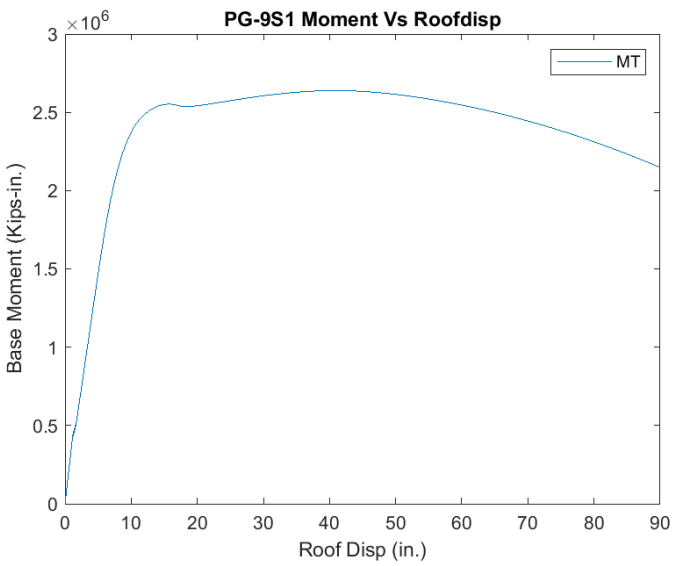

(b)

Figure 9-3. Pushover analysis results for 9-story archetype (a) Base shear versus IDR; (b) Moment vs roof displacement

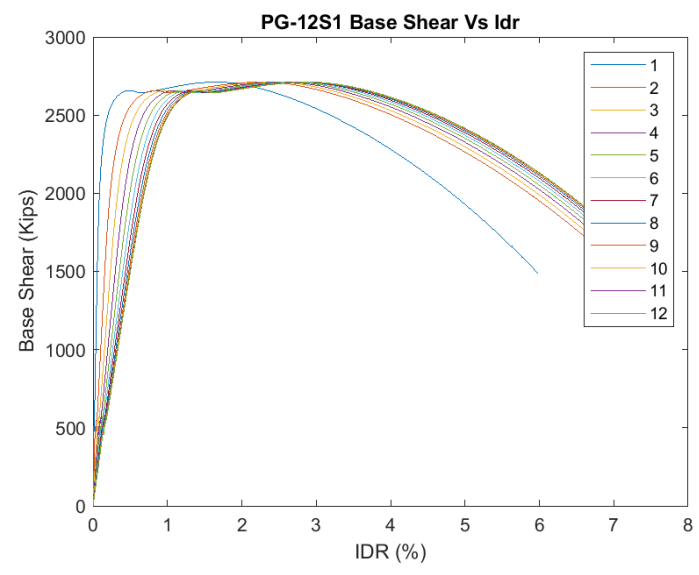

(a)

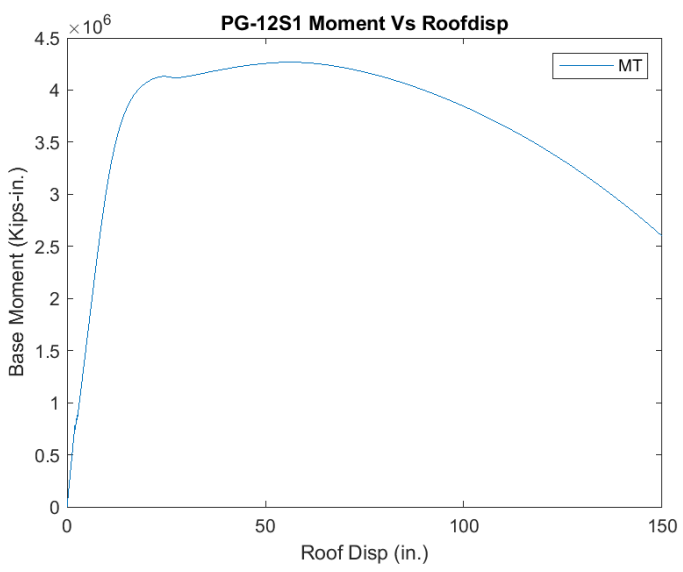

(b)

Figure 9-4. Pushover analysis results for 12-story archetype (a) Base shear versus IDR; (b) Moment vs roof displacement

Figure 9-5 shows base shear versus roof displacement plots for the 3-story, 6-story, 9-story, and 12-story archetypes. It also provides the estimate of Maximum Base Shear, $\mathrm{V}_{\max }$, ELF Base Shear demand, $\mathrm{V}_{\mathrm{ELF}}$, and ultimate roof displacement, $\delta_{\mathrm{u}}$ (at $80 \%$ remaining capacity). These values are then used to calculate the overstrength factor, $\Omega_{0}$, and period-based ductility, $\mu_{\mathrm{t}}$. The nonlinear pushover analysis results of the planar archetypes are presented in Table 9-1. 


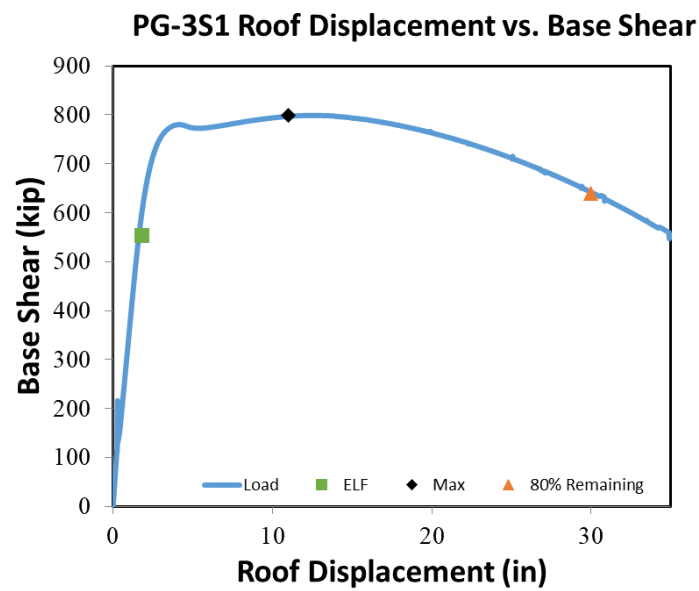

(a)

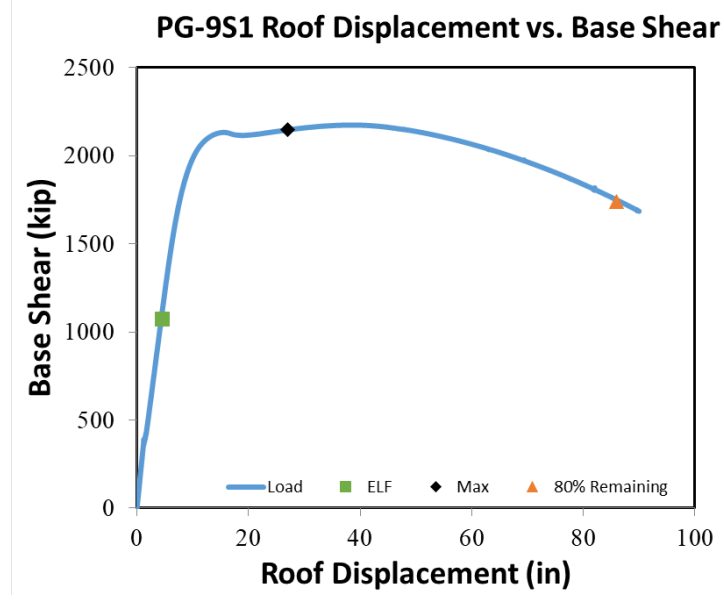

(c)

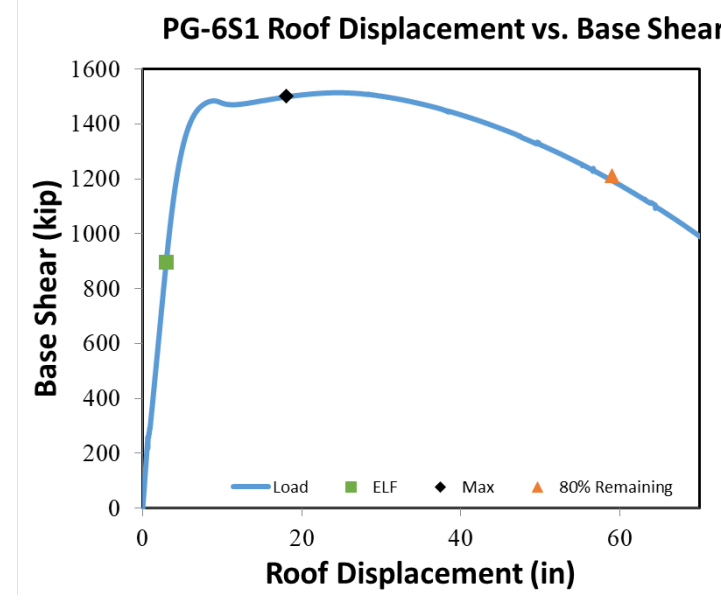

(b)

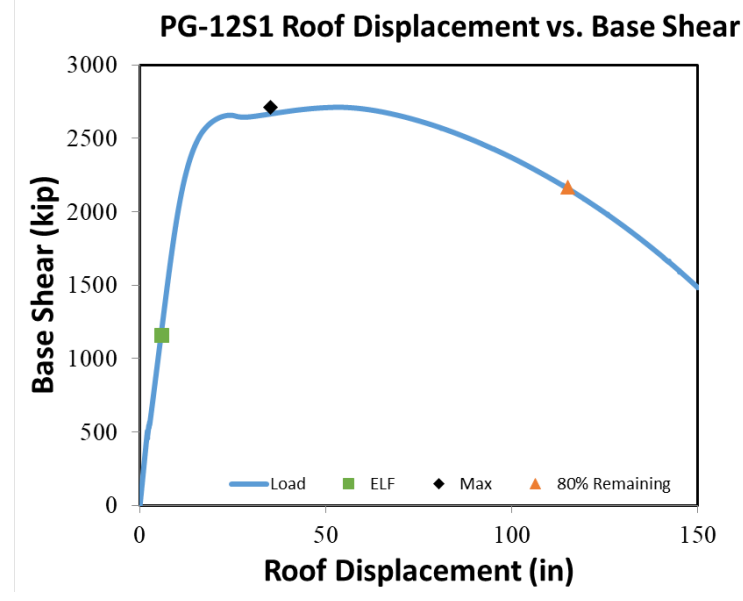

(d)

Figure 9-5. Maximum base shear capacity, ELF displacement and ultimate displacement (a) 3S1; (b) 6S1; (c) 9S1; (d) 12S1

Table 9-1. Pushover analysis results for planar archetype structures

\begin{tabular}{|c|c|c|c|c|c|c|}
\hline Structure & $\begin{array}{c}\mathrm{V}_{\text {ELF, }} \\
\text { (kips) }\end{array}$ & $\begin{array}{c}\mathrm{V}_{\max }, \\
\text { (kips) }\end{array}$ & $\begin{array}{c}\delta_{\mathrm{y}, \text { eff, }} \\
\text { in }\end{array}$ & $\begin{array}{c}\delta_{\mathrm{u}}, \\
\text { in }\end{array}$ & $\begin{array}{c}\text { Overstrength, } \\
\Omega\end{array}$ & $\begin{array}{c}\text { Period-based } \\
\text { ductility, } \mu \mathrm{t}\end{array}$ \\
\hline $3 \mathrm{~S} 1$ & 553 & 799 & 1.2 & 30 & 1.44 & 25.1 \\
\hline $6 \mathrm{~S} 1$ & 897 & 1514 & 2.4 & 58 & 1.69 & 24.1 \\
\hline 9S1 & 1074 & 2175 & 4.4 & 86 & 2.02 & 19.7 \\
\hline $12 \mathrm{~S} 1$ & 1160 & 2710 & 6.7 & 115 & 2.34 & 17.2 \\
\hline \multicolumn{7}{r}{} \\
\end{tabular}




\subsection{Incremental Dynamic Analysis}

The incremental dynamic analyses (IDA) as described in Section 2.4 .2 are conducted in compliance with the approach prescribed in FEMA P695 methodology. IDA is used to determine median collapse intensity, $S_{C T}$, and collapse margin ratio, $C M R$. As mentioned previously, the IDA analyses are performed for 44 ground motion specified in FEMA P695.

An example of the incremental dynamic analysis of the 6-story archetype for the 1994 Northridge earthquake (NGA record seq. no. 953) is presented here to describe the process used to estimate the collapse margin ratio. This process is repeated for all the other ground motion records for every archetype structure and the results are summarized later in this section. Figure 9-6 shows the variation of roof displacement and inter-story drift ratio of the 6-story archetype structure when it is subjected to the scaled 1994 Northridge ground motion record. This scaled ground motion resulted in a maximum IDR of $0.8 \%$ at the top level of the wall as marked in Figure 9-6a. The ground motion record is scaled up and the analysis is repeated until the defined collapse level is reached. The maximum archetype structure IDR caused by the given ground motion record is obtained for each of the scaling intensity. Figure 9-7 shows the plot between the scale factor and the maximum inter-story drift caused for that scaling intensity. Figure 9-8 shows the plot between the spectral acceleration and the maximum inter-story drift caused for that scaling intensity.

The process is then repeated for all other far-field ground motions and the spectral acceleration vs the maximum inter-story drift ratio for each of the 44 far-field ground motion is obtained. Figure 9-9 illustrates the combined spectral acceleration vs maximum IDR plot for all of the 44 ground motion records. The median spectral acceleration collapse intensity is then obtained as the spectral acceleration resulting in the collapse of the archetype structure for half of the ground motion records, i.e. 22 records for a given collapse criterion (i.e. 3\%). The median collapse intensity for a $3 \%$ collapse criterion is found to be 2.0 and is represented by the red line in Figure 9-9. 


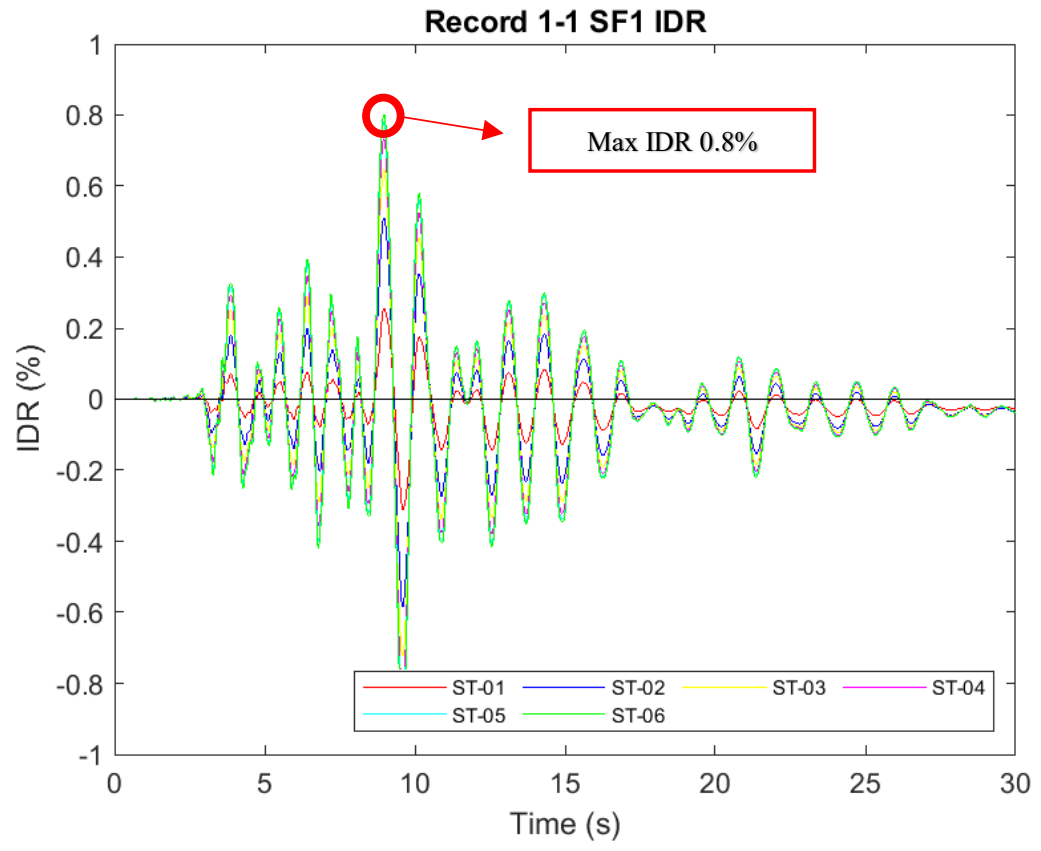

(a)

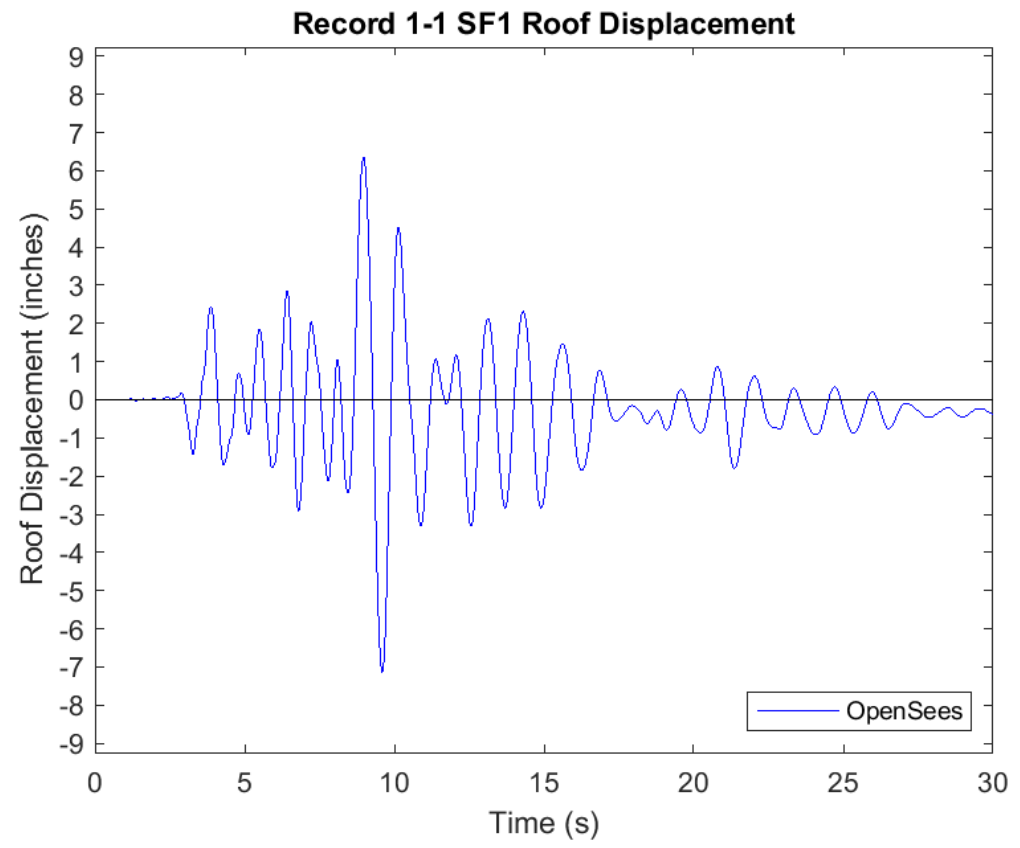

(b)

Figure 9-6. Response history analysis for 6-story archetype (a) IDR vs time (s); (b) Roof displacement vs time 


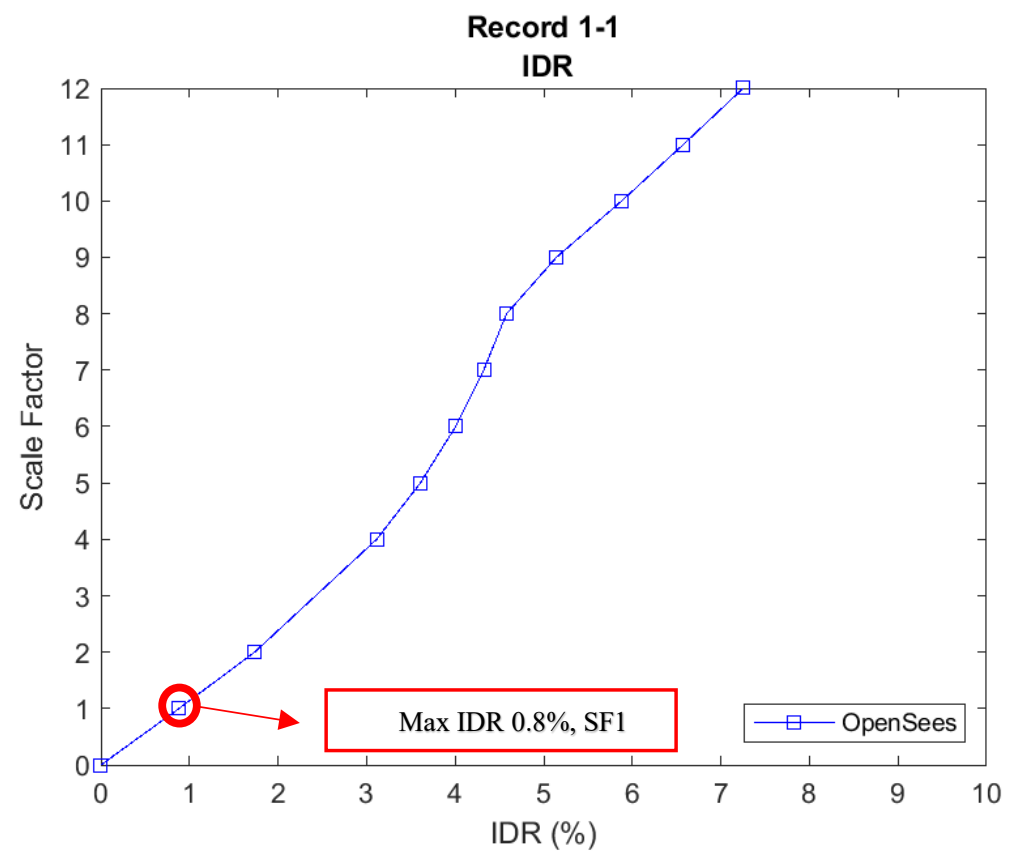

Figure 9-7. 6-story archetype scale factor vs IDR

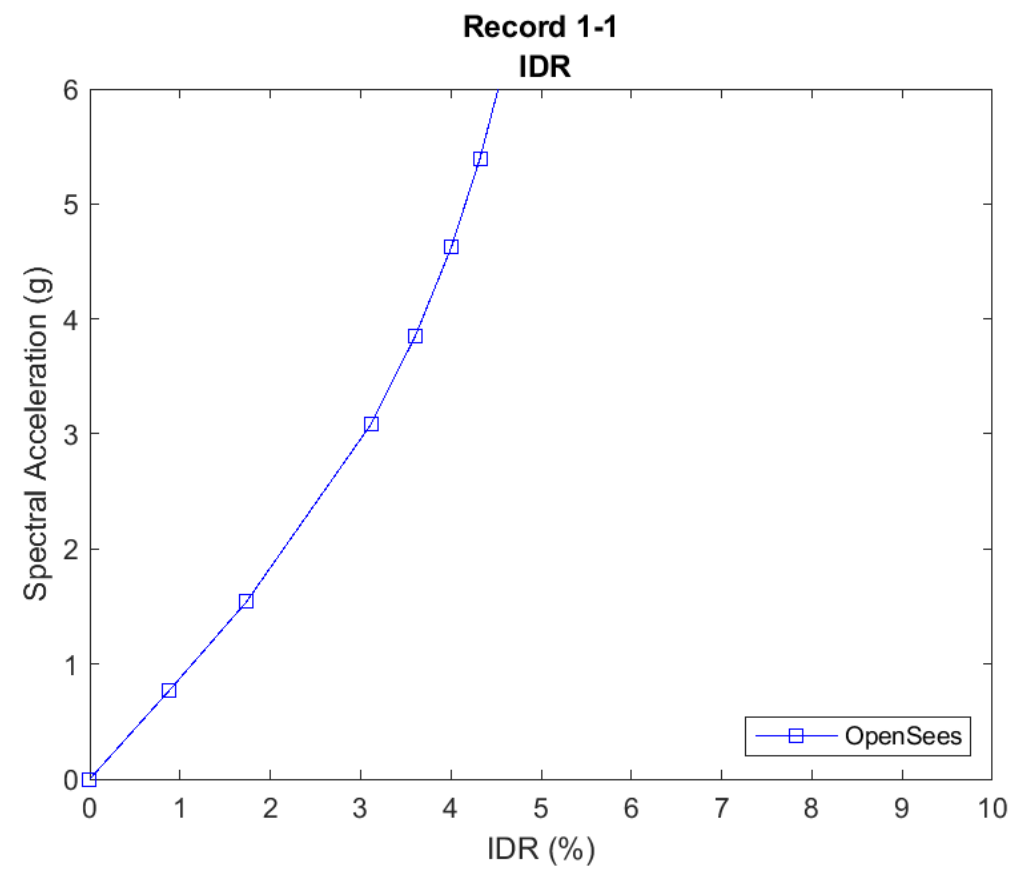

Figure 9-8. 6-story archetype spectral acceleration vs IDR 


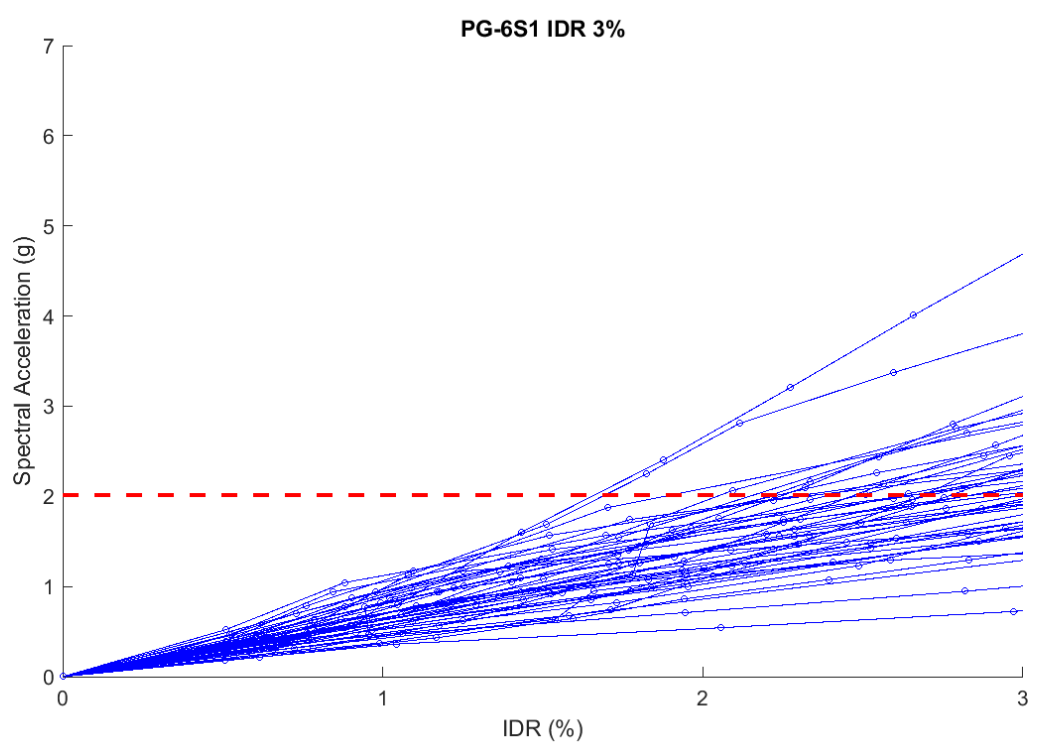

Figure 9-9. 6-story archetype IDA plot, spectral acceleration vs IDR

The whole procedure mentioned above is repeated for all the other archetypes.

Figure 9-10 to Figure 9-14 illustrates the spectral acceleration vs maximum inter-story drift ratio plot and cumulative failure probability vs spectral acceleration for 3-story, 6-story, 9-story, and 12-story. These figures are provided considering different levels of collapse criterion.

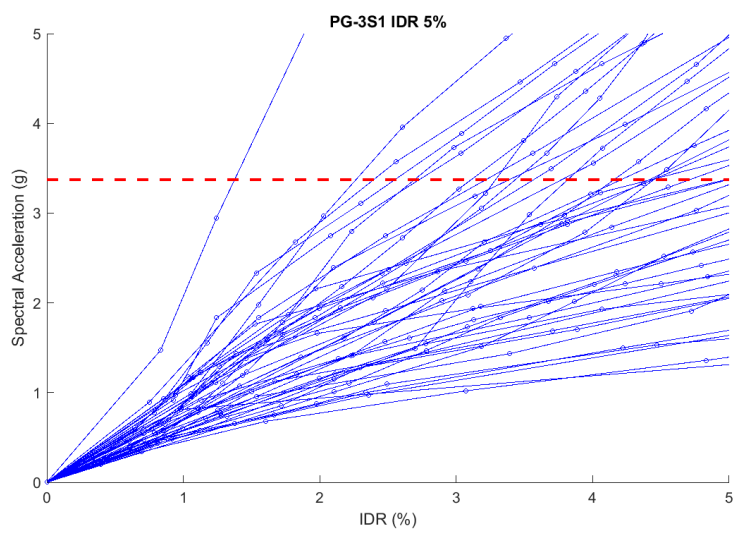

(a)

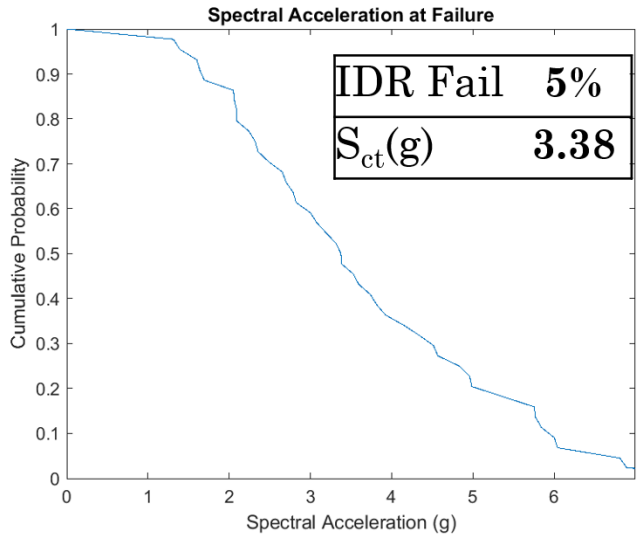

(b)

Figure 9-10. IDA Plot for 3-story archetype with 5\% collapse criterion (a) Spectral acceleration vs IDR; (b) Cumulative probability of failure vs spectral acceleration 


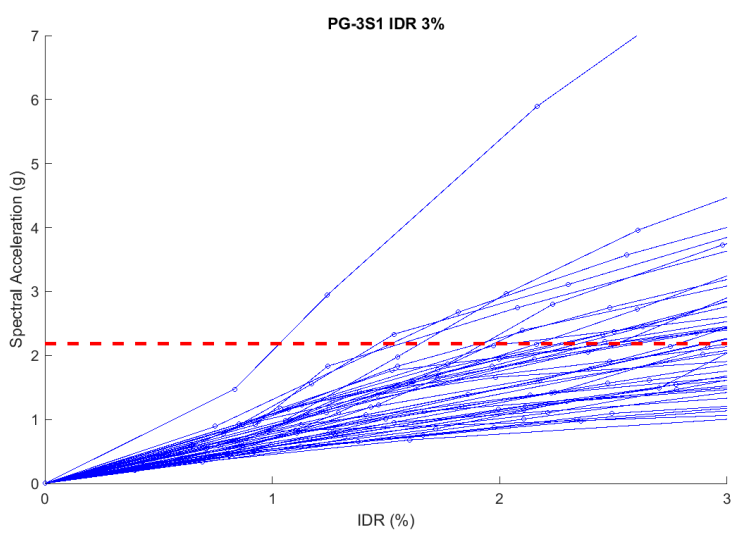

(a)

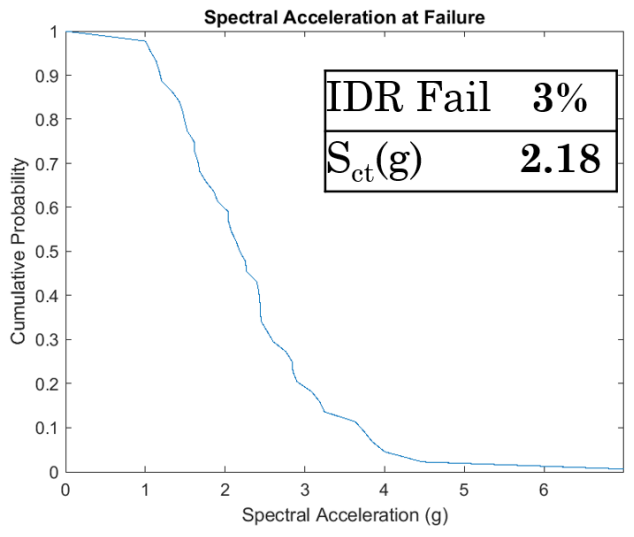

(b)

Figure 9-11. IDA plot for 3-story archetype with 3\% collapse criterion (a) Spectral acceleration vs IDR; (b) Cumulative probability of failure vs spectral acceleration

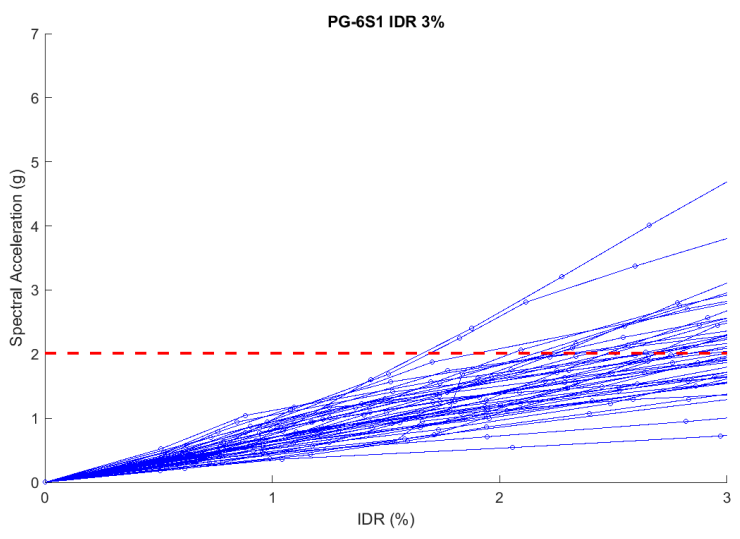

(a)

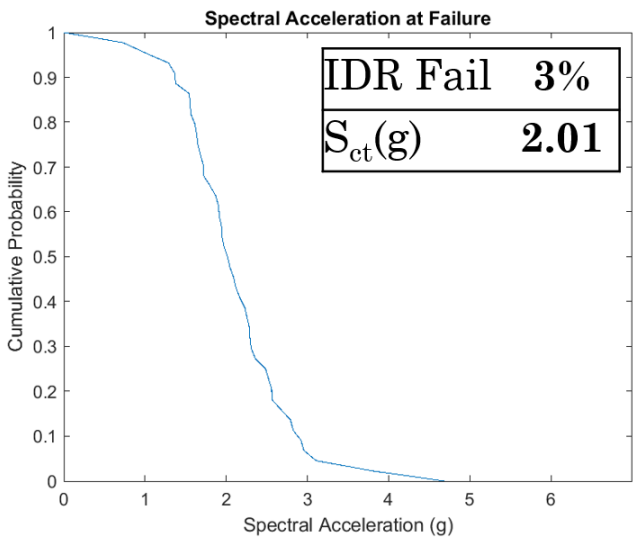

(b)

Figure 9-12. IDA plot for 6-story archetype with 3\% collapse criterion (a) Spectral acceleration vs IDR; (b) Cumulative probability of failure vs spectral acceleration 


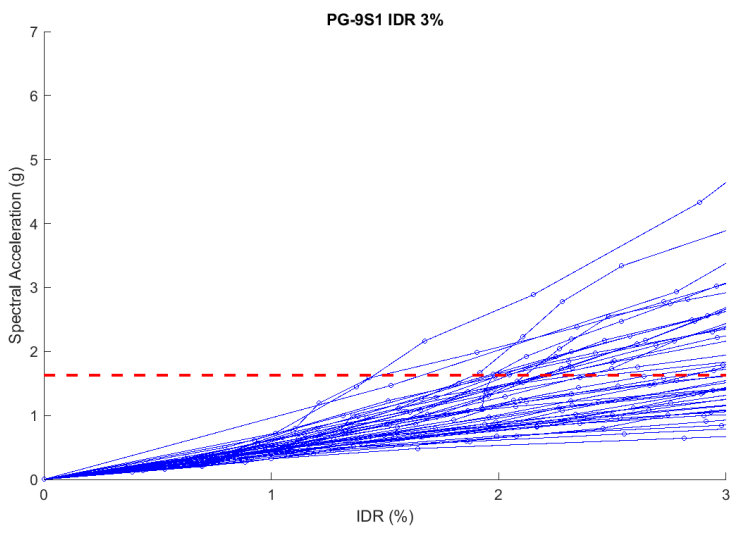

(a)

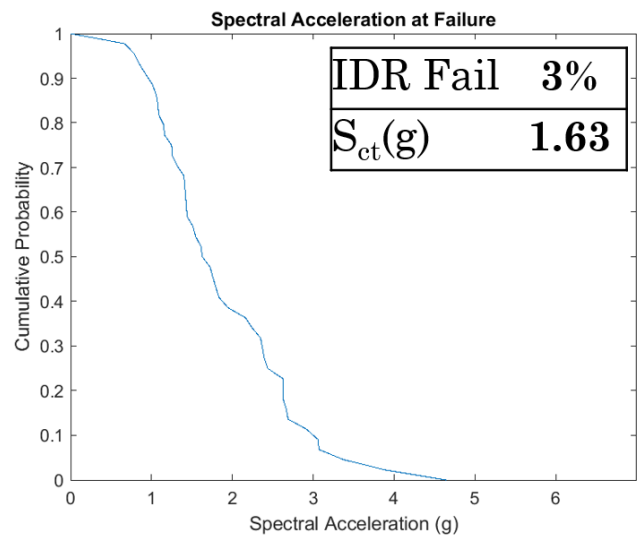

(b)

Figure 9-13. IDA plot for 9-story archetype with 3\% collapse criterion (a) Spectral acceleration vs IDR; (b) Cumulative probability of failure vs spectral acceleration

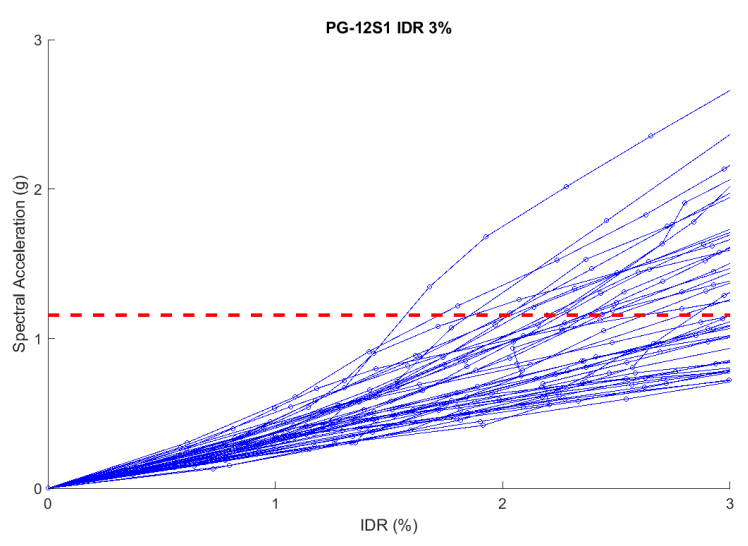

(a)

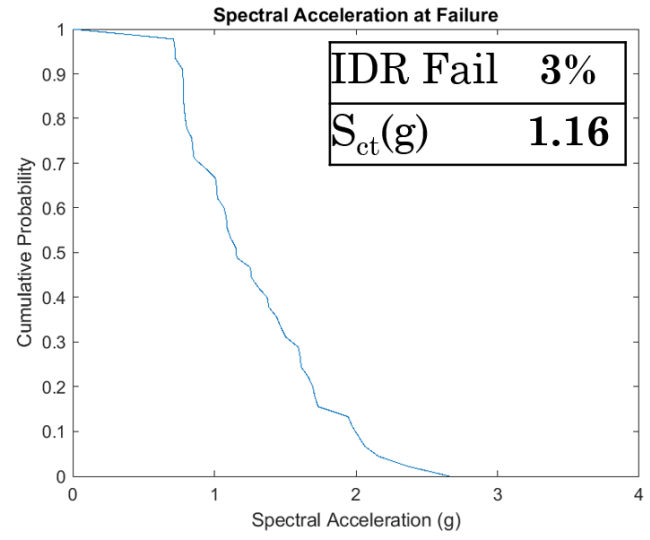

(b)

Figure 9-14. IDA plot for 12-story archetype with 3\% collapse criterion (a) Spectral acceleration vs IDR; (b) Cumulative probability of failure vs spectral acceleration

\subsection{Performance Evaluation}

The performance of the planar composite walls seismic resisting system is assessed according to FEMA P695 methodology as described in Section 2.4. It is used to check the validity of the seismic performance factors used to design the archetype. The median spectral acceleration collapse intensity, $S_{C T}$, collapse margin ratio, $C M R$, and adjusted collapse margin ratio, $A C M R$ were calculated and summarized in Table 9-2. The value of the adjusted collapse margin ratio, $A C M R$, 
is then compared to the acceptable value of adjusted collapse margin ratio at $10 \%$ probability of failure, $A C M R_{10 \%}$ (Table 2-1), for the level of uncertainty, $\beta_{\mathrm{T}}$, considered as good.

Table 9-2. Performance evaluations results for planar archetype structures

\begin{tabular}{|c|c|c|c|c|c|}
\hline Structure & OS Period (s) & $\mathrm{S}_{\mathrm{ct}}(\mathrm{g})$ & $\mathrm{CMR}$ & $\operatorname{ACMR}\left(\boldsymbol{\mu}_{\mathrm{T}}>8\right)$ & $\operatorname{ACMR}\left(\boldsymbol{\mu}_{\mathrm{T}}=3\right)$ \\
\hline $3 \mathrm{~S} 1$ & 0.65 & 2.18 & 1.58 & 2.16 & 1.90 \\
\hline $6 \mathrm{~S} 1$ & 0.95 & 2.01 & 2.12 & 3.08 & 2.64 \\
\hline 9S1 & 1.32 & 1.63 & 2.39 & 3.72 & 3.09 \\
\hline $12 \mathrm{~S} 1$ & 1.74 & 1.16 & 2.24 & 3.61 & 2.96 \\
\hline \multicolumn{4}{|r|}{ Average } & 3.14 & 2.65 \\
\hline
\end{tabular}

It can be seen from Table 9-2 calculated $A C M R$ values for all planar composite wall archetype is greater than the required acceptable value of $A C M R_{10 \%}$. This suggests that the seismic performance factors selected to design the required archetype provide the required level of seismic resistance and collapse prevention. The $A C M R$ values increased as the number of building levels was increased. This suggests that a taller structure has better seismic performance and collapse prevention than a shorter structure. 


\section{C-SHAPED COMPOSITE WALLS ANALYSIS AND RESULTS}

This chapter presents the non-linear static pushover and incremental dynamic analysis study conducted on the $\mathrm{C}$-shaped composite walls. It also summarizes the results of collapse assessment and performance evaluation of the $\mathrm{C}$-shaped composite walls.

\subsection{General}

Three C-shaped archetypes (15-story, 18-story, and 22-story) were analyzed as part of the study. The details of composite walls dimensions, floor plans, and archetype structure are presented in Section 5.2. The material properties and finite element models used for the nonlinear analysis are presented in Chapters 7 and 8 . The procedure similar to the planar wall was used to analyze the performance of $\mathrm{C}$-shaped walls. The results of this section are applicable for archetype with an Ishaped configuration. Since only uncoupled direction was considered and the 2D FEA model was used for analysis, the effects of torsion were neglected for the study.

\subsection{Nonlinear Static (Pushover) Analysis}

The nonlinear pushover analysis of the C-shaped composite wall was conducted in compliance with FEMA P695 approach as described in Section 2.4.1. The results of the pushover analyses of 15-story, 18-story, and 22-story archetypes are presented below. Figure 10-1 to Figure 10-3 provides base shear versus IDR plot, base shear vs maximum IDR plot, and moment vs roof displacement plot for the 15-story, 18-story, and 22-story archetypes. 


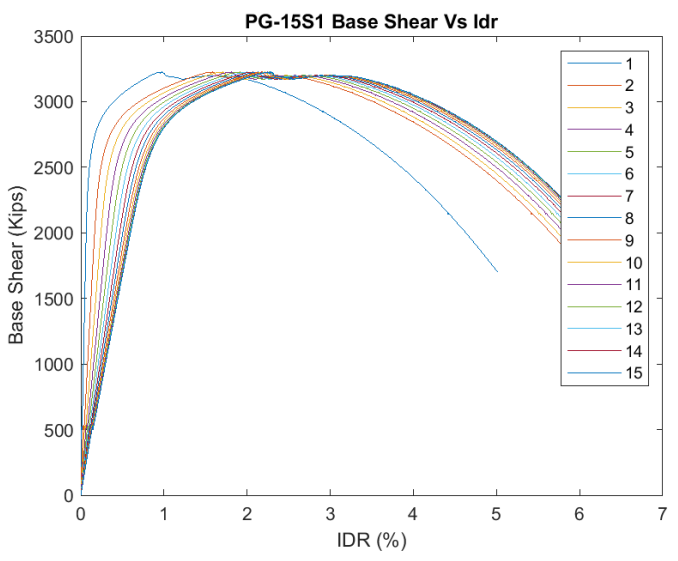

(a)

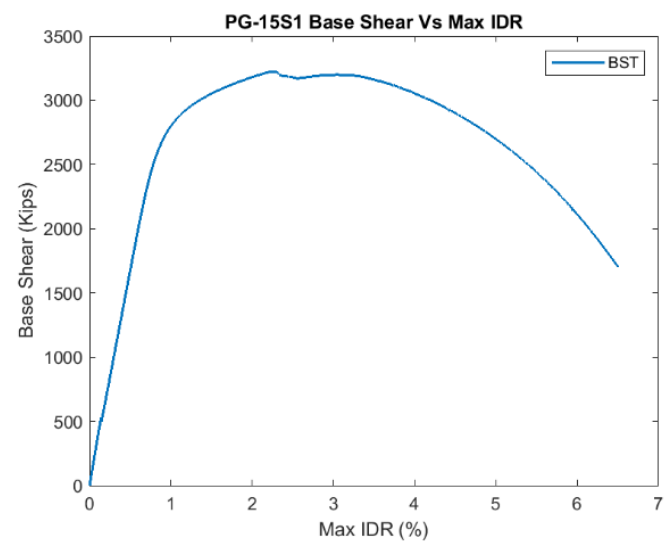

(b)

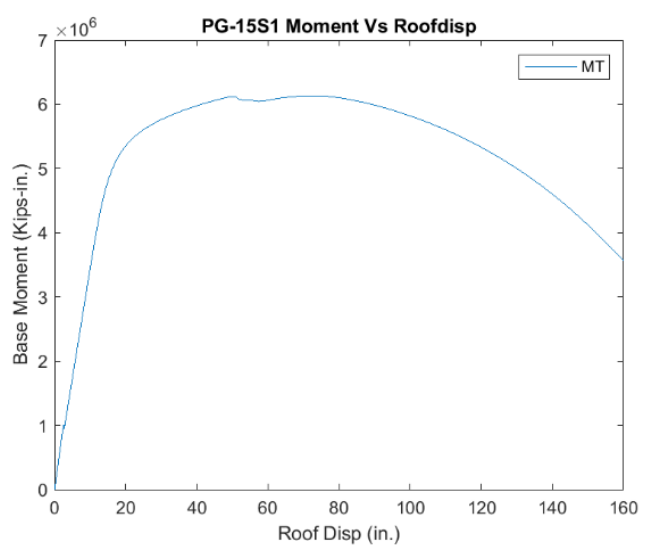

(c)

Figure 10-1. Pushover analysis results for 15-story archetype (a) Base shear vs IDR; (b) Base shear vs maximum IDR; (c) Moment vs roof displacement

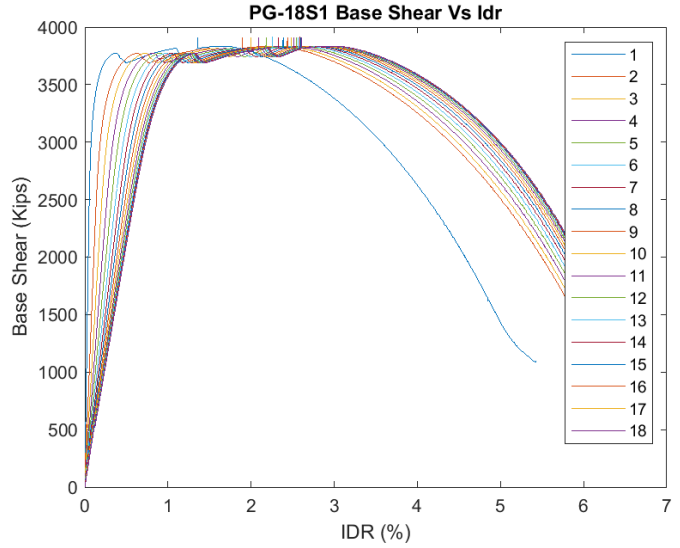

(a)

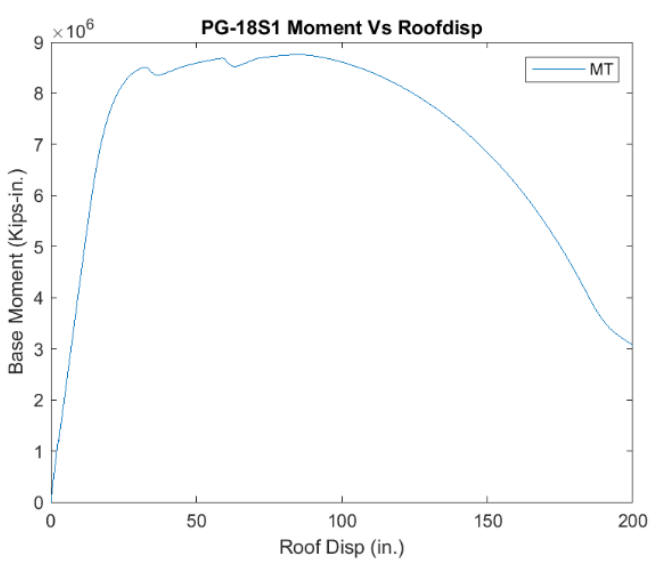

(b)

Figure 10-2. Pushover analysis results for 18-story archetype (a) Base shear vs IDR; (b) Moment vs roof displacement 


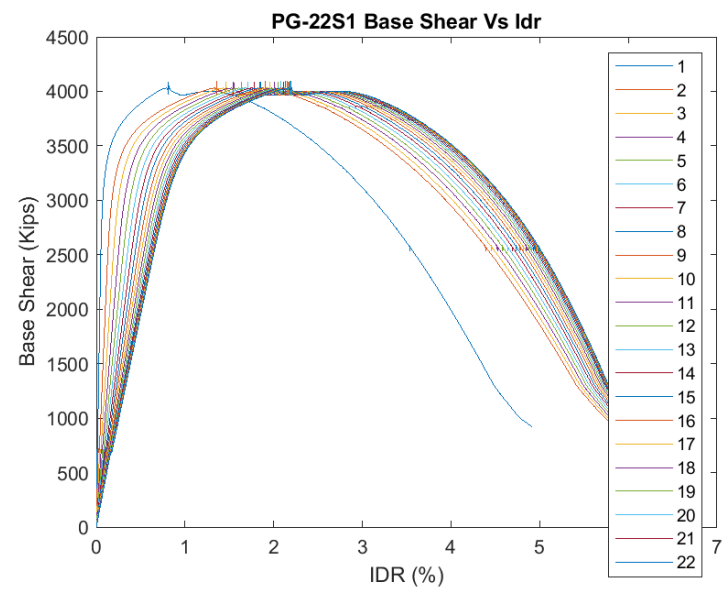

(a)

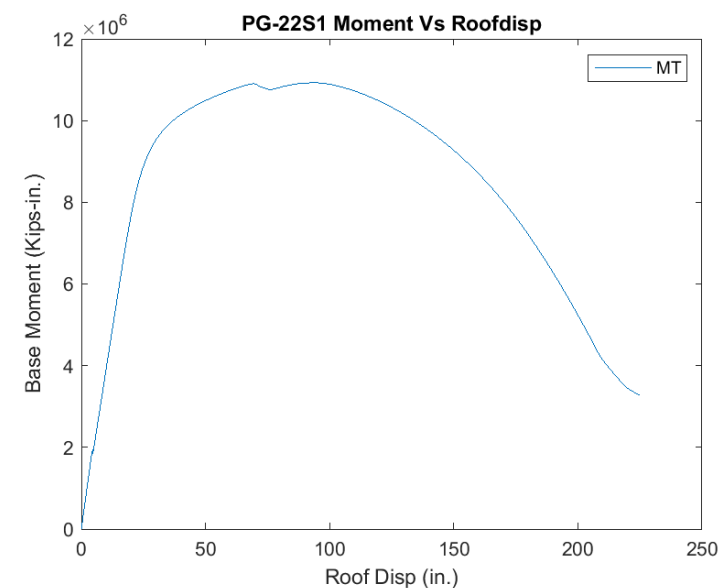

(b)

Figure 10-3. Pushover analysis results for 22-story archetype (a) Base shear vs IDR; (b) Moment vs roof displacement

The nonlinear pushover analysis results of the planar archetypes are presented in Table 10-1.

Table 10-1. Pushover analysis results for C-shaped archetype structures

\begin{tabular}{|c|c|c|c|c|c|c|}
\hline Structure & $\begin{array}{c}\mathrm{V}_{\mathrm{ELF}}, \\
\text { (kips) }\end{array}$ & $\begin{array}{c}\mathrm{V}_{\max }, \\
\text { (kips) }\end{array}$ & $\begin{array}{c}\delta_{\mathrm{y}, \text { eff, }} \\
\text { in }\end{array}$ & $\begin{array}{c}\delta_{\mathrm{u}}, \\
\text { in }\end{array}$ & $\begin{array}{c}\text { Overstrength, } \\
\Omega\end{array}$ & $\begin{array}{c}\text { Period-based } \\
\text { ductility, } \mu_{\mathrm{t}}\end{array}$ \\
\hline $15 \mathrm{~S} 1$ & 1230 & 3230 & 9.7 & 125 & 2.63 & 12.9 \\
\hline $18 \mathrm{~S} 1$ & 1470 & 3910 & 11.3 & 140 & 2.66 & 12.4 \\
\hline $22 \mathrm{~S} 1$ & 1485 & 4090 & 16.1 & 150 & 2.75 & 9.3 \\
\hline \multicolumn{7}{r}{} \\
\hline
\end{tabular}

Figure 10-4 shows base shear (kips) vs roof displacement (in) plots for the 15-story, 18-story, and 22-story archetypes. It also provides the estimate of Maximum Base Shear, $\mathrm{V}_{\max }$, ELF Base Shear demand, $\mathrm{V}_{\mathrm{ELF}}$, and ultimate roof displacement, $\delta_{\mathrm{u}}$ (at $80 \%$ remaining capacity). These values are then used to calculate the overstrength factor, $\Omega_{0}$, and period-based ductility, $\mu_{\mathrm{t}}$. 


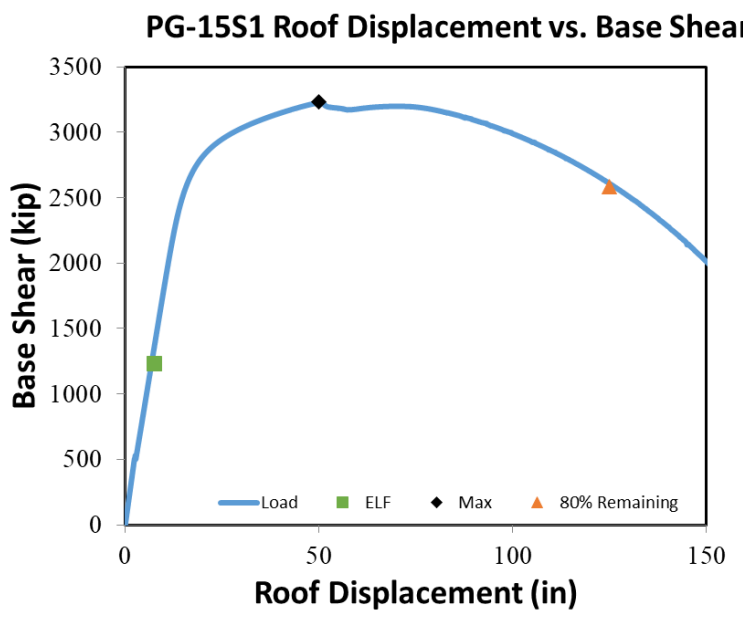

(a)

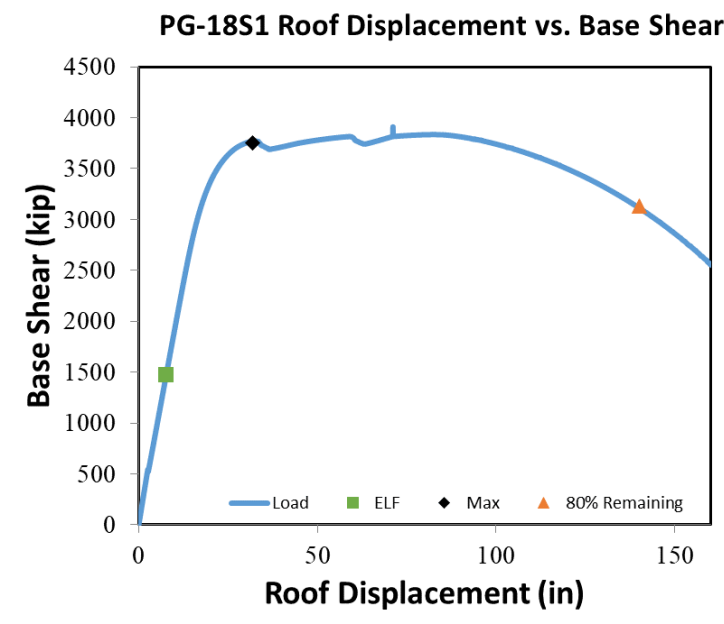

(b)

PG-22S1 Roof Displacement vs. Base Shear

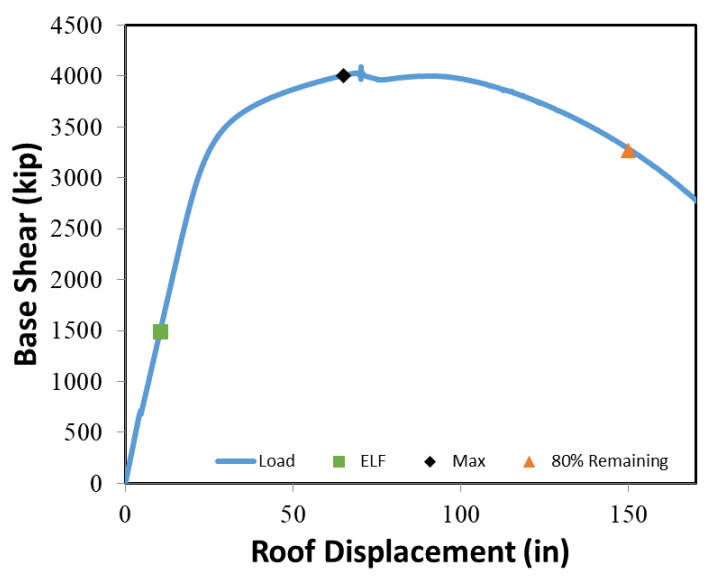

(c)

Figure 10-4. Maximum base shear capacity, ELF base shear and ultimate displacement (a) 15S1; (b) 18S1; (c) 22S1

\subsection{Incremental Dynamic Analysis}

The incremental dynamic analysis for C-shaped composite walls archetypes is conducted in compliance with the approach prescribed in FEMA P695 methodology as described in Section 2.4.2. The steps similar to the steps explained in Section 9.3 are used to create the spectral acceleration vs maximum inter-story drift curve and hence create the IDA plots and estimate median collapse intensity. A conservative collapse criterion of 3\% was used for C-shaped mediumrise walls. 
Figure 10-5 to Figure 10-7 illustrates the spectral acceleration vs maximum inter-story drift ratio plot and cumulative failure probability vs spectral acceleration for 15-story, 18-story, and 22-story. It also lists down the median collapse intensity for the $3 \%$ collapse criterion.

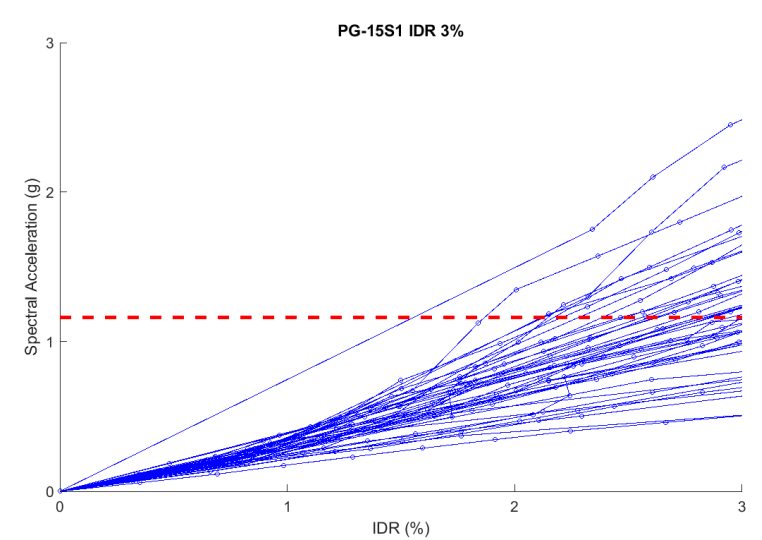

(a)

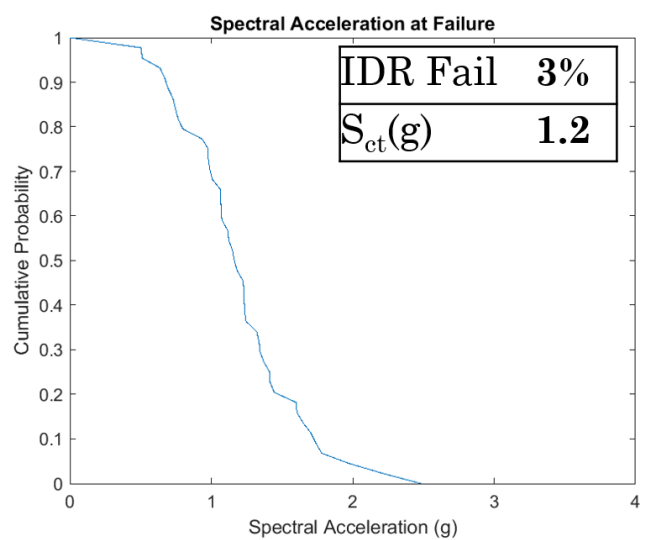

(b)

Figure 10-5. IDA plot for 15-story archetype with 3\% collapse criterion (a) Spectral acceleration vs IDR; (b) Cumulative probability of failure vs spectral acceleration

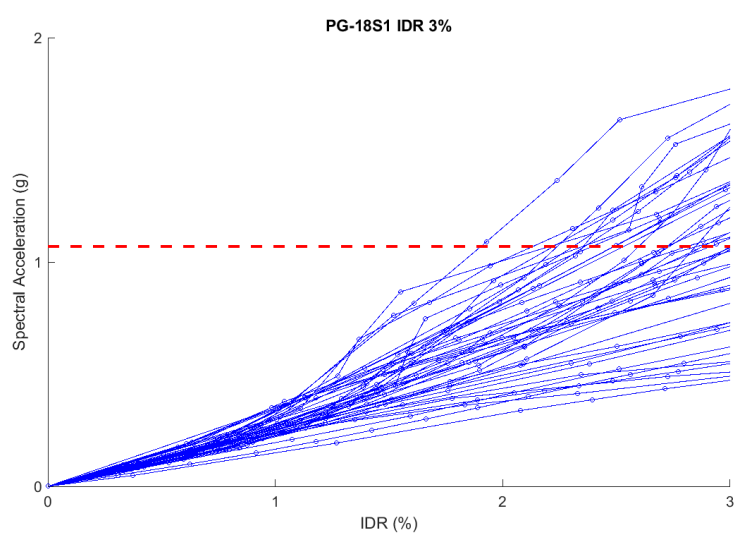

(a)

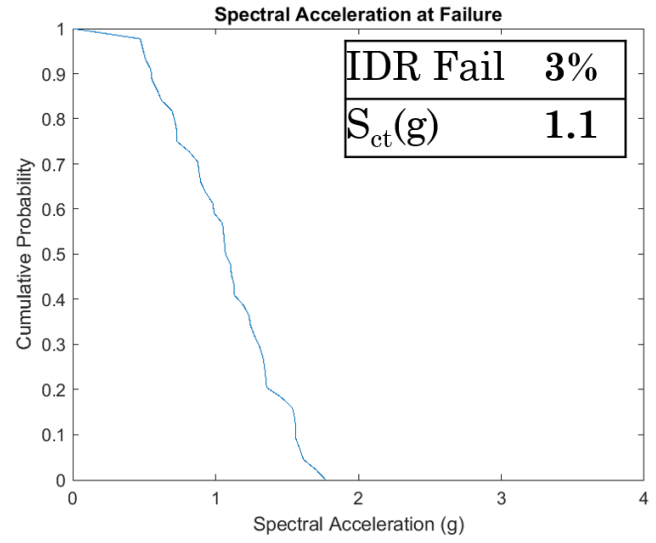

(b)

Figure 10-6. IDA Plot for 18-story archetype with 3\% collapse criterion (a) Spectral acceleration vs IDR; (b) Cumulative probability of failure vs spectral acceleration 


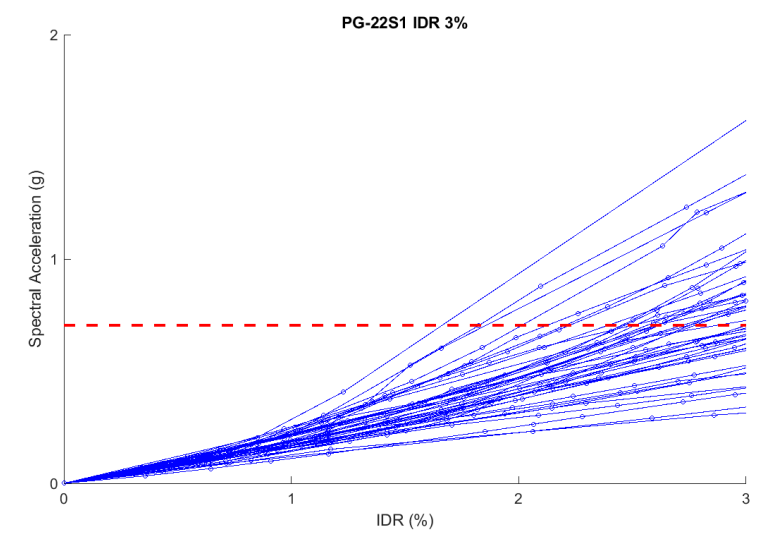

(a)

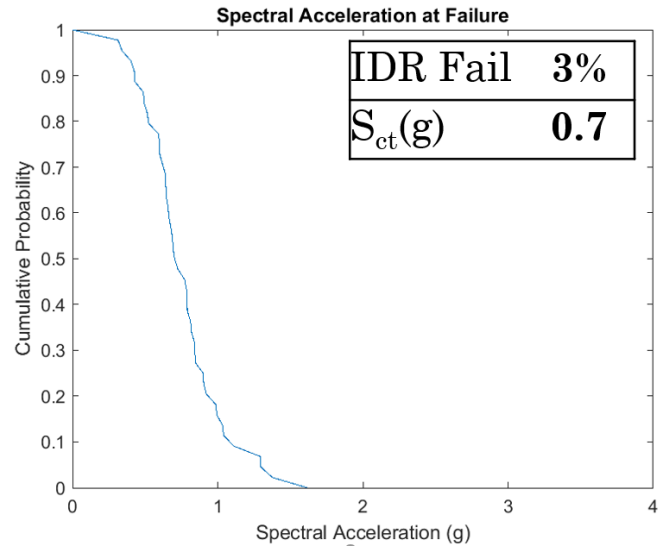

(b)

Figure 10-7. IDA Plot for 22-story archetype with $3 \%$ collapse criterion (a) Spectral acceleration vs IDR; (b) Cumulative probability of failure vs spectral acceleration

\subsection{Performance Evaluation}

The performance of the C-shaped composite walls seismic resisting system is assessed according to the FEMA P695 methodology as described in Section 2.4. The validity of the seismic performance factors used to design the archetype is evaluated in this section. The collapse margin ratio, $C M R$, and adjusted collapse margin ratio, $A C M R$, are presented in Table 10-2. The value of the adjusted collapse margin ratio, $A C M R$, is then compared to the acceptable value of adjusted collapse margin ratio at $10 \%$ probability of failure, $A C M R_{10 \%}$ provided in Table $2-1$.

Table 10-2. Performance evaluations results for $\mathrm{C}$-shaped archetype structures

\begin{tabular}{|c|c|c|c|c|c|}
\hline PG & OS Period (s) & $\mathrm{S}_{\mathrm{ct}}(\mathrm{g})$ & CMR & $\operatorname{ACMR}\left(\boldsymbol{\mu}_{\mathrm{t}}>3\right)$ & $\operatorname{ACMR}\left(\boldsymbol{\mu}_{\mathrm{t}}=3\right)$ \\
\hline $15 \mathrm{~S} 1$ & 2.0 & 1.2 & 2.62 & 4.22 & 3.46 \\
\hline $18 \mathrm{~S} 1$ & 2.4 & 1.1 & 2.82 & 4.53 & 3.72 \\
\hline $22 \mathrm{~S} 1$ & 2.9 & 0.7 & 2.29 & 3.68 & 3.02 \\
\hline \multicolumn{4}{|c|}{ Average } & 4.14 & 3.40 \\
\hline
\end{tabular}


The calculated $A C M R$ values for all planar composite wall archetypes are greater than the required acceptable value of $A C M R_{10 \%}$. This suggests that the seismic performance factors selected to design the archetype provide a sufficient level of seismic resistance and collapse prevention. 


\section{WALLS WITHOUT CLOSURE FLANGE PLATES}

This chapter presents the details of planar composite walls without boundary elements (without closure plates) as shown in Figure 11-1. The infill concrete is confined by steel faceplates. Closure plates in C-PSW/CF walls discussed earlier provide additional confinement to the infill concrete and reduce the effects of steel faceplate fracture and buckling. The closure plate also prevents concrete from crushing and spalling near the toes of the composite walls. Closure plates also eliminate the requirement of formwork during construction. Walls without closure plates lack all these benefits provided by having the closure plates. These lead to the question of the adequacy of walls without boundary elements compared to walls with a boundary element. This chapter presents the FEMA P695 based study for the walls without closure plates.

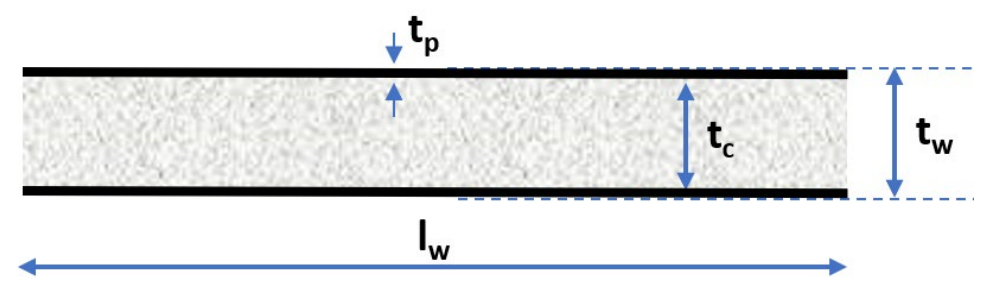

Figure 11-1. Planar composite plate shear wall without closure plate

\subsection{Material Models and Model Benchmarking}

As discussed earlier the closure plate enhances the confinement in the infill concrete provided by the faceplates. The properties of walls without closure plates differ from the properties of walls with closure plates. Kurt et al. (2016) from his experiments on walls without closure plates observed flexural cracking of concrete followed by local buckling of steel faceplates. Further increase in the drift on the test specimen leads to crushing and spalling of concrete and eventually resulting in ductile fracture of the steel faceplates near the base. The level of confinement observed in the infill concrete also varied along the length of the walls. The concrete near the toes of the walls had a lesser degree of confinement compared to the concrete present on the center of the wall length. The overall behavior of infill concrete was in between a confined model used for walls with closure plate and unconfined concrete. For this reason, two different material models for 
concrete and steel were selected to create the OpenSees model. The first model was based on the Tao concrete model (confined concrete model) and the second model was based on the Popovics concrete model (unconfined concrete model). The steel behavior was then adjusted to achieve proper benchmarking with the experimental results. Figure 11-2 presents the concrete and steel effective stress-strain curve for the first model. Figure 11-3 presents the concrete and steel effective stress-strain curve for the second model.

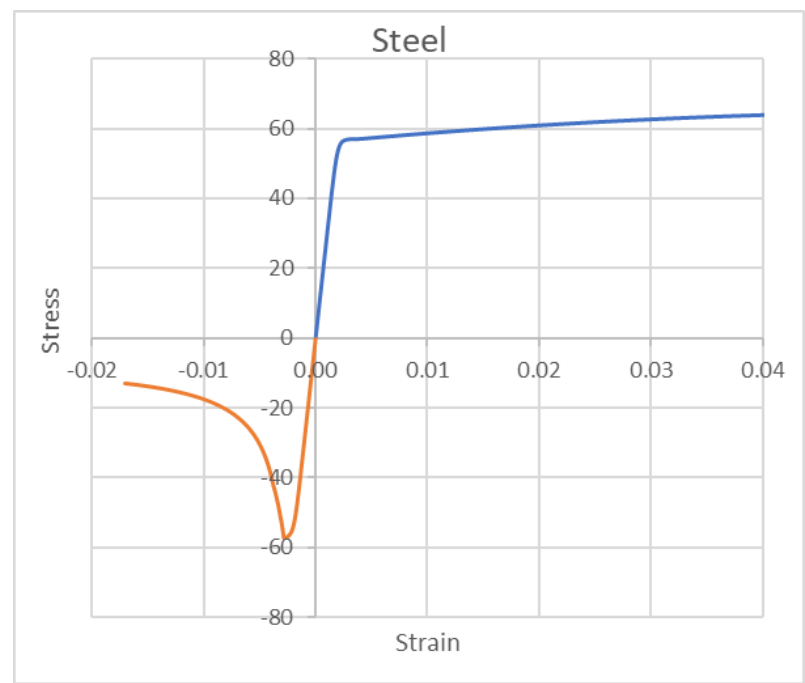

(a)

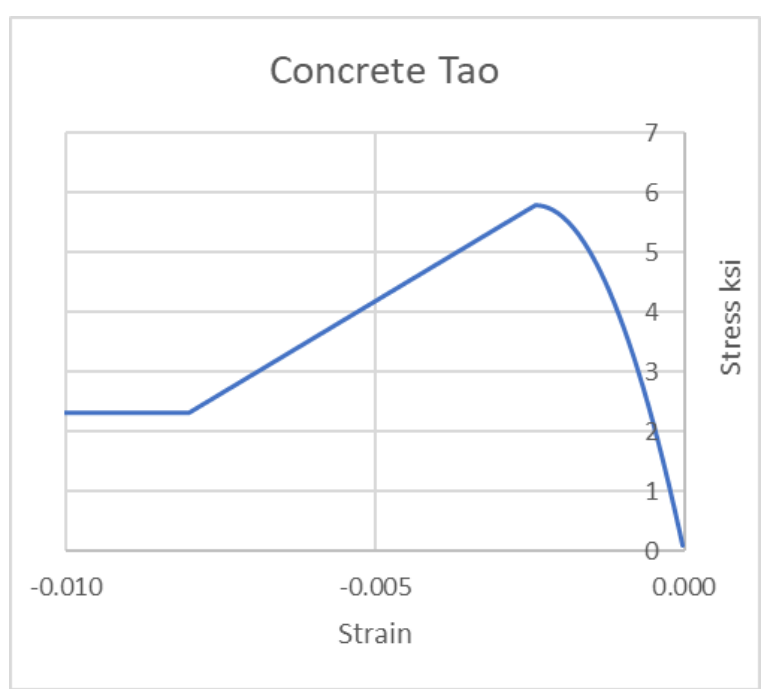

(b)

Figure 11-2. Effective stress-strain curve for the first case with the Tao confined concrete model (a) Steel stress vs strain; (b) Confined concrete stress vs strain

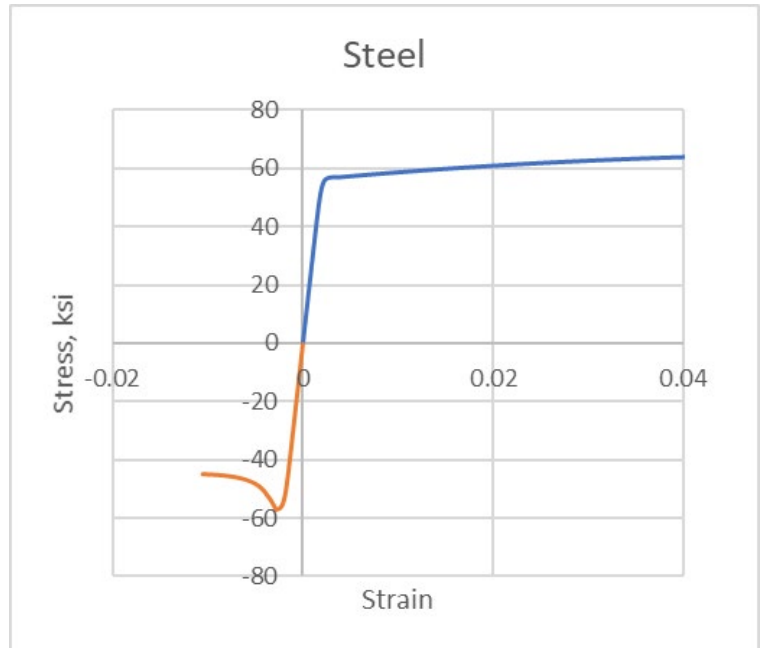

(a)

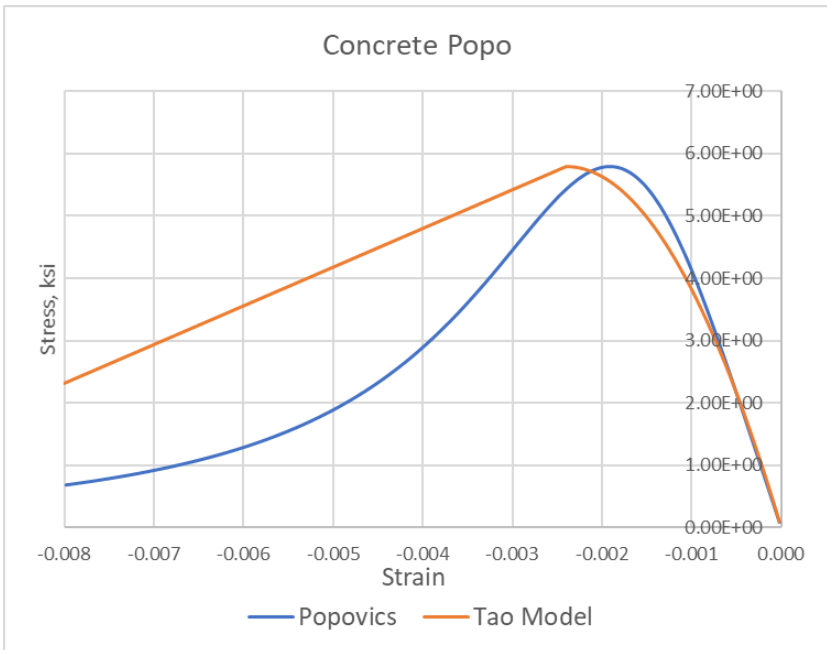

(b) 
Figure 11-3. Effective stress-strain curve for the second case with the Popovics unconfined concrete model (a) Steel stress vs strain; (b) Unconfined concrete stress vs strain

Figure 11-4 compares the experimental results with the two OpenSees models. The overall behavior and seismic behavior of these walls shall be in between the results obtained from the two models.

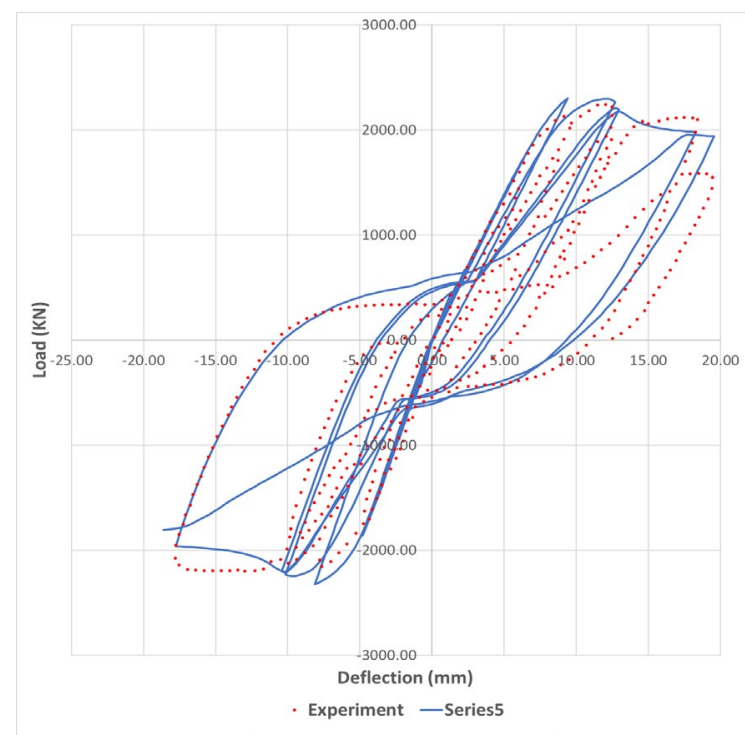

(a)

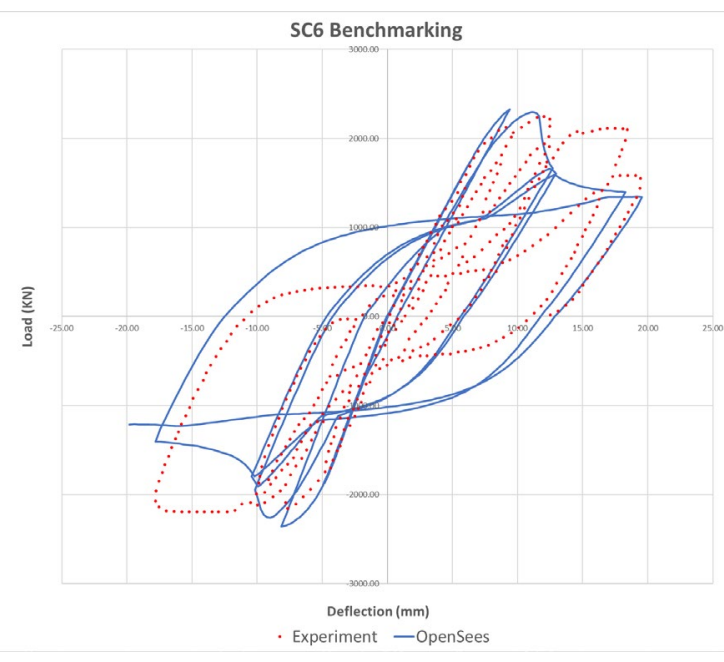

(b)

Figure 11-4. Experiment result vs OpenSees model (a) First model (Tao concrete); (b) Second model (Popovics concrete)

\subsection{Archetype Models}

This section presents the development of the archetype model for walls without closure plates. As observed from the results of planar composite walls (with closure plates) archetype, 3-story and 6story structure had the least value of adjusted collapse margin ratio, $A C M R$. The $A C M R$ value increased as the number of stories i.e. the height of the structure was increased. Higher $A C M R$ values correspond to better seismic performance and lower probability of collapse. For this reason, the most critical cases 3-story and 6-story archetype structure in terms of seismic performance were considered for analysis. 
Experiment results by Kurt et al. (2016) indicated that local buckling of steel and crushing of unconfined concrete occurred at almost the same instant. The crushing of concrete resulted in spalling hence eventual degradation in flexural strength. Hence, for these walls flexural capacity was taken as the yield moment capacity, $\mathrm{M}_{\mathrm{yc}}$, instead of the plastic moment capacity, $\mathrm{M}_{\mathrm{p}}$, used for walls with closure plates. The yield moment capacity, $\mathrm{M}_{\mathrm{yc}}$, is found using the stress block shown in Figure 11-5 based on the lower bound plasticity theorem. For this, the concrete behavior was assumed linear elastic with the compressive stress limited to $0.70 f^{\prime} c$. The estimate of the neutral axis location, $\mathrm{c}$, and the corresponding yield moment capacity, $\mathrm{M}_{\mathrm{yc}}$, is given by Equation 11.1 and 11.2 respectively.

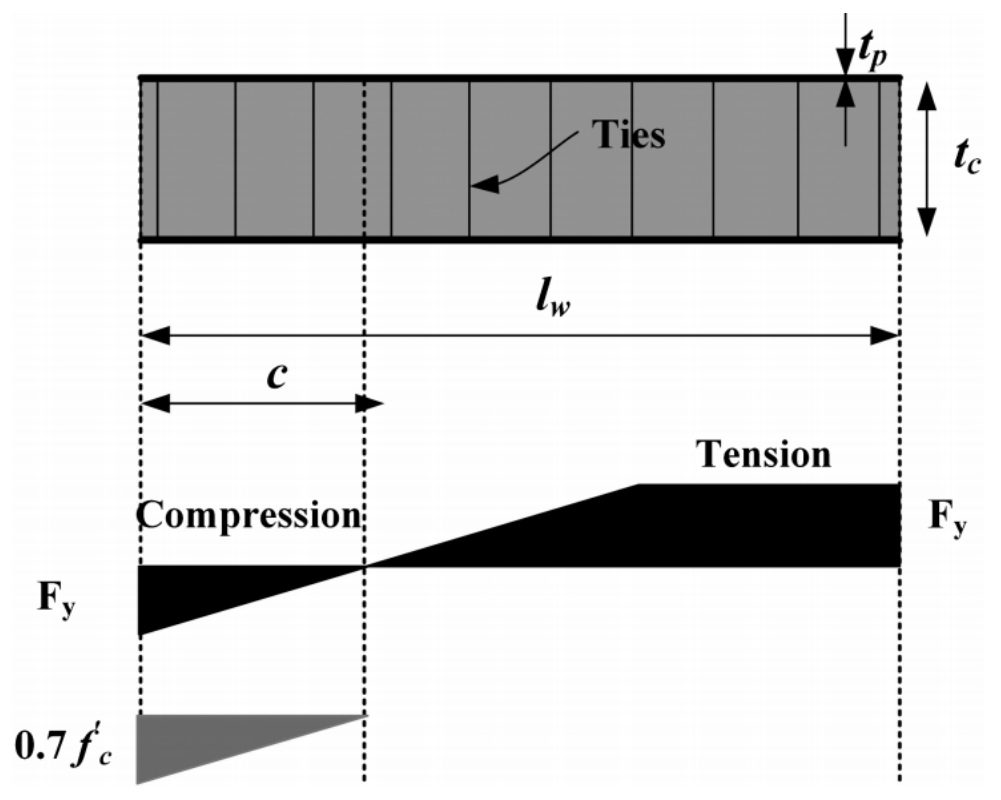

Figure 11-5. Stress distribution assumed to calculate the yield moment (Kurt et al. 2016)

$$
\begin{gathered}
c=\frac{2 t_{p} F_{y} l_{w}}{0.35 t_{c} f_{c}^{\prime}+4 t_{p} F_{y}} \\
M_{y c}=\frac{0.7 f_{c}^{\prime} t_{c} c^{2}}{3}+F_{y} t_{p}\left(\frac{4}{3} c^{2}-2 l_{w} c+l_{w}^{2}\right)
\end{gathered}
$$

where $t_{c}$ is the thickness of concrete, $t_{p}$ is one faceplate thickness and $l_{w}$ is the length of the wall 
The similar floor plan and story height used for the 3-story and 6-story planar archetypes are used for the archetype structures without closure plates. Table 11-1 summarizes the dimensions and additional details of the wall used for the two archetypes.

Table 11-1. Planar composite wall archetypes

\begin{tabular}{|c|c|c|c|c|c|c|c|}
\hline \multirow{2}{*}{ Case } & \multirow{2}{*}{$\begin{array}{l}\text { No. of } \\
\text { Stories }\end{array}$} & \multirow{2}{*}{$\begin{array}{c}\text { Wall } \\
\text { Thickness, } \\
\text { in }\end{array}$} & \multirow{2}{*}{$\begin{array}{c}\text { Wall } \\
\text { Length, } \\
\text { ft }\end{array}$} & \multirow{2}{*}{$\begin{array}{c}\text { Plate } \\
\text { Thickness, } \\
\text { in }\end{array}$} & \multicolumn{2}{|c|}{$\begin{array}{c}\text { Wall Strength } \\
\text { Margin }\end{array}$} & \multirow{2}{*}{$\begin{array}{c}\text { Max } \\
\text { IDR (\%) }\end{array}$} \\
\hline & & & & & $\begin{array}{c}\phi M_{n, \text { wall }} \\
M_{u, \text { wall }}\end{array}$ & $\begin{array}{l}\phi V_{n, \text { wall }} \\
4 V_{u, \text { wall }}\end{array}$ & \\
\hline 1 & 3 & 12 & 15 & $4 / 16$ & 1.15 & 1.83 & 2.0 \\
\hline 2 & 6 & 16 & 25 & $5 / 16$ & 1.22 & 2.20 & 2.0 \\
\hline
\end{tabular}

\subsection{Nonlinear Pushover (Static) Analysis}

The nonlinear pushover analysis of the wall without closure plates was conducted in compliance with FEMA P695 approach as described in Section 2.4.1. The results of the pushover analyses of 3-story and 6-story archetypes without closure plates are presented below. Figure 11-6 to Figure 11-8 provides base shear versus IDR plots and moment versus roof displacement plots for the 3story (Tao model - 3WF1 and Popovics model - 3WF2) and 6-story (Tao model - 6WF1) archetypes. The pushover results show that both walls with the Tao concrete model and the Popovics concrete model have a sudden drop in base shear carrying capacity just after reaching the peak capacity. The sudden drop is then followed with a gradual decrease in the capacity resulting from buckling and fracture of steel fibers. These walls have lower ductility compared to walls with the closure plate. The effective flexural stiffness of the walls without closure plates is nearly equal to that of the walls with closure plates. This is because of the similar initial behavior of both the walls with and without closure plate. The main difference between the two wall systems is in the post-peak behavior once the concrete reaches its peak. 


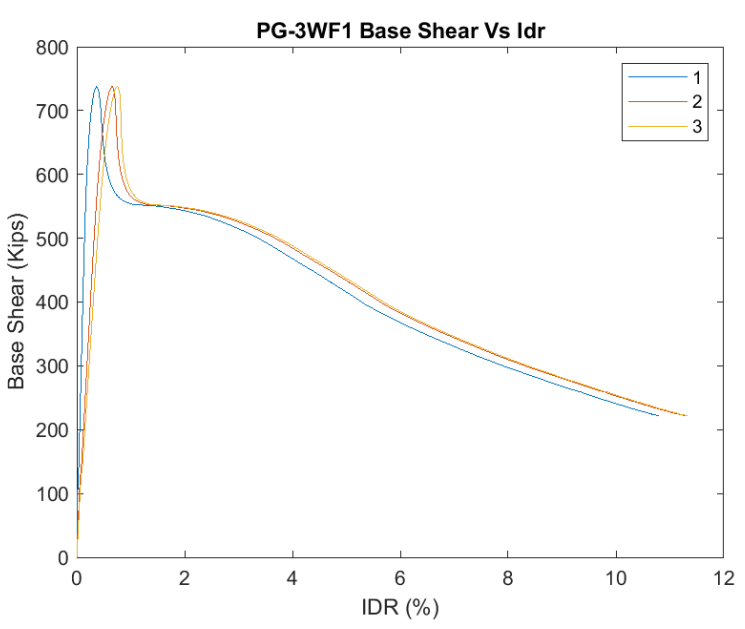

(a)

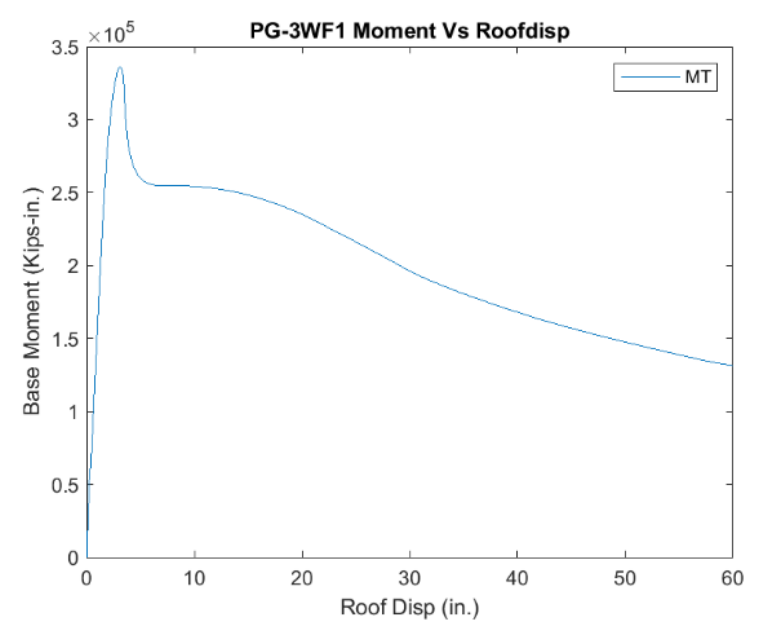

(b)

Figure 11-6. Pushover analysis results for 3-story archetype (3WF1 - Tao concrete model) (a) Base shear vs IDR; (b) Moment vs roof displacement

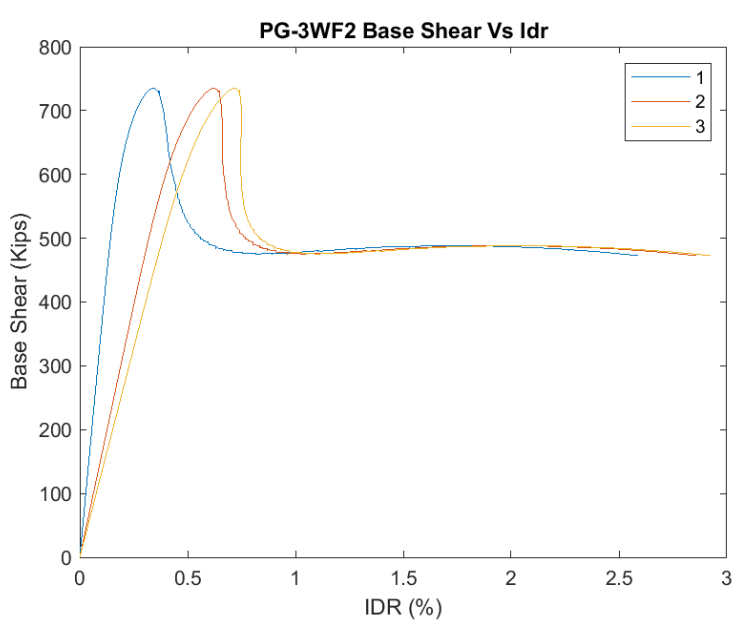

(a)

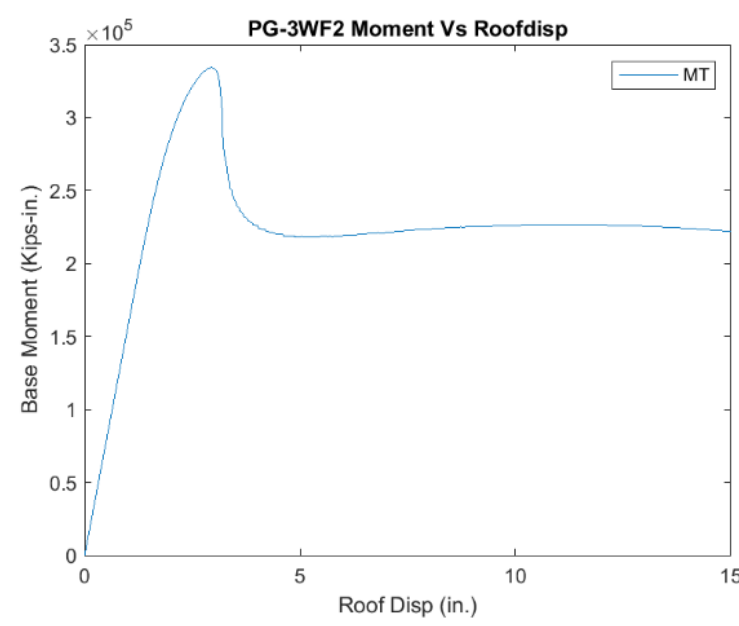

(b)

Figure 11-7. Pushover analysis results for 3-story archetype (3WF2 - Popovics concrete model) (a) Base shear vs IDR; (b) Moment vs roof displacement 


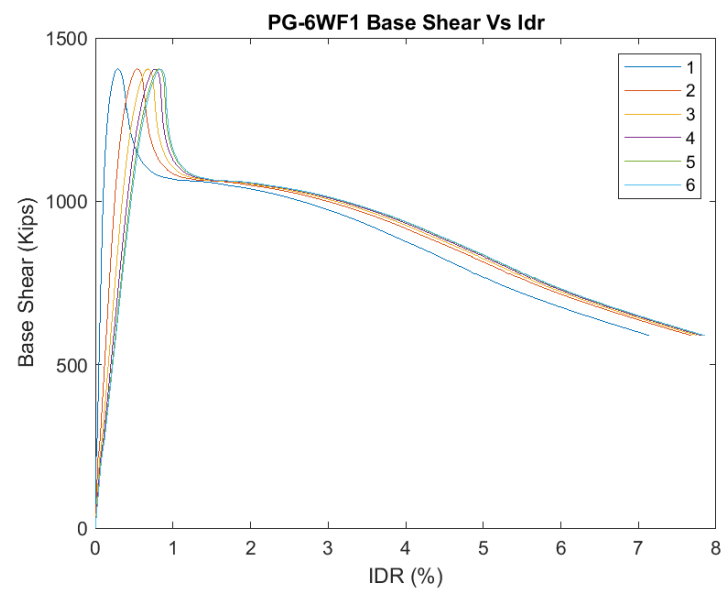

(a)

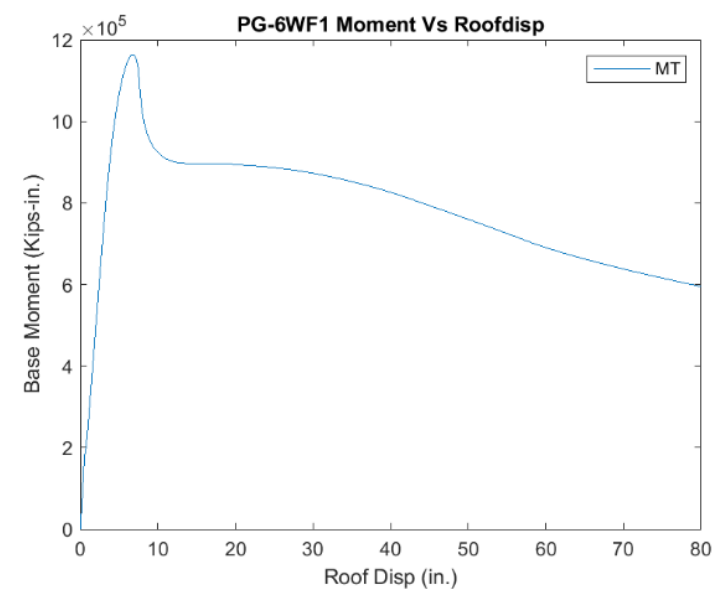

(b)

Figure 11-8. Pushover analysis results for 6-story archetype (6WF1 - Tao concrete model) (a) Base shear vs IDR; (b) Moment vs roof displacement

Figure 11-9 shows base shear (kips) vs roof displacement (in) plots for the 3-story and 6-story archetypes. It also provides the estimate of Maximum Base Shear, $\mathrm{V}_{\max }$, ELF Base Shear demand, $\mathrm{V}_{\text {ELF }}$, and ultimate roof displacement, $\delta_{\mathrm{u}}$ (at $80 \%$ remaining capacity). These values are then used to calculate the overstrength factor, $\Omega_{0}$, and period-based ductility, $\mu_{\mathrm{t}}$.

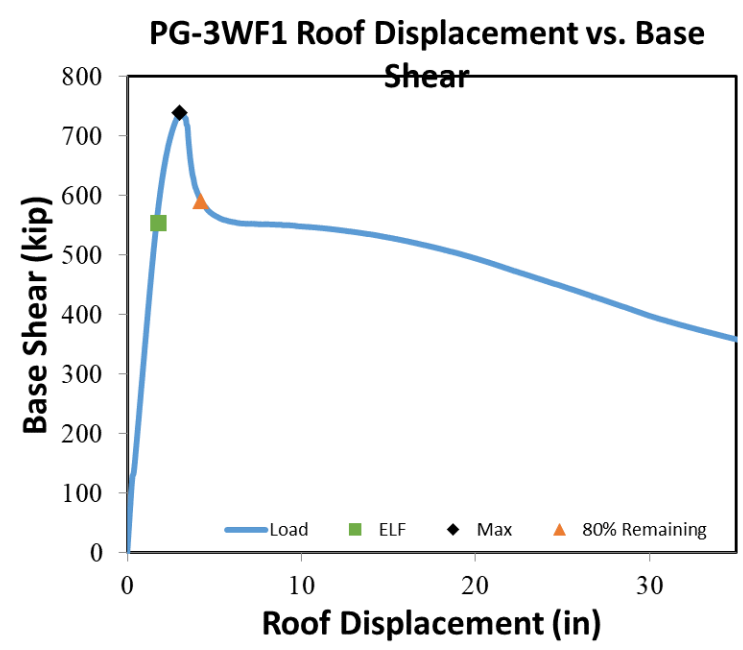

(a)

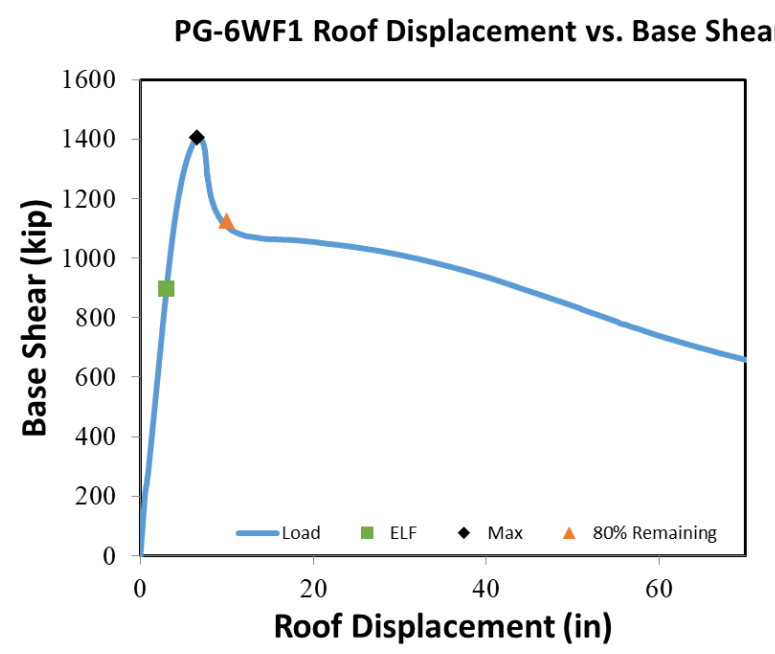

(b)

Figure 11-9. Maximum base shear capacity, yield displacement and ultimate displacement (a) 3WF1; (b) 6WF1 
The nonlinear pushover analysis results of the planar archetypes are presented in Table 11-2. The $20 \%$ drop in strength occurred immediately after the peak was reached. This reduction in strength resulted in a lower value of ultimate displacement and hence lower period-based ductility. The period-based ductility calculated for walls without closure plate ranged from 2.9 to 3.8 while the same factor ranged from 17.2 to 25.1 for planar walls with closure plates.

Table 11-2. Pushover analysis results for planar archetype structures

\begin{tabular}{|c|c|c|c|c|c|c|}
\hline Structure & $\begin{array}{c}\mathrm{V}_{\text {ELF, }} \\
\text { (kips) }\end{array}$ & $\begin{array}{c}\mathrm{V}_{\max }, \\
\text { (kips) }\end{array}$ & $\begin{array}{c}\delta_{\mathrm{y}, \text { eff, }} \\
\text { in }\end{array}$ & $\begin{array}{c}\delta_{\mathrm{u}}, \\
\text { in }\end{array}$ & $\begin{array}{c}\text { Overstrength, } \\
\boldsymbol{\Omega}\end{array}$ & $\begin{array}{c}\text { Period-based } \\
\text { ductility, } \mu_{\mathrm{t}}\end{array}$ \\
\hline 3WF1 & 554 & 739 & 1.2 & 4.2 & 1.33 & 3.6 \\
\hline 3WF2 & 554 & 735 & 1.2 & 3.4 & 1.33 & 2.9 \\
\hline 6WF1 & 897 & 1405 & 2.5 & 9.6 & 1.57 & 3.8 \\
\hline & & & & Avg & $\mathbf{1 . 4 1}$ & $\mathbf{3 . 4}$ \\
\hline
\end{tabular}

\subsection{Incremental Dynamic Analysis}

The incremental dynamic analysis for walls without closure plate is conducted in compliance with the approach prescribed in FEMA P695 methodology as described in Section 2.4.2. The steps similar to the steps explained in Section 9.3 are used to create the spectral acceleration vs maximum inter-story drift curve and hence create the IDA plots and estimate median collapse intensity. Figure 11-10 to Figure 11-12 illustrates the spectral acceleration vs maximum inter-story drift ratio plot and cumulative failure probability vs spectral acceleration for 3WF1, 3WF2, and $6 \mathrm{WF} 1$. It also lists down the median collapse intensity for the $3 \%$ collapse criterion. 


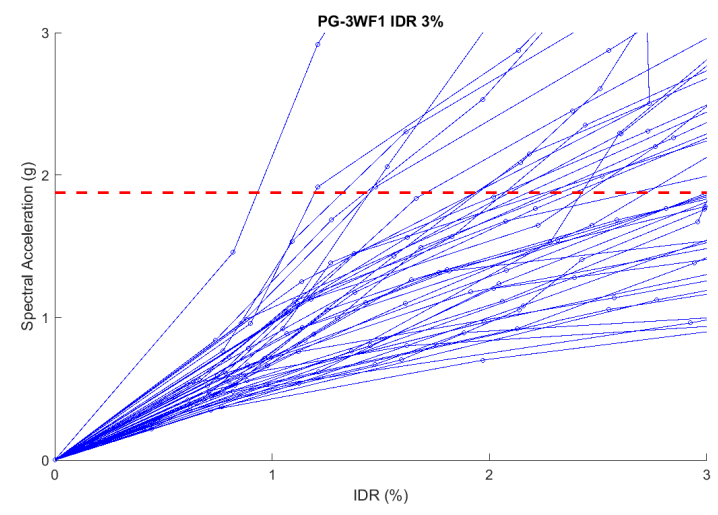

(a)

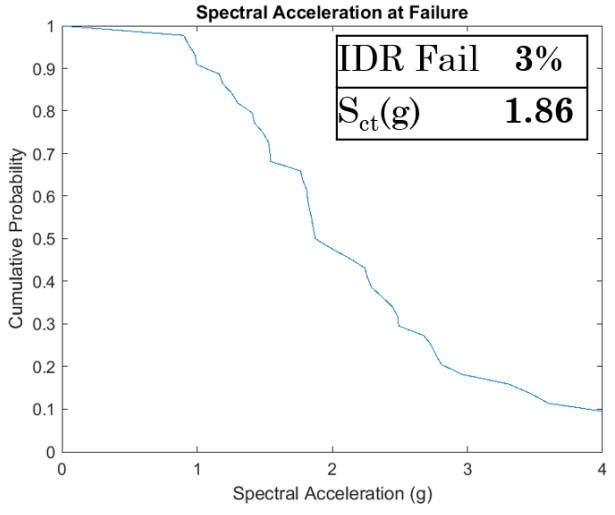

(b)

Figure 11-10. IDA plot for 3 WF1 with $3 \%$ collapse criterion (a) Spectral acceleration vs IDR; (b) Cumulative probability of failure vs spectral acceleration

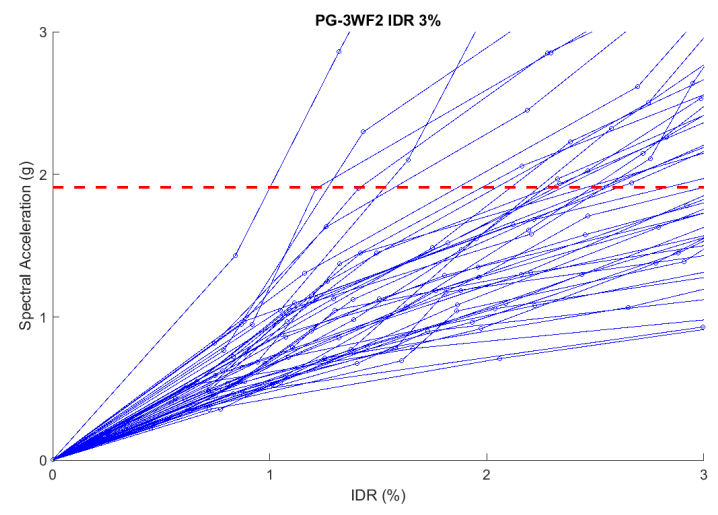

(a)

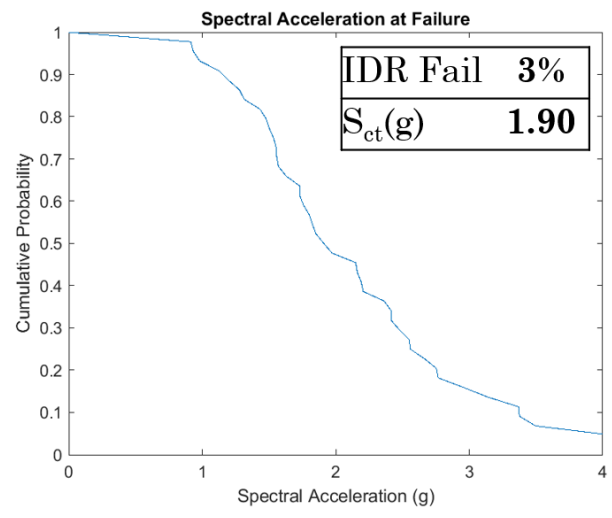

(b)

Figure 11-11. IDA plot for 3WF2 with 3\% collapse criterion (a) Spectral acceleration vs IDR; (b) Cumulative probability of failure vs spectral acceleration 


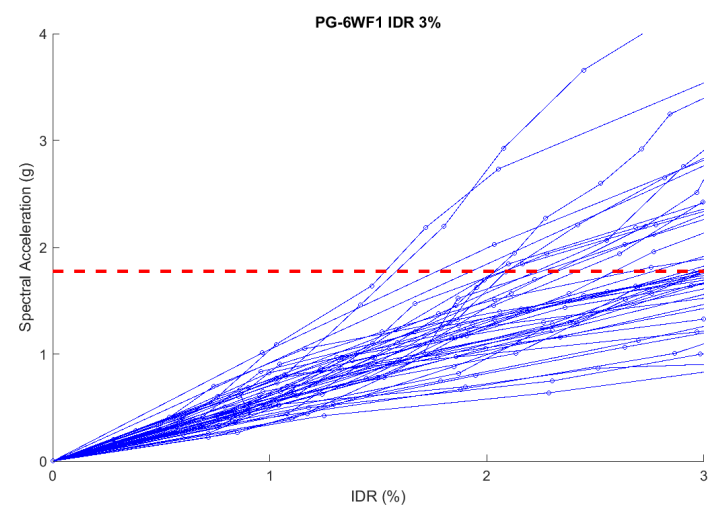

(a)

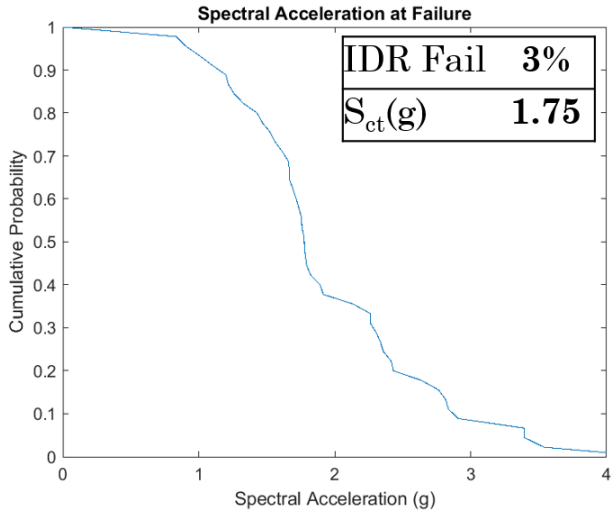

(b)

Figure 11-12. IDA plot for 6WF1 with 3\% collapse criterion (a) Spectral acceleration vs IDR; (b) Cumulative probability of failure vs spectral acceleration

\subsection{Performance Evaluation}

The performance of the walls without closure plates is assessed according to the FEMA P695 methodology as described in Section 2.4. The validity of the seismic performance factors used to design the archetype is evaluated in this section. The collapse margin ratio, $C M R$, and adjusted collapse margin ratio, $A C M R$, are presented in Table 11-3. The value of the adjusted collapse margin ratio, $A C M R$, is then compared to the acceptable value of adjusted collapse margin ratio at $10 \%$ probability of failure, $A C M R_{10 \%}$ provided in Table $2-1$.

Table 11-3. Performance evaluations results for C-shaped archetype structures

\begin{tabular}{|c|c|c|c|c|}
\hline Structure & OS Period $(\mathrm{s})$ & $\mathrm{S}_{\mathrm{ct}}(\mathrm{g})$ & $\mathrm{CMR}$ & $\operatorname{ACMR}\left(\boldsymbol{\mu}_{\mathrm{t}}=3\right)$ \\
\hline 3WF1 (Tao) & 0.64 & 1.9 & 1.34 & 1.62 \\
\hline 3WF2 (Popovics) & 0.65 & 1.9 & 1.38 & 1.66 \\
\hline 6WF1 & 0.99 & 1.8 & 1.93 & 2.40 \\
\hline \multicolumn{4}{|r|}{ Average } & $\mathbf{1 . 8 9}$ \\
\hline
\end{tabular}

The calculated $A C M R$ values for all 3-story wall archetype is smaller than the required acceptable value of $A C M R_{10 \%}$. This suggests that the 3-story archetype does not pass the required ACMR criteria and the selected seismic performance factors do not provide enough seismic performance 
and collapse prevention capacity. The 6-story had acceptable $A C M R$ value for $3 \%$ drift collapse criteria. Experimental results from Kurt indicate that the specimen undergoes concrete crushing and faceplate fracture below a 2\% drift ratio. Table 11-4 and Table 11-5 present the variation of adjusted collapse margin ratio for different levels of collapse criteria.

The 6-story archetype does not satisfy the $A C M R_{10 \%}$ requirement for a $2 \%$ drift limit taken as collapse criteria. This suggests that the seismic performance factors selected to design a wall without closure plates do not provide the required level of seismic resistance and collapse prevention.

Overall considering the results of performance evaluation and ease of construction provided by the inclusion of closure plates, it is recommended that that the boundary elements or closure plates shall be provided. If walls without closure plates are used, it is recommended to use more conservative values seismic performance factors.

Table 11-4. Performance evaluation results for C-shaped archetype structures

\begin{tabular}{|c|c|c|c|c|c|}
\hline Structure & IDR Collapse & $\mathrm{S}_{\mathrm{ct}}(\mathrm{g})$ & CMR & ACMR $\left(\mathrm{u}_{\mathrm{t}}>8\right)$ & ACMR $\left(\mathrm{u}_{\mathrm{t}}=3\right)$ \\
\hline 3WF1 & $2.0 \%$ & 1.4 & 1.00 & 1.36 & 1.20 \\
\hline 3WF1 & $2.5 \%$ & 1.7 & 1.21 & 1.65 & 1.46 \\
\hline 3WF1 & $3.0 \%$ & 2.0 & 1.43 & 1.96 & 1.72 \\
\hline $3 \mathrm{WF} 1$ & $4.0 \%$ & 2.6 & 1.85 & 2.53 & 2.23 \\
\hline 3WF1 & $5.0 \%$ & 3.2 & 2.28 & 3.11 & 2.74 \\
\hline
\end{tabular}

Table 11-5. Performance evaluation results for C-shaped archetype structures

\begin{tabular}{|c|c|c|c|c|c|}
\hline Structure & IDR Collapse & $\mathrm{S}_{\mathrm{ct}}(\mathrm{g})$ & CMR & ACMR $\left(\mathrm{u}_{\mathrm{t}}>8\right)$ & ACMR $\left(\mathrm{u}_{\mathrm{t}}=3\right)$ \\
\hline $6 \mathrm{WF} 1$ & $2.0 \%$ & 1.3 & 1.39 & 2.02 & 1.73 \\
\hline $6 \mathrm{WF} 1$ & $2.5 \%$ & 1.5 & 1.69 & 2.47 & 2.12 \\
\hline $6 \mathrm{WF} 1$ & $3.0 \%$ & 1.8 & 1.93 & 2.81 & 2.40 \\
\hline $6 \mathrm{WF} 1$ & $4.0 \%$ & 2.3 & 2.49 & 3.62 & 3.11 \\
\hline $6 \mathrm{WF} 1$ & $5.0 \%$ & 2.6 & 2.88 & 4.20 & 3.60 \\
\hline
\end{tabular}




\section{STIFFNESS AND SEISMIC PERFORMANCE FACTOR ESTIMATES AND VALIDATION}

This chapter presents the estimation of cracked section flexural stiffness for the C-PSW/CF. It also presents the validation of the trial seismic performance factors used to design the C-PSW/CF archetype structure.

\subsection{Flexural Stiffness Estimate}

The effective flexural stiffness defined in Section 3.3.1 was used to design the planar and C-shaped C-PSW/CF archetype structure. Planar wall C-PSW/CF archetype design used an effective stiffness calculated using the cracked transformed section properties corresponding to $60 \%$ of the nominal flexural capacity. Effective flexural stiffness calculated using Equation 3.1 was used to design the C-shaped C-PSW/CF archetypes. The stiffness depends on the total overturning moment applied on the walls due to the equivalent lateral loads. As the height of the composite walls increases, the wall design becomes more drift critical and the flexural overstrength also becomes larger. The lower overturning moment relative to wall strength for taller structures will result in less cracking in the concrete. The cracked properties also vary along with the height of the wall due to lower moment demands at upper levels. Figure 12-1 shows an example of the ratio of the overturning moment and design strength along the height of the wall for an 18-story archetype. The 18 -story archetype structure does not reach $60 \%$ of the nominal moment and should have more stiffness then what is estimated corresponding to $60 \%$ of the nominal flexural capacity.

The use of different stiffness along with the height of the structure and for different archetypes increases the complexity of the design procedure. For this reason, a simple equation for stiffness estimation is provided (See Equation 3.1). This equation is based on the stiffness calculated for the cracked reinforced concrete wall per Table 6.6.3.1.1(a) of ACI 318-14. A nonlinear model as shown in Figure 8-3 was used to validate for the above equation. Nonlinear wall elements as discussed in Chapter 8 were used for the entire structure instead of a small region near the base of the wall. Equivalent lateral forces as calculated in Section 4.2 were applied to the nonlinear model 
to obtain the maximum IDR. This model was compared to a full elastic model with an effective elastic stiffness, $\mathrm{EI}_{1}$, which would result in the same maximum IDR calculated from the fully nonlinear model. Table 12-1 compares the effective elastic stiffness, $\mathrm{EI}_{1}$, and stiffness calculated using Equation 3.1.

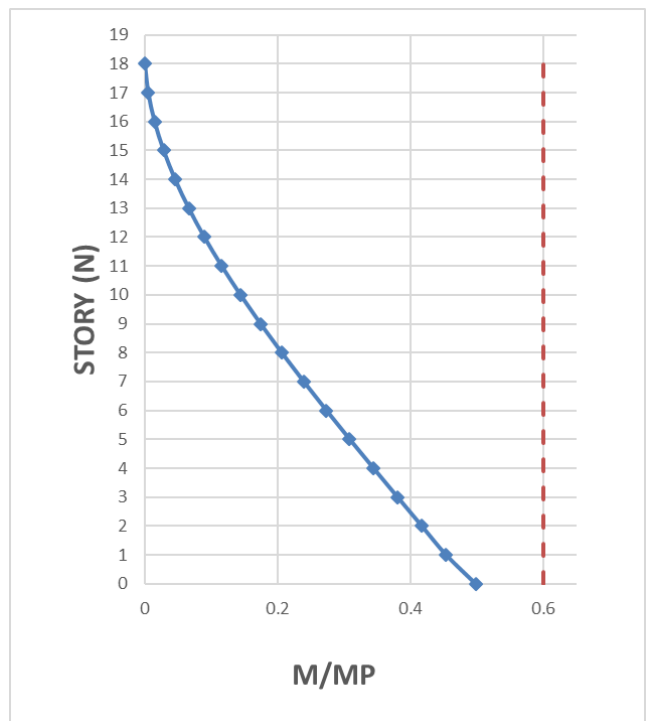

Figure 12-1. Ratio of the overturning moment and design strength for the 18-story archetype

Table 12-1. Effective stiffness estimates for C-PSW/CF archetype structures

\begin{tabular}{|c|c|c|c|c|}
\hline Case & Wall & $\begin{array}{c}\text { EI }_{1} \\
\text { Effective EI (Fiber) }\end{array}$ & $\begin{array}{c}\text { EI } I_{\text {eff }} \\
E_{s} I_{s}+0.35 E_{c} I_{c}\end{array}$ & $\mathbf{E I}_{1} / \mathbf{E I}_{\text {eff }}$ \\
\hline 1 & $3 \mathrm{~S} 1$ & $1.6 \mathrm{E}+10$ & $1.7 \mathrm{E}+10$ & 0.92 \\
\hline 2 & $6 \mathrm{~S} 1$ & $9.7 \mathrm{E}+10$ & $1.0 \mathrm{E}+11$ & 0.97 \\
\hline 3 & 9S1 & $2.6 \mathrm{E}+11$ & $2.6 \mathrm{E}+11$ & 1.01 \\
\hline 4 & $12 \mathrm{~S} 1$ & $5.1 \mathrm{E}+11$ & $5.1 \mathrm{E}+11$ & 0.99 \\
\hline 5 & $15 \mathrm{~S} 1$ & $7.1 \mathrm{E}+11$ & $6.8 \mathrm{E}+11$ & 1.04 \\
\hline 6 & $18 \mathrm{~S} 1$ & $1.3 \mathrm{E}+12$ & $1.1 \mathrm{E}+12$ & 1.16 \\
\hline 7 & $22 \mathrm{~S} 1$ & $1.8 \mathrm{E}+12$ & $1.6 \mathrm{E}+12$ & 1.10 \\
\hline \multicolumn{4}{|r|}{ Average } & 1.03 \\
\hline
\end{tabular}


As seen in Table 12-1, the average effective stiffness estimated using the nonlinear fiber model equates well with the stiffness calculated using Equation 3.1. Hence, Equation 3.1 reasonably estimates the effective flexural stiffness for the composite walls system. The use of different stiffness along the height of the walls is permitted using a through cracked transformed section analysis. The gravity loads due to the tributary floor area result in $0.05 \mathrm{Ag}_{\mathrm{g}}$ to $0.07 \mathrm{Ag}_{\mathrm{c}}$ axial force in the wall. This axial force increases the overall effective stiffness by $10-20 \%$ for the archetype structures. Considering slightly less relative effective stiffness for the 3 -story of 0.92 , the increase in effective stiffness due to the tributary axial force is neglected to get a more conservative design procedure.

\subsection{Response Modification Factor, $R$}

The response modification factor is defined at the ratio of the elastic base shear demand to the design base shear. A response modification factor, R, of 6.5 was used to design the C-PSW/CF archetype. This report validates the use of a response modification factor of 6.5 using FEMA P695 based nonlinear static and dynamic analysis. This analysis was conducted on both planar and Cshaped C-PSW/CFs. FEMA P695 methodology requires the adjusted collapse margin ratio, $A C M R$, to be greater than two performance criteria, namely for individual archetypes $\left(A C M R_{20 \%}\right)$ and performance groups $\left(A C M R_{10 \%}\right)$. If these two criteria are satisfied, then the trial factor $\mathrm{R}$ factor used to design the archetype is deemed acceptable. C-PSW/CF. Chapters 9 and 10 discussed the incremental dynamic analysis and performance evaluation conducted on planar C-PSW/CF and Cshaped C-PSW/CF, respectively. Table 9-2 and Table 10-2 summarizes the results of the performance evaluation conducted on these walls. The adjusted collapse margin ratio, $A C M R$, was found to be greater than the required $A C M R_{10 \%}$ and $A C M R_{20 \%}$ value for the planar and C-shaped C-PSW/CF. This justifies the use of an R factor of 6.5 for planar and C-shaped C-PSW/CFs. The same study was conducted for walls without a closure plate and discussed previously in Chapter 11. The $A C M R$ values of walls without closure plates did not satisfy the $10 \%$ collapse $A C M R_{10 \%}$ requirement. Hence, a lower R factor is recommended to design of walls without closure plates. This additional study on walls without closure plates was not performed but would require designing structures with $\mathrm{R}$ factor until an acceptable seismic performance is reached. 


\subsection{Deflection Amplification Factor, $C_{d}$}

A deflection amplification factor, $C_{d}$, of 5.5 was used to design the C-PSW/CF archetypes. The $C_{d}$ factor depends on the ratio of nonlinear displacement to the elastic displacement of the system. The maximum IDR of a nonlinear at the Design Basis Earthquake (DBE) level was found for each of the C-PSW/CF archetype structure for all the 44 ground motion responses. The mean and $90^{\text {th }}$ percentile IDR values were calculated from these results. Table 12-2 lists the average IDR,

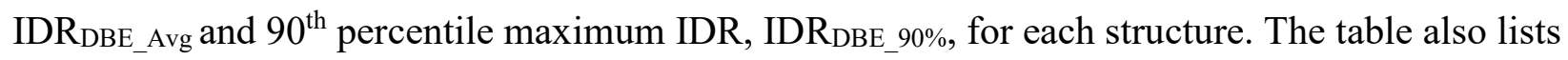
the elastic drift, IDR $\mathrm{ELF}_{\mathrm{f}}$, from the equivalent lateral force loading on the composite walls.

Table 12-2. Deflection amplification factor, $\mathrm{Cd}$, estimate for $\mathrm{C}-\mathrm{PSW} / \mathrm{CF}$ archetype structures

\begin{tabular}{|c|c|c|c|c|c|c|}
\hline Archetype & IDR $_{\text {DBE_Mean }}$ & IDR $_{\text {DBE_90\% }}$ & IDR $_{M C E}$ & IDR $_{\text {ELF }}$ & C $_{\text {d_DBE_Mean }}$ & Cd_DBE_90\% $_{1}$ \\
\hline $3 \mathrm{~S} 1$ & 1.36 & 1.96 & 2.04 & 0.30 & 4.5 & 6.5 \\
\hline $6 \mathrm{~S} 1$ & 1.19 & 1.67 & 1.78 & 0.30 & 4.0 & 5.6 \\
\hline $9 \mathrm{~S} 1$ & 1.17 & 1.70 & 1.75 & 0.30 & 3.8 & 5.6 \\
\hline $12 \mathrm{~S} 1$ & 1.24 & 1.79 & 1.85 & 0.29 & 4.2 & 6.1 \\
\hline $15 \mathrm{~S} 1$ & 1.11 & 1.52 & 1.67 & 0.35 & 3.2 & 4.4 \\
\hline $18 \mathrm{~S} 1$ & 1.11 & 1.60 & 1.67 & 0.36 & 3.1 & 4.4 \\
\hline $22 \mathrm{~S} 1$ & 1.22 & 1.61 & 1.83 & 0.37 & 3.3 & 4.4 \\
\hline \multicolumn{7}{r}{} \\
\end{tabular}

The average deflection amplification factor, $\mathrm{C}_{\mathrm{d}_{-} \text {DBE_Mean, }}$, for the mean DBE response was calculated as 3.7 and $\mathrm{C}_{\mathrm{d}_{-} \mathrm{DBE}}$ 90\% for the $90^{\text {th }}$ percentile DBE response was found to be 5.3. The deflection amplification factor calculated for the $90^{\text {th }}$ percentile DBE response compares well with 5.5 value used for the design of archetype. Drift calculations do not incorporate a safety factor similar to the resistance factor for strength-based limits; therefore, the $\mathrm{Cd}$ used in the design should be a lower-bound value. Using the $90^{\text {th }}$ percentile result captures this conservatism while also 
mirroring the observed structural response. The average value of $\mathrm{C}_{\mathrm{d}}$ for the $90^{\text {th }} \mathrm{DBE}$ response was calculated as 5.3, which is close to a $C_{d}$ value of 5.5 as assumed in the design procedure.

\subsection{Overstrength Factor, $\Omega_{0}$}

The overstrength provides a ratio of the maximum base shear resistance to the design base shear. The system overstrength is the largest value of calculated overstrength in all the performance group. The design procedure of uncoupled composite walls does not require the use of the overstrength factor apart from the usual safety factor and material overstrength. The design of the C-PSW/CF archetype structures was drift-governed and large walls were used to limit the IDR to $2 \%$ for equivalent lateral forces. This design limit resulted in an inherent overstrength strength in the system. The overstrength factor generally increased as the height of the structure was increased with the largest overstrength observed for the 22-story archetype. The overstrength factors listed in Table 9-1 and Table 10-1 were determined using nominal material properties and do not account for additional material strength above the minimum yield capacity. A separate nonlinear static analysis using expected steel strength was conducted on the planar and C-shaped and the results are summarized in Table 12-3. Here, Overstrength, $\Omega_{1}$, is the overstrength calculated in Table 9-1 and Table 10-1 which does not include any additional material strength and Overstrength, $\Omega_{2}$ includes the steel overstrength, $\mathrm{R}_{\mathrm{y}}$, of 1.1. Based on these results, an overstrength factor of 2.5 is recommended. Although the overstrength factor for taller structures did exceed this value, especially when considering expected material properties, 2.5 represents the median value. As this value is not used in the design process the median overstrength value is sufficient to capture the performance while maintaining the conservative design philosophy.

Table 12-3. Overstrength for planar and C-shaped archetype structures. $\Omega_{1}$ considers nominal material properties and $\Omega_{2}$ considers the expected strength of steel.

\begin{tabular}{|c|c|c|c|c|c|c|c|}
\hline \multirow{2}{*}{$\mathrm{PG}$} & \multicolumn{4}{|c|}{ Planar C-PSW/CF } & \multicolumn{3}{c|}{ C-shaped C-PSW/CF } \\
\cline { 2 - 8 } & $3 \mathrm{~S} 1$ & $6 \mathrm{~S} 1$ & $9 \mathrm{~S} 1$ & $12 \mathrm{~S} 1$ & $15 \mathrm{~S} 1$ & $18 \mathrm{~S} 1$ & $22 \mathrm{~S} 1$ \\
\hline $\begin{array}{c}\text { Overstrength, } \\
\Omega_{1}\end{array}$ & 1.44 & 1.69 & 2.02 & 2.34 & 2.63 & 2.66 & 2.75 \\
\hline $\begin{array}{c}\text { Overstrength, } \\
\Omega_{2}\end{array}$ & 1.54 & 1.81 & 2.18 & 2.52 & 2.8 & 2.82 & 2.92 \\
\hline
\end{tabular}




\section{POST-PROCESSING RESULTS}

This chapter discusses the behavior of planar and C-shaped C-PSW/CF at three different levels of seismic hazard. The behavior of each archetype was analyzed at the Design Basis Earthquake (DBE) level, the Maximum Considered Earthquake (MCE) level, and the collapse criterion (3\% maximum IDR). The study was conducted for three different ground motions corresponding to the $25^{\text {th }}, 50^{\text {th }}$ (median), and $75^{\text {th }}$ percentile response at failure. The global response was captured in moment and base shear as a function of time plots, and the local behavior was considered by looking at the moment versus rotation demand and curvature for the base of the wall, and stressstrain response of extreme fibers of the wall at the base.

\subsection{Planar Walls}

The nonlinear time-history response of planar walls is assessed in this section. An example of postprocessing conducted is presented in detail for the 3-story archetype, and then tabulated results for all planar archetypes are listed in Table 13-1 to Table 13-4. Figure 13-1 shows the spectral acceleration (SA) versus maximum IDR plot and the ground motion responses selected corresponding to the $25^{\text {th }}, 50^{\text {th }}$ (median), and $75^{\text {th }}$ percentile spectral acceleration at $3 \%$ IDR. For the 3 -story archetype, 25 th percentile, $50^{\text {th }}$ percentile, and 75 th percentile response corresponds to a record from the Chi-Chi, Taiwan (PEER-NGA Record CHICHI/CHY101-E), Northridge (NORTHR/MUL279), and Cape Mendocino (CAPEMEND/RIO270), respectively.

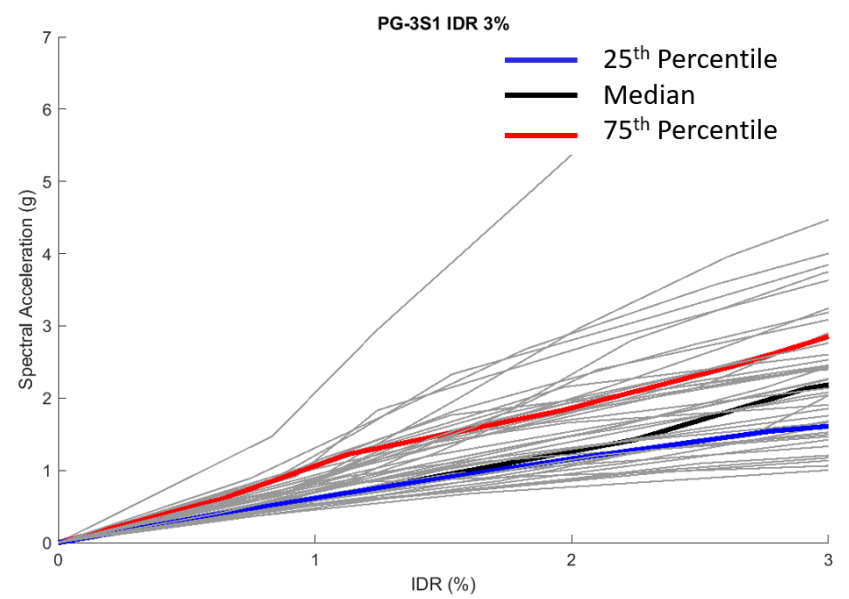

Figure 13-1. Spectral acceleration (g) vs IDR (\%) for 3-story archetype highlighting three selected ground motions 
The median response was used to calculate the collapse margin ratio and evaluate the performance of the building. A collapse criterion of 3 maximum IDR was considered for the 3-story and 6-story archetypes. For the 3-story archetype, the MCE level earthquake is reached at a ground motion scale factor of 2.4 and the DBE level earthquake at a scale factor of 1.6 (two-thirds of MCE level). These ground motion scale factors are applied to the normalized record set detailed in FEMA P695. The ground motions are normalized based on the peak ground velocity. This process is described in detail in FEMA P695 Appendix A.8. The 3\% IDR was observed at different scale factors depending on the drift experienced by the archetype structures. Figure 13-2 shows the normalized moment at the base of the 3-story archetype wall at DBE, MCE, and 3\% IDR for the median SA ground motion. Figure 13-3 shows the normalized moment at the base of the 3-story archetype wall at $3 \%$ IDR hazard level for the $25^{\text {th }}$ percentile and $75^{\text {th }}$ percentile ground motion response.

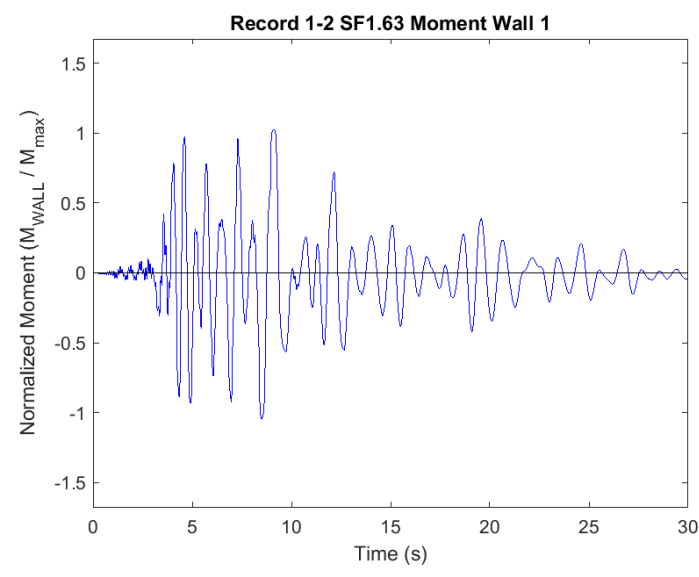

(a)

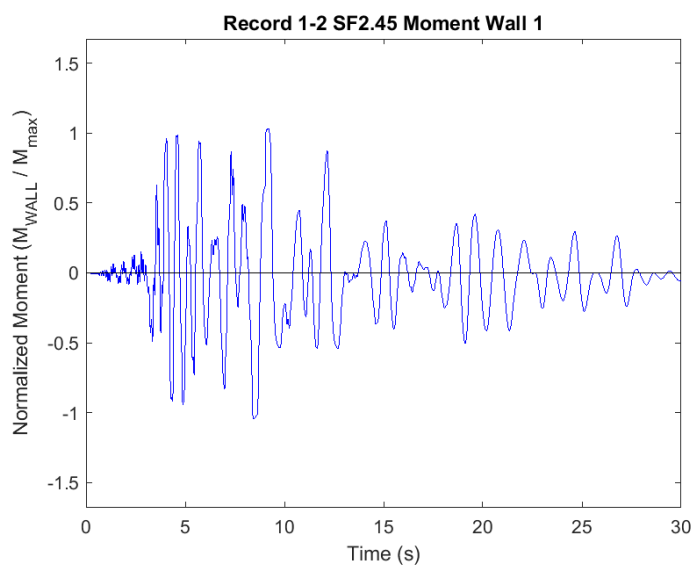

(b)

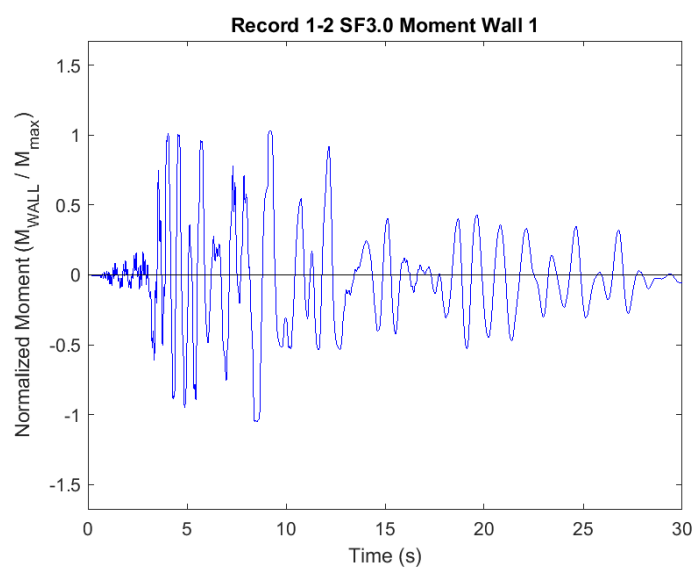

(c)

Figure 13-2. Normalized moment vs time of 3-story archetype for median response for different hazard levels (a) DBE level; (b) MCE level; (c) 3\% IDR 


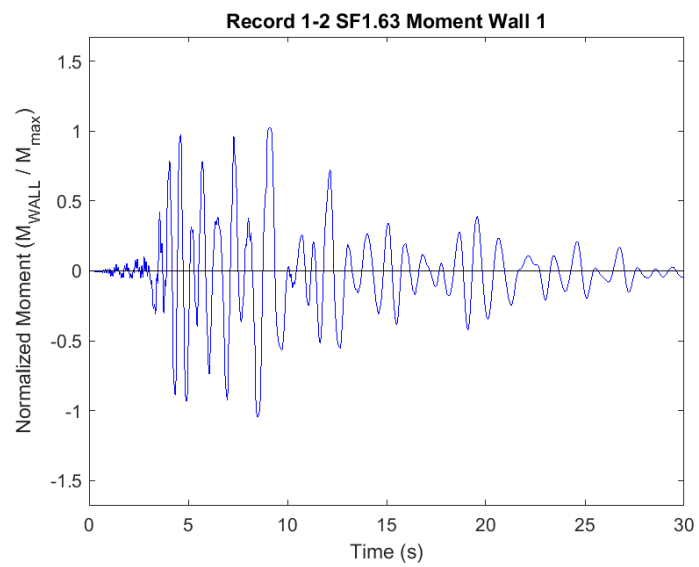

(a)

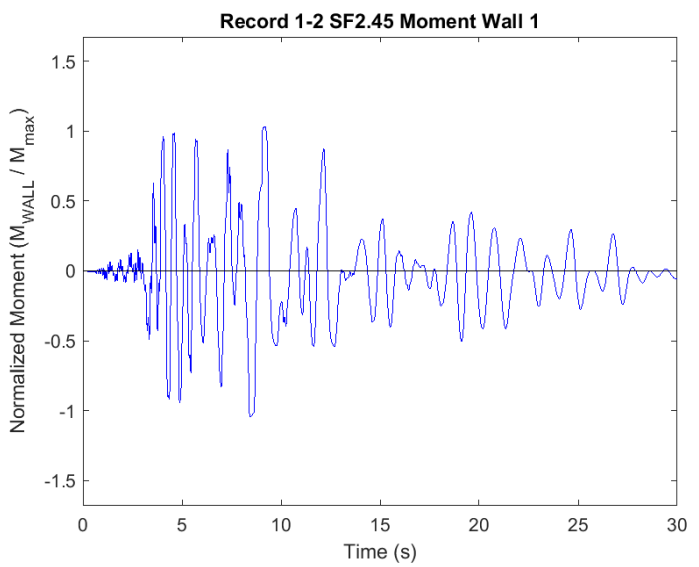

(b)

Figure 13-3. Normalized moment vs time of 3-story archetype at 3\% IDR hazard level (a) $25^{\text {th }}$ percentile; (b) $75^{\text {th }}$ percentile ground motion response

The 3-story structure nearly reaches yield moment at the base for DBE and yields for MCE and 3\% IDR hazard levels. The yielding spreads through the cross-section along the height resulting in plastic hinge formation near the base of the wall. This plastic hinge at the base acts as the main source of energy dissipation. Figure 13-4 shows the variation of the normalized moment versus change in rotation along the height of the nonlinear zone of the 3-story archetype at a 3\% IDR hazard level. Here, element 1 represents the lowermost element near the base and elements 2, 3 and 4 are subsequently present along the nonlinear wall height. 


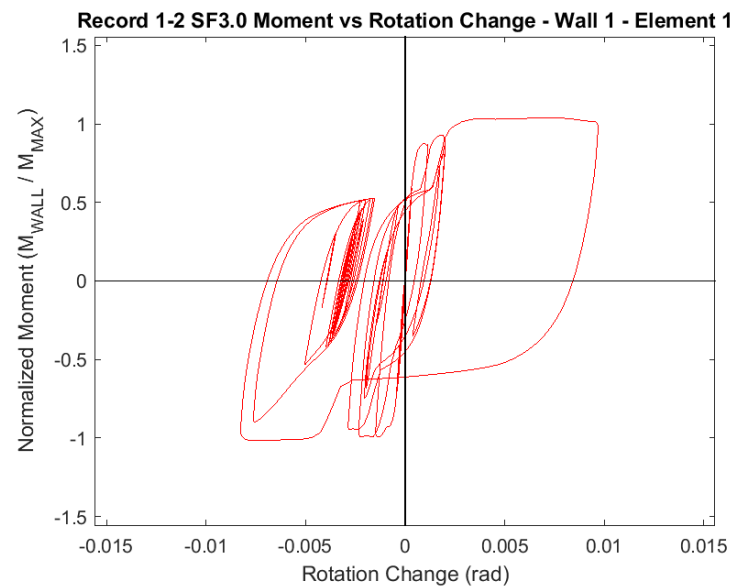

(a)

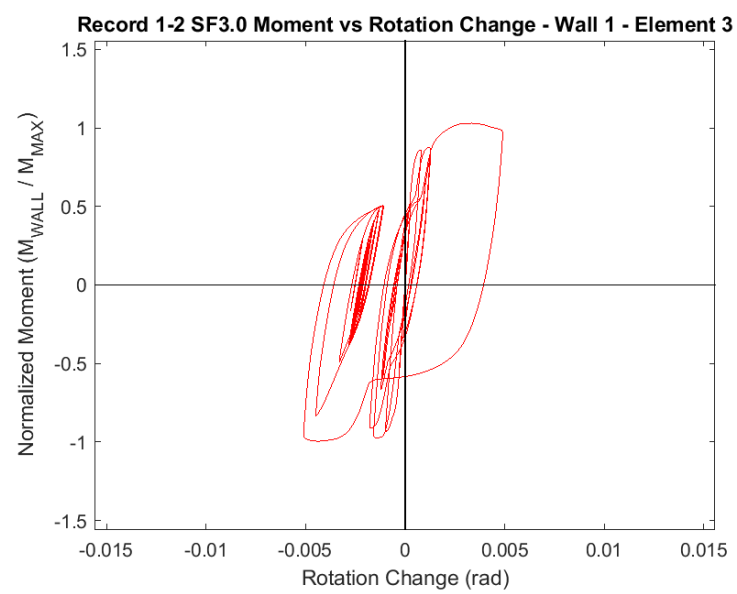

(c)

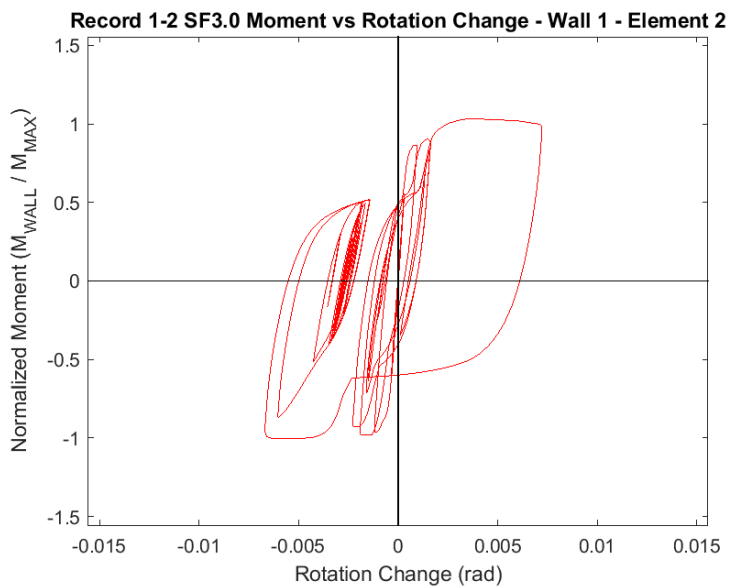

(b)

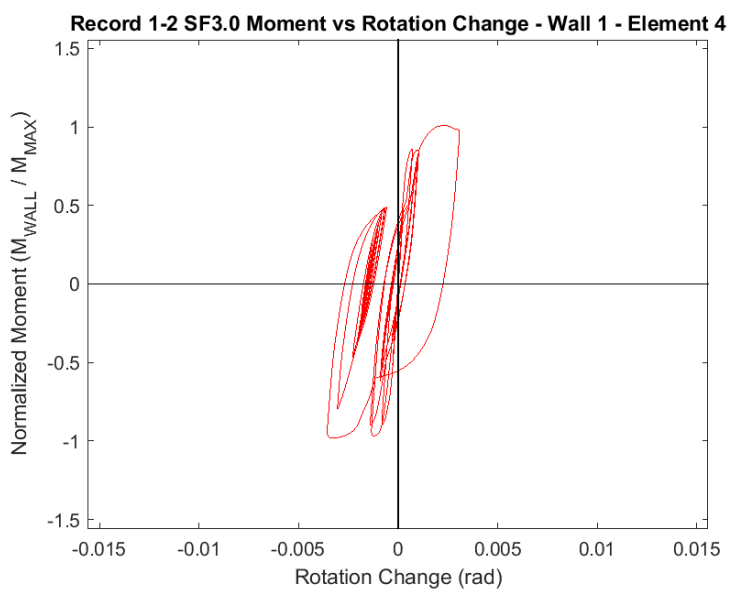

(d)

Figure 13-4. Normalized moment vs change in rotation of 3-story archetype for median response at 3\% IDR (a) Element 1; (b) Element 2; (c) Element 3; (d) Element 4

The change in rotation demand decreased along the height of the structure with the highest amount of change in rotation in element 1 and lowest in element 4. Figure 13-5 shows the variation in the behavior of element 1 at the median response for the different hazard levels. 


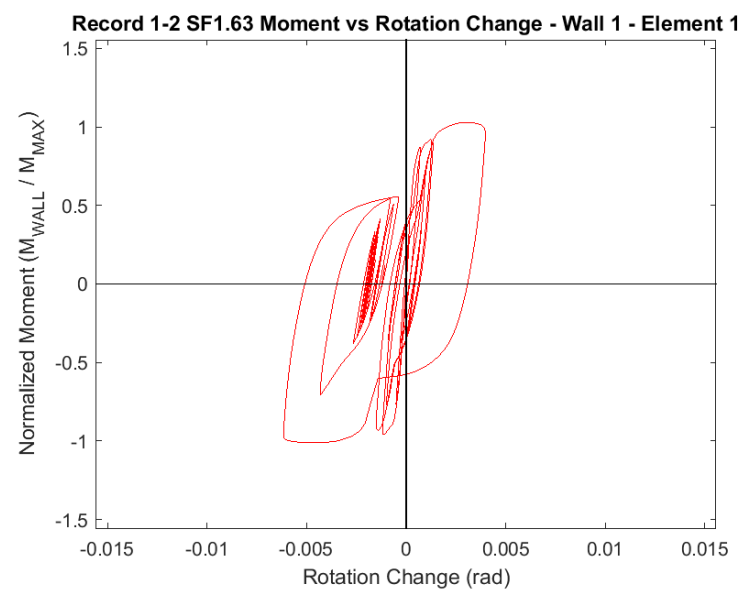

(a)

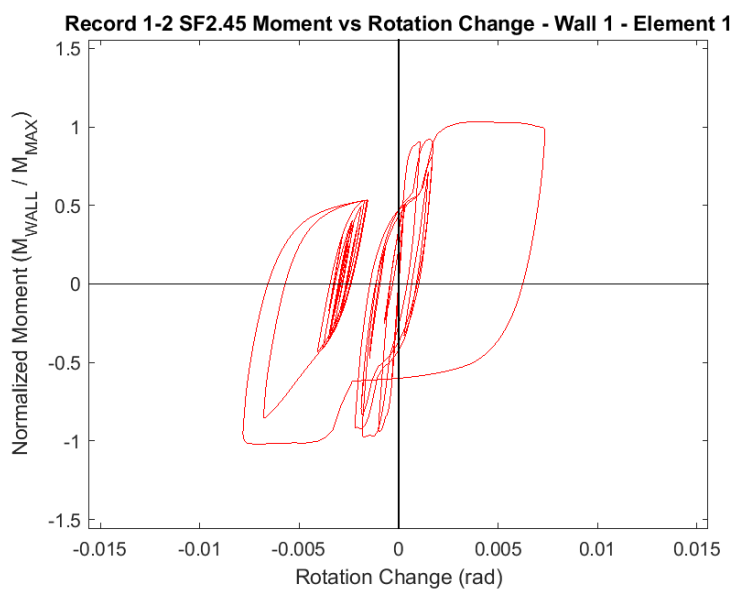

(b)

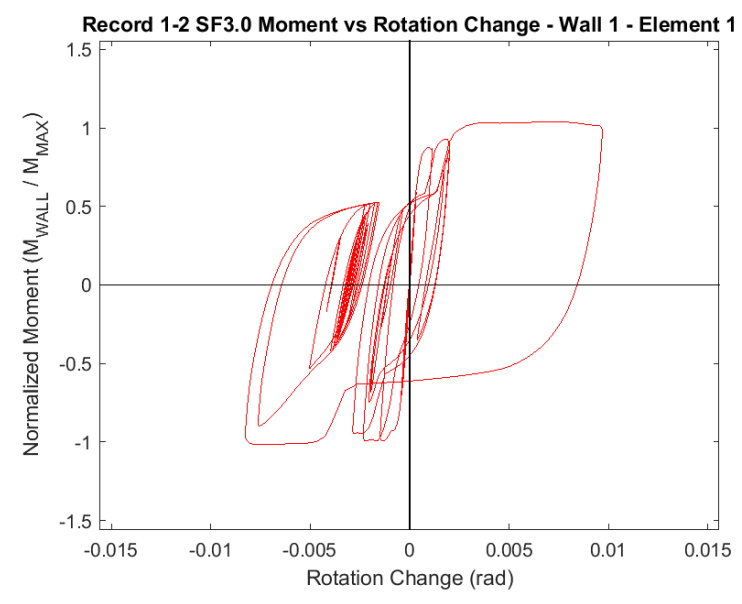

(c)

Figure 13-5 Normalized moment vs change in rotation for element 1 of 3-story archetype at median response (a) DBE; (b) MCE; (c) 3\% IDR

Element 1 has a low rotational demand (less than $0.008 \mathrm{rad}$ ) for the DBE and MCE hazard levels but starts to see high rotational demand (more than $0.01 \mathrm{rad}$ ) at 3\% IDR. To prevent the collapse of the wall, the total rotation of the base of the wall should not exceed 0.04 rad. Figure 13-6 shows the variation of total plastic hinge rotational demand for different hazard levels at the median ground response. Here the total rotational demand represents the sum of the change in rotation for all four elements (i.e. element 1, element 2, element 3, and element 4) present in the nonlinear zone of the wall. 


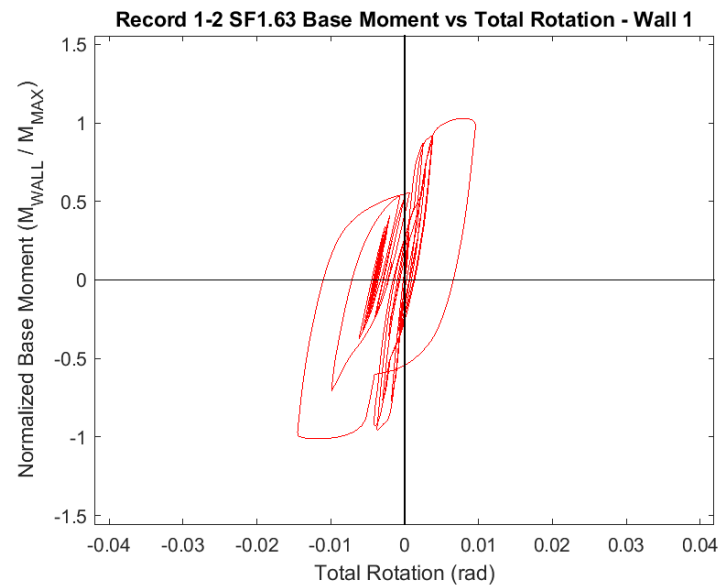

(a)

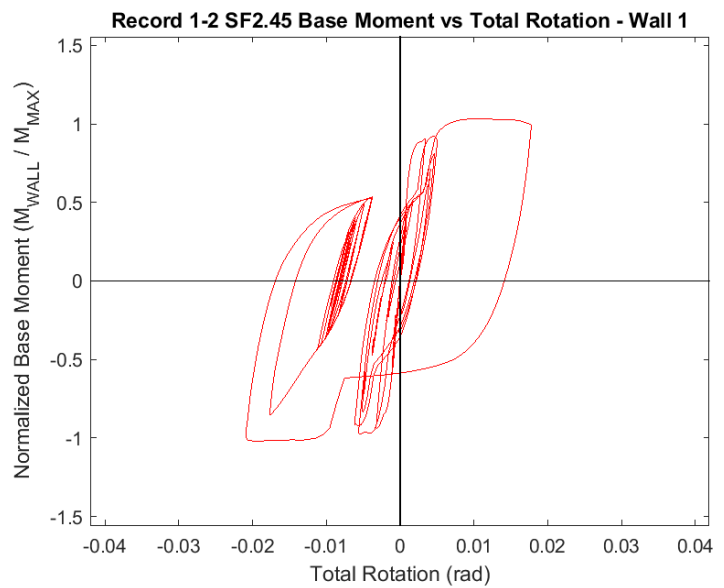

(b)

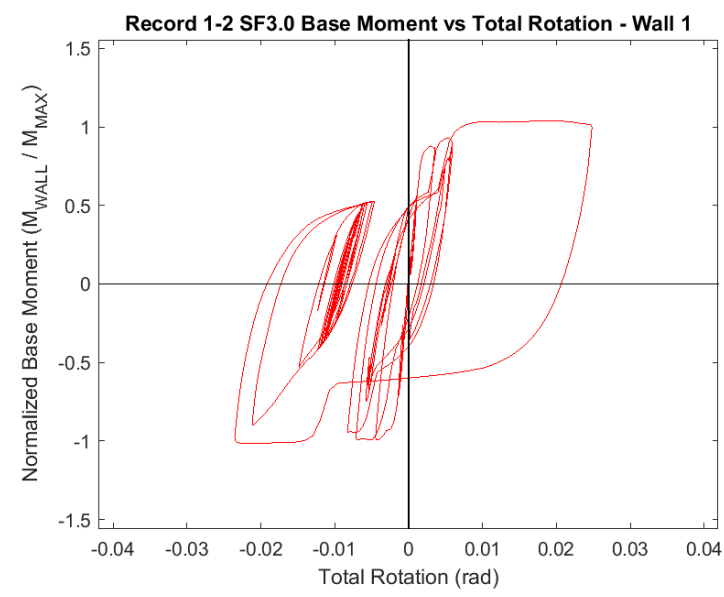

(c)

Figure 13-6. Normalized moment vs total plastic rotation of 3-story archetype for the median response (a) DBE level; (b) MCE level; (c) 3\% IDR

The walls have a total plastic rotation of $0.015 \mathrm{rad}, 0.021 \mathrm{rad}$, and $0.024 \mathrm{rad}$ for DBE, MCE, and 3\% IDR hazard levels, respectively. Figure 13-7 shows the variation of total plastic hinge rotation for the three different ground motion responses at a 3\% IDR collapse level. The archetype wall has a nearly equivalent plastic rotation for all three ground motion responses as the collapse criterion was fixed at 3\% IDR level. Since both, the walls work as an individual seismic forceresisting system, the same amount of inter-story drift results in a nearly identical value of maximum rotation at the base for a given archetype structure. 


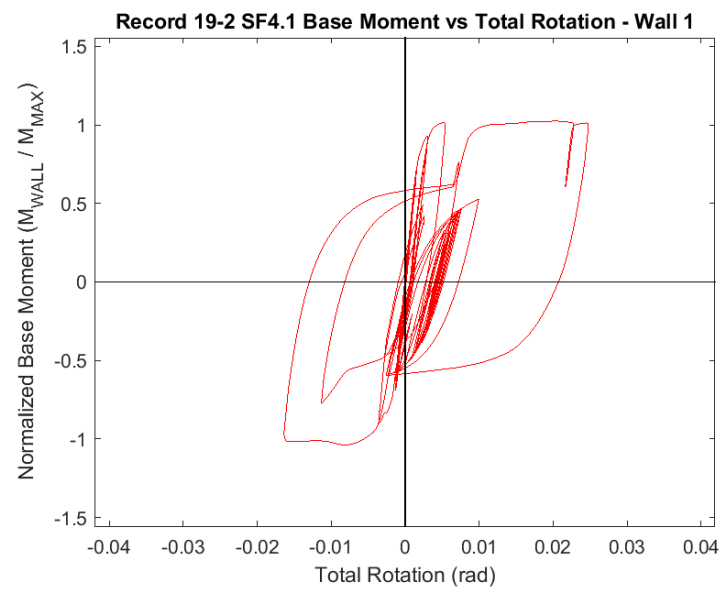

(a)

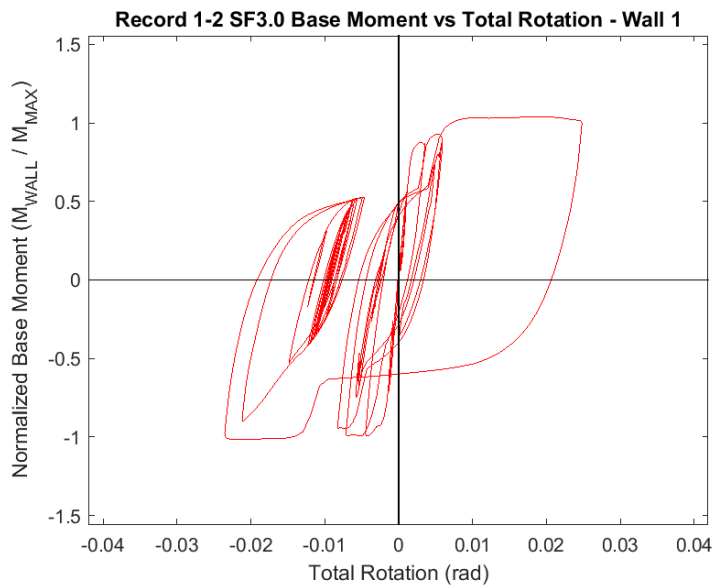

(b)

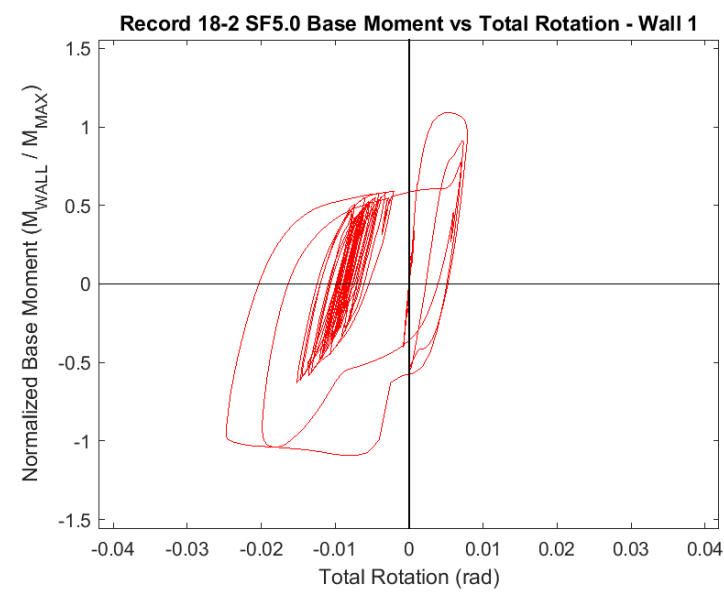

(c)

Figure 13-7. Normalized moment vs total plastic rotation of 3-story archetype at 3\% IDR hazard level for (a) 25th percentile ground motion response; (b) Median ground motion response; (c) 75th percentile ground motion response

The stress-strain curve for the extreme steel fiber (i.e. outer edge of the closure plate) of the 3story archetype for median ground motion response is presented in Figure 13-8. The maximum tensile strain of $0.039 \mathrm{in} / \mathrm{in}, 0.049 \mathrm{in} / \mathrm{in}$, and $0.057 \mathrm{in} / \mathrm{in}$ was observed at the DBE, MCE, and 3\% IDR hazard levels, respectively. A minimum compressive strain of $-0.013 \mathrm{in} / \mathrm{in},-0.018 \mathrm{in} / \mathrm{in}$, and $-0.024 \mathrm{in} /$ in was observed at the DBE, MCE, and 3\% IDR hazard level, respectively. 


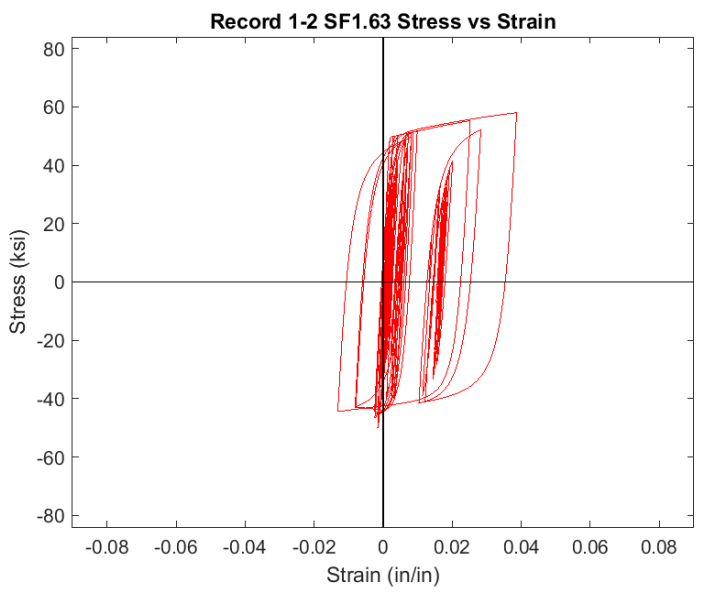

$\mathrm{n}(\mathrm{a})$

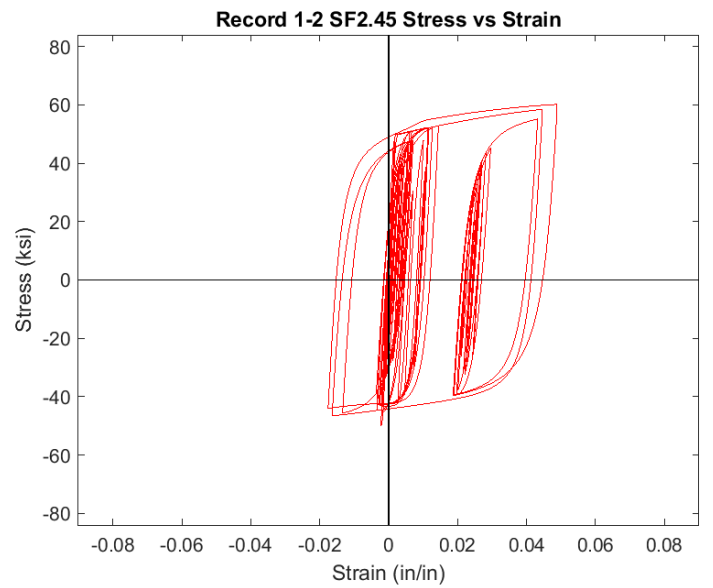

(b)

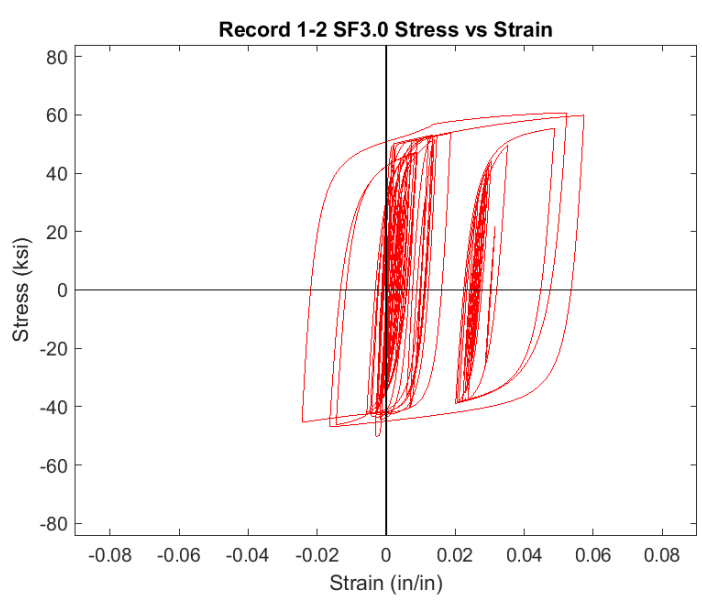

(c)

Figure 13-8. Stress-strain curve for extreme steel fibers of 3-story archetype at the median response (a) DBE level; (b) MCE level; (c) 3\% IDR

The post-processing results including global response and local response of 3-story, 6-story, 9story, and 12-story archetype structures are summarized in Table 13-1 to Table 13-4, respectively. The table lists each structure's response including the maximum inter-story drift ratio, maximum rotation at the base, and maximum tensile and minimum compression strain. The archetype responses are listed for the $25^{\text {th }}$ percentile, $50^{\text {th }}$ percentile, and $75^{\text {th }}$ percentile ground motion records at the hazard $\mathrm{DBE}$ and $\mathrm{MCE}$ hazard levels and 3\% collapse criteria. 
Table 13-1. Post-processing results for 3-story planar archetype structures

\begin{tabular}{|c|c|c|c|c|c|c|c|c|}
\hline $\begin{array}{c}\text { Percentile SA } \\
\text { (a) 3\% IDR }\end{array}$ & $\begin{array}{l}\text { Ground Motion } \\
\text { (PEER-NGA } \\
\text { Record) }\end{array}$ & $\begin{array}{c}\text { Hazard } \\
\text { Level }\end{array}$ & $\begin{array}{l}\text { Scale } \\
\text { Factor }\end{array}$ & $\begin{array}{l}\text { SA } \\
(\mathrm{g})\end{array}$ & $\begin{array}{l}\text { IDR } \\
(\%)\end{array}$ & $\begin{array}{c}\text { Max } \\
\text { Base } \\
\text { Rot } \\
(\mathrm{rad})\end{array}$ & $\begin{array}{l}\text { Max } \\
\text { Tensile } \\
\text { Strain* } \\
\text { (in/in) }\end{array}$ & $\begin{array}{l}\text { Min } \\
\text { Comp } \\
\text { Strain } \\
\text { (in/in) }\end{array}$ \\
\hline \multirow{3}{*}{$25 \%$ Response } & \multirow{3}{*}{$\begin{array}{c}19-2 \\
\text { (CHICHI/ } \\
\text { CHY101-E) }\end{array}$} & & 1.0 & 0.6 & 1.0 & 0.006 & 0.019 & -0.005 \\
\hline & & $\mathrm{MCE}$ & 2.4 & 0.9 & 1.6 & 0.014 & 0.039 & -0.014 \\
\hline & & $3 \%$ IDR & 4.1 & 1.6 & 2.9 & 0.025 & 0.068 & -0.026 \\
\hline \multirow{3}{*}{$50 \%$ Response } & \multirow{3}{*}{$\begin{array}{c}1-2 \\
\text { (NORTHR/ } \\
\text { MUL279) }\end{array}$} & $\mathrm{DB}$ & 16 & 1.2 & 1.7 & 0.0 & 0.039 & -0.013 \\
\hline & & $\mathrm{MC}$ & 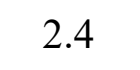 & 1.9 & 2.6 & 0.0 & 0.0 & -0.018 \\
\hline & & $3 \%$ II & 3.0 & 2.1 & 2.9 & 0.024 & 0.057 & -0.024 \\
\hline \multirow{3}{*}{$75 \%$ Response } & \multirow{3}{*}{$\begin{array}{c}18-2 \\
\text { (CAPEMEND/ } \\
\text { RIO270) }\end{array}$} & DBE & 1.6 & 0.9 & 0.9 & 0.005 & 0.013 & -0.003 \\
\hline & & MCE & 2.4 & 2.3 & 1.4 & 0.010 & 0.025 & -0.009 \\
\hline & & $3 \%$ IDR & 5.0 & 3.0 & 3.1 & 0.025 & 0.049 & -0.020 \\
\hline
\end{tabular}

Table 13-2. Post-processing results for 6-story planar archetype structures

\begin{tabular}{|c|c|c|c|c|c|c|c|c|}
\hline $\begin{array}{c}\text { Percentile SA } \\
\text { @ } 3 \% \text { IDR }\end{array}$ & $\begin{array}{l}\text { Ground Motion } \\
\text { (PEER-NGA } \\
\text { Record) }\end{array}$ & $\begin{array}{c}\text { Hazard } \\
\text { Level }\end{array}$ & $\begin{array}{l}\text { Scale } \\
\text { Factor }\end{array}$ & $\begin{array}{l}\text { SA } \\
(\mathrm{g})\end{array}$ & $\begin{array}{l}\text { IDR } \\
(\%)\end{array}$ & $\begin{array}{c}\text { Max } \\
\text { Base } \\
\text { Rot } \\
(\mathrm{rad})\end{array}$ & $\begin{array}{l}\text { Max } \\
\text { Tensile } \\
\text { Strain* } \\
\text { (in/in) }\end{array}$ & $\begin{array}{l}\text { Min } \\
\text { Comp } \\
\text { Strain* } \\
\text { (in/in) }\end{array}$ \\
\hline \multirow{3}{*}{ 25\% Response } & \multirow{3}{*}{$\begin{array}{c}9-1 \\
\text { (KOCAELI/ } \\
\text { DZC180) }\end{array}$} & & 1.70 & .53 & 0.71 & 0.003 & 0.006 & -0.002 \\
\hline & & MCE & 2.55 & 0.81 & 1.18 & 0.007 & 0.016 & -0.006 \\
\hline & & $3 \%$ IDR & 5.20 & 1.64 & 2.97 & 0.022 & 0.055 & -0.024 \\
\hline \multirow{3}{*}{$50 \%$ Response } & \multirow{3}{*}{$\begin{array}{c}4-1 \\
\text { (HECTOR/ } \\
\text { HEC000) }\end{array}$} & DRF & 1.70 & 0.52 & 1.15 & 0.007 & 0.017 & -0.005 \\
\hline & & MCE & 2.55 & 0.8 & 1.43 & 0.008 & 0.020 & -0.005 \\
\hline & & $3 \%$ IDR & 6.20 & 1.93 & 2.87 & 0.022 & 0.053 & -0.019 \\
\hline \multirow{3}{*}{$75 \%$ Response } & \multirow{3}{*}{$\begin{array}{c}13-1 \\
\text { (LOMAP/ } \\
\text { CAP000) }\end{array}$} & DBE & 1.70 & 0.83 & 1.7 & 0.012 & 0.033 & -0.012 \\
\hline & & $\mathrm{MCE}$ & 2.55 & 1.25 & 2.1 & 0.015 & 0.040 & -0.015 \\
\hline & & $3 \%$ IDR & 5.10 & 2.5 & 2.9 & 0.022 & 0.052 & -0.022 \\
\hline
\end{tabular}

\footnotetext{
${ }^{*}$ Maximum strains were calculated in the extreme fiber in the element at the base of the wall (element 1). These strains are not representative of average strains in the plastic hinge section. Strains observed in experimental studies such as Shafaei et al. (2019) may be representative of average strains experienced in this region.
} 
Table 13-3. Post-processing results for 9-story planar archetype structures

\begin{tabular}{|c|c|c|c|c|c|c|c|c|}
\hline $\begin{array}{c}\text { Percentile SA } \\
\text { @ } 3 \% \text { IDR }\end{array}$ & $\begin{array}{c}\text { Ground Motion } \\
\text { (PEER-NGA } \\
\text { Record) }\end{array}$ & $\begin{array}{c}\text { Hazard } \\
\text { Level }\end{array}$ & $\begin{array}{l}\text { Scale } \\
\text { Factor }\end{array}$ & $\begin{array}{l}\text { SA } \\
(\mathrm{g})\end{array}$ & $\begin{array}{l}\text { IDR } \\
(\%)\end{array}$ & $\begin{array}{c}\text { Max } \\
\text { Base } \\
\text { Rot } \\
(\mathrm{rad})\end{array}$ & $\begin{array}{c}\text { Max } \\
\text { Tensile } \\
\text { Strain* } \\
\text { (in/in) }\end{array}$ & $\begin{array}{l}\text { Min } \\
\text { Comp } \\
\text { Strain } \\
\text { (in/in) }\end{array}$ \\
\hline \multirow{3}{*}{$25 \%$ Response } & \multirow{3}{*}{$\begin{array}{c}22-1 \\
\text { (SFERN/ } \\
\text { PEL090) }\end{array}$} & DE & 1.07 & 0.72 & 1.47 & 0.008 & 0.020 & -0.006 \\
\hline & & MCE & 2.51 & 1.08 & 2.58 & 0.017 & 0.041 & -0.015 \\
\hline & & $3 \%$ IDR & 2.80 & 1.21 & 2.92 & 0.021 & 0.047 & -0.018 \\
\hline \multirow{3}{*}{$50 \%$ Response } & \multirow{3}{*}{$\begin{array}{c}3-1 \\
\text { (DUZCE/ } \\
\text { BOL000 }\end{array}$} & DBE & 1.67 & 0.41 & 0.92 & 0.003 & 0.005 & -0.002 \\
\hline & & MCE & 2 & 0.61 & 1.32 & 0.0 & 0.0 & -0.004 \\
\hline & & $3 \%$ IDR & 6.60 & 1.62 & 2.98 & 0.020 & 0.047 & -0.019 \\
\hline \multirow{3}{*}{$75 \%$ Response } & \multirow{3}{*}{$\begin{array}{c}1-2 \\
\text { (NORTHR/ } \\
\text { MUL279) }\end{array}$} & DBE & 1.67 & 0.72 & 1.43 & 0.008 & 0.016 & -0.005 \\
\hline & & MCE & 2.51 & 1.3 & 2.4 & 0.010 & 0.021 & -0.007 \\
\hline & & $3 \%$ IDR & 5.50 & 2.4 & 2.93 & 0.023 & 0.043 & -0.017 \\
\hline
\end{tabular}

Table 13-4. Post-processing results for 12-story planar archetype structures

\begin{tabular}{|c|c|c|c|c|c|c|c|c|}
\hline $\begin{array}{c}\text { Percentile SA } \\
\text { @ 3\% IDR }\end{array}$ & $\begin{array}{l}\text { Ground Motion } \\
\text { (PEER-NGA } \\
\text { Record) }\end{array}$ & $\begin{array}{c}\text { Hazard } \\
\text { Level }\end{array}$ & $\begin{array}{l}\text { Scale } \\
\text { Factor }\end{array}$ & $\begin{array}{l}\text { SA } \\
(\mathrm{g})\end{array}$ & $\begin{array}{l}\text { IDR } \\
(\%)\end{array}$ & $\begin{array}{l}\text { Max } \\
\text { Base } \\
\text { Rot } \\
(\mathrm{rad})\end{array}$ & $\begin{array}{l}\text { Max } \\
\text { Tensile } \\
\text { Strain* } \\
\text { (in/in) }\end{array}$ & $\begin{array}{l}\text { Min } \\
\text { Comp } \\
\text { Strain } \\
\text { (in/in) }\end{array}$ \\
\hline \multirow{3}{*}{$25 \%$ Response } & \multirow{3}{*}{$\begin{array}{c}10-1 \\
\text { (KOCAELI/ } \\
\text { ARC000) }\end{array}$} & & 1.93 & 0.12 & 0.36 & 0.001 & 0.001 & -0.001 \\
\hline & & MCE & 2.89 & 0.17 & 0.55 & 0.001 & 0.002 & -0.001 \\
\hline & & $3 \%$ IDR & 14.20 & 0.84 & 3.00 & 0.022 & 0.051 & -0.020 \\
\hline \multirow{3}{*}{$50 \%$ Response } & \multirow{3}{*}{$\begin{array}{c}11-2 \\
\text { (LANDERS/ } \\
\text { YER360) }\end{array}$} & DBE & 1.93 & 0.27 & 0.77 & 0.002 & 0.004 & -0.001 \\
\hline & & MC & 2 & 0.40 & 1.06 & 0.004 & 0.0 & -0.002 \\
\hline & & $3 \%$ IDR & 8.10 & 1.13 & 2.91 & 0.022 & 0.046 & -0.019 \\
\hline \multirow{3}{*}{$75 \%$ Response } & \multirow{3}{*}{$\begin{array}{c}2-1 \\
\text { (NORTHR/ } \\
\text { LOS000) }\end{array}$} & DBE & 1.93 & 0.57 & 1.35 & 0.006 & 0.012 & -0.003 \\
\hline & & MCE & 2.89 & 0.76 & 1.83 & 0.008 & 0.017 & -0.005 \\
\hline & & $3 \%$ IDR & 6.20 & 1.63 & 3.04 & 0.017 & 0.038 & -0.016 \\
\hline
\end{tabular}




\subsection{C-Shaped Walls}

This section summarizes the post-processing results of C-shaped walls. An example of postprocessing conducted is presented in detail for the 3-story archetype and then tabulated results for all planar archetypes are listed in Table 13-5 to Table 13-7. Figure 13-9 shows the SA versus maximum IDR plot and the three ground motion responses selected corresponding to the $25^{\text {th }}, 50^{\text {th }}$ (median), and $75^{\text {th }}$ percentile spectral acceleration at 3\% IDR. For the 15-story archetype, 25th percentile, $50^{\text {th }}$ percentile, and 75 th percentile response corresponds to a record from the Superstition Hills (PEER-NGA Record SUPERST/B-ICC000), Friuli, Italy (FRIULI/A-TMZ000), and Loma Prieta (LOMAP/CAP090), respectively. For the 15-story archetype, the MCE level earthquake was observed at the scale factor 3.1 and the DBE level earthquake. The 3\% IDR was observed at different scale factors depending on the response of the archetype structures.

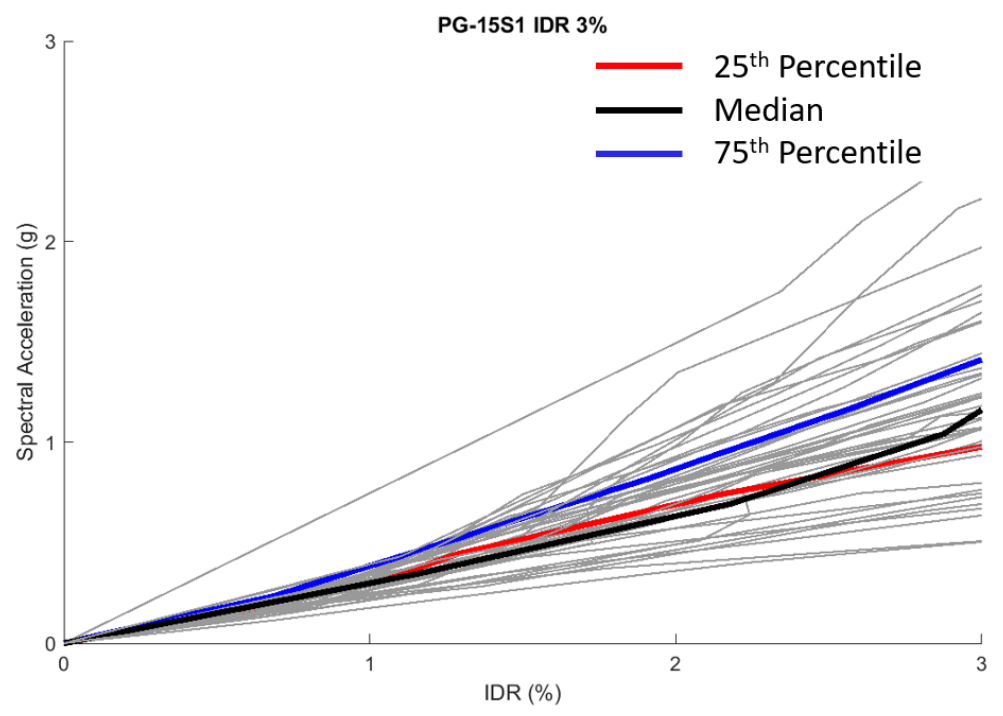

Figure 13-9. Spectral acceleration (g) vs IDR (\%) highlighting $25^{\text {th }}$ percentile, $50^{\text {th }}$ percentile, and $75^{\text {th }}$ percentile ground motion response

Figure 13-10 to Figure 13-12 shows the normalized moment at the base of the 15-story archetype wall at DBE and 5\% IDR for the median, $25^{\text {th }}$ percentile, and the $75^{\text {th }}$ percentile ground motion. 


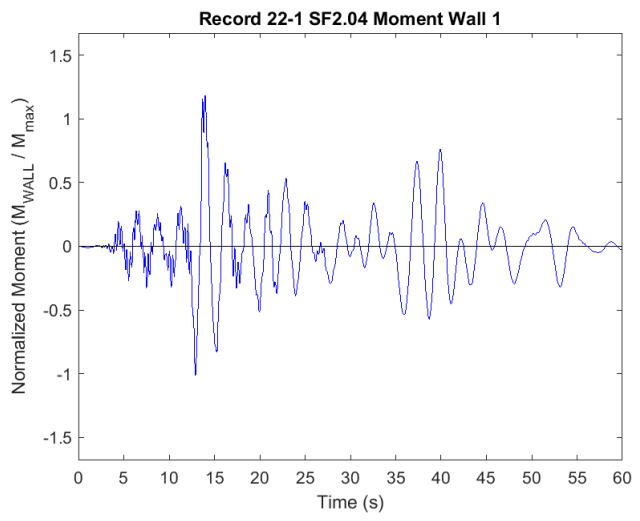

(a)

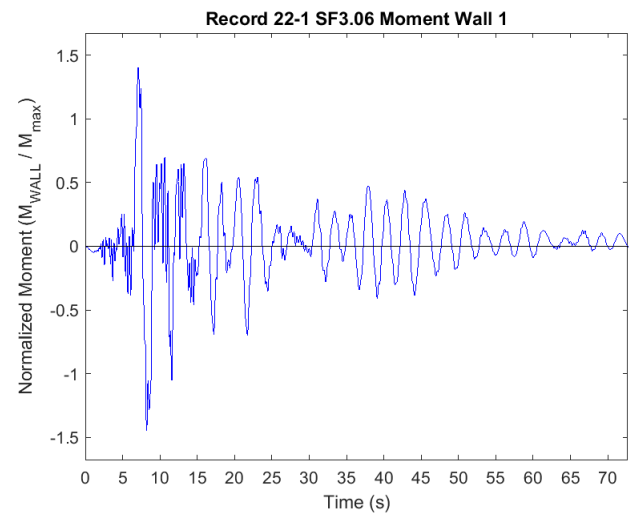

(b)

Figure 13-10. Normalized moment vs time of 15-story archetype for median response (a) DBE level; (b) 3\% IDR

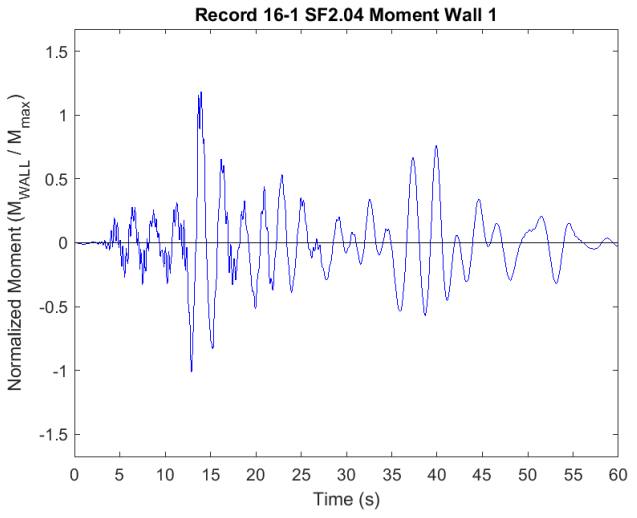

(a)

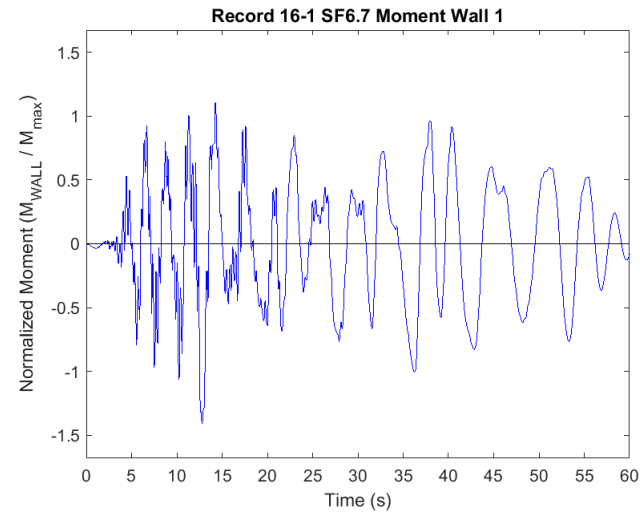

(b)

Figure 13-11. Normalized moment vs time of 15-story archetype for 25th percentile response (a) DBE level; (b) 3\% IDR

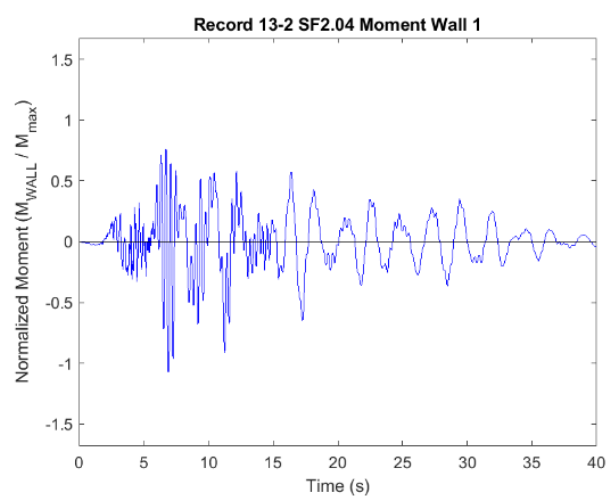

(a)

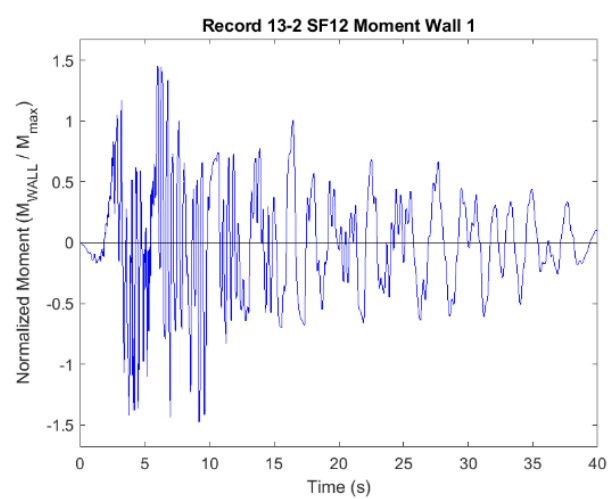

(b)

Figure 13-12. Normalized moment vs time of 15-story archetype for 75 th percentile response (a) MCE level; (b) 3\% IDR 
Figure 13-13 shows the variation of total plastic hinge rotational demand at different hazard levels for the $75^{\text {th }}$ percentile ground response. The maximum plastic rotation of $0.003 \mathrm{rad}, 0.009 \mathrm{rad}$, and $0.012 \mathrm{rad}$ were observed for the $75^{\text {th }}$ percentile ground motion response at DBE level, MCE level and 3\% IDR collapse level, respectively. Overall less plastic rotation was observed for taller Cshaped walls compared to the shorter planar wall archetype (approximately $20 \%$ difference). The archetype structure reached the yield point for the DBE level earthquake and the remainder of the hazard levels.

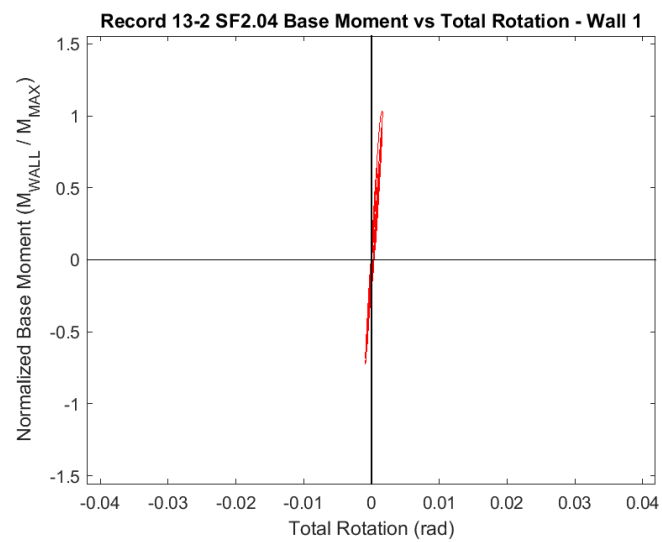

(a)

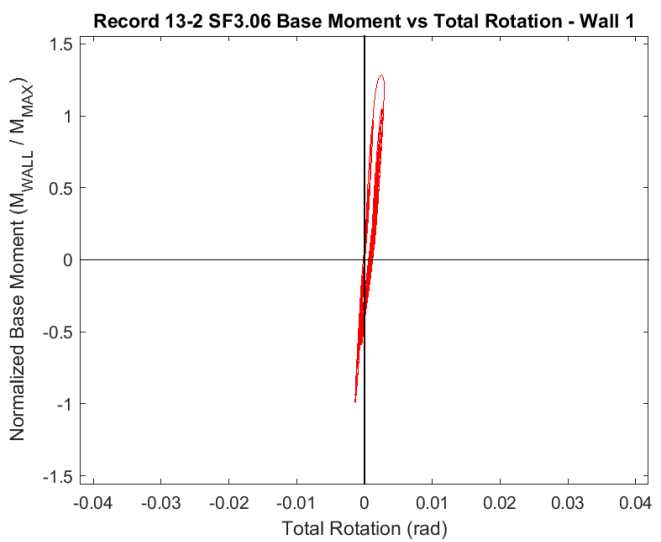

(b)

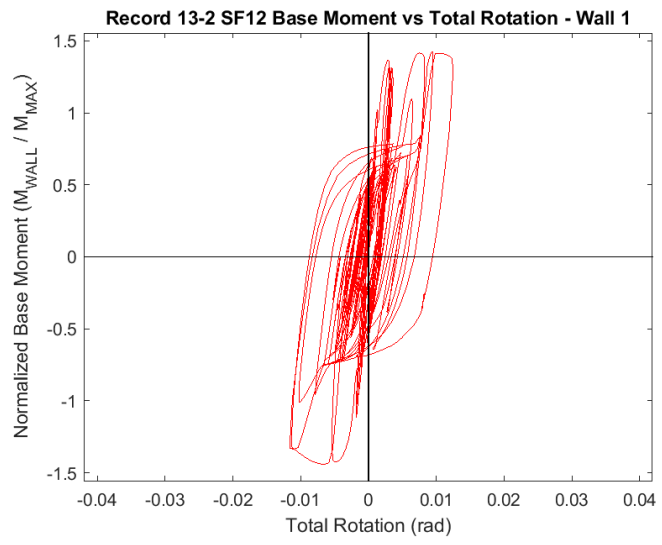

(c)

Figure 13-13. Normalized moment vs total plastic rotation of 15 -story archetype for the $75^{\text {th }}$ percentile response (a) DBE level; (b) MCE level; (c) 3\% IDR

The stress-strain curve of extreme steel fiber (i.e. extreme flange plate) of 15-story archetype for the $75^{\text {th }}$ percentile ground motion response is presented in Figure 13-14. The maximum tensile strain of $0.006 \mathrm{in} / \mathrm{in}, 0.020 \mathrm{in} / \mathrm{in}$, and $0.029 \mathrm{in} / \mathrm{in}$ was observed at the DBE, MCE, and 3\% IDR 
hazard level, respectively. The minimum compressive strain of $-0.002 \mathrm{in} / \mathrm{in},-0.004 \mathrm{in} / \mathrm{in}$, and $0.012 \mathrm{in} /$ in was observed at the DBE, MCE, and 3\% IDR hazard level respectively. The absolute value maximum tensile and compressive strain observed for the $\mathrm{C}$-shaped archetypes were comparatively less than that of planar archetype for similar hazard levels.

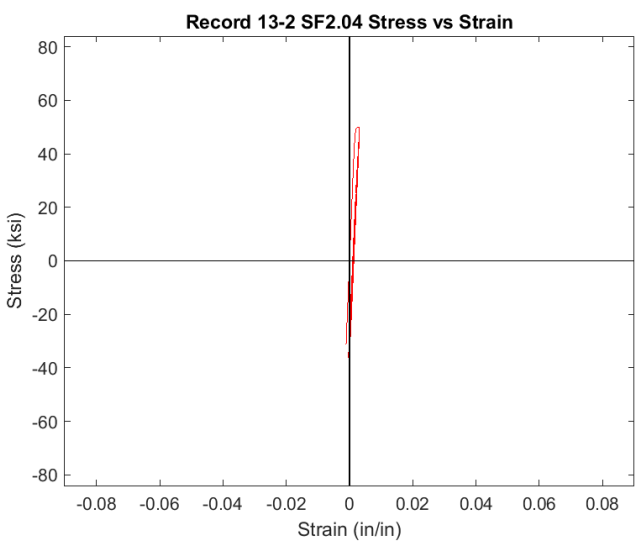

(a)

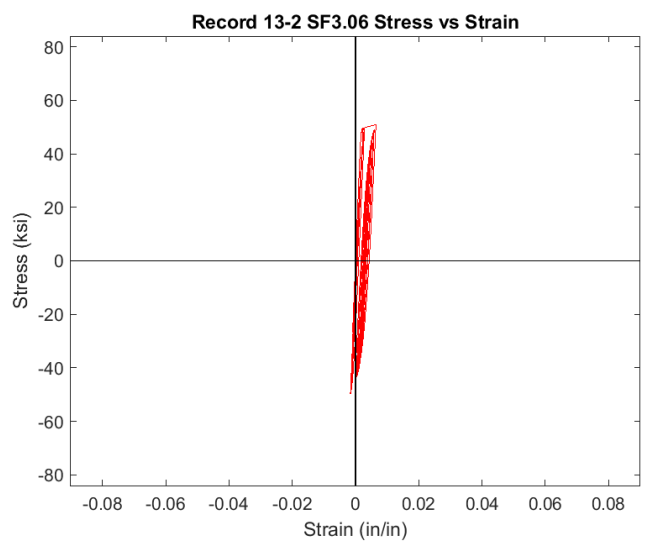

(b)

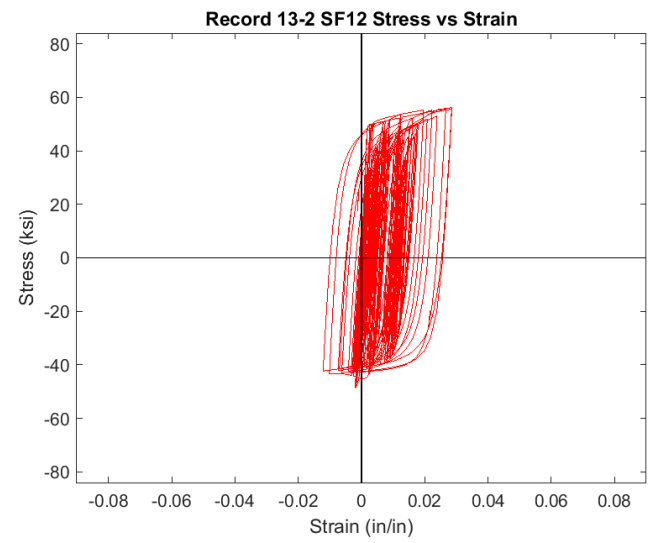

(c)

Figure 13-14. Stress-strain curve for extreme steel fibers of 15-story archetype for the $7^{\text {th }}$ percentile response at (a) DBE level; (b) MCE level; (c) 3\% IDR

The post-processing results including global response and local response of 15-story, 18-story, and 22-story archetype structures are summarized in Table 13-5 to Table 13-7, respectively. The behavior of archetypes at $25^{\text {th }}$ percentile, $50^{\text {th }}$ percentile, and $75^{\text {th }}$ percentile at the hazard levels of DBE, MCE, and 3\% IDR (collapse criterion) are presented in these tables. 
Table 13-5. Post-processing results for 15-story C-shaped archetype structure

\begin{tabular}{|c|c|c|c|c|c|c|c|c|}
\hline $\begin{array}{c}\text { Percentile SA } \\
\text { @ } 3 \% \text { IDR }\end{array}$ & $\begin{array}{l}\text { Ground Motion } \\
\text { (PEER-NGA } \\
\text { Record) }\end{array}$ & $\begin{array}{l}\text { Hazard } \\
\text { Level }\end{array}$ & $\begin{array}{l}\text { Scale } \\
\text { Factor }\end{array}$ & $\begin{array}{l}\text { SA } \\
(\mathrm{g})\end{array}$ & $\begin{array}{l}\text { IDR } \\
(\%)\end{array}$ & $\begin{array}{c}\text { Max } \\
\text { Base } \\
\text { Rot } \\
\text { (rad) }\end{array}$ & $\begin{array}{l}\text { Max } \\
\text { Tensile } \\
\text { Strain* } \\
\text { (in/in) }\end{array}$ & $\begin{array}{c}\text { Min } \\
\text { Comp } \\
\text { Strain } \\
\text { (in/in) }\end{array}$ \\
\hline \multirow{3}{*}{$25 \%$ Response } & \multirow{3}{*}{$\begin{array}{c}16-1 \\
\text { (SUPERST/ } \\
\text { B-ICC000) }\end{array}$} & DBE & 2.04 & 0.30 & 1.02 & 0.003 & 0.007 & -0.001 \\
\hline & & MCE & 3.06 & 0.45 & 1.31 & 0.005 & 0.011 & -0.002 \\
\hline & & $3 \%$ IDR & 6.70 & 1.00 & 3.04 & 0.016 & 0.032 & -0.011 \\
\hline \multirow{2}{*}{$50 \%$ Response } & \multirow{2}{*}{$\begin{array}{c}22-1 \\
\text { (SFERN/ } \\
\text { PEL090) }\end{array}$} & DBE & 2.04 & 0.71 & 2.21 & 0.009 & 0.020 & -0.004 \\
\hline & & $\begin{array}{c}\mathrm{MCE} / 3 \% \\
\mathrm{IDR}\end{array}$ & 3.06 & 1.04 & 2.87 & 0.014 & 0.029 & -0.005 \\
\hline \multirow{3}{*}{$75 \%$ Response } & \multirow{3}{*}{$\begin{array}{c}\text { 13-2 } \\
\text { (LOMAP/ } \\
\text { CAP090) }\end{array}$} & DBE & 2.04 & 0.24 & 0.70 & 0.003 & 0.006 & -0.002 \\
\hline & & MCE & 3.06 & 0.36 & 0.98 & 0.009 & 0.020 & -0.004 \\
\hline & & $3 \%$ IDR & 12.00 & 1.40 & 2.98 & 0.012 & 0.029 & -0.012 \\
\hline
\end{tabular}

Table 13-6. Post-processing results for 18-story C-shaped archetype structure

\begin{tabular}{|c|c|c|c|c|c|c|c|c|}
\hline $\begin{array}{c}\text { Percentile SA } \\
\text { (a) 3\% IDR }\end{array}$ & $\begin{array}{c}\text { Ground } \\
\text { Motion } \\
\text { (PEER-NGA } \\
\text { Record) }\end{array}$ & $\begin{array}{c}\text { Hazard } \\
\text { Level }\end{array}$ & $\begin{array}{l}\text { Scale } \\
\text { Factor }\end{array}$ & $\begin{array}{l}\text { SA } \\
(\mathrm{g})\end{array}$ & $\begin{array}{l}\text { IDR } \\
(\%)\end{array}$ & $\begin{array}{l}\text { Max } \\
\text { Base } \\
\text { Rot } \\
\text { (rad) }\end{array}$ & $\begin{array}{l}\text { Max } \\
\text { Tensile } \\
\text { Strain* } \\
\text { (in/in) }\end{array}$ & $\begin{array}{l}\text { Min } \\
\text { Comp } \\
\text { Strain } \\
\text { (in/in) }\end{array}$ \\
\hline \multirow{3}{*}{$25 \%$ Response } & \multirow{3}{*}{$\begin{array}{c}11-1 \\
\text { (LANDERS/ } \\
\text { YER270) }\end{array}$} & DBE & 2.15 & 0.30 & 1.10 & 0.003 & 0.007 & -0.002 \\
\hline & & MCE & 3.23 & 0.45 & 1.51 & 0.005 & 0.013 & -0.003 \\
\hline & & $3 \%$ IDR & 6.30 & 0.88 & 2.80 & 0.018 & 0.046 & -0.019 \\
\hline \multirow{3}{*}{$50 \%$ Response } & \multirow{3}{*}{$\begin{array}{c}17-1 \\
\text { (SUPERST/ } \\
\text { B-POE270) }\end{array}$} & DBE & 2.15 & 0.37 & 1.40 & 0.005 & 0.016 & -0.004 \\
\hline & & MCE & 3.23 & 0.59 & 1.97 & 0.009 & 0.024 & -0.009 \\
\hline & & $3 \%$ IDR & 5.60 & 1.05 & 2.92 & 0.017 & 0.039 & -0.018 \\
\hline \multirow{3}{*}{$75 \%$ Response } & \multirow{3}{*}{$\begin{array}{c}4-2 \\
\text { (HECTOR/ } \\
\text { HEC090) }\end{array}$} & DBE & 2.15 & 0.32 & 1.25 & 0.003 & 0.009 & -0.002 \\
\hline & & MCE & 3.23 & 0.48 & 1.56 & 0.006 & 0.016 & -0.004 \\
\hline & & $3 \%$ IDR & 9.20 & 1.38 & 3.07 & 0.019 & 0.042 & -0.018 \\
\hline
\end{tabular}

\footnotetext{
* Maximum strains were calculated in the extreme fiber in the element at the base of the wall (element 1). These strains are not representative of average strains in the plastic hinge section. Strains observed in experimental studies such as Kizilarslan et al. (2019) may be representative of average strains experienced in this region.
} 
Table 13-7. Post-processing results for 22-story C-shaped archetype structure

\begin{tabular}{|c|c|c|c|c|c|c|c|c|}
\hline $\begin{array}{c}\text { Percentile SA } \\
\text { @ } 3 \% \text { IDR }\end{array}$ & $\begin{array}{c}\text { Ground Motion } \\
\text { (PEER-NGA } \\
\text { Record) }\end{array}$ & $\begin{array}{c}\text { Hazard } \\
\text { Level }\end{array}$ & $\begin{array}{l}\text { Scale } \\
\text { Factor }\end{array}$ & $\begin{array}{l}\text { SA } \\
\text { (g) }\end{array}$ & $\begin{array}{l}\text { IDR } \\
(\%)\end{array}$ & $\begin{array}{c}\text { Max } \\
\text { Base } \\
\text { Rot } \\
(\mathrm{rad})\end{array}$ & $\begin{array}{l}\text { Max } \\
\text { Tensile } \\
\text { Strain* } \\
\text { (in/in) }\end{array}$ & $\begin{array}{l}\text { Min } \\
\text { Comp } \\
\text { Strain } \\
\text { (in/in) }\end{array}$ \\
\hline \multirow{3}{*}{$25 \%$ Response } & \multirow{3}{*}{$\begin{array}{c}16-1 \\
\text { (SUPERST/ } \\
\text { B-ICC000) }\end{array}$} & 2 & 2.47 & 0.20 & 1.05 & 0.002 & 0.005 & -0.001 \\
\hline & & MCE & 3.70 & 0.29 & 1.52 & 0.004 & 0.012 & -0.002 \\
\hline & & $3 \%$ IDR & 7.50 & 0.54 & 2.85 & 0.017 & 0.045 & -0.013 \\
\hline \multirow{3}{*}{$50 \%$ Response } & \multirow{3}{*}{$\begin{array}{c}7-2 \\
\text { (KOBE/ } \\
\text { NIS090) }\end{array}$} & DBE & 2.47 & 0.22 & 1.32 & 0.003 & 0.009 & -0.002 \\
\hline & & MCE & 3.70 & 0.33 & 1.77 & 0.006 & 0.015 & -0.005 \\
\hline & & $3 \% \mathrm{IDR}$ & 8.10 & 0.73 & 3.08 & 0.016 & 0.038 & -0.017 \\
\hline \multirow{3}{*}{$75 \%$ Response } & \multirow{3}{*}{$\begin{array}{c}9-2 \\
\text { (KOCAELI/ } \\
\text { DZC270) }\end{array}$} & DBE & 2.47 & 0.25 & 1.02 & 0.002 & 0.005 & -0.001 \\
\hline & & MCE & 3.70 & 0.33 & 1.46 & 0.003 & 0.009 & -0.001 \\
\hline & & $3 \%$ IDR & 10.30 & 0.92 & 3.04 & 0.013 & 0.035 & -0.007 \\
\hline
\end{tabular}




\section{SUMMARY AND CONCLUSION}

Composite plate shear walls - concrete filled (C-PSW/CF) are a highly efficient and effective seismic force-resisting system. This system along with the coupled composite wall system is transforming the construction of tall buildings. The system significantly reduces construction duration compared to the conventional reinforced concrete systems. The system has many of the benefits of reinforced concrete walls in terms of strength and stiffness without having problems with rebar congestion. C-PSW/CF construction does not require complex formwork, reducing the

time and cost of onsite construction. Overall, this system provides a viable alternative for conventional reinforced concrete walls.

As presented in this report, a study based on FEMA P695 methodology was conducted to quantify the seismic response of the C-PSW/CF system. This study validates the seismic performance and collapse assessment of C-PSW/CF. The details on the seismic design philosophy of C-PSW/CF are outlined in Chapters 3 and 4. Four planar C-PSW/CF archetypes (3-story, 6-story, 9-story, and 12-story) and three C-shaped C-PSW/CF archetypes (15-story, 18-story, and 22-story) were designed using a seismic response modification factor, $R$, of 6.5 and a deflection amplification factor, $C_{d}$, of 5.5. The details of the seven archetypes were presented in Chapter 5. OpenSees was used to develop a 2D fiber-based nonlinear finite element model (See Chapter 6). The OpenSees models accounted for the steel and concrete material properties, and the model was benchmarked using experimental test results conducted on composite walls (See Chapters 7 and 8). Nonlinear static and dynamic analyses were conducted using this OpenSees model. The results of the nonlinear analysis were used to evaluate the performance of the C-PSW/CF system (see Chapters 9 and 10). After nonlinear analysis, post-processing of structural response was performed to further understand the wall behavior and material response under time-history analysis. All planar and Cshaped C-PSW/CF archetype reached a 3\% inter-story drift before collapse for each of the 44 ground motions. Collapse and a large amount of base rotation were observed before $5 \%$ inter-story drift in some of the analyses. Hence, a conservative value of $3 \%$ IDR (less than the actual collapse point) was assumed as the collapse criterion. 
In general, a larger value of the collapse margin ratio was observed for taller structures. The adjusted collapse margin ratio, $A C M R$, (period-based ductility, $\mu_{\mathrm{t}}=3$ ) was 1.90, 2.64, 3.09, 2.96, $3.46,3.72$, and 3.02 for the $3,6,9,12,15,18$ and 22 story archetypes, respectively. The $A C M R$ using actual period-based ductility was found to be $2.16,3.08,3.72,3.61,4.22,4.53$, and 3.68 for the $3,6,9,12,15,18$ and 22 story archetypes, respectively. These values were compared to the $A C M R_{10 \%}$ collapse criterion of 1.96 and $A C M R_{20 \%}$ collapse criterion of 1.56 for the total system collapse uncertainty, $\beta_{\text {TOT }}$, rated as "Good".

The overstrength factor, $\Omega_{o}$, was calculated in two ways. First, the overstrength factor was calculated using nominal material properties. These values ranged from 1.44 to 2.75 for the given archetypes. Then the overstrength factor, $\Omega_{0}$, was calculated using expected steel behavior (yield strength of $\mathrm{R}_{\mathrm{y}} \mathrm{F}_{\mathrm{y}}$ ). The overstrength strength calculated using these materials ranged from 1.54 to 2.92. The overstrength factor for planar and C-shaped archetype is summarized in Table 12-3. As the overstrength factor is intended to quantify the inherent overdesign in the structure, an overstrength factor, $\Omega_{o}$, of 2.5 is recommended as this value follows the upper bound of the overstrength factor calculated for the archetype structures.

The deflection amplification factors, $C_{d}$, found for the planar and C-shaped archetypes are summarized in Table 12-2. The average deflection amplification factor was 5.3. This value was calculated at the $90^{\text {th }}$ percentile confidence level for the design basis earthquake. This value compares well with the current ASCE7-16 $\mathrm{C}_{\mathrm{d}}$ factor of 5.5. Therefore, the Cd factor is recommended to remain at 5.5.

A study was also conducted for walls without closure plates (See Chapter 11). The period-based ductility of these walls was found to be considerably lower than the planar walls with closure plates. The adjusted collapse margin ratio found for walls without closure plates did not satisfy the required collapse prevention criterion. Hence, a more conservative value for the response modification factor is required to design walls without closure plates. Considering the many drawbacks of using C-PSW/CF walls without closure plates, the use of this type of wall should be limited and used only when the inclusion of closure plate or boundary elements is not possible. 
Based the findings of this study, walls with semicircular and circular boundary elements should have similar, if not better performance, to walls with rectangular boundary elements as the inclusion of these closure plates increases the concrete confinement without introducing potential areas of undesired stress concentrated like the corners of rectangular closure plates. In the future, A FEMA P695 study on C-PSW/CF walls with semicircular or circular boundary elements could be conducted to verify appropriate seismic performance factors for these wall elements. 


\section{REFERENCES}

AISC341 (2016). "Seismic provisions for structural steel buildings.", ANSI/AISC 341-16, American Institute of Steel Construction, Inc., Chicago, Illinois.

AISC (2013). "Steel Construction Manual." American Institute of Steel Construction, ANSI/AISC, American Institute of Steel Construction, Inc., Chicago, Illinois.

AISC (2019). "Speedcore." Retrieved from https://www.aisc.org/why-steel/innovativesystems/SpeedCore/, 07/10/2019.

Alzeni, Y., and Bruneau, M. (2014). "Cyclic Inelastic Behavior Of Concrete Filled Sandwich Panel Walls Subjected To In-Plane Flexure." MCEER Report, The State University of New York at Buffalo.

Alzeni, Y., and Bruneau, Y. "In-plane cyclic testing of concrete-filled sandwich steel panel walls with and without boundary elements." Journal of Structural Engineering 143, no. 9 (2017): 04017115.

ASCE (2016). Minimum design loads for buildings and other structures., American Society of Civil Engineers Inc., Chicago, Illinois.

Bhardwaj, S., and Varma, A.H. (2016). AISC Design Guide 32: Design of Modular Steel Plate Composite (SC) Walls for Safety Related Nuclear Facilities. AISC, Chicago, IL.

Bhardwaj, S., Wang, A.Y., and Varma, A.H. (2018). "Slenderness Requirements for CF-CPSW: The Effects of Concrete Casting." Proceedings of the Eighth International Conference on Thin-Walled Structures, ICTWS 2018, Lisbon, Portugal, July 24-27.

Booth, P.N., Bhardwaj, S. R., Tseng, T.Z., Seo, J. and Varma, A. H. (2020). "Ultimate shear strength of steel-plate compostie (SC) walls with boundary elements." Journal of Contructional Steel Research 165: 105810. 
Brown, J., and Kunnath, S. K. (2000). "Low-cycle fatigue behavior of longitudinal reinforcement in reinforced concrete bridge columns." MCEER Report, The State University of New York at Buffalo.

Broberg, M. R., Shafaei, S., Seo, J., Varma, A. H., Agrawal, S. (2019). "Introduction to Seismic Analysis of Coupled Composite Plate Shear Walls -- Concrete-Filled (CC-PSW/CF)." SSRC Conferences, April 2-5.

Bruneau, M., Varma, A. H., Kizilarslan, E., Broberg, M. R., Shafaei, S., Seo, J., "R-Factors for Coupled Composite Plate Shear Walls / Concrete Filled (CC-PSW/CF)." Charles Pankow Foundation \& American Institute of Steel Construction

Chang, G., and Mander, J. B. (1994). "Seismic energy based fatigue damage analysis of bridge columns: part 1-evaluation of seismic capacity." MCEER Report, The State University of New York at Buffalo.

CIS (2017). "SAP2000: integrated finite element analysis and design of structures." Computers and Structures, Berkeley, California.

Coffin, J. L. F. (1954). "A study of the effects of cyclic thermal stresses on a ductile metal." trans. ASME, 76, 931-950.

Coffin, L. (1971). "A note on low cycle fatigue laws (Plastic strain range-fatigue life behavior as two slope relationship, considering low cycle fatigue laws in terms of crack propagation mode change)." Journal of Materials, 6, 388-402.

Dhakal, R. P., and Maekawa, K. (2002). "Modeling for postyield buckling of reinforcement." Journal of Structural Engineering, 128(9), 1139-1147.

Ezzeldin, M., Wiebe, L., and El-Dakhakhni, W. (2016). "Seismic collapse risk assessment of reinforced masonry walls with boundary elements using the FEMA P695 methodology." Journal of Structural Engineering, 142(11), 04016108. 
FEMA (2009). "FEMA P695: Quantification of Building Seismic Performance Factors." Applied Technology Council. Federal Emergency Management Agency.

Filiatrault, A., and Christovasilis, I. "Example application of the FEMA P695 (ATC-63) Methodology for the collapse performance evaluation of wood light-frame systems." Proc., 9th US National \& 10th Canadian Conference on Earthquake Engineering.

Fiorino, L., Shakeel, S., Macillo, V., and Landolfo, R. (2017). "Behaviour factor (q) evaluation the CFS braced structures according to FEMA P695." Journal of Constructional Steel Research, 138, 324-339.

Gogus, A., and Wallace, J. W. (2015). "Seismic safety evaluation of reinforced concrete walls through FEMA P695 methodology." Journal of Structural Engineering, 141(10), 04015002 .

Gomes, A., and Appleton, J. (1997). "Nonlinear cyclic stress-strain relationship of reinforcing bars including buckling." Engineering Structures, 19(10), 822-826.

Kaufmann, E., Metrovich, B., and Pense, A. (2001). "Characterization of cyclic inelastic strain behavior on properties of A572 Gr. 50 and A913 Gr. 50 rolled sections." ATLSS Report No. 01-13.

Kechidi, S., Bourahla, N., and Castro, J. M. (2017). "Seismic design procedure for cold-formed steel sheathed shear wall frames: Proposal and evaluation." Journal of Constructional Steel Research, 128, 219-232.

Kircher, C., Deierlein, G., Hooper, J., Krawinkler, H., Mahin, S., Shing, B., and Wallace, J. (2010). "Evaluation of the FEMA P-695 Methodology for Quantification of Building Seismic Performance Factors| NIST." Grant/Contract Reports (NISTGCR) - 10-917-8. 
Kizilarslan, E., Kenarangi, H., and Bruneau, M. (2019). "Cyclic Behavior of C-Shaped Composite Plate Shear Walls - Concrete Filled." Journal of Structural Engineering, ASCE, sumbitted for review.

Kunnath, S. K., Heo, Y., and Mohle, J. F. (2009). "Nonlinear uniaxial material model for reinforcing steel bars." Journal of Structural Engineering, 135(4), 335.

Kuşyılmaz, A., and Topkaya, C. (2016). "Evaluation of seismic response factors for eccentrically braced frames using FEMA P695 methodology." Earthquake Spectra, 32(1), 303-321.

Manson, S. (1965). "Fatigue: a complex subject—some simple approximations." Experimental mechanics, 5(4), 193-226.

Masroor, A., and Mosqueda, G. (2015). "Assessing the collapse probability of base-isolated buildings considering pounding to moat walls using the FEMA P695 methodology." Earthquake Spectra, 31(4), 2069-2086.

Mathworks (1992). "Matlab, User’s Guide." Inc., Natick, MA, 1992.

McKenna, F., Mazzoni, S., and Fenves, G. (2016). "Open System for Earthquake Engineering Simulation (OpenSees) Software Version 2.2. 5." University of California, Berkeley, CA. Available from http://opensees.berkeley.edu.

Menegotto, M. "Pinto,(1973), PE, Method of Analysis for Cyclically Loaded Reinforced Concrete Plane Frames Including Changes in Geometry and Non-elastic Behavior of Elements Under Combined Normal Force and Bending." Proc., IABSE Symposium on the Resistance and Ultimate Deformability of Structures Acted on by Well-Defined Repeated Loads, Lisbon.

Miner, M. A. (1945). "Cumulative damage in fatigue." J. Appl. Mech., 12, A159-A164. 
Neuenhofer, A., and Filippou, F. C. (1997). "Evaluation of nonlinear frame finite-element models." Journal of structural engineering, 123(7), 958-966.

Nicknam, A. (2015). Seismic analysis and design of buildings equipped with propped rocking wall systems, ProQuest Dissertations Publishing, 2015. 3683065, The State University of New York at Buffalo.

Nie, J.-G., Hu, H.-S., and Eatherton, M. R. (2014). "Concrete filled steel plate composite coupling beams: Experimental study." Journal of Constructional Steel Research, 94, 49-63.

Nobahar, E., Farahi, M., and Mofid, M. (2016). "Quantification of seismic performance factors of the buildings consisting of disposable knee bracing frames." Journal of Constructional Steel Research, 124, 132-141.

Panthaki, F. D. (1992). "Low cycle fatigue behavior of high strength and ordinary reinforcing steels." Doctoral dissertation, The State University of New York at Buffalo.

PEER (2005). "PEER NGA Database." Pacific Earthquake Engineering Research Center (PEER), University of California, Berkeley, California <http://peer.berkeley.edu/nga/>.

PEER, T. (2010). "Guidelines for performance-based seismic design of tall buildings." University of California Berkeley, USA.

Post, N. M. (2019). "Erector Proves Speed Predictions for Radical Steel Frame of Seattle's Rainier Square Tower." Engineering News-Records.

Purba, R., and Bruneau, M. (2014). "Seismic performance of steel plate shear walls considering two different design philosophies of infill plates. I: Deterioration model development." Journal of Structural Engineering, 141(6), 04014160.

Restrepo-Posada, J., Dodd, L., Park, R., and Cooke, N. (1994). "Variables affecting cyclic behavior of reinforcing steel." Journal of Structural Engineering, 120(11), 3178-3196. 
Seo, J., Varma, A.H., Sener, K., and Ayhan, D. (2016). "Steel-Plate Composite (SC) Walls: InPlane Shear Behavior, Database, and Design.” Journal of Constructional Steel Research, Elsevier Science, 119, 202-215.

Susantha, K., Ge, H., and Usami, T. (2001). "Uniaxial stress-strain relationship of concrete confined by various shaped steel tubes." Engineering Structures, 23(10), 1331-1347.

Shafaei, S., Varma, A. H., Broberg, M. R., Seo, J. "An Introduction to Numerical Modeling of Composite Plate Shear Walls / Concrete Filled (C-PSW/CF)." Proceedings of the Structureal Stability Research Council Conference, April 2-5, 2019.

Shafaei, S., Seo, J., and Varma, A.H. (2020a). "Cyclic Behavior of Planar Composite Plate Shear Walls - Concrete Filled.” Journal of Structural Engineering, ASCE, Submitted for review.

Shafaei, S., Varma, A.H., and Broberg, M. (2020b). "Effective Stress-Strain Curves for Modeling the Cyclic Behavior of Planar CPSW/CF." Journal of Constructional Steel Research, Elsevier, submitted for review.

Tao, Z., Wang, Z.-B., and Yu, Q. (2013). "Finite element modelling of concrete-filled steel stub columns under axial compression." Journal of Constructional Steel Research, 89, 121-131.

Vamvatsikos, D., and Cornell, C. A. (2002). "Incremental dynamic analysis." Earthquake Engineering \& Structural Dynamics, 31(3), 491-514.

Varma, A., Seo, J., and Lai, Z. (2017). "On the Lateral Behavior of Concrete-Filled Composite Plate Shear Walls." Proceedings of the 9th International Symposium on Steel Structures, Nov. 1-4, 2017, 426-427.

Varma, A. H., Shafaei, S. and Klemencic, R. "Steel modules of composite plate shear walls: Behavior, stability, and design." Thin-Walled Structures 145 (2019): 106384. 
Zareian, F., Lignos, D., and Krawinkler, H. "Evaluation of seismic collapse performance of steel special moment resisting frames using FEMA P695 (ATC-63) methodology." Proc., Structures Congress 2010, 1275-1286.

Zhang, K., Varma, A. H., Malushte, S. R., and Gallocher, S. (2014). "Effect of shear connectors on local buckling and composite action in steel concrete composite walls." Nuclear Engineering and Design, 269, 231-239.

Zhang, K., Seo, J., and Varma, A.H. (2020). "Steel-Plate Composite (SC) Walls: Behavior and Design and Behavior for Axial Compressive Loading." Journal of Structural Engineering, 146(4), 04020044. 


\section{APPENDIX A - PLASTIC MOMENT AND STIFFNESS \\ CALCULATION}

\subsection{Planar Walls}

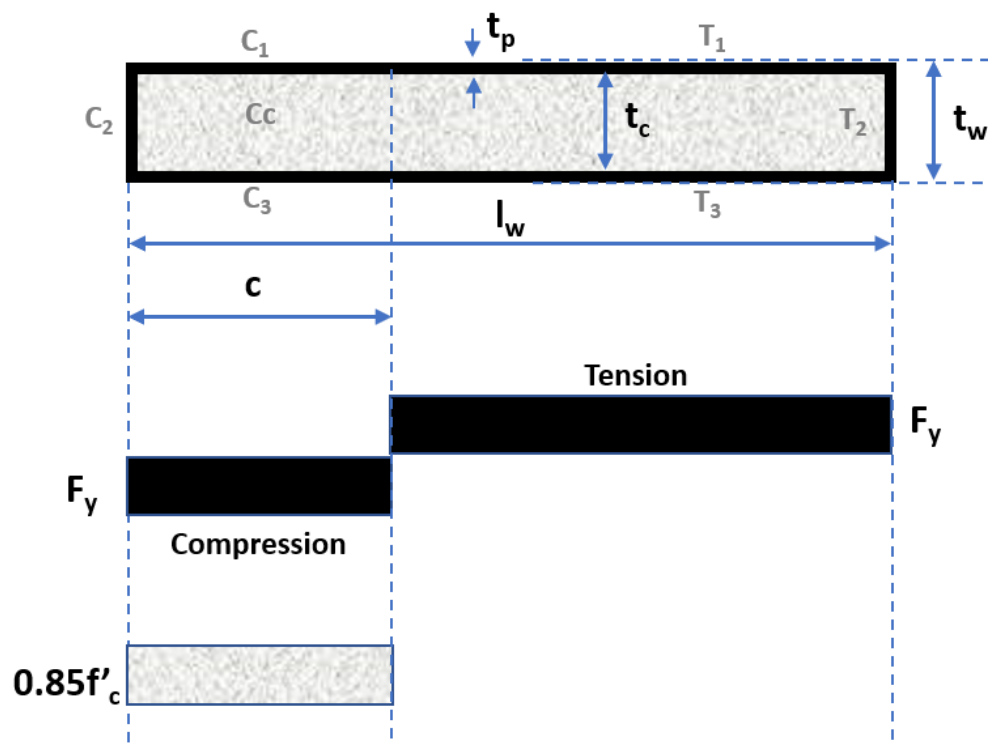

Figure 16-1. Stress distribution assumed in concrete infill and steel plates of Planar CPSW/CFs for calculating the plastic moment capacity, $M_{p}$

\section{Compression Block}

$$
\begin{aligned}
& C_{1}=\left(c-t_{p}\right) t_{p} F_{y} \\
& C_{2}=t_{p} t_{w} F_{y} \\
& C_{3}=\left(c-t_{p}\right) t_{p} F_{y} \\
& C_{c}=\left(c-t_{p}\right) t_{c w}\left(0.85 f_{c}^{\prime}\right) \\
& C=C_{1}+C_{2}+C_{3}+C_{c}
\end{aligned}
$$

\section{Tension Block}

$$
\begin{aligned}
& T_{1}=\left(l_{w}-c-t_{p}\right) t_{p} F_{y} \\
& T_{2}=t_{p} t_{w} F_{y} \\
& T_{3}=\left(l_{w}-c-t_{p}\right) t_{p} F_{y} \\
& T=T_{1}+T_{2}+T_{3}
\end{aligned}
$$


Here, assuming axial force equal to zero/negligible

$$
C=T
$$

Solving the above equations, we get,

Neutral axis, c

$$
c=\frac{2 l_{w} F_{y} t_{p}+0.85 f_{c}^{\prime} t_{c} t_{p}}{4 F_{y} t_{p}+0.85 f_{c}^{\prime} t_{c}}
$$

\section{Plastic Moment Capacity, $\mathbf{M}_{\mathbf{p}}$}

$$
M_{p}=\frac{\left(C_{1}+C_{3}+C_{c}\right)\left(c-t_{p}\right)}{2}+C_{2}\left(c-\frac{t_{p}}{2}\right)+\left(T_{1}+T_{3}\right) \frac{\left(l_{w}-c-t_{p}\right)}{2}+T_{2}\left(l_{w}-c-\frac{t_{p}}{2}\right)
$$

Flexural Stiffness, EIeff

$$
\begin{aligned}
& I_{s}=\frac{2 t_{p}\left(l_{w}-2 t_{p}\right)^{3}}{12}+2 t_{p} t_{w}\left(\frac{l_{w}-t_{p}}{2}\right)^{2} \\
& I_{c}=\frac{t_{c w}\left(l_{w}-2 t_{p}\right)^{3}}{12} \\
& E I_{\text {eff }}=E_{s} I_{s}+0.35 E_{c} I_{c} \\
& o r \\
& E I_{\text {eff }}=\frac{M_{0.6}}{\varphi_{0.6}}
\end{aligned}
$$




\subsection{C-Shaped Walls}

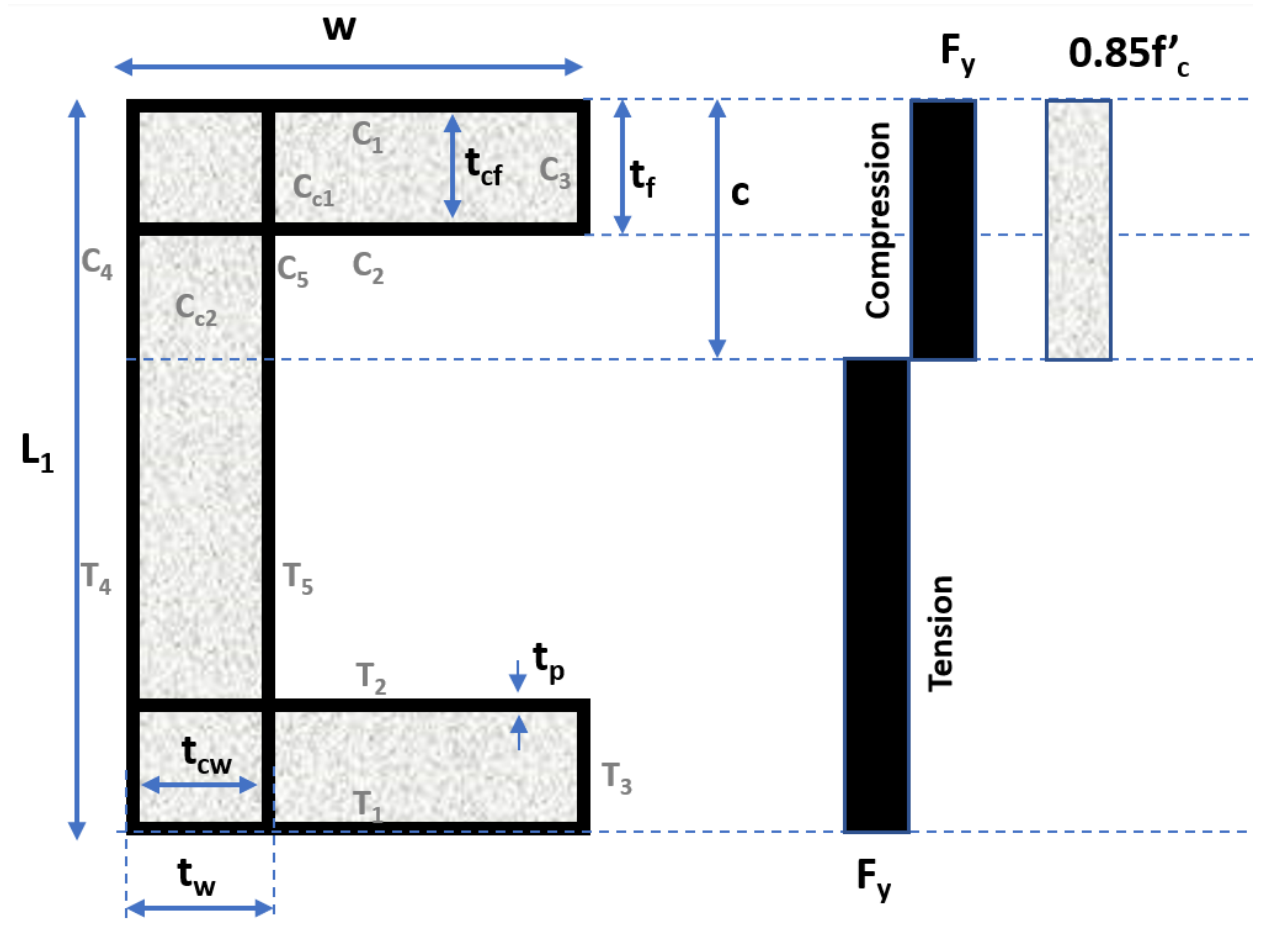

Figure 16-2. Stress distribution assumed in concrete infill and steel plates of C-Shaped CPSW/CFs for calculating the plastic moment capacity, $M_{p}$

Compression Block

$$
\begin{aligned}
& C_{1}=\left(w-3 t_{p}\right) t_{p} F_{y} \\
& C_{2}=\left(w-3 t_{p}\right) t_{p} F_{y} \\
& C_{3}=t_{f} t_{p} F_{y} \\
& C_{4}=c t_{p} F_{y} \\
& C_{5}=c t_{p} F_{y} \\
& C_{c 1}=\left(w-3 t_{p}\right)\left(t_{c f}\right)\left(0.85 f_{c}^{\prime}\right) \\
& C_{c 2}=\left(c-t_{f}\right) t_{c w}\left(0.85 f_{c}^{\prime}\right) \\
& C=C_{1}+C_{2}+C_{3}+C_{4}+C_{5}+C_{c 1}+C_{c 2} \\
& w_{c}=w-3 t_{p}
\end{aligned}
$$




\section{Tension Block}

$$
\begin{aligned}
& T_{1}=\left(w-3 t_{p}\right) t_{p} F_{y} \\
& T_{2}=\left(w-3 t_{p}\right) t_{p} F_{y} \\
& T_{3}=t_{f} t_{p} F_{y} \\
& T_{4}=\left(l_{1}-c\right) t_{p} F_{y} \\
& T_{5}=\left(l_{1}-c\right) t_{p} F_{y} \\
& T=T_{1}+T_{2}+T_{3}+T_{4}+T_{5}
\end{aligned}
$$

A.10a

A.10c

A.10d

A.10e

A.10f

Here, assuming negligible axial force

$$
C=T
$$

Solving the above equations, we get,

\section{Neutral axis, c}

$$
c=\frac{2 l_{1} F_{y} t_{p}-0.85 f_{c}^{\prime}\left(t_{c f} w_{c}-t_{c w} t_{f}\right)}{4 F_{y} t_{p}+0.85 f_{c}^{\prime} t_{c w}}
$$

Plastic Moment Capacity, $\mathbf{M}_{\mathbf{p}}$

$$
\begin{aligned}
M_{p}= & C_{1}\left(c-\frac{t_{p}}{2}\right)+C_{2}\left(c-t_{f}+\frac{t_{p}}{2}\right)+C_{3}\left(c-\frac{t_{f}}{2}\right)+\left(C_{4}+C_{5}\right) \frac{c}{2}+ \\
& C_{c 1}\left(c-\frac{t_{f}}{2}\right)+C_{c 2}\left(\frac{c-t_{f}}{2}\right)+T_{1}\left(L_{1}-c-\frac{t_{p}}{2}\right)+T_{2}\left(L_{1}-c-t_{f}+\frac{t_{p}}{2}\right)+ \\
& T_{3}\left(L_{1}-c-\frac{t_{f}}{2}\right)+\left(T_{4}+T_{5}\right) \frac{\left(L_{1}-c\right)}{2}
\end{aligned}
$$

Flexural Stiffness, EI $I_{\text {eff }}$

$$
\begin{aligned}
& I_{s}=2 t_{p} w_{c} \frac{\left(L_{1}-t_{p}\right)^{2}}{4}+2 t_{p} w_{c}\left(\frac{L_{1}-2 t_{f}+t_{p}}{2}\right)^{2}+2 t_{p} \frac{L_{1}^{3}}{12} \\
& I_{c}=\frac{2 w_{c} t_{c f}^{3}}{12}+2 w_{c} t_{c f}\left(\frac{L_{1}-t_{f}}{2}\right)^{2}+t_{c w} \frac{\left(L_{1}-2 t_{f}\right)^{3}}{12} \\
& E I_{e f f}=E_{s} I_{s}+0.35 E_{c} I_{c} \\
& o r \\
& E I_{e f f}=\frac{M_{0.6}}{\varphi_{0.6}}
\end{aligned}
$$




\section{APPENDIX B - EQUIVALENT LATERAL FORCE CALCULATIONS FOR 6-STORY ARCHETYPE}

This section shows the equivalent lateral force calculation for the 6-story planar C-PSW/CF archetype.

\section{Equivalent Lateral Force Calculations - 6-story Archetype}

\section{Step 1: Initial Parameters}

\section{Floor Plan}

$\mathrm{N}_{\text {wall }}:=2$

Number of walls in each direction

$\mathrm{w}_{\mathrm{fl}}:=0.12 \mathrm{ksf}$

$\mathrm{Fl}_{\text {width }}:=205 \mathrm{ft}$

Floor dead load

$\mathrm{Fl}_{\text {depth }}:=105 \mathrm{ft}$

Building width

Building depth

$\mathrm{n}_{\mathrm{fl}}:=6$

Number of floors

$\mathrm{h}_{\text {typ }}:=14 \mathrm{ft}$

Typical floor height

$\mathrm{h}_{1}:=17 \mathrm{ft}$

First floor height

$\mathrm{h}_{\mathrm{n}}:=\mathrm{h}_{1}+\mathrm{h}_{\mathrm{typ}} \cdot\left(\mathrm{n}_{\mathrm{fl}}-1\right)=87 \cdot \mathrm{ft}$

Total height of the building

$\mathrm{i}:=1 . . \mathrm{n}_{\mathrm{fl}}$

$\mathrm{w}_{\mathrm{i}}:=\mathrm{w}_{\mathrm{fl}} \cdot \mathrm{Fl}_{\text {width }} \cdot \mathrm{Fl}_{\mathrm{depth}}$

Story weight

$\mathrm{w}_{1}=2.58 \times 10^{3} \cdot \mathrm{kip}$

$\mathrm{W}:=\sum_{\mathrm{j}=1}^{\mathrm{n}_{\mathrm{fl}}} \mathrm{w}_{\mathrm{j}}=1.55 \times 10^{4} \cdot \mathrm{kip}$

Total weight 


\section{Step 2: Equivalent Lateral Force Analysis}

Step 2-1: Develop response spectra

Calculated from $D_{\max }$

The response spectra provided in FEMA P695 was used to select $S_{D S}$ and $S_{D 1}$

Response Spectra Parameters Site Class: D

$\mathrm{S}_{\mathrm{DS}}:=1.0$

FEMA P695 Table 6-1,(ASCE7 11.4-3)

$\mathrm{S}_{\mathrm{D} 1}:=0.6$

FEMA P695 Table 6-1, (ASCE7 11.4-3)

Seismic Design Coefficients for C-PSW/CF walls

$\mathrm{R}:=6.5$

Response modification factor

$\mathrm{Cd}:=5.5$

Deflection amplification factor

$\Omega:=2.5$

Overstrength factor

$\mathrm{I}_{\mathrm{e}}:=1$

Importance factor

$\rho:=1$

Seismic redundancy factor taken one for FEMA P695 study

Step 2-2: Estimate Fundamental Period (T)

$$
\begin{aligned}
& C_{t}:=0.02 \\
& x:=0.75
\end{aligned}
$$
Table 12.8-2) selected considering "All other structural systems"

$\mathrm{T}_{\mathrm{L}}:=8$

Long Period

$\mathrm{T}_{\mathrm{o}}:=0.2 \cdot \frac{\mathrm{S}_{\mathrm{D} 1}}{\mathrm{~S}_{\mathrm{DS}}}=0.12$

$0.2 \mathrm{~S}_{\mathrm{DS}} / \mathrm{S}_{\mathrm{D} 1}$, (ASCE7 Chapter 11)

$\mathrm{T}_{\mathrm{S}}:=\frac{\mathrm{S}_{\mathrm{D} 1}}{\mathrm{~S}_{\mathrm{DS}}}=0.6$

$\mathrm{S}_{\mathrm{DS}} / \mathrm{S}_{\mathrm{D} 1}$, (ASCE7 Chapter 11)

$\mathrm{T}_{\mathrm{a}}:=\mathrm{C}_{\mathrm{t}} \cdot\left(\frac{\mathrm{h}_{\mathrm{n}}}{\mathrm{ft}}\right)^{\mathrm{x}}=0.57$

Approximate fundamental period 


$$
\mathrm{C}_{\mathrm{u}}:=\mid \begin{aligned}
& 1.7 \text { if } \mathrm{S}_{\mathrm{D} 1} \leq 0.15 \\
& 1.6 \text { if } 0.2 \geq \mathrm{S}_{\mathrm{D} 1} \geq 0.15 \\
& 1.4 \text { if } \mathrm{S}_{\mathrm{D} 1} \geq 0.3 \\
& 1.5 \text { if } 0.3 \geq \mathrm{S}_{\mathrm{D} 1} \geq 0.2
\end{aligned}=1.4
$$$$
\mathrm{T}:=\mathrm{C}_{\mathrm{u}} \cdot \mathrm{T}_{\mathrm{a}}=0.8
$$

Step 2-3: Seismic Response Coefficients $\left(C_{s}\right)$

$$
\begin{aligned}
& \mathrm{C}_{\mathrm{S}_{-} \text {cal }}:=\frac{\mathrm{S}_{\mathrm{DS}}}{\frac{\mathrm{R}}{\mathrm{I}_{\mathrm{e}}}}=0.15
\end{aligned}
$$

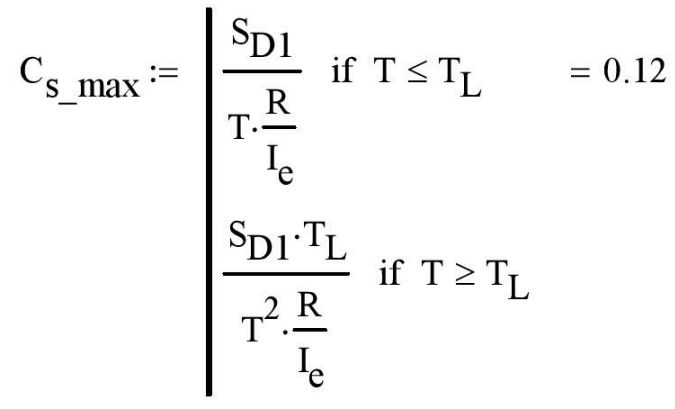

$$
\begin{aligned}
& \mathrm{C}_{\mathrm{S} 1}:=\max \left(0.044 \cdot \mathrm{S}_{\mathrm{DS}} \cdot \mathrm{I}_{\mathrm{e}}, 0.01, \mathrm{C}_{\mathrm{S} \_\max }\right)=0.12 \\
& \mathrm{C}_{\mathrm{S}}:=\min \left(\mathrm{C}_{\mathrm{S} \_ \text {cal }}, \mathrm{C}_{\mathrm{S} \_ \text {max }}\right)=0.12
\end{aligned}
$$

Step 2-4: Base Shear Calculation

$$
\mathrm{V}:=\mathrm{C}_{\mathrm{S}} \cdot \mathrm{W}=1.79 \times 10^{3} \cdot \mathrm{kip}
$$

\section{Step 2-5: Vertical Distribution of Seismic Forces}

$$
\mathrm{k}:=\mid \begin{aligned}
& {\left[1+\frac{(\mathrm{T}-0.5)}{2}\right] \text { if } 0.5 \leq \mathrm{T} \leq 2.5=1.15} \\
& 1 \text { if } \mathrm{T} \leq 0.5 \\
& 2 \text { if } \mathrm{T} \geq 2.5
\end{aligned}
$$

Coefficients for upper limit period (ASCE7-16 Table 12.8-1) Interpolation may be required

\section{Upper Limit Period}

Sturcuture period is greater than $C_{u} T_{a}$, so $C_{u} T_{a}$ is selected for design

(ASCE7 12.8-3)

(ASCE7 12.8-5)

Seismic response coefficient

Base Shear

(ASCE7 12.8.3) 
Story Elevations

$$
\begin{array}{ll}
\mathrm{ht}_{\mathrm{i}}:=\mathrm{h}_{\text {typ }} \quad \mathrm{ht}_{1}:=\mathrm{h}_{1} \\
\mathrm{~h}_{\mathrm{i}}:=\sum_{\mathrm{j}=1}^{\mathrm{i}} \mathrm{ht}_{\mathrm{j}} \quad \mathrm{h}=\left(\begin{array}{c}
0 \\
17 \\
31 \\
45 \\
59 \\
73 \\
87
\end{array}\right) \mathrm{ft}
\end{array}
$$

\section{Story Elevations}

Story Shear

$$
\mathrm{Cv}_{\mathrm{i}}:=\frac{\mathrm{w}_{\mathrm{i}} \cdot\left(\frac{\mathrm{h}_{\mathrm{i}}}{\mathrm{ft}}\right)^{\mathrm{k}}}{\sum_{\mathrm{j}=1}^{\mathrm{n} f \mathrm{l}}\left[\mathrm{w}_{\mathrm{j}} \cdot\left(\frac{\mathrm{h}_{\mathrm{j}}}{\mathrm{ft}}\right)^{\mathrm{k}}\right]}
$$

$\mathrm{Fx}_{\mathrm{i}}:=\mathrm{V} \cdot \mathrm{Cv}_{\mathrm{i}} \quad \mathrm{Fx}=\left(\begin{array}{c}0 \\ 81 \\ 162 \\ 248 \\ 339 \\ 433 \\ 530\end{array}\right) \cdot \mathrm{kip}$

$$
\text { Fcum }_{\mathrm{i}}:=\sum_{\mathrm{j}=\mathrm{i}}^{\mathrm{n}_{\mathrm{fl}}} \mathrm{Fx}_{\mathrm{j}} \quad \text { Fcum }=\left(\begin{array}{c}
0 \\
1794 \\
1712 \\
1550 \\
1302 \\
963 \\
530
\end{array}\right) \cdot \text { kip }
$$


Step 2-6: Base Shear Amplification

Amplification Factor

ShearAmpFactor $:=4$

See Section 4.2.4

$\mathrm{V}_{\mathrm{ELF}}:=\mathrm{V}=1.8 \times 10^{3} \cdot \mathrm{kip}$

ELF base shear

$\mathrm{V}_{\text {req }}:=4 \cdot \mathrm{V}_{\mathrm{ELF}}=7.2 \times 10^{3} \cdot \mathrm{kip}$

Amplified base shear

Step 2-7: Overturning Moment

$\mathrm{OTM}_{\mathrm{i}}:=\sum_{\mathrm{j}=\mathrm{i}}^{\mathrm{n}_{\mathrm{fl}}}\left(\right.$ Fsum $\left.\left._{\mathrm{j}} \cdot \mathrm{ht}\right) \quad \mathrm{j}\right)\left(\begin{array}{c}0 \\ 1.4 \times 10^{6} \\ 1 \times 10^{6} \\ 7.3 \times 10^{5} \\ 4.7 \times 10^{5} \\ 2.5 \times 10^{5} \\ 8.9 \times 10^{4}\end{array}\right) \cdot \mathrm{kip} \cdot \mathrm{in}$

Overtuming moment

$\mathrm{OTM}_{\text {wall }}:=\frac{\mathrm{OTM}_{1}}{\mathrm{~N}_{\text {wall }}}=6.9 \times 10^{5} \cdot \mathrm{kip} \cdot \mathrm{in}$

Overturning moment at base of the wall 


\section{APPENDIX C - ARCHETYPE DESIGN PROCEDURE}

\subsection{Planar Walls - 6 Story Archetype}

\section{Step 3: Preliminary Design}

Wall Dimensions

$$
\begin{aligned}
& \mathrm{l}_{\mathrm{W}}:=25 \mathrm{ft} \\
& \mathrm{t}_{\mathrm{p}}:=0.3125 \mathrm{in} \\
& \mathrm{t}_{\mathrm{W}}:=16 \mathrm{in} \\
& \text { Material Properties } \\
& \mathrm{F}_{\mathrm{y}}:=50 \mathrm{ksi} \\
& \mathrm{f}_{\mathrm{C}}:=6 \mathrm{ksi} \\
& \mathrm{E}_{\mathrm{S}}:=29000 \mathrm{ksi} \\
& \mathrm{G}_{\mathrm{S}}:=11500 \mathrm{ksi} \\
& \mathrm{E}_{\mathrm{c}}:=57 \mathrm{ksi} \cdot \sqrt{\frac{\mathrm{f}_{\mathrm{c}}}{\mathrm{psi}}}=4.42 \times 10^{3} \cdot \mathrm{ksi}
\end{aligned}
$$

Length of wall

Plate thickness

Wall thickness

Nominal steel strength

Nominal concrete strength

Modulus of elasticity of steel

(AISC B4.1)

Shear modulus

Modulus of elasticity of concrete

(AISC 12.1b)

\section{Step 4: Structural Analysis}

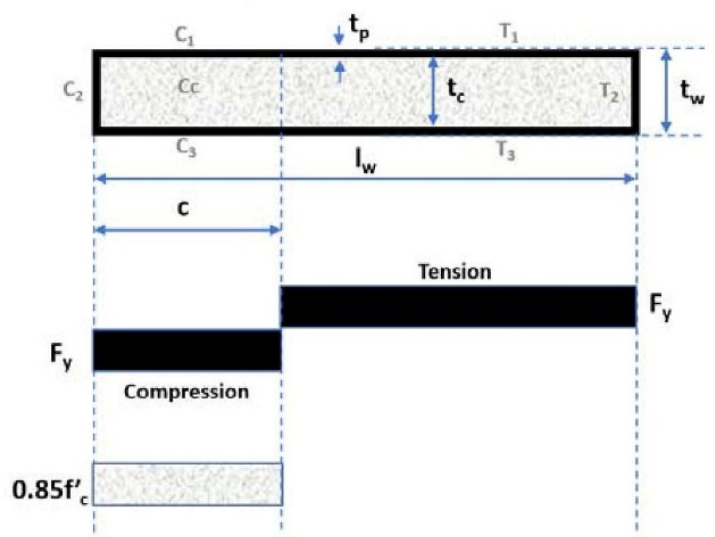

Cross Section

$$
\begin{aligned}
& \mathrm{A}_{\mathrm{S}}:=2 \mathrm{t}_{\mathrm{p}} \cdot \mathrm{t}_{\mathrm{w}}+2 \mathrm{t}_{\mathrm{p}} \cdot\left(\mathrm{l}_{\mathrm{w}}-2 \cdot \mathrm{t}_{\mathrm{p}}\right)=197 \cdot \mathrm{in}^{2} \\
& \mathrm{~A}_{\mathrm{SW}}:=2 \cdot \mathrm{t}_{\mathrm{p}} \cdot \mathrm{l}_{\mathrm{W}}=187.5 \mathrm{in}^{2} \\
& \mathrm{t}_{\mathrm{c}}:=\mathrm{t}_{\mathrm{w}}-2 \cdot \mathrm{t}_{\mathrm{p}}=15.4 \cdot \mathrm{in}
\end{aligned}
$$

Area of steel

Area of web steel

Concrete infill thickness 


$$
\begin{aligned}
& A_{c}:=t_{c} \cdot\left(l_{w}-2 t_{p}\right)=4603 \cdot i^{2} \\
& A_{T}:=A_{c}+A_{s}=4800 \cdot i^{2}
\end{aligned}
$$

\section{Strength Calculation per Section 3.5}

$c_{n}:=\frac{\left(21_{w} \cdot F_{y} \cdot t_{p}+0.85 f_{c} \cdot t_{c} \cdot t_{p}\right)}{4 F_{y} \cdot t_{p}+0.85 f_{c} \cdot t_{c}}=67 \cdot$ in

\section{Compression Block}

$\mathrm{C}_{1}:=\left(\mathrm{c}_{\mathrm{n}}-\mathrm{t}_{\mathrm{p}}\right) \cdot \mathrm{t}_{\mathrm{p}} \cdot \mathrm{F}_{\mathrm{y}}=1037 \cdot \mathrm{kip}$

$\mathrm{C}_{2}:=\mathrm{t}_{\mathrm{p}} \cdot \mathrm{t}_{\mathrm{w}} \cdot \mathrm{F}_{\mathrm{y}}=250 \cdot \mathrm{kip}$

$\mathrm{C}_{\mathrm{c}}:=\left(\mathrm{c}_{\mathrm{n}}-\mathrm{t}_{\mathrm{p}}\right) \cdot \mathrm{t}_{\mathrm{c}} \cdot 0.85 \mathrm{f}_{\mathrm{c}}=5206 \cdot \mathrm{kip}$

$\mathrm{C}_{3}:=\mathrm{C}_{1}$

$\mathrm{C}_{\mathrm{T}}:=\mathrm{C}_{1}+\mathrm{C}_{2}+\mathrm{C}_{3}+\mathrm{C}_{\mathrm{c}}=7.53 \times 10^{3} \cdot \mathrm{kip}$

Tension Block

$$
\begin{aligned}
& \mathrm{T}_{1}:=\left(\mathrm{l}_{\mathrm{w}}-\mathrm{c}_{\mathrm{n}}-\mathrm{t}_{\mathrm{p}}\right) \cdot \mathrm{t}_{\mathrm{p}} \cdot \mathrm{F}_{\mathrm{y}}=3640 \cdot \mathrm{kip} \\
& \mathrm{T}_{2}:=\mathrm{t}_{\mathrm{p}} \cdot \mathrm{t}_{\mathrm{w}} \cdot \mathrm{F}_{\mathrm{y}} \\
& \mathrm{T}_{3}:=\mathrm{T}_{1} \\
& \mathrm{~T}_{\mathrm{T}}:=\mathrm{T}_{1}+\mathrm{T}_{2}+\mathrm{T}_{3}=7.53 \times 10^{3} \cdot \mathrm{kip}
\end{aligned}
$$

Moment Capacity per Section 3.5 .2

$$
\begin{array}{ll}
\mathrm{M}_{\mathrm{p}}:=\frac{\left(\mathrm{C}_{1}+\mathrm{C}_{3}+\mathrm{C}_{\mathrm{c}}\right) \cdot\left(\mathrm{c}_{\mathrm{n}}-\mathrm{t}_{\mathrm{p}}\right)}{2}+\mathrm{C}_{2} \cdot\left(\mathrm{c}_{\mathrm{n}}-\frac{\mathrm{t}_{\mathrm{p}}}{2}\right)+\left(\mathrm{T}_{1}+\mathrm{T}_{3}\right) \cdot \frac{\left(\mathrm{l}_{\mathrm{w}}-\mathrm{c}_{\mathrm{n}}-\mathrm{t}_{\mathrm{p}}\right)}{2}+\mathrm{T}_{2} \cdot\left(\mathrm{l}_{\mathrm{w}}-\mathrm{c}_{\mathrm{n}}-\frac{\mathrm{t}_{\mathrm{p}}}{2}\right) \\
\mathrm{M}_{\mathrm{p}}=1.16 \times 10^{6} \cdot \mathrm{kip} \cdot \mathrm{in} & \text { Plastic moment } \\
\phi \mathrm{M}_{\mathrm{p}}:=0.9 \cdot \mathrm{M}_{\mathrm{p}}=1.05 \times 10^{6} \cdot \mathrm{kip} \cdot \mathrm{in} & \text { Factored flexural strength }
\end{array}
$$

\section{Factored flexural strength}


Shear Capacity per Section 3.5 .3

$$
\begin{aligned}
& \mathrm{K}_{\mathrm{S}}:=\mathrm{G}_{\mathrm{s}} \cdot \mathrm{A}_{\mathrm{sw}}=2.16 \times 10^{6} \cdot \mathrm{kip} \\
& \mathrm{K}_{\mathrm{sc}}:=\frac{0.7 \cdot\left(\mathrm{E}_{\mathrm{c}} \cdot \mathrm{A}_{\mathrm{c}}\right) \cdot \mathrm{E}_{\mathrm{s}} \cdot \mathrm{A}_{\mathrm{sw}}}{4 \cdot \mathrm{E}_{\mathrm{s}} \cdot \mathrm{A}_{\mathrm{sw}}+\mathrm{E}_{\mathrm{c}} \cdot \mathrm{A}_{\mathrm{c}}} \\
& \mathrm{V}_{\mathrm{n}}:=\frac{\mathrm{K}_{\mathrm{S}}+\mathrm{K}_{\mathrm{Sc}}}{\sqrt{3 \mathrm{~K}_{\mathrm{s}}^{2}+\mathrm{K}_{\mathrm{Sc}}^{2}} \cdot \mathrm{A}_{\mathrm{sw}} \cdot \mathrm{F}_{\mathrm{y}}=9 \times 10^{3} \cdot \mathrm{kip}} \\
& \phi \mathrm{V}_{\mathrm{n}}:=0.9 \cdot \mathrm{V}_{\mathrm{n}}=8.1 \times 10^{3} \cdot \mathrm{kip}
\end{aligned}
$$

\section{Step 5: Design Check}

\section{Step 5-2 Shear Check}

$\mathrm{V}_{\mathrm{u} \_ \text {wall }}:=$ ShearAmpFactor $\cdot \frac{\mathrm{V}_{\text {ELF }}}{\mathrm{N}_{\text {wall }}}=3.59 \times 10^{3} \cdot \mathrm{kip}$

$\frac{\phi \mathrm{V}_{\mathrm{n}}}{\mathrm{V}_{\mathrm{u} \_ \text {wall }}}=2.3$

Step 5-3 Flexure Check

$$
\begin{aligned}
& \mathrm{M}_{\mathrm{u} \_ \text {wall }_{\text {w }}}:=\mathrm{OTM}_{\text {wall }}=6.92 \times 10^{5} \cdot \mathrm{kip} \cdot \mathrm{in} \\
& \frac{\phi \mathrm{M}_{\mathrm{p}}}{\mathrm{M}_{\mathrm{u}_{-} \text {wall }}}=1.5
\end{aligned}
$$

\section{Factored shear strength}

\section{Required shear after amplification}

Shear strength ratio

Wall strength ratio 


\section{Step 5-4 Drift Check}

$$
\begin{aligned}
& \mathrm{M}_{\text {phi }} 0.6:=8.2 \cdot 10^{10} \cdot \mathrm{kip} \cdot \mathrm{in}^{2} \\
& \mathrm{EI}_{\text {eff }}:=\mathrm{M} \mathrm{phi}_{0.6}
\end{aligned}
$$$$
\operatorname{Defl}_{\text {ELF }}:=\left(\begin{array}{c}
0 \\
0.16 \\
0.50 \\
0.96 \\
1.50 \\
2.09 \\
2.70
\end{array}\right) \cdot \text { in }
$$$$
\text { ElasticDrift }{ }_{\text {max }}:=\frac{\operatorname{Defl}_{\mathrm{ELF}_{6}}-\mathrm{Defl}_{\mathrm{ELF}}{ }_{5}}{14 \mathrm{ft}}=0.36 \%
$$$$
\text { InelasticDrift }_{\max }:=\text { ElasticDrift }_{\max } \cdot \mathrm{Cd}=1.997 . \%
$$$$
\text { Check }_{\text {Drift }}:=\mid \begin{array}{ll}
\text { "Ok" } & \text { if InelasticDrift } \\
\text { max } & <2 \%=\text { "Ok" } \\
\text { "NG" } & \text { otherwise }
\end{array}
$$

Hence design of wall is adequate
Tangent of moment curvature at $60 \%$ capacity from OpenSees

\author{
Deflection calculated from elastic \\ analysis
}

Max elastic drift using above effective stiffness

Inelastic drift

Drift check 


\subsection{C-Shaped Walls - 18-Story Archetype}

\section{Step 3: Preliminary Design}

C-shaped Wall Dimensions

$\mathrm{L}_{1}:=40 \mathrm{ft}$

Length of wall in uncoupled direction

$\mathrm{t}_{\mathrm{p}}:=0.5 \mathrm{in}$

Plate thickness

$\mathrm{t}_{\mathrm{W}}:=18$ in

Wall web thickness

$\mathrm{t}_{\mathrm{f}}:=18 \mathrm{in}$

Wall flange thickness

$\mathrm{w}:=10 \mathrm{ft}$

Wall flange length

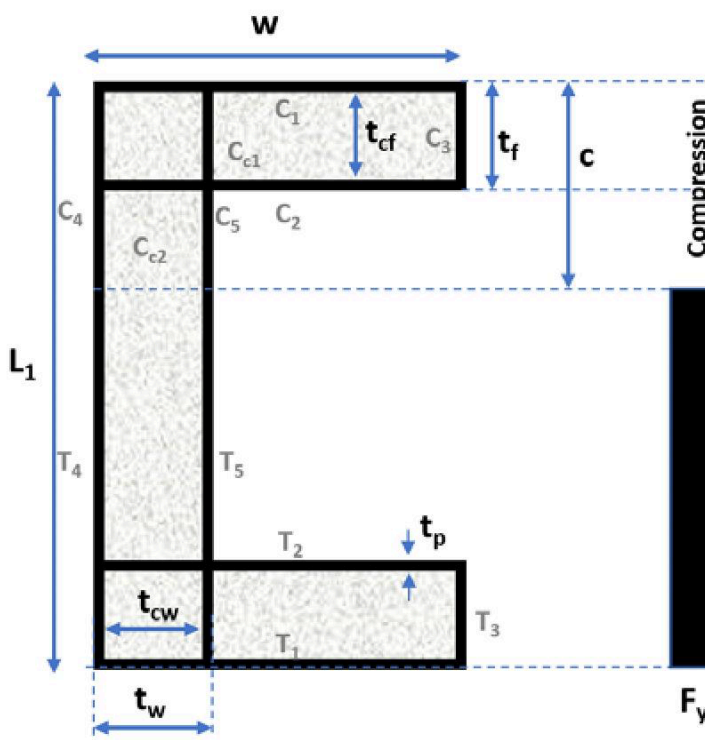

$\mathrm{t}_{\mathrm{CW}}:=\mathrm{t}_{\mathrm{w}}-2 \cdot \mathrm{t}_{\mathrm{p}}=17 \mathrm{in}$

Web concrete thickness

$t_{c f}:=t_{f}-2 \cdot t_{p}=17$ in

Flange concrete thickness

$\mathrm{w}_{\mathrm{c}}:=\mathrm{w}-3 \mathrm{t}_{\mathrm{p}}=118.5$ in

Material Properties

$\mathrm{F}_{\mathrm{y}}:=50 \mathrm{ksi}$

Nominal steel strength

$\mathrm{f}_{\mathrm{c}}:=6 \mathrm{ksi}$

Nominal concrete strength

$\mathrm{E}_{\mathrm{S}}:=29000 \mathrm{ksi}$

Modulus of elasticity of steel

(AISC B4.1)

$\mathrm{G}_{\mathrm{S}}:=11500 \mathrm{ksi}$

Shear modulus

$\mathrm{E}_{\mathrm{c}}:=57 \mathrm{ksi} \cdot \sqrt{\frac{\mathrm{f}_{\mathrm{C}}}{\mathrm{psi}}}=4.42 \times 10^{3} \mathrm{ksi}$

Modulus of elasticity of concrete (AISC 12.1b) 


\section{Step 4: Structural Analysis}

Cross Section
$\mathrm{A}_{\mathrm{sW}}:=2 \mathrm{t}_{\mathrm{p}} \cdot \mathrm{L}_{1}=480 \cdot \mathrm{in}^{2}$
Area of steel web
$\mathrm{A}_{\mathrm{s}}:=735 \mathrm{in}^{2}$
Total area of steel
$A_{c}:=2498$ in $^{2}$
Total area of concrete
$\mathrm{A}_{\mathrm{T}}:=\mathrm{t}_{\mathrm{cw}} \cdot\left(\mathrm{L}_{1}-2 \mathrm{t}_{\mathrm{f}}\right)+2 \mathrm{w}_{\mathrm{c}} \cdot \mathrm{t}_{\mathrm{cf}}=1.158 \times 10^{4} \cdot \mathrm{in}^{2}$
Total area

Strength Calculation per Section 3.5

$\mathrm{c}_{\mathrm{n}}:=\frac{\left[2 \mathrm{~L}_{1} \cdot \mathrm{F}_{\mathrm{y}} \cdot \mathrm{t}_{\mathrm{p}}-0.85 \mathrm{f}_{\mathrm{c}} \cdot\left(\mathrm{t}_{\mathrm{cf}} \cdot \mathrm{w}_{\mathrm{c}}-\mathrm{t}_{\mathrm{cw}} \cdot \mathrm{t}_{\mathrm{f}}\right)\right]}{4 \mathrm{~F}_{\mathrm{y}} \cdot \mathrm{t}_{\mathrm{p}}+0.85 \mathrm{f}_{\mathrm{c}} \cdot \mathrm{t}_{\mathrm{cw}}}=82 \cdot$ in $\quad$ Neutral axis

Compression Block

$\mathrm{C}_{1}:=\mathrm{w}_{\mathrm{c}} \cdot \mathrm{t}_{\mathrm{p}} \cdot \mathrm{F}_{\mathrm{y}}=2.96 \times 10^{3} \cdot \mathrm{kip}$

$\mathrm{C}_{2}:=\mathrm{C}_{1}=2.96 \times 10^{3} \cdot \mathrm{kip}$

$\mathrm{C}_{3}:=\mathrm{t}_{\mathrm{f}} \cdot \mathrm{t}_{\mathrm{p}} \cdot \mathrm{F}_{\mathrm{y}}=450 \cdot \mathrm{kip}$

$\mathrm{C}_{4}:=\mathrm{c}_{\mathrm{n}} \cdot \mathrm{t}_{\mathrm{p}} \cdot \mathrm{F}_{\mathrm{y}}=2.05 \times 10^{3} \cdot \mathrm{kip}$

$\mathrm{C}_{5}:=\mathrm{C}_{4}=2.05 \times 10^{3} \cdot \mathrm{kip}$

$\mathrm{C}_{\mathrm{cl}}:=\mathrm{w}_{\mathrm{c}} \cdot \mathrm{t}_{\mathrm{cf}} \cdot 0.85 \mathrm{f}_{\mathrm{c}}=1.03 \times 10^{4} \cdot \mathrm{kip}$

$\mathrm{C}_{\mathrm{c} 2}:=\left(\mathrm{c}_{\mathrm{n}}-\mathrm{t}_{\mathrm{f}}\right) \cdot \mathrm{t}_{\mathrm{cw}} \cdot 0.85 \cdot \mathrm{f}_{\mathrm{c}}=5.54 \times 10^{3} \cdot \mathrm{kip}$

Tension Block

$$
\begin{aligned}
& \mathrm{T}_{1}:=\mathrm{w}_{\mathrm{c}} \cdot \mathrm{t}_{\mathrm{p}} \cdot \mathrm{F}_{\mathrm{y}}=2.96 \times 10^{3} \cdot \mathrm{kip} \\
& \mathrm{T}_{2}:=\mathrm{T}_{1}=2.96 \times 10^{3} \cdot \mathrm{kip} \\
& \mathrm{T}_{3}:=\mathrm{t}_{\mathrm{f}} \cdot \mathrm{t}_{\mathrm{p}} \cdot \mathrm{F}_{\mathrm{y}}=450 \cdot \mathrm{kip} \\
& \mathrm{T}_{4}:=\left(\mathrm{L}_{1}-\mathrm{c}_{\mathrm{n}}\right) \cdot \mathrm{t}_{\mathrm{p}} \cdot \mathrm{F}_{\mathrm{y}}=9.95 \times 10^{3} \cdot \mathrm{kip} \\
& \mathrm{T}_{5}:=\mathrm{T}_{4}
\end{aligned}
$$




$$
\begin{aligned}
& \mathrm{C}_{\mathrm{T}}:=\mathrm{C}_{1}+\mathrm{C}_{2}+\mathrm{C}_{3}+\mathrm{C}_{4}+\mathrm{C}_{5}+\mathrm{C}_{\mathrm{c} 1}+\mathrm{C}_{\mathrm{c} 2}=2.63 \times 10^{4} \cdot \mathrm{kip} \\
& \mathrm{T}_{\mathrm{T}}:=\mathrm{T}_{1}+\mathrm{T}_{2}+\mathrm{T}_{3}+\mathrm{T}_{4}+\mathrm{T}_{5}=2.63 \times 10^{4} \cdot \mathrm{kip}
\end{aligned}
$$

Moment Capacity

$$
\begin{aligned}
& \mathrm{M}_{\mathrm{p} 1}:=\mathrm{C}_{1} \cdot\left(\mathrm{c}_{\mathrm{n}}-\frac{\mathrm{t}_{\mathrm{p}}}{2}\right)+\mathrm{C}_{2} \cdot\left(\mathrm{c}_{\mathrm{n}}-\mathrm{t}_{\mathrm{f}}+\frac{\mathrm{t}_{\mathrm{p}}}{2}\right)+\mathrm{C}_{3} \cdot\left(\mathrm{c}_{\mathrm{n}}-\frac{\mathrm{t}_{\mathrm{f}}}{2}\right)+\left(\mathrm{C}_{4}+\mathrm{C}_{5}\right) \cdot \frac{\mathrm{c}_{\mathrm{n}}}{2} \\
& \mathrm{M}_{\mathrm{p} 2}:=\mathrm{C}_{\mathrm{c} 1} \cdot\left(\mathrm{c}_{\mathrm{n}}-\frac{\mathrm{t}_{\mathrm{f}}}{2}\right)+\mathrm{C}_{\mathrm{c} 2} \cdot\left(\frac{\mathrm{c}_{\mathrm{n}}-\mathrm{t}_{\mathrm{f}}}{2}\right) \\
& \mathrm{M}_{\mathrm{p} 3}:=\mathrm{T}_{1} \cdot\left(\mathrm{L}_{1}-\mathrm{c}_{\mathrm{n}}-\frac{\mathrm{t}_{\mathrm{p}}}{2}\right)+\mathrm{T}_{2} \cdot\left(\mathrm{L}_{1}-\mathrm{c}_{\mathrm{n}}-\mathrm{t}_{\mathrm{f}}+\frac{\mathrm{t}_{\mathrm{p}}}{2}\right)+\mathrm{T}_{3} \cdot\left(\mathrm{L}_{1}-\mathrm{c}_{\mathrm{n}}-\frac{\mathrm{t}_{\mathrm{f}}}{2}\right)+\left(\mathrm{T}_{4}+\mathrm{T}_{5}\right) \cdot\left(\frac{\mathrm{L}_{1}-\mathrm{c}_{\mathrm{n}}}{2}\right)
\end{aligned}
$$$$
M_{p}:=M_{p 1}+M_{p 2}+M_{p 3}=8 \times 10^{6} \cdot k i p \cdot \text { in }
$$

Plastic Moment

$\phi \mathrm{M}_{\mathrm{p}}:=0.9 \cdot \mathrm{M}_{\mathrm{p}}=7.2 \times 10^{6} \cdot \mathrm{kip} \cdot \mathrm{in}$

\title{
Factored flexural capacity
}

Shear Capacity per Section 3.5 .2

$\mathrm{K}_{\mathrm{S}}:=\mathrm{G}_{\mathrm{s}} \cdot \mathrm{A}_{\mathrm{sw}}=5.52 \times 10^{6} \cdot \mathrm{kip}$

$\mathrm{K}_{\mathrm{sc}}:=\frac{0.7 \cdot\left(\mathrm{E}_{\mathrm{c}} \cdot \mathrm{A}_{\mathrm{c}}\right) \cdot \mathrm{E}_{\mathrm{s}} \cdot \mathrm{A}_{\mathrm{sw}}}{4 \cdot \mathrm{E}_{\mathrm{s}} \cdot \mathrm{A}_{\mathrm{sW}}+\mathrm{E}_{\mathrm{c}} \cdot \mathrm{A}_{\mathrm{c}}}$

$\mathrm{V}_{\mathrm{n}}:=\frac{\mathrm{K}_{\mathrm{s}}+\mathrm{K}_{\mathrm{sc}}}{\sqrt{3 \mathrm{~K}_{\mathrm{s}}^{2}+\mathrm{K}_{\mathrm{sc}}^{2}}} \cdot \mathrm{A}_{\mathrm{sw}} \cdot \mathrm{F}_{\mathrm{y}}=1.77 \times 10^{4} \cdot \mathrm{kip}$

$\phi \mathrm{V}_{\mathrm{n}}:=0.9 \cdot \mathrm{V}_{\mathrm{n}}=1.59 \times 10^{4} \cdot \mathrm{kip}$

\author{
Factored shear strength
}

\section{Step 5: Design Check}

\section{Step 5.2 Shear Check}

$\mathrm{V}_{\mathrm{u}_{-} \text {wall }}:=$ ShearAmpFactor $\cdot \frac{\mathrm{V}_{\text {ELF }}}{\mathrm{N}_{\text {wall }}}=5.89 \times 10^{3} \cdot \mathrm{kip}$

Amplified base shear in each walls

$\frac{\phi \mathrm{V}_{\mathrm{n}}}{\mathrm{V}_{\mathrm{u} \_ \text {wall }}}=2.7$

\author{
Shear strength Ratio
}


Step 5.3 Flexure Check

$\mathrm{M}_{\mathrm{u}_{\text {_wall }}}:=\mathrm{OTM}_{\mathrm{wall}}=3.36 \times 10^{6} \cdot \mathrm{kip} \cdot \mathrm{in}$

Required wall moment

$\frac{\phi \mathrm{M}_{\mathrm{p}}}{\mathrm{M}_{\mathrm{u} \_ \text {wall }}}=2.1$

Flexural strength ratio

\section{Step 5.4 Drift Check}

Effective Stiffness Calculation

$$
\begin{aligned}
& \mathrm{I}_{\mathrm{s}}:=2 \cdot \mathrm{t}_{\mathrm{p}} \cdot \mathrm{w}_{\mathrm{c}} \cdot\left(\frac{\mathrm{L}_{1}-\mathrm{t}_{\mathrm{p}}}{2}\right)^{2}+2 \cdot \mathrm{t}_{\mathrm{p}} \cdot \mathrm{w}_{\mathrm{c}} \cdot\left(\frac{\mathrm{L}_{1}-2 \mathrm{t}_{\mathrm{f}}+\mathrm{t}_{\mathrm{p}}}{2}\right)^{2}+2 \cdot \mathrm{t}_{\mathrm{p}} \cdot \frac{\mathrm{L}_{1}{ }^{3}}{12}=2.2 \times 10^{7} \cdot \mathrm{in}^{4} \\
& \mathrm{I}_{\mathrm{c}}:=\frac{2 \cdot \mathrm{w}_{\mathrm{c}} \cdot \mathrm{t}_{\mathrm{cf}}{ }^{3}}{12}+2 \cdot \mathrm{w}_{\mathrm{c}} \cdot \mathrm{t}_{\mathrm{cf}} \cdot\left(\frac{\mathrm{L}_{1}-\mathrm{t}_{\mathrm{f}}}{2}\right)^{2}+\frac{\mathrm{t}_{\mathrm{cw}} \cdot\left(\mathrm{L}_{1}-2 \cdot \mathrm{t}_{\mathrm{f}}\right)^{3}}{12} \\
& \mathrm{EI}_{\mathrm{eff}}:=\mathrm{E}_{\mathrm{s}} \cdot \mathrm{I}_{\mathrm{S}}+0.35 \mathrm{E}_{\mathrm{c}} \cdot \mathrm{I}_{\mathrm{c}}=1.159 \times 10^{12} \cdot \mathrm{kip} \cdot \mathrm{in}^{2} \\
& \mathrm{I}_{\text {eff }}:=\frac{\mathrm{EI}_{\text {eff }}}{\mathrm{E}_{\mathrm{S}}}=4 \times 10^{7} \cdot \mathrm{in}^{4} \\
& \text { ElasticDrift }_{\max }:=0.35 \% \\
& \text { InelasticDrift }_{\max }:=\text { ElasticDrift }_{\max } \cdot \mathrm{Cd}=1.925 . \% \\
& \text { Check }_{\text {Drift }}:=\mid \begin{array}{ll}
\text { "Ok" } & \text { if InelasticDrift } \\
\text { max } & <2 \%=\text { "Ok" } \\
\text { "NG" } & \text { otherwise }
\end{array} \\
& \text { Effective stiffness } \\
& \text { Max elastic drift using above } \\
& \text { effective stiffness } \\
& \text { Inelastic drift }
\end{aligned}
$$

Hence design of wall is adequate 